\title{
Obesity and pulmonary host defense
}

Citation for published version (APA):

Ubags, N. D. J. (2016). Obesity and pulmonary host defense. [Doctoral Thesis, Maastricht University]. Maastricht University. https://doi.org/10.26481/dis.20160324nu

Document status and date:

Published: 01/01/2016

DOI:

10.26481/dis.20160324nu

Document Version:

Publisher's PDF, also known as Version of record

\section{Please check the document version of this publication:}

- A submitted manuscript is the version of the article upon submission and before peer-review. There can be important differences between the submitted version and the official published version of record.

People interested in the research are advised to contact the author for the final version of the publication, or visit the DOI to the publisher's website.

- The final author version and the galley proof are versions of the publication after peer review.

- The final published version features the final layout of the paper including the volume, issue and page numbers.

Link to publication

\footnotetext{
General rights rights.

- You may freely distribute the URL identifying the publication in the public portal. please follow below link for the End User Agreement:

www.umlib.nl/taverne-license

Take down policy

If you believe that this document breaches copyright please contact us at:

repository@maastrichtuniversity.nl

providing details and we will investigate your claim.
}

Copyright and moral rights for the publications made accessible in the public portal are retained by the authors and/or other copyright owners and it is a condition of accessing publications that users recognise and abide by the legal requirements associated with these

- Users may download and print one copy of any publication from the public portal for the purpose of private study or research.

- You may not further distribute the material or use it for any profit-making activity or commercial gain

If the publication is distributed under the terms of Article $25 \mathrm{fa}$ of the Dutch Copyright Act, indicated by the "Taverne" license above, 


\section{Obesity and Pulmonary Host Defense}

Niki D.J. Ubags 


\section{$\mathscr{0}$ NUTRIM}

The studies presented in this thesis were performed within NUTRIM School for Nutrition and Translational Research in Metabolism which participates in the Graduate School VLAG (Food Technology, Agrobiotechnology, Nutrition and Health Sciences), accredited by the Royal Netherlands Academy of Arts and Sciences.

Financial support of this thesis from Stichting Pulmonologie (PUL, Maastricht) was gratefully acknowledged.

Copyright (C) Niki Ubags, Maastricht, 2016

All rights reserved. No part of this book may be reproduced or transmitted, in any form or by any means, without written permission from the author.

Layout: Niki Ubags

Cover design: Matthew Randall

Production: Ipskamp Printing, Enschede

ISBN: 978-94-028-0049-4 


\title{
Obesity and Pulmonary Host Defense
}

\author{
PROEFSCHRIFT
}

Ter verkrijging van de graad van doctor aan de Universiteit Maastricht, op gezag van de Rector Magnificus, Prof. dr. L.L.G. Soete, volgens het besluit van het College van Decanen, in het openbaar te verdedigen op donderdag 24 maart 2016 om 12:00 uur

door

Niki Dominique Josephina Ubags 


\section{Promotor}

Prof. dr. E.F.M. Wouters

\section{Copromotores}

Prof. dr. B.T. Suratt (University of Vermont, U.S.A.)

Dr. J.H.J. Vernooy

\section{Beoordelingscommissie}

Prof. dr. P. Savelkoul (voorzitter)

Prof. dr. S. Herold (University of Giessen and Marburg Lung Center, Germany)

Prof. dr. T. van der Poll (Academisch Medisch Centrum, Amsterdam)

Prof. dr. P. Roekaerts

Dr. R. Shiri-Sverdlov

The studies described in this thesis were supported by The Weijerhorst Foundation. 
It is not the strongest of the species that survives, nor the most intelligent that survives. It is the one that is most adaptable to change.

Charles Darwin paraphrased by Leon Megginson; 1963 



\section{Table of contents}

Chapter 1 General Introduction 9

Chapter 2 Aims and Thesis Outline 29

Chapter 3 Obesity is Associated with Neutrophil Dysfunction and Attenuation 33 of Murine Acute Lung Injury American Journal of Cell and Molecular Biology. 2012; 47(1): p. 120-127

Chapter 4 A comparative study of pulmonary host defense in murine obesity models: important insights into neutrophil function

Submitted

Chapter 5 Paradoxical Modulation of the Pulmonary Innate Immune Response in 87 Murine Obese ARDS

In preparation

Chapter 6 Leptin as Regulator of Pulmonary Immune Responses: Involvement in 105 Respiratory Diseases

Pulmonary Pharmacology \& Therapeutics. 2013; 26(4): p. 464-72

Chapter 7 The Role of Leptin in the Development of Pulmonary Neutrophilia 129 in Infection and Acute Lung injury Critical Care Medicine. 2014; 42(2):e143-51

Chapter 8 Hyperleptinemia Impairs Pulmonary Host Defense 159 In Revision

Chapter 9 General Discussion and Future Perspectives 185

Summary 201

Samenvatting 207

Valorisation 213

List of abbreviations 221

Acknowledgements/Dankwoord 225

List of Publications 233

Curriculum Vitae 



\section{CHAPTER 1}

General Introduction 


\section{Obesity}

Obesity is a rapidly expanding epidemic globally, with a markedly increased prevalence of overweight and obesity for adults $(27.5 \%)$ and for children $(47.1 \%)$ in the past 30 years (1). Recent reports from the World Health Organization (WHO) indicate that in 2014 more than 1.9 billion adults (18 years and older) were overweight, and of this overweight population, over 600 million people were obese. About $13 \%$ of the world's adult population was obese in 2014 ( $11 \%$ men and 15\% women). Furthermore, another $39 \%$ of the adult population was overweight ( $38 \%$ men and $40 \%$ women)(2). Body Mass Index (BMI) (3) is a population measure $\left(\mathrm{kg} / \mathrm{m}^{2}\right)$ that is commonly used to classify underweight, overweight, and obesity in adults (Table 1.1), and although the most recent classification index includes $\mathrm{BMI}$ over 40 , the incidence of subjects with a $\mathrm{BMI}$ as high as 60 and over is growing. The increased prevalence of overweight and obesity has been accompanied by a substantial increase of direct medical costs of obesity. Obesity alone accounted for between $0.7 \%$ (4) and $2.8 \%$ (5) of total health care expenditures worldwide and when costs associated with being overweight were also included, this increased to $9.1 \%(6)$ of total health care expenditures worldwide (7).

Table 1.1 BMI classification.

\begin{tabular}{|l|l|}
\hline Classification & $\mathrm{BMI}\left(\mathbf{k g} / \mathbf{m}^{\mathbf{2}}\right)$ \\
\hline Underweight & $<18.50$ \\
\hline Normal weight & $18.50-24.99$ \\
\hline Overweight & $25.00-29.99$ \\
\hline Obese Class I & $30.00-34.99$ \\
\hline Obese Class II & $35.00-39.99$ \\
\hline Obese Class III & $\geq 40.00$ \\
\hline
\end{tabular}

\section{Obesity and Comorbidities}

Obesity contributes to a number of comorbidities that can occur in many organ systems, including the endocrine system, cardiovascular system, and respiratory system, among others. Overweight and obesity lead to adverse metabolic effects on blood pressure, cholesterol, triglycerides, adipokines and insulin resistance. Obesity is a risk factor for cardiovascular diseases (CVD), which includes: coronary heart disease (CHD), myocardial infarction, angina pectoris, congestive heart failure, stroke, hypertension and atrial fibrillation $(8,9)$. In the Framingham Heart Study the effect of obesity on the risk of CVD, diabetes, hypertension and hypercholesterolemia was evaluated. The age-adjusted risk for both CVD and hypertension was increased in obese subjects, with a slightly higher risk reported in women compared to men (10). Hypertension is considered a risk factor for CVD and is also related to obesity. Analysis of the Women's Health Study found a significant association between obesity, development of hypertension and diabetes in an 
on average 10 year follow-up study (11). In addition, the long-term risk for type 2 diabetes is significantly elevated with increasing body weight (12). Despite the known risk of type 2 diabetes associated with obesity, weight loss has the potential to improve outcomes, but is also associated with improved diabetes control and a reduction in cardiovascular disease risk factors and medication use (13).

Furthermore, it has been shown that obesity is associated with elevated cholesterol levels, which results in an elevation of total cholesterol and triglycerides and a reduction in high-density cholesterol (HDL). Abdominal obesity can cause an increased production of low-density cholesterol (LDL) particles that are smaller and denser than normal, putting an obese individual at greater risk of atherosclerosis (14). Endothelial cell dysfunction may be one of the consequences of obesity-associated low grade inflammation and dyslipidemia, and increases the formation and evolution of atheroma (15). Obesity is also a risk factor for liver disease, in particular nonalcoholic steatohepatitis (NASH) or "fatty liver" (16-18). NASH is associated with obesity, dyslipidemia, hypertension, and insulin resistance, which are all components of the metabolic syndrome that increase cardiovascular risk (19). NASH has a prevalence of approximately $70 \%$ in people with type 2 diabetes (19), and although evidence is limited, weight loss may be beneficial for reducing the risk of NASH in obese patients (20). The net impact of the increased burden of disease associated with obesity is increased mortality, which is well established in the obese population. An increase in years of life lost was found among obese versus non-obese subjects in an analysis of the NHANES database (21), and obese subjects experience a lower health-related quality of life compared with normal weight subjects (22).

The chronic low-grade inflammatory response seen in obesity has been described as 'metainflammation' (metabolically triggered inflammation). This is principally triggered by nutrients and metabolic surplus, and engages a similar set of molecules and signaling pathways to those involved in classical inflammation (23). However, obesity-induced inflammation is different from classical inflammation in several key aspects. Obesity is a chronic disease and produces a tonic low-grade activation of the innate immune system, and additionally, there are recurrent acute episodes of nutrition-related immune activation that is induced by nutrient availability (24-26), and as mentioned before, the multi-organ involvement of obesity-induced inflammation is also unique (27). An important feature of inflammation is infiltration of inflamed tissues by immune cells, such as neutrophils, macrophages and eosinophils. However, little is known about the effects of obesity on innate immune cell function and consequently their role in the pathogenesis of pulmonary diseases.

\section{Adipokine Dysregulation}

One of the characteristics of obesity is adipokine dysregulation, and this may promote obesity-linked metabolic disorders and cardiovascular disease. Adipose tissue is an endocrine organ and secretes a number of adipokines which play a central role in energy 
and vascular homeostasis as well as in immunity. Some adipokines such as adiponectin and omentin are downregulated in obesity, while most adipokines are overproduced, including leptin, visfatin and apelin. Leptin and adiponectin are well characterized over the past years and are shown to have multiple implications in the immune response as well as in the pathogenesis of a variety of diseases. Leptin is a $16 \mathrm{kDa}$ non-glycosylated polypeptide encoded by the 'obese' $(o b)$ gene (28). Circulating leptin levels parallel adipose tissue mass but also reflect immediate changes in nutritional status as they decrease soon after the beginning of fasting (29). Obesity is typically associated with high circulating leptin levels and a leptin-resistant state (30). Leptin has been reported to participate in diverse physiological functions in both the central nervous system and the periphery, including appetite and body mass control, metabolism, endocrine function, immune response, wound healing, reproduction, cardiovascular pathophysiology, and respiratory tissue development, remodelling and function. Moreover, several metabolic effects of leptin include stimulation of fatty acid oxidation $(31,32)$ and glucose uptake $(33,34)$, in addition to preventing lipid accumulation in adipose as well as non-adipose tissue. An extensive review on leptin as a regulator of the pulmonary immune response can be found in Chapter 6. In contrast to leptin, circulating adiponectin is negatively correlated with $\mathrm{BMI}(35,36)$ and is decreased in obese subjects, in patients with type 2 diabetes or cardiovascular disease (37). Adiponectin is a $30 \mathrm{kDa}$ protein which is abundantly produced by adipose tissue and it circulates in blood in relatively large amounts in different molecular forms $(38,39)$. It plays an important role in energy metabolism such that total adiponectin and high molecular weight (HMW) adiponectin concentrations decrease in obesity and increase following weight loss (40-43). Furthermore, an inverse correlation was observed of total and HMW adiponectin with $\mathrm{BMI}$, glucose-, insulin- and triglyceride levels, the degree of insulin resistance, and visceral fat accumulation (41). Altered expression of adiponectin and its receptors as seen in obesity and type 2 diabetes reduces adiponectin sensitivity and subsequently insulin resistance which aggravates hyperinsulinemia.

\section{Pulmonary Innate Immune Response and Obesity}

The most important function of the respiratory system is to diffuse $\mathrm{O}_{2}$ into the body and remove $\mathrm{CO}_{2}$ from the body. With each breath the lung is exposed to various noxious gasses, particulates, pathogens and allergens which may cause adverse reactions leading to inflammation and may consequently increase the risk for respiratory infections. The pulmonary innate immune response forms a first line of defense against invading pathogens by recognizing particles and inducing effector cell responses to fight and clear the exogenous trigger. Invading microorganisms are detected by myeloid and structural/resident cells of the respiratory system by binding to their pattern recognition receptors (PRR) to bacterial ligands (44). Neutrophils and macrophages are the main effector cells in bacterial pneumonia as well as acute respiratory distress syndrome 
(ARDS), whereas epithelial and dendritic cells also play an important role in bridging the innate and adaptive immune response. As a reaction to invading pathogens, molecules on the microbe called pathogen-associated molecular patterns (PAMPs), will bind and activate Toll-like receptors (TLRs) and other PRRs (45). TLR4 recognizes lipopolysaccharide (LPS), which is a component of the outer membrane of Gramnegative bacteria, and TLR2 recognizes peptidoglycan on Gram-positive bacteria. Following TLR (typically present on alveolar macrophages and type II epithelial cells) activation, intracellular signaling cascades are initiated through the adaptor proteins MyD88 and TRIF, and lead to the activation of transcription factors, thereby regulating the expression of pro-inflammatory mediators, including cytokines (IL-1, TNF $\alpha$ and IL-6), chemokines and adhesion molecules (44). This initial inflammatory phase includes the controlled, alveolar macrophage-driven recruitment of neutrophils to the lung. Activation of resident macrophages, that combat the offending invaders, also initiates the release of early components of the innate immune response. Movement of neutrophils from the bone marrow, through the circulation and infiltration of the lung will then be induced by these pro-inflammatory mediators (e.g. IL-6 and IL-8) via activation and recruitment of neutrophils to release more cytokines and chemokines (46), which further enhance the inflammatory response. Following the neutrophil response, monocytes are recruited to the site of infection/inflammation at which they differentiate into macrophages to participate in pathogen clearance and help in the resolution phase of the inflammatory response. Critical for the resolution phase of the inflammatory response is the process of 'efferocytosis,' or the change in macrophage phenotype from pro-inflammatory to anti-inflammatory (also described as ' $\mathrm{M} 1$ ' to ' $\mathrm{M} 2$ ' shift), that is driven by phagocytosis of the dying neutrophils (47). One of the ligands expressed by apoptotic cells, phosphatidylserine (PS) carries particular importance. PS is normally confined to the inner leaflet of the cell membrane, but is rapidly exposed on the cell surface during early apoptosis (48). Interestingly, neutrophils as well as other leukocytes may also expose PS on their cell surfaces when they become activated, though in this case the exposure is transient rather than permanent as seen in apoptosis. Nevertheless, it has become apparent that such transient exposure itself may be enough to trigger some recognition and removal before the cells actually die (47). Recent studies suggest that clearance of apoptotic neutrophils is driven by signaling species of an oxidized form of PS, lysophosphatidylserine (lyso-PS) (49). Lyso-PS is expressed on the surface of neutrophils upon activation of NADPH oxidase, and can enhance the engulfment of apoptotic neutrophils by macrophages via the G-protein-coupled receptor G2A (50). Lyso-PS is thus considered to be one of several "eat-me" signals that mark neutrophils entering apoptosis for rapid removal by alveolar macrophages.

\section{Monocytes and Macrophages}

Monocytes and macrophages are part of the mononuclear phagocyte system (MPS), which plays major roles in development, scavenging, inflammation and anti-pathogen defenses. Homeostatic control of monocyte/macrophage development is mostly 
influenced by CSF-1 (better known as M-CSF) (51). Granulocyte-macrophage colonystimulating factor (GM-CSF) is another factor involved in the development of mononuclear phagocytes but only during the inflammatory state and not under homeostatic conditions $(52,53)$. Recruited monocytes are innate effectors of the host defense against microbes, and they kill pathogens via phagocytosis, production of reactive oxygen species (ROS), nitric oxide (NO), myeloperoxidase (MPO), and inflammatory cytokines (54). The original concept of the MPS suggested that classical monocytes are recruited in the tissue to become tissue-resident macrophages under homeostatic condition, and inflammatory activated macrophages during an infection (54). However, the theory that tissue macrophages only originate from circulating peripheral blood monocytes that migrate into tissues upon stimulation, needs to be reconsidered. Recent studies showed that tissue-resident macrophages in the lung can also develop from fetal monocytes that adopt a stable phenotype shortly after birth in response to instructive cytokines, and then self-maintain throughout life $(55,56)$. Key features of macrophages and their activation state are plasticity and flexibility. The macrophage phenotype can be modified from a pro-inflammatory state (M1 macrophages) to a more anti-inflammatory state (M2 macrophages). M1 activating stimuli include IFN $\gamma$, LPS and TNF $\alpha$, whereas anti-inflammatory (M2) stimuli include IL-4, IL-10, IL-13 and TGF $\beta$ (57).

In obesity, excessive amounts of adipose tissue are present, and adipose tissue is seen as an important endocrine organ (58) producing adipokines, which not only serve as metabolic regulators, but also possess immunoregulatory properties. Macrophages are the most abundant leukocyte population in adipose tissue and appear to be at the center of obesity-related inflammation (59). Increased tissue inflammation through adipocyte release of cytokines (e.g. TNF $\alpha(60,61)$ ), chemokines (e.g. MCP1/CCL2 (55)), and proinflammatory fatty acids (62) drives alterations in leukocyte number and phenotype, thereby expanding the inflammatory environment within adipose tissue beds. In obese subjects, adipose tissue macrophage numbers are markedly increased, and this population shifts toward the classical pro-inflammatory (M1) state, whereas adipose tissue macrophages in lean subjects are mostly M2 (63). M1 macrophages form crownlike structures around necrotic adipocytes in the inflamed tissue and produce substantial amounts of pro-inflammatory cytokines, such as IL-6, TNF $\alpha$, and MCP-1. The increased adipose tissue inflammation seen in obese subjects may consequently lead to the lowgrade systemic inflammatory state that is associated with obesity. The effects of obesity on adipose tissue macrophage function and phenotype are very well characterized, however, the downstream effects of the alterations that occur in this setting on, in particular, the alveolar compartment remains under-investigated.

\section{Neutrophils}

Neutrophils are continuously generated in the bone marrow from myeloid precursors and are the first leukocytes to be recruited to sites of inflammation (64-68). Neutrophil 
recruitment is initiated by changes on the surface of the endothelium induced by inflammatory mediators (histamine, cysteinyl-leukotrienes and cytokines), which are released by tissue-resident leukocytes when they come into contact with pathogens (6971). Endothelial cells can also be activated by PRR-mediated detection of pathogens that increase the expression of adhesion molecules, such as E-selectin and P-selectin (69, 72). The selectins will bind to their glycosylated ligands (PSGL1), leading to the capturing of free-flowing neutrophils to the endothelial surface and subsequent rolling along to vessel. During the 'rolling' process, neutrophils become activated after contact with chemokines (CXCL8 (human IL-8), CXCL1 (murine KC), CXCL2 and CXCL5 (LIX)) on the endothelial surface. These chemokines signal through CXCR2 to activate neutrophils and promote their adhesion to the endothelium $(73,74)$. The adhesion step prepares neutrophils for transmigration. Neutrophils usually transmigrate at endothelial cell-cell junctions, to which they actively crawl. The tendency of the neutrophils is to crawl perpendicularly (shortest distance from neutrophil adherence point to endothelial junction). The active crawling depends on the interaction of endothelial cell-expressed ICAM1 with neutrophil expressed MAC1 (75). In order to leave the vasculature, neutrophils first cross the endothelium and then the basement membrane. This transmigration process requires integrins and CAM's (ICAM1, ICAM2, and VCAM1), as well as junctional proteins (PECAM1, JAMs, ECAM). Once neutrophils are emigrated, they move away from the endothelium, suggesting that a new chemotactic gradient is required which overrides the first gradient. Thus, chemoattractants can be functionally divided into intermediate and end-target chemoattractants. Once neutrophils arrive at the site of inflammation and encounter microorganisms, they phagocytose them. After encapsulation in phagosomes, the neutrophils release several antimicrobial factors, such as ROS or antibacterial proteins (cathepsins, defensins, lactoferrin and lysozyme) (76-78) , in order to kill the pathogens. The antibacterial proteins are released from the neutrophil granules either into phagosomes or into the extracellular milieu, thus acting on either intra- or extracellular pathogens. Although neutrophils provide a first line of defense against pathogens and microbes, excessive recruitment and activation can lead to bystander tissue damage.

A limited amount of studies have been performed investigating the effects of obesity on neutrophil development and function. Human peripheral blood derived neutrophils from obese subjects are suggested to be hyperresponsive in their superoxide response and appear to have increased chemotactic features (79). However, studies performed in mouse models of obesity, show that bone-marrow derived neutrophils from obese and hypercholesterolemic mice may have defects in their development and functional responses compared to lean controls $(80,81)$. Therefore, more research is needed to delineate the obesity-associated alterations in effector cell response (neutrophils and macrophages) that may consequently affect host defense. 


\section{Obesity and Respiratory Diseases}

Since the obesity epidemic is increasing worldwide, the number of obese subjects with respiratory complaints has been rising. It is believed that obese people with respiratory disease may have worse exacerbations of asthma and chronic obstructive pulmonary disease (COPD), but are also thought to be more prone to develop respiratory infections, as well as sleep apnea. Obesity is associated with chronic low-grade systemic inflammation that is thought to enhance systemic complications. These systemic complications may in turn lead to dysregulation of the immune response and consequently affect onset and progression of respiratory diseases.

\section{Obesity and Asthma}

Asthma is a prevalent and complex disorder that can occur in genetically predisposed individuals, through a series of gene-environment interactions (82). Acute and chronic inflammation of the bronchi and the conducting airways plays a central role in the pathogenesis of asthma, and lead to airflow obstruction and the respiratory symptoms of the disease, such as wheezing, coughing, chest tightness, and dyspnea. Inflammation is also important in the development of the airway hyperresponsiveness observed in asthmatics, as well as in the emergence of airway remodeling. Originally, a Th1/Th2 imbalance was proposed to explain the Th2 mediated allergic airway inflammation in asthmatics. However, recent research has focused increasingly on the failure of endogenous tolerance mechanisms, including impaired function of regulatory T-cells (Tregs) (83) and airway epithelial cells (82).

An increasing amount of studies have suggested that obesity may increase the prevalence and incidence of asthma, and modify the phenotype and prognosis of asthma. Obese asthmatics tend to have more severe and poorly controlled disease, which is in part due to the fact that they do not respond as well to standard therapy (84). In recent work two distinct phenotypes of asthma have been observed and described: 1) classic early onset asthma that is complicated by subsequent development of obesity, and 2) late onset asthma arising as a consequence of obesity. In the former phenotype, patients have a high prevalence of atopy and allergic disease and tend to be younger at diagnosis. Subjects suffering from asthma with the late onset phenotype have a lower prevalence of allergic disease and their late onset asthma arises as a consequence of obesity (85). There are several factors that may be involved in the existence of these different phenotypes and may complicate the assessment of underlying mechanisms. Obesity has well described effects on lung function and mechanics, and physiological studies suggest that obesity-associated altered lung mechanics leads to symptoms of dyspnea that occur in the absence of airway inflammatory changes commonly observed in asthma (86). Furthermore, alterations in inflammatory profiles and adipokine dysregulation seen in obesity may be a key-player in the diverse asthma phenotypes observed in the obese population. Several publications have reported an inverse 
relationship between airway eosinophilia and BMI (87) or waist circumference (88). In addition, some studies suggest an increase in airway neutrophilia in obese asthmatics $(89,90)$; however, this effect may be gender-dependent. A recent study by Rastogi et al. identified systemic inflammation as a potential mechanism linking metabolic dysregulation and pulmonary function deficits in obese adolescent asthma suggesting that aspects of the metabolic syndrome may influence the lung innate and adaptive immune response and increase susceptibility to obesity-related asthma (91).

\section{Obesity and Chronic Obstructive Pulmonary Disease}

Chronic Obstructive Pulmonary Disease (COPD) is the third leading cause of mortality globally (92) and symptoms include shortness of breath, exercise limitation, cough and chest tightness. COPD is usually progressive and patients commonly suffer from disease exacerbations. Cigarette smoke is the primary cause of COPD; however, other risk factors have been identified including occupational exposure to noxious particles or gasses, air pollution as well as genetic predisposition (93). COPD is recognized as a complex and heterogeneous multi-component disease characterized by airflow obstruction (chronic bronchitis and emphysema) associated with both structural changes and low-grade systemic inflammation (94).

The relationship between COPD and body composition has been extensively studied. Underweight and low BMI are risk factors for mortality in COPD patients, independent of disease severity $(95,96)$. Furthermore, at the other end of the spectrum, overweight and obesity are common in COPD (97), particularly in those with mild to moderate airflow obstruction. Obesity is recognized as a risk factor for respiratory symptoms (98) and functional limitation (99) in COPD patients. Differential effects have been observed regarding mortality and disease severity. While obesity may be associated with lower mortality in patients with severe airflow obstruction, an increase in mortality was observed in obese patients with mild to moderate $\operatorname{COPD}(96,100)$. In a recent study Sood and colleagues examined current and former smokers at risk for or with mild to moderate COPD with a follow up period of $\sim 6$ years (101). Their results demonstrated that at baseline, high $\mathrm{BMI}$ in obese smokers (BMI $>30 \mathrm{~kg} / \mathrm{m}^{2}$ ) was associated with worse health status and lower $\mathrm{FEV}_{1}$, whereas in lean smokers $\left(\mathrm{BMI}<25 \mathrm{~kg} / \mathrm{m}^{2}\right)$ these associations were reversed (101).

\section{Obesity, Acute Respiratory Distress Syndrome and Respiratory Infections}

Recent studies have demonstrated that human obesity is associated with increased risk for developing bacterial and viral respiratory infections (102), as well as an elevated risk of developing Acute Respiratory Distress Syndrome (ARDS) (103). Interestingly, however, we and others have shown that, once ARDS has developed, obesity is also associated with rapid attenuation of the inflammatory response and improved outcomes in both patients $(103,104)$, and animal models $(80)$. As a corollary to the impaired inflammatory response seen in obese ARDS models, it was demonstrated that pulmonary host defense 
is diminished following both influenza $(105,106)$ and bacterial pneumonias $(107,108)$, with consequent lung injury and death. Recent clinical studies have demonstrated associations between obesity and risk for both bacterial and viral pneumonias, as well as, increased disease severity and mortality (109-111), whereas others have suggested a protective effect of increasing BMI on mortality in this setting $(112,113)$. Reasons for this inconsistency may include pathogen-specific defects in the immune response or differences in the metabolic state (lipid-, glucose-, and adipokine levels amongst others) of individual obese subjects. Differences between mouse models of obesity may also, in part, determine the effects on the pulmonary immune response and subsequently the susceptibility to and outcome of respiratory infections. However, there are a limited data available comparing different models of obesity and their metabolic state on the level of immune cell dysfunction and consequently the effects on host defense.

\section{Animal Models of Obesity}

Thorough investigation of complex diseases requires that the disease be studied in the context of the entire organism. The increase in overweight and obesity worldwide makes it imperative to develop animal models which share similarities with human obesity and its co-morbidities. Animal models of obesity can be placed into two different categories, with the first one being based on manipulations or mutations of one or several genes, and the second one in which genetically normal animals are exposed to an obesogenic environment, such as a high fat diet. A variety of different mouse models have been used for obesity-related studies on respiratory diseases. Although it has been suggested that human obesity is best mimicked in the diet-induced obesity mouse model of high fat diet ( $10 \%$ vs. $60 \%$ fat) (114-116), three hyperphagic mutant models are also commonly reported, including leptin 'resistant' db/db mice (leptin receptor (ObRb) deficient) (117), aleptinemic ob/ob mice (leptin (ob-gene) deficient) (118), and otherwise hyperphagic $\mathrm{CPE}^{\text {fat/fat }}$ mice (carboxypeptidase-E deficient) (119). Here, the outcomes of studies looking at obesity's effects on various pulmonary diseases.

\section{Asthma}

Innate airway hyperresponsiveness was observed in obese ob/ob, $\mathrm{db} / \mathrm{db}$ and $\mathrm{CPE}^{\text {fat/fat }}$ mice, as well as in DIO mice, but only when they gained over $45 \%$ of their initial body weight (120-123), and since this was observed in both mice that lack leptin, as well as mice with very high leptin levels, it was suggested to be unlikely that leptin was involved, even though leptin has the potential to augment airway responsiveness by itself (124). In addition, obesity has been shown to augment the pulmonary inflammatory response following acute ozone $\left(\mathrm{O}_{3}\right)$ exposure, a common trigger for asthmatic episodes in different mouse models of obesity, including ob/ob (124), db/db (125) , CPE ${ }^{\text {fat/fat }}$ (121) and DIO mice (120). 


\section{Chronic Obstructive Pulmonary Disease}

The characteristic features of human COPD can be modeled in mice by exogenous administration of proteases, chemicals, particulates and exposure to cigarette smoke (126-129). Cigarette smoke is the major cause of COPD, and is a profound stimulus of the innate immune response leading to inflammation that drives COPD pathogenesis. The "smoking-mouse model" has many of the characteristic features of human COPD, including chronic lung inflammation, impaired lung function, emphysema, mucus hypersecretion, small airway thickening and remodeling, vascular remodeling, lymphoid aggregates and pulmonary hypertension. However, chronic bronchitis as well as the severe states (GOLD 3-4) of COPD cannot be modeled in mice (128). Furthermore, only a limited amount of studies have examined the effects of obesity on COPD in animal models. Vernooy et al. showed that cigarette exposure of genetically obese ob/ob and $\mathrm{db} / \mathrm{db}$ mice resulted in increased pulmonary neutrophilia and a decrease in the amount of CD4+, CD8+ and dendritic cells in the lung compared to smoke exposed controls, suggesting that obesity modulates the innate and adaptive immune response upon cigarette smoke exposure in mice (130). In addition, a recent study from Esquivel et al. suggests that chronic cigarette smoke exposure decreases the inflammatory response caused by sucrose-induced obesity in rats, however, obesity did not prevent development of emphysematous lesions (131).

\section{Acute Lung Injury}

Obese leptin receptor deficient mice are suggested to be protected against oxidantinduced lung injury by exposure to hypoxia and also against the development of lung injury and fibrosis following intratracheal bleomycin instillation $(132,133)$. Acute lung injury is the leading cause of death in sepsis (134). A study by Khan et al., suggests that diet-induced obesity reduces myeloperoxidase levels (a measure of pulmonary inflammation) in the lung in a sepsis model of cecal-ligation puncture (CLP), thereby protecting the mice from early sepsis-induced lung injury (135). Obesity is associated with alterations in several metabolic factors and adipokine dysregulation is one of them, resulting in increased serum leptin levels, whereas adiponectin levels are decreased. Adiponectin deficiency has been shown to increase lung injury and inflammation early after LPS exposure, likely through an exaggerated inflammatory response in the pulmonary vascular endothelium (136). These results were extended in a study using diet-induced obese mice, showing that alterations in pulmonary endothelial cells observed in obese mice were associated with enhanced susceptibility to LPS-induced lung injury. Restoration of serum adiponectin levels in these mice reversed the effects of obesity on the lung endothelium and the increased susceptibility to acute injury, suggesting that the impaired pulmonary vascular homeostasis and enhanced susceptibility to injury seen in obese mice may, at least in part, be due to adipokine dysregulation (137). In this thesis the effects of the adipokine leptin on pulmonary immune function in obesity will be discussed. 


\section{Respiratory Infection}

Until now, bacterial infections have only been examined in mouse models of geneticallyinduced obesity, and results have been inconsistent. Obese ob/ob mice show impaired survival following infection with Klebsiella pneumoniae, Streptococcus pneumoniae, and Mycobacterium abscessus $(107,138,139)$. The reduced bacterial clearance witnessed in these leptin-deficient ob/ob mice does not appear to be due to impaired recruitment of inflammatory cells, but rather from defective phagocytosis of bacteria by macrophages and neutrophils $(107,138,140)$. Moreover, macrophages from leptin-deficient mice show diminished leukotriene synthesis in vitro, and leukotrienes have been shown to enhance macrophage phagocytosis. Both the phagocytic response of macrophages and neutrophils and the synthesis of leukotrienes can be restored by exogenous administration of leptin in these leptin-deficient mice $(107,138,140)$. Recently, it was shown that the pulmonary host defense in obese hyperphagic $\mathrm{CPE}^{\text {fat/fat }}$ mice (with modest metabolic abnormalities) following Streptococcus pneumoniae infection appeared to be functional (141).

When looking at viral infections in obese mouse models, it was shown that DIO mice have a higher mortality rate following infection with influenza compared to their lean controls $(142,143)$. Furthermore, it has been shown that diet-induced obesity results in selective impairment of dendritic cell (DC) functions and that obesity leads to delayed recruitment of mononuclear cells to the lung during influenza infection. In addition, while migration of antigen-loaded DCs to the lymph node appears to be normal in obese mice, the ability of DCs to present antigens to $C D 8^{+}$T-cells is impaired, and this may be caused by a lack of co-stimulation by DCs (144). In a study by Karlsson et al., it was shown that increased morbidity and mortality during a secondary influenza infection is due to impairment in the ability to generate and maintain functional influenza specific memory T-cells (145). Furthermore, increased mortality after H1N1 infection in DIO and ob/ob mice was also associated with increased lung pathology, impaired wound repair and subsequent pulmonary edema (146). It has also been shown that diet-induced obesity impairs antibody responses following influenza vaccination (147). In addition, a recent study by Radigan et al., showed that global leptin receptor deficiency (db/db model) impairs viral clearance and reduced survival during influenza A pneumonia, similar to studies in DIO mice. However, loss of leptin receptor specifically in alveolar macrophages and lung epithelial cells did not explain these findings, suggesting that other cells (T-cells and NK-cells) within or outside the lung may be responsible for this observation (148). Moreover, the effects of obesity-associated metabolic factors on the immune response may also play an important role in this impaired response to viral pneumonia, and further studies dissecting the effects of various metabolic factors, such as high lipid levels and adipokine dysregulation, on the immune response need to be tested outside of the obesogenic environment. 


\section{References}

1. Ng, M., Fleming, T., Robinson, M., Thomson, B., Graetz, N., Margono, C., Mullany, E.C., Biryukov, S., Abbafati, C., Abera, S.F., et al. 2014. Global, regional, and national prevalence of overweight and obesity in children and adults during 1980-2013: a systematic analysis for the Global Burden of Disease Study 2013. Lancet 384:766-781.

2. World Health Organization, 2015. Obesity and overweight Factsheet $\mathrm{N}^{\circ} 311$. Available from: http://www.who.int/mediacentre/factsheets/fs311/en/.

3. Garrow, J.S., and Webster, J. 1985. Quetelet's index (W/H2) as a measure of fatness. International journal of obesity 9:147-153.

4. Detournay, B., Fagnani, F., Phillippo, M., Pribil, C., Charles, M.A., Sermet, C., Basdevant, A., and Eschwege, E. 2000. Obesity morbidity and health care costs in France: an analysis of the 1991-1992 Medical Care Household Survey. Int J Obes Relat Metab Disord 24:151-155.

5. Long, D.A., Reed, R., and Lehman, G. 2006. The cost of lifestyle health risks: obesity. J Occup Environ Med 48:244-251.

6. Finkelstein, E.A., Fiebelkorn, I.C., and Wang, G. 2003. National medical spending attributable to overweight and obesity: how much, and who's paying? Health Aff (Millwood) Suppl Web Exclusives:W3-219-226.

7. Withrow, D., and Alter, D.A. 2011. The economic burden of obesity worldwide: a systematic review of the direct costs of obesity. Obes Rev 12:131-141.

8. Must, A., Spadano, J., Coakley, E.H., Field, A.E., Colditz, G., and Dietz, W.H. 1999. The disease burden associated with overweight and obesity. JAMA 282:1523-1529.

9. Klein, S., Burke, L.E., Bray, G.A., Blair, S., Allison, D.B., Pi-Sunyer, X., Hong, Y., and Eckel, R.H. 2004. Clinical implications of obesity with specific focus on cardiovascular disease: a statement for professionals from the American Heart Association Council on Nutrition, Physical Activity, and Metabolism: endorsed by the American College of Cardiology Foundation. Circulation 110:29522967.

10. Wilson, P.W., D'Agostino, R.B., Sullivan, L., Parise, H., and Kannel, W.B. 2002. Overweight and obesity as determinants of cardiovascular risk: the Framingham experience. Archives of internal medicine 162:1867-1872.

11. Conen, D., Ridker, P.M., Mora, S., Buring, J.E., and Glynn, R.J. 2007. Blood pressure and risk of developing type 2 diabetes mellitus: the Women's Health Study. European heart journal 28:29372943.

12. Colditz, G.A., Willett, W.C., Rotnitzky, A., and Manson, J.E. 1995. Weight gain as a risk factor for clinical diabetes mellitus in women. Annals of internal medicine 122:481-486.

13. Fujimoto, W.Y., Jablonski, K.A., Bray, G.A., Kriska, A., Barrett-Connor, E., Haffner, S., Hanson, R., Hill, J.O., Hubbard, V., Stamm, E., et al. 2007. Body size and shape changes and the risk of diabetes in the diabetes prevention program. Diabetes 56:1680-1685.

14. Khaodhiar, L., McCowen, K.C., and Blackburn, G.L. 1999. Obesity and its comorbid conditions. Clinical cornerstone 2:17-31.

15. Libby, P., Ridker, P.M., and Maseri, A. 2002. Inflammation and atherosclerosis. Circulation 105:11351143.

16. Riquelme, A., Arrese, M., Soza, A., Morales, A., Baudrand, R., Perez-Ayuso, R.M., Gonzalez, R., Alvarez, M., Hernandez, V., Garcia-Zattera, M.J., et al. 2009. Non-alcoholic fatty liver disease and its association with obesity, insulin resistance and increased serum levels of C-reactive protein in Hispanics. Liver Int 29:82-88.

17. Zelber-Sagi, S., Nitzan-Kaluski, D., Halpern, Z., and Oren, R. 2006. Prevalence of primary nonalcoholic fatty liver disease in a population-based study and its association with biochemical and anthropometric measures. Liver Int 26:856-863.

18. Church, T.S., Kuk, J.L., Ross, R., Priest, E.L., Biltoft, E., and Blair, S.N. 2006. Association of cardiorespiratory fitness, body mass index, and waist circumference to nonalcoholic fatty liver disease. Gastroenterology 130:2023-2030.

19. Targher, G., and Arcaro, G. 2007. Non-alcoholic fatty liver disease and increased risk of cardiovascular disease. Atherosclerosis 191:235-240. 
20. Adams, L.A., and Angulo, P. 2006. Treatment of non-alcoholic fatty liver disease. Postgrad Med J 82:315-322.

21. Fontaine, K.R., Redden, D.T., Wang, C., Westfall, A.O., and Allison, D.B. 2003. Years of life lost due to obesity. JAMA 289:187-193.

22. Muennig, P., Lubetkin, E., Jia, H., and Franks, P. 2006. Gender and the burden of disease attributable to obesity. Am J Public Health 96:1662-1668.

23. Hotamisligil, G.S. 2006. Inflammation and metabolic disorders. Nature 444:860-867.

24. Alipour, A., Elte, J.W., van Zaanen, H.C., Rietveld, A.P., and Cabezas, M.C. 2007. Postprandial inflammation and endothelial dysfuction. Biochemical Society transactions 35:466-469.

25. Kosteli, A., Sugaru, E., Haemmerle, G., Martin, J.F., Lei, J., Zechner, R., and Ferrante, A.W., Jr. 2010. Weight loss and lipolysis promote a dynamic immune response in murine adipose tissue. The Journal of clinical investigation 120:3466-3479.

26. Blackburn, P., Despres, J.P., Lamarche, B., Tremblay, A., Bergeron, J., Lemieux, I., and Couillard, C. 2006. Postprandial variations of plasma inflammatory markers in abdominally obese men. Obesity 14:1747-1754.

27. Butler, A.A., and Kozak, L.P. 2010. A recurring problem with the analysis of energy expenditure in genetic models expressing lean and obese phenotypes. Diabetes 59:323-329.

28. Zhang, Y., Proenca, R., Maffei, M., Barone, M., Leopold, L., and Friedman, J.M. 1994. Positional cloning of the mouse obese gene and its human homologue. Nature 372:425-432.

29. Becker, D.J., Ongemba, L.N., Brichard, V., Henquin, J.C., and Brichard, S.M. 1995. Diet- and diabetesinduced changes of ob gene expression in rat adipose tissue. FEBS letters 371:324-328.

30. Ahima, R.S. 2008. Revisiting leptin's role in obesity and weight loss. The Journal of clinical investigation 118:2380-2383.

31. Minokoshi, Y., Kim, Y.B., Peroni, O.D., Fryer, L.G., Muller, C., Carling, D., and Kahn, B.B. 2002. Leptin stimulates fatty-acid oxidation by activating AMP-activated protein kinase. Nature 415:339-343.

32. Muoio, D.M., Dohm, G.L., Fiedorek, F.T., Jr., Tapscott, E.B., and Coleman, R.A. 1997. Leptin directly alters lipid partitioning in skeletal muscle. Diabetes 46:1360-1363.

33. Haque, M.S., Minokoshi, Y., Hamai, M., Iwai, M., Horiuchi, M., and Shimazu, T. 1999. Role of the sympathetic nervous system and insulin in enhancing glucose uptake in peripheral tissues after intrahypothalamic injection of leptin in rats. Diabetes 48:1706-1712.

34. Kamohara, S., Burcelin, R., Halaas, J.L., Friedman, J.M., and Charron, M.J. 1997. Acute stimulation of glucose metabolism in mice by leptin treatment. Nature 389:374-377.

35. Arita, Y., Kihara, S., Ouchi, N., Takahashi, M., Maeda, K., Miyagawa, J., Hotta, K., Shimomura, I., Nakamura, T., Miyaoka, K., et al. 1999. Paradoxical decrease of an adipose-specific protein, adiponectin, in obesity. Biochemical and biophysical research communications 257:79-83.

36. Brichard, S.M., Delporte, M.L., and Lambert, M. 2003. Adipocytokines in anorexia nervosa: a review focusing on leptin and adiponectin. Hormone and metabolic research = Hormon- und Stoffwechselforschung = Hormones et metabolisme 35:337-342.

37. Ouchi, N., and Walsh, K. 2007. Adiponectin as an anti-inflammatory factor. Clinica chimica acta; international journal of clinical chemistry 380:24-30.

38. Kadowaki, T., and Yamauchi, T. 2005. Adiponectin and adiponectin receptors. Endocrine reviews 26:439-451.

39. Oh, D.K., Ciaraldi, T., and Henry, R.R. 2007. Adiponectin in health and disease. Diabetes, obesity \& metabolism 9:282-289.

40. Daniele, A., Cammarata, R., Masullo, M., Nerone, G., Finamore, F., D'Andrea, M., Pilla, F., and Oriani, G. 2008. Analysis of adiponectin gene and comparison of its expression in two different pig breeds. Obesity 16:1869-1874.

41. De Rosa, A., Monaco, M.L., Capasso, M., Forestieri, P., Pilone, V., Nardelli, C., Buono, P., and Daniele, A. 2013. Adiponectin oligomers as potential indicators of adipose tissue improvement in obese subjects. European journal of endocrinology / European Federation of Endocrine Societies 169:37-43.

42. Kaser, S., Tatarczyk, T., Stadlmayr, A., Ciardi, C., Ress, C., Tschoner, A., Sandhofer, A., Paulweber, B., Ebenbichler, C.F., and Patsch, J.R. 2008. Effect of obesity and insulin sensitivity on adiponectin isoform distribution. European journal of clinical investigation 38:827-834.

43. Meyer, L.K., Ciaraldi, T.P., Henry, R.R., Wittgrove, A.C., and Phillips, S.A. 2013. Adipose tissue depot and cell size dependency of adiponectin synthesis and secretion in human obesity. Adipocyte 2:217226. 
44. Balamayooran, G., Batra, S., Fessler, M.B., Happel, K.I., and Jeyaseelan, S. 2010. Mechanisms of neutrophil accumulation in the lungs against bacteria. Am J Respir Cell Mol Biol 43:5-16.

45. Akira, S., Uematsu, S., and Takeuchi, O. 2006. Pathogen recognition and innate immunity. Cell 124:783-801.

46. Kolaczkowska, E., and Kubes, P. 2013. Neutrophil recruitment and function in health and inflammation. Nature reviews. Immunology 13:159-175.

47. Vandivier, R.W., Henson, P.M., and Douglas, I.S. 2006. Burying the dead: the impact of failed apoptotic cell removal (efferocytosis) on chronic inflammatory lung disease. Chest 129:1673-1682.

48. Janssen, W.J., and Henson, P.M. 2012. Cellular regulation of the inflammatory response. Toxicol Pathol 40:166-173.

49. $\quad$ Frasch, S.C., Berry, K.Z., Fernandez-Boyanapalli, R., Jin, H.S., Leslie, C., Henson, P.M., Murphy, R.C., and Bratton, D.L. 2008. NADPH oxidase-dependent generation of lysophosphatidylserine enhances clearance of activated and dying neutrophils via G2A. The Journal of biological chemistry 283:3373633749.

50. Frasch, S.C., Fernandez-Boyanapalli, R.F., Berry, K.Z., Leslie, C.C., Bonventre, J.V., Murphy, R.C., Henson, P.M., and Bratton, D.L. 2011. Signaling via macrophage G2A enhances efferocytosis of dying neutrophils by augmentation of Rac activity. The Journal of biological chemistry 286:12108-12122.

51. Hamilton, J.A. 2008. Colony-stimulating factors in inflammation and autoimmunity. Nat Rev Immunol 8:533-544.

52. Burgess, A.W., and Metcalf, D. 1980. The nature and action of granulocyte-macrophage colony stimulating factors. Blood 56:947-958.

53. Gasson, J.C. 1991. Molecular physiology of granulocyte-macrophage colony-stimulating factor. Blood 77:1131-1145.

54. Serbina, N.V., Jia, T., Hohl, T.M., and Pamer, E.G. 2008. Monocyte-mediated defense against microbial pathogens. Annu Rev Immunol 26:421-452.

55. Guilliams, M., De Kleer, I., Henri, S., Post, S., Vanhoutte, L., De Prijck, S., Deswarte, K., Malissen, B., Hammad, H., and Lambrecht, B.N. 2013. Alveolar macrophages develop from fetal monocytes that differentiate into long-lived cells in the first week of life via GM-CSF. J Exp Med 210:1977-1992.

56. Yona, S., Kim, K.W., Wolf, Y., Mildner, A., Varol, D., Breker, M., Strauss-Ayali, D., Viukov, S., Guilliams, M., Misharin, A., et al. 2013. Fate mapping reveals origins and dynamics of monocytes and tissue macrophages under homeostasis. Immunity 38:79-91.

57. Italiani, P., and Boraschi, D. 2014. From Monocytes to M1/M2 Macrophages: Phenotypical vs. Functional Differentiation. Frontiers in immunology 5:514.

58. Grant, R.W., and Dixit, V.D. 2015. Adipose tissue as an immunological organ. Obesity 23:512-518.

59. Chawla, A., Nguyen, K.D., and Goh, Y.P. 2011. Macrophage-mediated inflammation in metabolic disease. Nat Rev Immunol 11:738-749.

60. Hotamisligil, G.S., Shargill, N.S., and Spiegelman, B.M. 1993. Adipose expression of tumor necrosis factor-alpha: direct role in obesity-linked insulin resistance. Science 259:87-91.

61. Kern, P.A., Saghizadeh, M., Ong, J.M., Bosch, R.J., Deem, R., and Simsolo, R.B. 1995. The expression of tumor necrosis factor in human adipose tissue. Regulation by obesity, weight loss, and relationship to lipoprotein lipase. J Clin Invest 95:2111-2119.

62. Nguyen, M.T., Favelyukis, S., Nguyen, A.K., Reichart, D., Scott, P.A., Jenn, A., Liu-Bryan, R., Glass, C.K., Neels, J.G., and Olefsky, J.M. 2007. A subpopulation of macrophages infiltrates hypertrophic adipose tissue and is activated by free fatty acids via Toll-like receptors 2 and 4 and JNK-dependent pathways. J Biol Chem 282:35279-35292.

63. Dey, A., Allen, J., and Hankey-Giblin, P.A. 2014. Ontogeny and polarization of macrophages in inflammation: blood monocytes versus tissue macrophages. Frontiers in immunology 5:683.

64. Amulic, B., Cazalet, C., Hayes, G.L., Metzler, K.D., and Zychlinsky, A. 2012. Neutrophil function: from mechanisms to disease. Annual review of immunology 30:459-489.

65. Ley, K., Laudanna, C., Cybulsky, M.I., and Nourshargh, S. 2007. Getting to the site of inflammation: the leukocyte adhesion cascade updated. Nature reviews. Immunology 7:678-689.

66. Mantovani, A., Cassatella, M.A., Costantini, C., and Jaillon, S. 2011. Neutrophils in the activation and regulation of innate and adaptive immunity. Nature reviews. Immunology 11:519-531.

67. Phillipson, M., and Kubes, P. 2011. The neutrophil in vascular inflammation. Nature medicine 17:1381-1390. 
68. Sadik, C.D., Kim, N.D., and Luster, A.D. 2011. Neutrophils cascading their way to inflammation. Trends in immunology 32:452-460.

69. Ley, K., Laudanna, C., Cybulsky, M.I., and Nourshargh, S. 2007. Getting to the site of inflammation: the leukocyte adhesion cascade updated. Nat Rev Immunol 7:678-689.

70. Phillipson, M., and Kubes, P. 2011. The neutrophil in vascular inflammation. Nat Med 17:1381-1390.

71. Sadik, C.D., Kim, N.D., and Luster, A.D. 2011. Neutrophils cascading their way to inflammation. Trends Immunol 32:452-460.

72. Zarbock, A., Ley, K., McEver, R.P., and Hidalgo, A. 2011. Leukocyte ligands for endothelial selectins: specialized glycoconjugates that mediate rolling and signaling under flow. Blood 118:6743-6751.

73. Williams, M.R., Azcutia, V., Newton, G., Alcaide, P., and Luscinskas, F.W. 2011. Emerging mechanisms of neutrophil recruitment across endothelium. Trends in immunology 32:461-469.

74. Pruenster, M., Mudde, L., Bombosi, P., Dimitrova, S., Zsak, M., Middleton, J., Richmond, A., Graham, G.J., Segerer, S., Nibbs, R.J., et al. 2009. The Duffy antigen receptor for chemokines transports chemokines and supports their promigratory activity. Nature immunology 10:101-108.

75. Phillipson, M., Heit, B., Colarusso, P., Liu, L., Ballantyne, C.M., and Kubes, P. 2006. Intraluminal crawling of neutrophils to emigration sites: a molecularly distinct process from adhesion in the recruitment cascade. J Exp Med 203:2569-2575.

76. Borregaard, N. 2010. Neutrophils, from marrow to microbes. Immunity 33:657-670.

77. Galli, S.J., Borregaard, N., and Wynn, T.A. 2011. Phenotypic and functional plasticity of cells of innate immunity: macrophages, mast cells and neutrophils. Nature immunology 12:1035-1044.

78. Hager, M., Cowland, J.B., and Borregaard, N. 2010. Neutrophil granules in health and disease. Journal of internal medicine 268:25-34.

79. Brotfain, E., Hadad, N., Shapira, Y., Avinoah, E., Zlotnik, A., Raichel, L., and Levy, R. 2015. Neutrophil functions in morbidly obese subjects. Clinical and experimental immunology 181:156-163.

80. Kordonowy, L.L., Burg, E., Lenox, C.C., Gauthier, L.M., Petty, J.M., Antkowiak, M., Palvinskaya, T., Ubags, N., Rincon, M., Dixon, A.E., et al. 2012. Obesity is associated with neutrophil dysfunction and attenuation of murine acute lung injury. Am J Respir Cell Mol Biol 47:120-127.

81. Palvinskaya, T., Antkowiak, M., Burg, E., Lenox, C.C., Ubags, N., Cramer, A., Rincon, M., Dixon, A.E., Fessler, M.B., Poynter, M.E., et al. 2013. Effects of acute and chronic low density lipoprotein exposure on neutrophil function. Pulm Pharmacol Ther 26:405-411.

82. Holgate, S.T. 2011. Pathophysiology of asthma: what has our current understanding taught us about new therapeutic approaches? J Allergy Clin Immunol 128:495-505.

83. Larche, M. 2007. Regulatory T cells in allergy and asthma. Chest 132:1007-1014.

84. Pradeepan, S., Garrison, G., and Dixon, A.E. 2013. Obesity in asthma: approaches to treatment. Current allergy and asthma reports 13:434-442.

85. Wenzel, S. 2012. Severe asthma: from characteristics to phenotypes to endotypes. Clin Exp Allergy 42:650-658.

86. Sutherland, E.R. 2014. Linking obesity and asthma. Annals of the New York Academy of Sciences 1311:31-41.

87. van Veen, I.H., Ten Brinke, A., Sterk, P.J., Rabe, K.F., and Bel, E.H. 2008. Airway inflammation in obese and nonobese patients with difficult-to-treat asthma. Allergy 63:570-574.

88. Lessard, A., Turcotte, H., Cormier, Y., and Boulet, L.P. 2008. Obesity and asthma: a specific phenotype? Chest 134:317-323.

89. Scott, H.A., Gibson, P.G., Garg, M.L., and Wood, L.G. 2011. Airway inflammation is augmented by obesity and fatty acids in asthma. The European respiratory journal 38:594-602.

90. Wood, L.G., Garg, M.L., and Gibson, P.G. 2011. A high-fat challenge increases airway inflammation and impairs bronchodilator recovery in asthma. The Journal of allergy and clinical immunology 127:1133-1140.

91. Rastogi, D., Fraser, S., Oh, J., Huber, A.M., Schulman, Y., Bhagtani, R.H., Khan, Z.S., Tesfa, L., Hall, C.B., and Macian, F. 2015. Inflammation, metabolic dysregulation, and pulmonary function among obese urban adolescents with asthma. Am J Respir Crit Care Med 191:149-160.

92. Lozano, R., Naghavi, M., Foreman, K., Lim, S., Shibuya, K., Aboyans, V., Abraham, J., Adair, T., Aggarwal, R., Ahn, S.Y., et al. 2012. Global and regional mortality from 235 causes of death for 20 age groups in 1990 and 2010: a systematic analysis for the Global Burden of Disease Study 2010. Lancet 380:2095-2128. 
93. Soriano, J.B., and Rodriguez-Roisin, R. 2011. Chronic obstructive pulmonary disease overview: epidemiology, risk factors, and clinical presentation. Proceedings of the American Thoracic Society 8:363-367.

94. Gan, W.Q., Man, S.F., Senthilselvan, A., and Sin, D.D. 2004. Association between chronic obstructive pulmonary disease and systemic inflammation: a systematic review and a meta-analysis. Thorax 59:574-580.

95. Chailleux, E., Laaban, J.P., and Veale, D. 2003. Prognostic value of nutritional depletion in patients with COPD treated by long-term oxygen therapy: data from the ANTADIR observatory. Chest 123:1460-1466.

96. Landbo, C., Prescott, E., Lange, P., Vestbo, J., and Almdal, T.P. 1999. Prognostic value of nutritional status in chronic obstructive pulmonary disease. American journal of respiratory and critical care medicine 160:1856-1861.

97. Poulain, M., Doucet, M., Major, G.C., Drapeau, V., Series, F., Boulet, L.P., Tremblay, A., and Maltais, F. 2006. The effect of obesity on chronic respiratory diseases: pathophysiology and therapeutic strategies. CMAJ : Canadian Medical Association journal = journal de l'Association medicale canadienne 174:1293-1299.

98. Cecere, L.M., Littman, A.J., Slatore, C.G., Udris, E.M., Bryson, C.L., Boyko, E.J., Pierson, D.J., and Au, D.H. 2011. Obesity and COPD: associated symptoms, health-related quality of life, and medication use. COPD 8:275-284.

99. Ramachandran, K., McCusker, C., Connors, M., Zuwallack, R., and Lahiri, B. 2008. The influence of obesity on pulmonary rehabilitation outcomes in patients with COPD. Chronic respiratory disease 5:205-209.

100. Wouters, E.F., and Schols, A.M. 1993. Prevalence and pathophysiology of nutritional depletion in chronic obstructive pulmonary disease. Respiratory medicine 87 Suppl B:45-47.

101. Sood, A., Petersen, H., Meek, P., and Tesfaigzi, Y. 2014. Spirometry and health status worsen with weight gain in obese smokers but improve in normal-weight smokers. American journal of respiratory and critical care medicine 189:274-281.

102. Phung, D.T., Wang, Z., Rutherford, S., Huang, C., and Chu, C. 2013. Body mass index and risk of pneumonia: a systematic review and meta-analysis. Obes Rev 14:839-857.

103. Gong, M.N., Bajwa, E.K., Thompson, B.T., and Christiani, D.C. 2010. Body mass index is associated with the development of acute respiratory distress syndrome. Thorax 65:44-50.

104. Stapleton, R.D., Dixon, A.E., Parsons, P.E., Ware, L.B., Suratt, B.T., and Network, N.A.R.D.S. 2010. The association between $\mathrm{BMI}$ and plasma cytokine levels in patients with acute lung injury. Chest 138:568-577.

105. Smith, A.G., Sheridan, P.A., Harp, J.B., and Beck, M.A. 2007. Diet-induced obese mice have increased mortality and altered immune responses when infected with influenza virus. J Nutr 137:1236-1243.

106. Easterbrook, J.D., Dunfee, R.L., Schwartzman, L.M., Jagger, B.W., Sandouk, A., Kash, J.C., Memoli, M.J., and Taubenberger, J.K. 2011. Obese mice have increased morbidity and mortality compared to non-obese mice during infection with the 2009 pandemic H1N1 influenza virus. Influenza Other Respir Viruses 5:418-425.

107. Mancuso, P., Gottschalk, A., Phare, S.M., Peters-Golden, M., Lukacs, N.W., and Huffnagle, G.B. 2002. Leptin-deficient mice exhibit impaired host defense in Gram-negative pneumonia. Journal of immunology 168:4018-4024.

108. Ubags, N.D., Vernooy, J.H., Burg, E., Hayes, C., Bement, J., Dilli, E., Zabeau, L., Abraham, E., Poch, K.R., Nick, J.A., et al. 2014. The Role of Leptin in the Development of Pulmonary Neutrophilia in Infection and Acute Lung Injury. Critical Care Medicine 42:E143-E151.

109. Fezeu, L., Julia, C., Henegar, A., Bitu, J., Hu, F.B., Grobbee, D.E., Kengne, A.P., Hercberg, S., and Czernichow, S. 2011. Obesity is associated with higher risk of intensive care unit admission and death in influenza A (H1N1) patients: a systematic review and meta-analysis. Obesity reviews : an official journal of the International Association for the Study of Obesity 12:653-659.

110. Mertz, D., Kim, T.H., Johnstone, J., Lam, P.P., Science, M., Kuster, S.P., Fadel, S.A., Tran, D., Fernandez, E., Bhatnagar, N., et al. 2013. Populations at risk for severe or complicated influenza illness: systematic review and meta-analysis. BMJ 347:f5061.

111. Phung, D.T., Wang, Z., Rutherford, S., Huang, C., and Chu, C. 2013. Body mass index and risk of pneumonia: a systematic review and meta-analysis. Obesity reviews : an official journal of the International Association for the Study of Obesity 14:839-857. 
112. Corrales-Medina, V.F., Valayam, J., Serpa, J.A., Rueda, A.M., and Musher, D.M. 2011. The obesity paradox in community-acquired bacterial pneumonia. Int J Infect Dis 15:e54-57.

113. Singanayagam, A., Singanayagam, A., and Chalmers, J.D. 2013. Obesity is associated with improved survival in community-acquired pneumonia. Eur Respir J 42:180-187.

114. Collins, S., Martin, T.L., Surwit, R.S., and Robidoux, J. 2004. Genetic vulnerability to diet-induced obesity in the C57BL/6J mouse: physiological and molecular characteristics. Physiology \& behavior 81:243-248.

115. Surwit, R.S., Kuhn, C.M., Cochrane, C., McCubbin, J.A., and Feinglos, M.N. 1988. Diet-induced type II diabetes in C57BL/6J mice. Diabetes 37:1163-1167.

116. West, D.B., Boozer, C.N., Moody, D.L., and Atkinson, R.L. 1992. Dietary obesity in nine inbred mouse strains. The American journal of physiology 262:R1025-1032.

117. Hummel, K.P., Dickie, M.M., and Coleman, D.L. 1966. Diabetes, a new mutation in the mouse. Science 153:1127-1128.

118. Ingalls, A.M., Dickie, M.M., and Snell, G.D. 1950. Obese, a new mutation in the house mouse. $J$ Hered 41:317-318.

119. Coleman, D.L., and Eicher, E.M. 1990. Fat (fat) and tubby (tub): two autosomal recessive mutations causing obesity syndromes in the mouse. The Journal of heredity 81:424-427.

120. Johnston, R.A., Theman, T.A., Lu, F.L., Terry, R.D., Williams, E.S., and Shore, S.A. 2008. Diet-induced obesity causes innate airway hyperresponsiveness to methacholine and enhances ozone-induced pulmonary inflammation. J Appl Physiol (1985) 104:1727-1735.

121. Johnston, R.A., Theman, T.A., and Shore, S.A. 2006. Augmented responses to ozone in obese carboxypeptidase E-deficient mice. Am J Physiol Regul Integr Comp Physiol 290:R126-133.

122. O'Donnell C, P., Schaub, C.D., Haines, A.S., Berkowitz, D.E., Tankersley, C.G., Schwartz, A.R., and Smith, P.L. 1999. Leptin prevents respiratory depression in obesity. Am J Respir Crit Care Med 159:1477-1484.

123. Van Heek, M., Compton, D.S., France, C.F., Tedesco, R.P., Fawzi, A.B., Graziano, M.P., Sybertz, E.J., Strader, C.D., and Davis, H.R., Jr. 1997. Diet-induced obese mice develop peripheral, but not central, resistance to leptin. J Clin Invest 99:385-390.

124. Shore, S.A., Rivera-Sanchez, Y.M., Schwartzman, I.N., and Johnston, R.A. 2003. Responses to ozone are increased in obese mice. J Appl Physiol (1985) 95:938-945.

125. Lu, F.L., Johnston, R.A., Flynt, L., Theman, T.A., Terry, R.D., Schwartzman, I.N., Lee, A., and Shore, S.A. 2006. Increased pulmonary responses to acute ozone exposure in obese $\mathrm{db} / \mathrm{db}$ mice. Am J Physiol Lung Cell Mol Physiol 290:L856-865.

126. Fricker, M., Deane, A., and Hansbro, P.M. 2014. Animal models of chronic obstructive pulmonary disease. Expert opinion on drug discovery 9:629-645.

127. Mercer, P.F., Abbott-Banner, K., Adcock, I.M., and Knowles, R.G. 2015. Translational models of lung disease. Clinical science 128:235-256.

128. Vlahos, R., and Bozinovski, S. 2015. Preclinical murine models of Chronic Obstructive Pulmonary Disease. European journal of pharmacology 759:265-271.

129. Brusselle, G.G., Bracke, K.R., Maes, T., D'Hulst A, I., Moerloose, K.B., Joos, G.F., and Pauwels, R.A. 2006. Murine models of COPD. Pulmonary pharmacology \& therapeutics 19:155-165.

130. Vernooy, J.H., Bracke, K.R., Drummen, N.E., Pauwels, N.S., Zabeau, L., van Suylen, R.J., Tavernier, J., Joos, G.F., Wouters, E.F., and Brusselle, G.G. 2010. Leptin modulates innate and adaptive immune cell recruitment after cigarette smoke exposure in mice. Journal of immunology 184:7169-7177.

131. Esquivel, A.L., Perez-Ramos, J., Cisneros, J., Herrera, I., Rivera-Rosales, R., Montano, M., and Ramos, C. 2014. The effect of obesity and tobacco smoke exposure on inflammatory mediators and matrix metalloproteinases in rat model. Toxicology mechanisms and methods 24:633-643.

132. Mutlu, G.M., Snyder, C., Bellmeyer, A., Wang, H., Hawkins, K., Soberanes, S., Welch, L.C., Ghio, A.J., Chandel, N.S., Kamp, D., et al. 2006. Airborne particulate matter inhibits alveolar fluid reabsorption in mice via oxidant generation. Am J Respir Cell Mol Biol 34:670-676.

133. Bellmeyer, A., Martino, J.M., Chandel, N.S., Scott Budinger, G.R., Dean, D.A., and Mutlu, G.M. 2007. Leptin resistance protects mice from hyperoxia-induced acute lung injury. Am J Respir Crit Care Med 175:587-594.

134. Varisco, B.M. 2011. The pharmacology of acute lung injury in sepsis. Adv Pharmacol Sci 2011:254619. 
135. Khan, M., Patrick, A.L., Fox-Robichaud, A.E., and Canadian Critical Care Translational Biology, G. 2014. Development of a murine model of early sepsis in diet-induced obesity. Biomed Res Int 2014:719853.

136. Konter, J.M., Parker, J.L., Baez, E., Li, S.Z., Ranscht, B., Denzel, M., Little, F.F., Nakamura, K., Ouchi, N., Fine, A., et al. 2012. Adiponectin attenuates lipopolysaccharide-induced acute lung injury through suppression of endothelial cell activation. J Immunol 188:854-863.

137. Shah, D., Romero, F., Duong, M., Wang, N., Paudyal, B., Suratt, B.T., Kallen, C.B., Sun, J., Zhu, Y., Walsh, K., et al. 2015. Obesity-induced adipokine imbalance impairs mouse pulmonary vascular endothelial function and primes the lung for injury. Sci Rep 5:11362.

138. Hsu, A., Aronoff, D.M., Phipps, J., Goel, D., and Mancuso, P. 2007. Leptin improves pulmonary bacterial clearance and survival in ob/ob mice during pneumococcal pneumonia. Clinical and experimental immunology 150:332-339.

139. Ordway, D., Henao-Tamayo, M., Smith, E., Shanley, C., Harton, M., Troudt, J., Bai, X., Basaraba, R.J., Orme, I.M., and Chan, E.D. 2008. Animal model of Mycobacterium abscessus lung infection. Journal of leukocyte biology 83:1502-1511.

140. Moore, S.I., Huffnagle, G.B., Chen, G.H., White, E.S., and Mancuso, P. 2003. Leptin modulates neutrophil phagocytosis of Klebsiella pneumoniae. Infection and immunity 71:4182-4185.

141. Mancuso, P., E, O.B., Prano, J., Goel, D., and Aronoff, D.M. 2014. No Impairment in host defense against Streptococcus pneumoniae in obese CPEfat/fat mice. PloS one 9:e106420.

142. Smith, A.G., Sheridan, P.A., Harp, J.B., and Beck, M.A. 2007. Diet-induced obese mice have increased mortality and altered immune responses when infected with influenza virus. The Journal of nutrition 137:1236-1243.

143. Easterbrook, J.D., Dunfee, R.L., Schwartzman, L.M., Jagger, B.W., Sandouk, A., Kash, J.C., Memoli, M.J., and Taubenberger, J.K. 2011. Obese mice have increased morbidity and mortality compared to non-obese mice during infection with the 2009 pandemic H1N1 influenza virus. Influenza and other respiratory viruses 5:418-425.

144. Smith, A.G., Sheridan, P.A., Tseng, R.J., Sheridan, J.F., and Beck, M.A. 2009. Selective impairment in dendritic cell function and altered antigen-specific CD8+ T-cell responses in diet-induced obese mice infected with influenza virus. Immunology 126:268-279.

145. Karlsson, E.A., Sheridan, P.A., and Beck, M.A. 2010. Diet-induced obesity impairs the T cell memory response to influenza virus infection. Journal of immunology 184:3127-3133.

146. O'Brien, K.B., Vogel, P., Duan, S., Govorkova, E.A., Webby, R.J., McCullers, J.A., and Schultz-Cherry, S. 2012. Impaired wound healing predisposes obese mice to severe influenza virus infection. $J$ Infect Dis 205:252-261.

147. Milner, J.J., Sheridan, P.A., Karlsson, E.A., Schultz-Cherry, S., Shi, Q., and Beck, M.A. 2013. Dietinduced obese mice exhibit altered heterologous immunity during a secondary 2009 pandemic H1N1 infection. J Immunol 191:2474-2485.

148. Radigan, K.A., Morales-Nebreda, L., Soberanes, S., Nicholson, T., Nigdelioglu, R., Cho, T., Chi, M., Hamanaka, R.B., Misharin, A.V., Perlman, H., et al. 2014. Impaired clearance of influenza A virus in obese, leptin receptor deficient mice is independent of leptin signaling in the lung epithelium and macrophages. PLoS One 9:e108138. 



\section{CHAPTER 2}

Aims and Thesis Outline 


\section{Aims and Thesis Outline}

Host defense against invading pathogens requires functional interplay between neutrophils, monocytes and macrophages, epithelial cells, and inflammatory cytokine signaling which are hallmarks of an intact innate immune response. Obesity is associated with dysregulation of the innate immune response, which is characterized by mildly increased levels of circulating pro-inflammatory cytokine levels and evidence of leukocyte and vascular activation. Previous studies have shown that obesity is associated with an increased risk of developing the Acute Respiratory Distress Syndrome (ARDS), while other studies have revealed obesity-associated defects in the innate immune response of subjects with ARDS, accompanied by improved outcomes from this disease. Furthermore, Recent meta-analyses suggest that obese individuals are at greater risk for and mortality from respiratory infections. However, the manner in which obesityassociated immune dysregulation may paradoxically contribute to increased susceptibility to ARDS and respiratory infections, yet improved outcomes from ARDS, as well as the involvement of host factors associated with an obese environment, remain unclear.

The overall aim of this thesis was to explore the mechanisms underlying the altered pulmonary innate immune response and host defense in obesity. It was demonstrated that obese subjects with ARDS have lower levels of several pro-inflammatory cytokines, suggesting that the inflammatory response may be altered in patients with ARDS and a high BMI. To further study the effects of obesity on the pulmonary innate immune response and subsequently the behavior of neutrophils in pulmonary host defense, we describe the effects of murine obesity on the pulmonary immune response following LPS-induced lung injury in Chapter 3. Two different models of murine obesity (dietinduced obese mice and obese mutant mice) were used to examine the pulmonary response to LPS-exposure. In addition, the effects of obesity on neutrophil function were preliminarily explored.

In Chapter $\mathbf{3}$ we found an attenuation of the inflammatory response in obese mice compared to their lean controls. However, differences were observed between the two models of obesity used. Therefore, we set out to examine the effects of obesity on bacterial infection and injury to the lung in the four most commonly used mouse models of obesity in Chapter 4. In addition, we further dissected the obesity-associated defects of neutrophil function.

Given that obesity is associated with an increased risk for the development of ARDS, yet is also associated with rapid attenuation of the inflammatory response and improved outcomes in both patients and animal models (Chapter 3), we decided to examine possible mechanisms controlling this paradoxical 'shift' in the inflammatory environment of the lung following injury. Little was known about obesity's effect on lung macrophages in either baseline or acutely inflamed conditions. Given the paradoxical findings witnessed in obese ARDS, one might predict that alveolar macrophage function and 
phenotype are abnormally 'skewed' by obesity in opposite directions between the baseline (uninjured) state and that of established ARDS. Chapter $\mathbf{5}$ describes the alveolar macrophage response in uninjured obese mice, and how the observed pro-inflammatory phenotype of these cells may be modulated in the course of established ARDS.

Obesity is associated with adipokine dysregulation and consequently a leptin-resistant state. Studies performed on the role and function of the adipokine leptin in a variety of diseases emphasize the importance of leptin as a key adipokine with several physiological processes, but also its potential implications in the pathogenesis of disease. Yet, many pieces of the pathogenic puzzle linking leptin to pathophysiology and clinical disease are missing. In Chapter 6, the involvement of leptin in the regulation of the pulmonary immune response in lung disease is reviewed.

One of the hallmarks of severe pneumonia and associated acute lung injury is neutrophil recruitment to the lung. Leptin is thought to be up-regulated in the lung following injury and to exert diverse effects on leukocytes. Therefore, Chapter $\mathbf{7}$ was aimed at determining whether leptin might participate directly to the development of pulmonary neutrophilia during pneumonia and ARDS.

Leptin is found in extremely high levels in obesity. Interestingly, several conditions that have inconsistently been associated with pneumonia risk, including pregnancy, diabetes, and chronic renal failure, are also associated with hyperleptinemia. In Chapter $\mathbf{8}$ we investigated whether obesity-associated hyperleptinemia, and not body mass per se, could be linked to the impaired response to pulmonary pathogens and increased susceptibility to infections.

In Chapter 9 the results of this thesis are discussed in a broader perspective and an outline of future directions is presented. 



\section{CHAPTER 3}

\section{Obesity and Neutrophil Dysfunction in Acute Lung Injury}

Lauren L. Kordonowy, Elianne Burg, Christopher C. Lenox, Lauren M. Gauthier, Joseph M. Petty, Maryellen Antkowiak, Tatsiana Palvinskaya, Niki D.J. Ubags, Mercedes Rincón, Anne E. Dixon, Juanita H.J. Vernooy, Michael B. Fessler, Matthew E. Poynter, and Benjamin T. Suratt.

Obesity is Associated with Neutrophil Dysfunction and Attenuation of Murine Acute Lung Injury. AJRCMB, July 2012, Volume 47, Issue 1, Pages 120-127 


\section{Abstract}

Rationale: Although obesity is implicated in numerous health complications leading to increased mortality, the relationship between obesity and outcomes for critically ill patients appears paradoxical. Recent studies have reported better outcomes and lower levels of inflammatory cytokines in obese patients with ALI/ARDS, suggesting that obesity may ameliorate the effects of this disease by yet unknown mechanisms.

Methods: We investigated the effects of obesity in both leptin-resistant $\mathrm{db} / \mathrm{db}$ obese and iet-induced obese mice using an inhaled lipopolysaccharide model of acute lung injury. Obesity-associated effects on neutrophil chemoattractant response were examined in bone marrow neutrophils using chemotaxis and adoptive transfer; neutrophil surface levels of chemokine receptor CXCR2 were determined by flow cytometry.

Results: Airspace neutrophilia, capillary leak, and plasma IL-6 were all decreased in obese relative to lean mice in established lung injury (24h). No difference in airspace inflammatory cytokine levels was found between obese and lean mice in both obesity models during the early phase of neutrophil recruitment ( $2 \mathrm{~h}-6 \mathrm{~h})$; yet early airspace neutrophilia was reduced in $\mathrm{db} / \mathrm{db}$ obese mice. Neutrophils from uninjured obese mice demonstrated diminished chemotaxis to the chemokine KC compared to lean controls, and adoptive transfer of obese mouse neutrophils into injured lean mice revealed a defect in airspace migration of these cells. Possibly contributing to this defect, neutrophil CXCR2 expression was significantly lower in obese $\mathrm{db} / \mathrm{db}$ mice, while a similar but nonsignificant decrease was seen in diet-induced obese mice.

Conclusions: Acute lung injury is attenuated in obese mice, and this blunted response is in part attributable to an obesity-associated abnormal neutrophil chemoattractant response. 


\section{Introduction}

Acute lung injury (ALI) and the acute respiratory distress syndrome (ARDS) are characterized by persistent, uncontrolled pulmonary inflammation that occurs in response to a wide range of insults, including pneumonia, sepsis and trauma $(1,2)$. Alveolar recruitment of neutrophils is thought to be a central factor in the onset and progression of this syndrome $(3,4)$, and increases in airspace neutrophilia and plasma neutrophilic cytokine levels, including TNF $\alpha, \mathrm{IL}-1 \beta, \mathrm{IL}-6$ and IL-8, are associated with increased morbidity and mortality from this disease $(3,5,6)$. It is increasingly recognized that ALI pathogenesis and outcome are strongly influenced by host factors, including genetic polymorphisms and comorbid conditions $(1,2)$. Preliminary clinical evidence suggests that obesity may have an ameliorative effect on ALI outcome (7). Although ambiguity exists in smaller studies $(8,9)$, recent large cohort studies from our group and others, as well as several meta-analyses, have shown a reduction in mortality with rising body mass index in ALI and critical illness in general (7, 10-16). Such an association, though tentative, is surprising because obesity is believed to be an inflammatory state with mild baseline elevations in blood TNF $\alpha$, IL-1 $\beta$, IL-6, and IL-8 (17) as well as increased blood neutrophil levels (18). Nevertheless, we have recently reported that in the context of established human ALI, plasma IL-6 and IL-8 fall with rising body mass index (19), suggesting that obesity may have an attenuating effect on inflammation in this disease.

Although animal studies examining the effects of obesity on ALI are scarce, recent reports demonstrate that spontaneously obese leptin-resistant ( $\mathrm{db} / \mathrm{db}$ ) and leptindeficient (ob/ob) mice (the most commonly used mouse models of obesity) have reduced lung injury and mortality from hyperoxic and ozone-induced lung injury (20-22). Only one report (22) has examined the effects of diet-induced obesity. Although these studies have implicated alterations in $\operatorname{IL}-6(22,23)$, and leptin $(20,21)$ signaling, mechanistic links between the obese state and the attenuation of ALI remain unclear. Most animal studies examining obesity-associated effects on pulmonary immunity have focused on models of asthma and pneumonia, and although airway inflammation appears to be amplified by obesity, the response to pneumonia is blunted $(24,25)$, suggesting that the inflammatory response in the alveoli (the site of ALI) is impaired. Although work in obese pneumonia models has highlighted alterations in macrophage function (26), little is known about obesity-associated effects on ALI pathogenesis, and even less is known of obesity's effects on the hallmark effector cell of ALI, the neutrophil.

In this study we demonstrate that obesity attenuates inflammatory response in an inhaled lipopolysaccharide (LPS) model of murine ALI, leading to a reduction in both pulmonary neutrophilia and injury. Furthermore, we show that obesity is associated with defects in neutrophil chemoattractant response common to both genetic and dietinduced models of obesity, indicating that disruption of neutrophil diapedesis into the lung contributes to the attenuated inflammatory response found in obese mice. 


\section{Materials and Methods}

\section{Mice}

For the diet-induced obesity model, male C57BL/6 mice (Jackson Labs, Bar Harbor, ME) were fed high vs. normal fat chow ( $60 \%$ vs. $10 \%$ fat; Research Diets, New Brunswick, NJ) for 20 wks. In a genetic model of obesity, male and female homozygous B6 db/db mice (leptin-resistant mice on a $\mathrm{C} 57 \mathrm{BI} / 6$ background that are spontaneously obese due to hyperphagia; Jackson Labs) and their lean heterozygous littermates were examined at 6 8 wks of age. Experiments were performed in accordance with the Animal Welfare Act and the USPHS Policy on Humane Care and Use of Laboratory Animals after review by the Animal Care and Use Committee of the University of Vermont.

\section{Lipopolysaccharide-induced Lung Injury}

Mice were exposed to aerosolized E.coli 0111:B4 lipopolysaccharide (LPS; Sigma, St. Louis, MO). The animals were euthanized 2, 6, or $24 \mathrm{~h}$ later and blood and bronchoalveolar lavage (BAL), and whole lungs were analyzed. Additional detail is provided in the online supplement.

\section{Determination of Cytokine, Total Protein, and Cholesterol Levels}

IL-6, KC, TNF- $\alpha$, MIP-2, and MCP-1 levels in mouse plasma and BAL supernatants were assessed by Bio-Plex suspension-array system (Bio-Rad, Hercules, CA). BAL protein levels were measured by Bradford assay (Bio-Rad). Uninjured-mouse plasma LDL cholesterol levels were assayed by FPLC. Additional detail is provided in the online supplement.

\section{Preparation of Morphologically-Mature Murine Bone Marrow Neutrophils}

Femurs/tibias of euthanized obese or lean mice were dissected, marrow flushed with HBSS, and layered on a 3-step Percoll (GE Healthcare, Piscataway, NJ) gradient (72\%, $64 \%$, and $52 \%$ ) which was centrifuged at $1060 \mathrm{~g}$ for $30 \mathrm{~min}$, as previously described (27, 28). Samples of the $72: 64 \%$ interface revealed $>95 \%$ morphologically mature-appearing neutrophils.

\section{Neutrophil Chemotaxis}

Chemotaxis of marrow neutrophils was measured in response to KC (R\&D Systems, Minneapolis, MN) using a 48-well modified Boyden Chamber with $5 \mu \mathrm{m}$ pore polycarbonate membranes (NeuroProbe Inc., Gaithersburg, MD), as previously described (29). 


\section{Neutrophil adoptive transfer}

Adoptive transfer of obese vs. lean mouse neutrophils was performed as we have previously described $(27,28)$. Briefly, $5 \times 106$ isolated bone marrow neutrophils/mouse were injected into lean mice by tail vein, after which recipient mice were exposed to inhaled LPS and examined at $24 \mathrm{~h}$, as described above.

\section{Calcium Flux Assays}

Calcium flux in marrow neutrophils was measured in response to $25 \mathrm{ng} / \mathrm{mL} \mathrm{KC}$ using Indo1/AM (Molecular Probes, Carlsbad, CA), as described (28).

\section{Determination of Neutrophil Surface CXCR2 Expression}

CXCR2 surface expression on marrow neutrophils was measured using an LSR II flow cytometer (BD, San Jose, CA) after dual-staining the cells with anti-Gr-1-Pacific Blue monoclonal antibody, and either Alexa-Fluor 647 anti-mouse CD182 (CXCR2; Biolegend, San Diego, CA) or isotype-control monoclonal antibodies, and the resulting data analyzed by FloJo software (TreeStar, Ashland, OR), as described (28).

\section{Statistical Analysis}

Correlations between weight and BAL neutrophil levels, as well as covariates that might affect BAL neutrophil levels, including age, and weight, were analyzed by linear regression using STATA 10.0 (College Station, TX). All other data were analyzed with the Student's or Welch's t-test, using Prism 5 software (GraphPad, La Jolla, CA). Results are reported with SEM in the case of t-test analysis, and with $95 \%$ confidence intervals for linear regressions. 


\section{Results}

\section{Obesity attenuates pulmonary neutrophilia and capillary leak yet increases blood neutrophilia in established acute lung injury}

To investigate possible mechanisms for obesity-induced attenuation of ALI, we examined LPS injury in both $\mathrm{db} / \mathrm{db}$ (leptin-resistant mice spontaneously obese due to hyperphagia) and diet-induced (fed high fat chow for 20 weeks) obese mice. Twenty-four hours after LPS exposure, this injury model reproduces many of the features of established human $A L I$, including the often extreme blood and pulmonary neutrophilia implicated in the pathogenesis of the disease, as well as the formation of proteinaceous alveolar edema, the sine qua non of ALI (1). Mice from both obesity models examined in these studies were found to weigh significantly more than their lean controls at the time of LPS exposure: lean heterozygous $\mathrm{db}$ mice weighed $22.2+/-0.9 \mathrm{~g}, \mathrm{db} / \mathrm{db}$ weighed $41.8+/-1.7 \mathrm{~g}$, $\mathrm{p}<0.0001 ; 10 \%$ fat diet mice weighed $32.1+/-0.9 \mathrm{~g}, 60 \%$ fat diet $47.5+/-0.8 \mathrm{~g}, \mathrm{p}<0.0001$. Twenty-four hours after LPS exposure, airspace neutrophilia was diminished in both $\mathrm{db} / \mathrm{db}$ and diet-induced obese (DIO) mice compared to their lean controls (Figure 1A/1D). In addition, bronchoalveolar lavage (BAL) fluid total protein content (a marker of alveolar injury and capillary leak) was decreased in both $\mathrm{db} / \mathrm{db}$ and diet-induced obese mice relative to lean mice after injury (Figure 1B/1E). Histological examination of lungs from injured animals (online data supplement Figure E1) demonstrated less injury in obese mice, with decreased airspace neutrophilia and serum protein leak seen in the obese $\mathrm{db} / \mathrm{db}$ and, to a slightly lesser degree, in the obese DIO compared to lean mice. Total lung tissue neutrophil content as gauged by whole-lung myeloperoxidase activity was decreased in the injured obese mice compared to leans in the $\mathrm{db} / \mathrm{db}$ model of obesity, but was similar between lean and obese mice in the DIO model (Figure E2). Similar to our findings in human ALI (19), higher levels of blood neutrophilia were present in $\mathrm{db} / \mathrm{db}$ and diet-induced obese mice (Figure $1 \mathrm{C} / 1 \mathrm{~F}$ ) relative to lean mice following injury. Obese and lean mice exposed to nebulized saline solution showed no evidence of inflammation or injury (data not shown).

These findings suggest that the obese state in mice attenuates two cardinal features of $\mathrm{ALI}$ that have been shown to predict poor outcomes from this disease in humans (1). In further confirmation of the effect of weight on lung injury, we noted an inverse correlation between pre-injury mouse weights and subsequent levels of airspace neutrophilia following injury in both obesity models (Figure 2A and B). Univariate regression analysis of the combined obese and lean mice from both mouse models ( $\mathrm{db} / \mathrm{db}$ and diet-induced) showed a highly significant relationship between BAL neutrophil levels and weight: $p=0.001$, adjusted $r 2=0.25$ (Figure $2 \mathrm{C}$ ). There was no relationship between age or obesity model ( $\mathrm{db} / \mathrm{db}$ versus diet-induced obesity) and BAL neutrophil levels ( $p=0.75$ and 0.77 , respectively). 

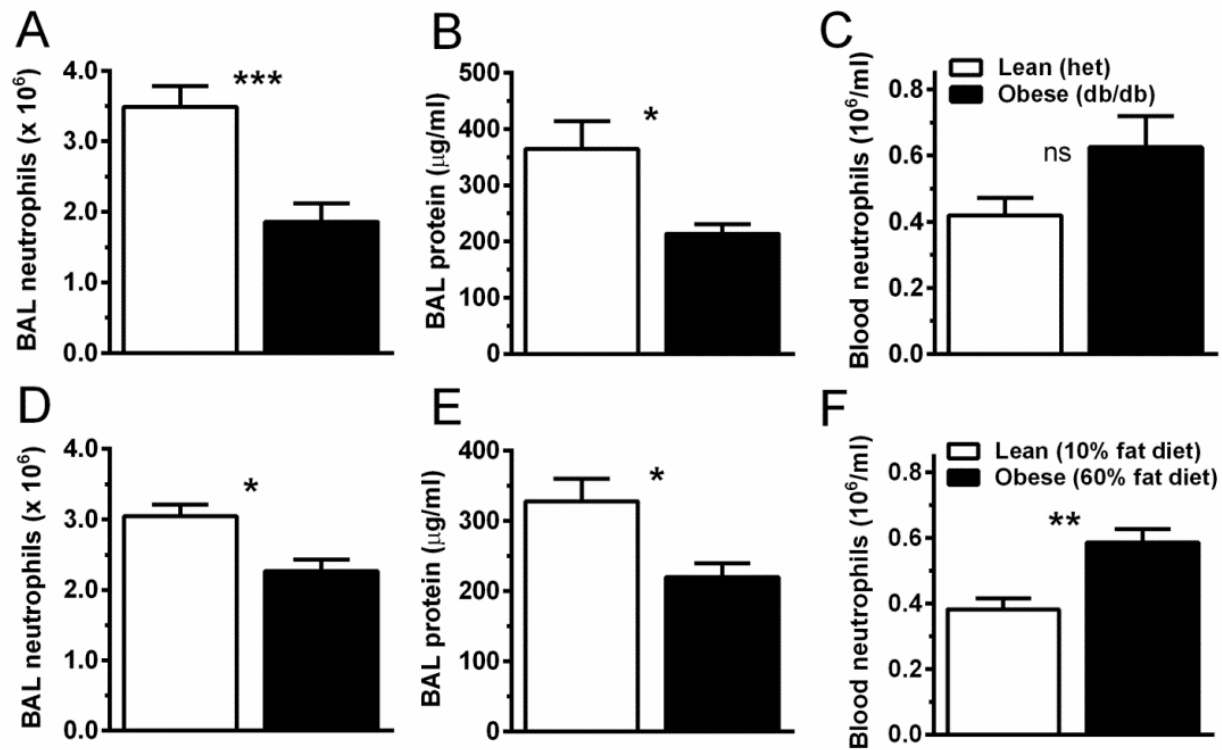

Figure 1 Obesity attenuates airspace neutrophilia and lung injury in $\mathrm{db} / \mathrm{db}$ and diet-induced obese mice. Acute lung injury was induced by the inhalation of LPS in genetically obese (db/db) versus lean (heterozygous littermate control) mice $(A-C)$, and diet-induced obese (60\% fat diet) versus lean (10\% fat diet) mice (D - F). Mice were exposed to nebulized Escherichia coli LPS (3 mg/ml; $15 \mathrm{~min}$ ) 24 hours before determining bronchoalveolar lavage (BAL) $(A, D)$ and blood $(C, F)$ neutrophil levels by cell counter. $B A L$ protein content $(B, E)$ was determined by Bradford assay. $\mathrm{n}=8$ (diet-induced) or $12(\mathrm{db} / \mathrm{db})$ mice per condition. $* P<0.05$; ${ }^{* *} P<0.01$; $* * * P<0.001$. ns= not significant.

\section{Early pulmonary cytokine response to injury is normal to elevated in obese mice}

To determine whether the impaired pulmonary neutrophilia seen in established LPSinduced injury was caused by attenuated pulmonary cytokine release or by a primary defect in neutrophil chemotaxis, we next examined BAL cytokine and neutrophil levels during the early phase of neutrophil recruitment ( $2 \mathrm{~h}$ after LPS injury). At this early time point, BAL levels of inflammatory cytokines including the CXC chemokines KC and MIP-2, critical in pulmonary neutrophil recruitment, were normal to elevated in $\mathrm{db} / \mathrm{db}$ and DIO obese mice compared to lean controls (Figure $3 \mathrm{~A} / \mathrm{C}$ ). However, despite this normal cytokine response, neutrophil recruitment into the airspace of obese mice was still significantly blunted at this early time point in the $\mathrm{db} / \mathrm{db}$ model (Figure 3B), while not significantly different in the DIO obese mice (Figure 3D). Examination of $6 \mathrm{~h}$ time points showed similar findings (Figure E3). As neutrophil recruitment to the lung is governed primarily by blood neutrophil mobilization (which we found to be elevated in obese mice, Figure $1 C / F$ ), pulmonary chemokine production (Figure $3 \mathrm{~A}$, also normal), and 
neutrophil chemotaxis, we next questioned whether the obese state confers an intrinsic migratory defect upon the neutrophil.

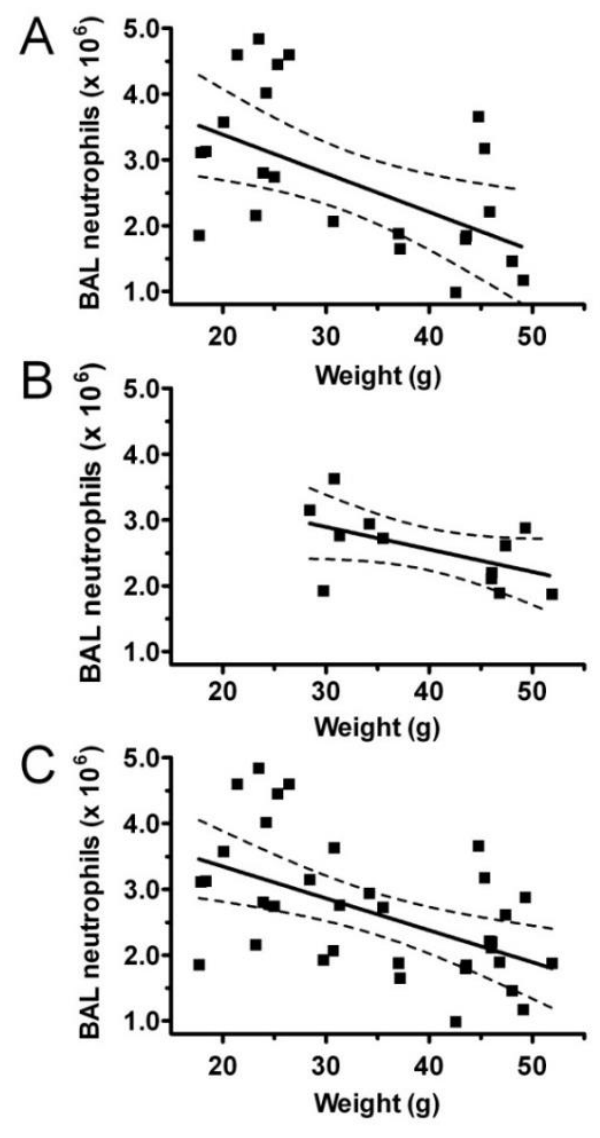

Figure 2 Airspace neutrophilia is inversely related to mouse weight in LPS-injured lean and obese mice. BAL neutrophil levels 24 hours after nebulized LPS exposure in genetically obese $(\mathrm{db} / \mathrm{db})$ and lean (heterozygous littermate control) mice $(A)$ and diet-induced obese $(60 \%$ fat diet) versus lean ( $10 \%$ fat diet) mice $(B)$ were graphed versus mouse weights measured immediately before injury. Db/db mice: $r^{2}=0.27$, $P=0.0096$ by linear regression; diet-induced mice: $r^{2}=0.32, P=0.02$. Combining lean and obese mice from $\mathrm{db} / \mathrm{db}$ and diet-induced models (C), an inverse relationship between weight and airspace neutrophilia remained and was not affected by mouse age or obesity model $(P=$ 0.001 , adjusted $\left.r^{2}=0.25\right)$. Dashed lines indicate $95 \%$ confidence intervals.

\section{Obesity attenuates neutrophil chemotaxis response and airspace entry}

To investigate whether intrinsic defects in neutrophil function might contribute to the attenuation of airspace neutrophil recruitment in obese mice, we examined chemoattractant response in neutrophils from lean and obese mice using modified Boyden chambers. Chemotaxis to the neutrophilic chemokine KC was found to be markedly attenuated in neutrophils from both $\mathrm{db} / \mathrm{db}$ and diet-induced obese animals compared to lean controls (Figure 4). Examination of neutrophil chemotaxis response to a range of $\mathrm{KC}$ concentrations demonstrated that obese neutrophil response is subtly impaired at low KC concentrations and this defect increases with rising concentrations of this chemokine (Figure E4), suggesting a rightward shift of the KC response curve in obese mouse neutrophils. To determine whether the obesity-associated defects in neutrophil airspace migration we found in vivo were conferrable using neutrophil 
adoptive transfer, we injected isolated marrow neutrophils from either obese or lean mice into recipient lean mice which were then exposed to inhaled LPS. At $24 \mathrm{~h}$, the resulting airspace neutrophilia was significantly lower in mice receiving obese compared to lean mouse neutrophils (Figure E5). Thus, obesity appears to be associated with previously undescribed intrinsic abnormalities in neutrophil function.
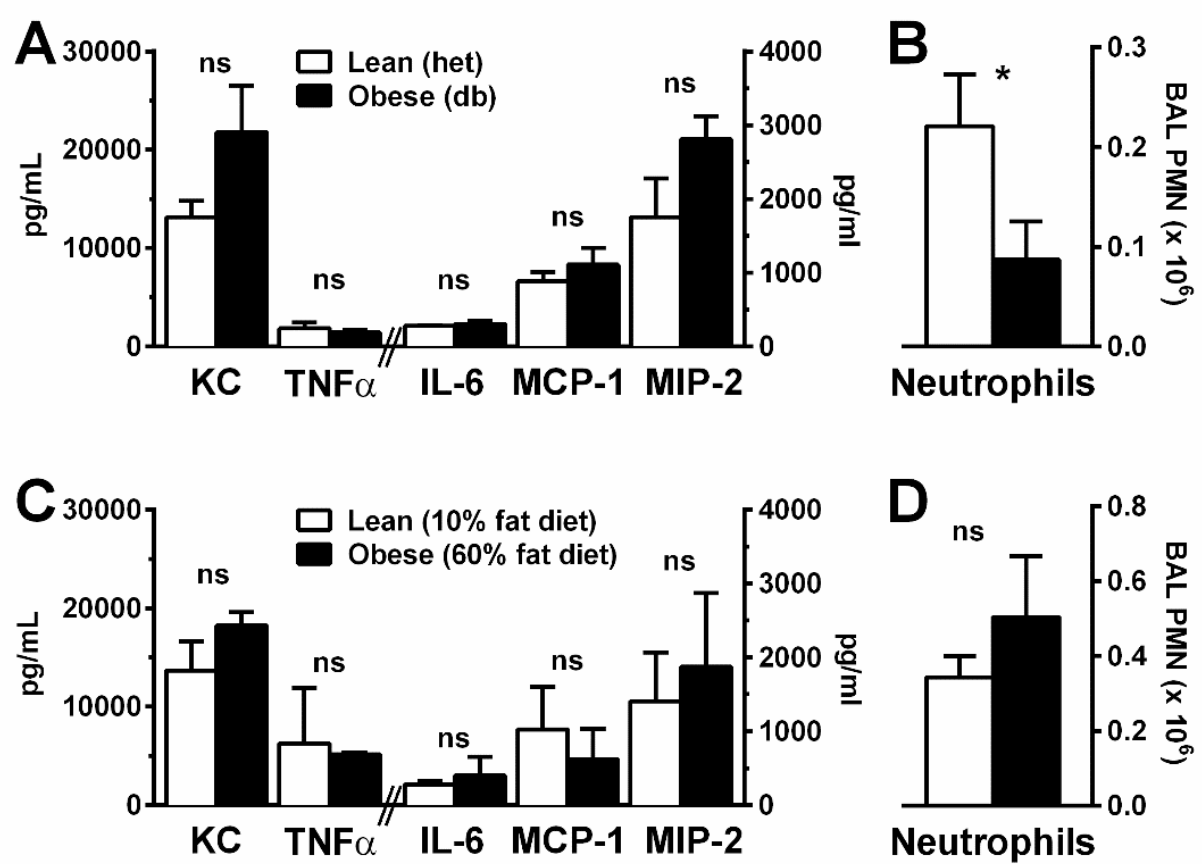

Figure 3 Initial lung cytokine response to injury is normal in obese mice, but early neutrophilia is decreased. BAL cytokine $(A, C)$ and neutrophil $(B, D)$ levels 2 hours after nebulized LPS exposure in lean compared with genetically obese $(\mathrm{db} / \mathrm{db})$ and diet-induced obese mice were determined by Bio-Plex and cell counter, respectively. $\mathrm{n}=6$ mice/condition. ${ }^{*} P<0.05$. $\mathrm{ns}=$ not significant. 


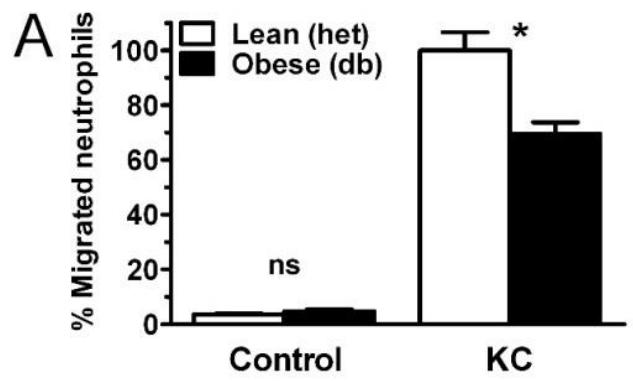

Figure 4 Obesity impairs neutrophil chemotaxis. Chemotaxis of density centrifugation-isolated mature bone marrow neutrophils from genetically obese $(\mathrm{db} / \mathrm{db})(A)$ and diet-induced obese (B) mice was compared with lean control mice using a modified Boyden chamber with $\mathrm{KC}(25 \mathrm{ng} / \mathrm{ml})$. Membrane counts were expressed as percentage

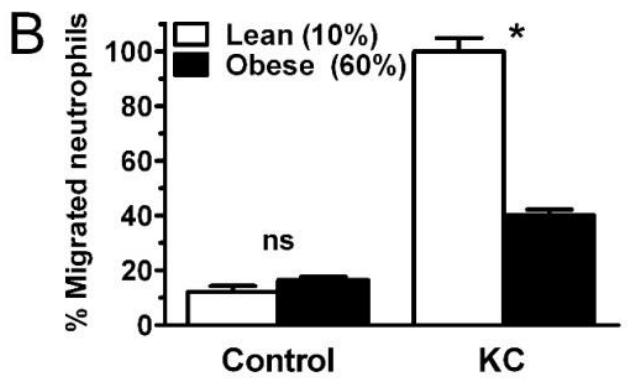
of lean control neutrophil migration to KC for each experiment. Four separate experiments were performed on $\mathrm{db} / \mathrm{db}$ and diet-induced obese mouse isolated neutrophils and respective control mice. ${ }^{*} P<0.01$.

Figure 5 Obesity attenuates calcium flux in response to chemoattractants. Cellular calcium flux in response to the CXC cytokine $\mathrm{KC}(25 \mathrm{ng} / \mathrm{ml})$ was determined in mature bone marrow neutrophils isolated from genetically obese (db/db) (A) and diet-induced obese (B) mice and compared with lean control mice using Indo-1AN cytosolic dyeloading and flow cytometry. Three separate experiments were performed on $\mathrm{db} / \mathrm{db}$ and dietinduced obese mouse isolated neutrophils and respective control mice; representative runs are shown for each source.

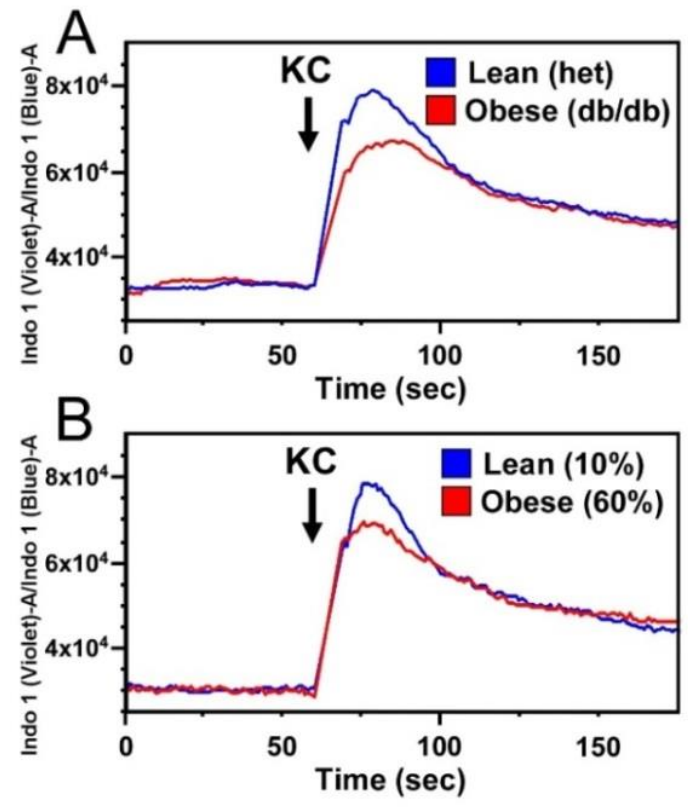




\section{Obesity is associated with blunted neutrophil signaling response to $\mathrm{KC}$ and decreased neutrophil surface display of the chemoattractant receptor CXCR2}

To explore the obesity-related defect in neutrophil chemotaxis, we first examined cellular calcium flux, an early response to ligation of receptors driving neutrophil chemotaxis. As shown in Figure 5, diminished calcium flux to KC was seen in neutrophils from obese $\mathrm{db} / \mathrm{db}$ and diet-induced obese mice. To further dissect this defect, we next examined neutrophil surface levels of CXCR2, the receptor for KC and MIP-2, in db/db and diet-induced obese compared to lean animals. Surface expression of CXCR2 was found to be significantly decreased in neutrophils from obese $\mathrm{db} / \mathrm{db}$ animals compared to lean littermates (Figure 6A). This effect was less pronounced and did not reach significance in the diet-induced obese mice (Figure 6B). Histographic representation of this data (Figure E6) demonstrates a broader range of surface CXCR2 staining intensity in neutrophils from obese mice as opposed to those from lean, which appear to express CXCR2 highly in a more uniform distribution. These histograms also illustrate differences between $\mathrm{db} / \mathrm{db}$ and DIO neutrophil CXCR2 expression patterns, in that DIO neutrophils, although appearing to stain less intensely that lean controls, show a more narrow distribution in expression than do obese $\mathrm{db} / \mathrm{db}$.

\section{Obesity is associated with decreased BAL and plasma IL-6 levels in LPS- induced acute lung injury}

Although obesity is generally believed to confer an inflammatory cytokine environment, we have previously shown that plasma levels of the key inflammatory cytokine, IL-6, are decreased in obese ALI patients (30). We therefore sought to determine whether obese mice might manifest a similar attenuation in the setting of established ALI. Interestingly, similar to ALI patients, plasma levels of IL- 6 were reduced in $\mathrm{db} / \mathrm{db}$ obese mice compared to lean controls 24 hours after LPS-induced lung injury (Figure 7A). The reduction in IL-6 levels was less pronounced in diet-induced obese mice and did not reach significance (Figure 7B). Similar to findings at both 2 and $6 \mathrm{~h}$ time points, 24h BAL levels of KC, TNF- $\alpha$, and MIP-2 did not differ between lean and obese lung-injured mice (Figure E7). However, in contrast to early time points, BAL levels of both IL- 6 and MCP-1 appeared to be blunted by $24 \mathrm{~h}$ in obese mice. 


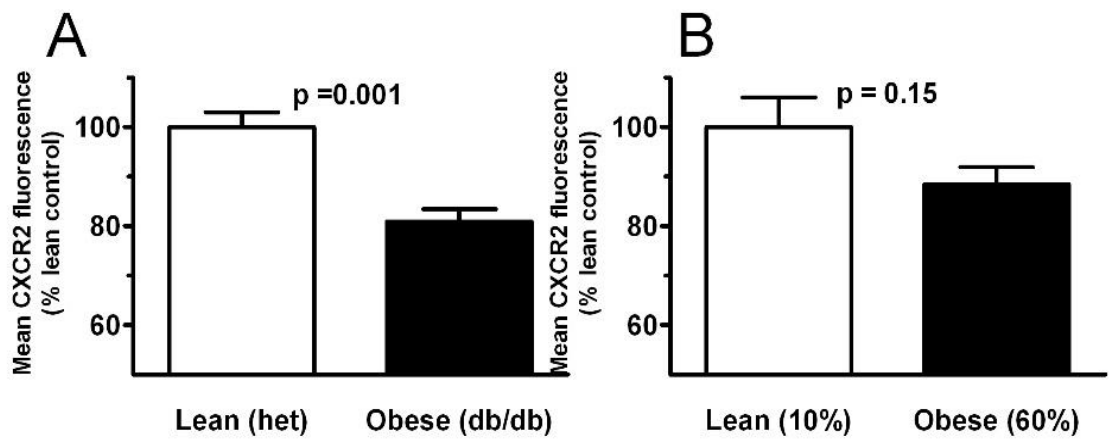

Figure 6 Obesity is associated with decreased neutrophil surface expression of CXCR2. Cell surface expression levels on CXCR2 were determined on mature bone marrow neutrophils isolated from genetically obese $(\mathrm{db} / \mathrm{db})$ (A) and diet-induced obese (B) mice and compared with lean control mice using flow cytometry. Three separate experiments were performed on $\mathrm{db} / \mathrm{db}$ and diet-induced obese mouse isolated neutrophils and respective control mice, and reported results are normalized to control for each experiment.
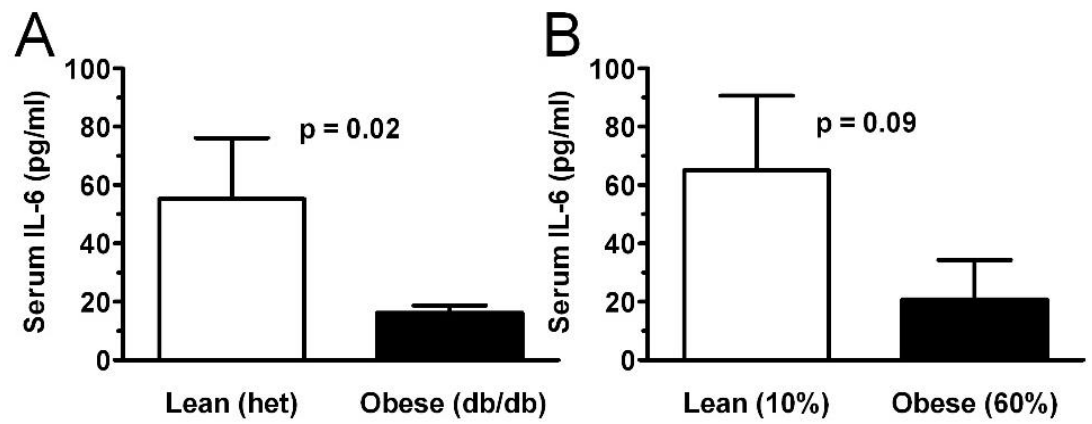

Figure 7 Obesity attenuates plasma IL-6 response in db/db and diet-induced obese mice. Plasma IL-6 levels 24 hours after inhaled LPS-induced lung injury were measured by Bio-Plex in genetically obese (db/db) (A) and diet-induced obese (B) mice compared with lean control mice. $n=6$ (diet-induced) or 12 (db/db) mice per condition. 


\section{Discussion}

In the present study we demonstrate an attenuating effect of obesity on LPS-induced lung injury and neutrophil trafficking in both genetically hyperphagic ( $\mathrm{db} / \mathrm{db})$ and dietinduced mouse models of obesity, and implicate obesity-related defects in neutrophil chemotaxis in this diminished response. This is consistent with our previously published findings on obesity's dampening effects on the inflammatory response in human ALI.

Previous work has suggested that obesity may have an attenuating effect on both hyperoxic and ozone-induced lung injury models, although in the case of ozone exposure, findings are mixed, and appear to vary with the acuity of exposure and possibly the timing of examination $(22,31,32)$. These findings, in light of the early evidence that obesity may have a 'protective' effect in human ALI/ARDS $(7,33,34)$, suggest that a clinically relevant alteration in the acute pulmonary inflammatory response may be associated with weight gain. Although limited work to date has explored this effect in animal models, both leptin-resistance (21) and alterations in IL-6 signaling (22) have been implicated in the attenuation of acute lung inflammation, yet the possible role of obesity-associated neutrophil function defects has not previously been investigated.

Examining an LPS-induced lung injury model, we find that both $\mathrm{db} / \mathrm{db}$ and diet-induced obese animals show decreased airspace neutrophilia and attenuated capillary leak. Interestingly, elevated levels of circulating neutrophils are seen in the obese mice in our studies, similar to findings we have previously reported in obese patients with ARDS (30). This suggests that neutrophil mobilization in response to injury is not impeded in obesity, implicating a defect in the recruitment of blood-borne neutrophils to the airspace as the cause of attenuated injury and neutrophilia. Although such a finding could result from an abnormal pulmonary cytokine response, in our models the pro-inflammatory cytokine response appears to be normal. Furthermore, in the case of the $\mathrm{db} / \mathrm{db}$ model of obesity, airspace neutrophilia is blunted even in this early phase of recruitment, suggesting that defects in neutrophil response may exist in obese animals leading to impaired neutrophil migration into the lung. This is further suggested by our adoptive transfer studies in which neutrophils from obese animals show significantly impaired airspace migration when infused into lung-injured, lean recipients. Thus, obesity appears to confer an intrinsically impaired neutrophil migratory response that is independent of any additional host defects that may accompany obesity.

Neutrophil diapedesis into the lung is a complex process, requiring endovascular rolling, adhesion, and subsequent chemokine-directed tissue migration to the alveolar space (35). Although defects in neutrophil chemotaxis may arise from alteration in multiple cellular processes, we find that impaired response to the CXC chemokine KC is evident in obese neutrophils during the earliest signaling event that initiates chemotaxis, calcium flux. Associated with this impairment, we find evidence of significantly decreased surface 
levels of the CXCR2 receptor on neutrophils from $\mathrm{db} / \mathrm{db}$ obese animals, and to a lesser degree in DIO mice. The cause of this reduction in CXCR2 is unclear. Although obesity is known to be accompanied by chronic low level systemic inflammation which could lead to CXC cytokine-mediated reduction in neutrophil CXCR2 display, plasma inflammatory cytokine levels including both CXCR2 ligands, KC and MIP-2, are not significantly different between naïve obese and lean mice in either model of obesity (Figure E8). It also is important to note that, even in the case of $\mathrm{db} / \mathrm{db}$-derived neutrophils, unknown mechanisms other than reduced CXCR2 display must contribute to obese-associated neutrophil chemotaxis defects, given the disproportionate magnitude of this defect in relation to the observed reduction in surface CXCR2.

The finding of an obesity-linked, primary defect in neutrophil function adds to the growing list of obesity-associated defects suggested to contribute to the attenuated pulmonary inflammatory response, including leptin resistance and abnormalities in IL-6 signaling, and is notably similar to our previously-published findings examining lean mouse models of dyslipidemia (36), a condition known to accompany obesity. In our previous studies, lean mice with diet-induced hypercholesterolemia demonstrated a small but significant reduction in pulmonary neutrophilia $24 \mathrm{~h}$ after exposure to nebulized LPS, which was associated with defects in neutrophil chemotaxis as well as decreased neutrophil surface levels of CXCR2 (36). Although the effects of hypercholesterolemia on neutrophil trafficking were less substantial than those we report here in obese mice, such findings suggest that hypercholesterolemia, present in both models of obesity in this report (online data supplement Figure E9), may in part contribute to the obesity-associated defects in neutrophil chemotaxis.

It is worth noting that, although the current literature is inconclusive, there are suggestions that obesity may affect the recruitment of neutrophils to the lung differently from recruitment to other sites. For instance, peritoneal recruitment of neutrophils may in fact be augmented in obesity in sterile peritonitis (37). How this may be reconciled with our current finding of obesity-associated impairment of neutrophil chemotaxis is as yet unclear. Interestingly, we have previously described a similar paradox in hypercholesterolemic mice (36), in which we find isolated neutrophils to have similar defects in chemotaxis associated with increased recruitment to the inflamed peritoneum despite impaired recruitment to the lung using the same inflammatory agents (LPS, Klebsiella infection). The etiology of this difference is unclear but may involve augmented cytokine response in the peritoneum compared to the lung.

Lastly, examination of inflammatory cytokine levels in our models demonstrates that although the initial pulmonary cytokine response in obese animals appears normal, a reduction in plasma IL-6 levels is seen in more established injury (24h). This finding is similar to our previous findings in human ALI patients, in which plasma IL- 6 was found to be decreased in the obese. Interestingly, both MCP-1 and to a lesser degree IL- 6 are reduced in the airspace of obese animals with lung injury at $24 \mathrm{~h}$ (Figure E9). It is unclear 
whether this occurrence reflects a downstream effect of attenuated neutrophil recruitment (as neutrophils are an important source of both IL- 6 and MCP-1 release following lung injury (38)), or an evolving defect in either the monocyte/macrophage or pulmonary epithelial response during the course of lung injury. Yet, in the case of IL-6, this decrease in alveolar cytokine release appears to mirror the defect seen in systemic cytokine response.

It should be noted that differences are evident between our two mouse models of obesity. We find that $\mathrm{db} / \mathrm{db}$ and diet-induced obesity models show similar defects in neutrophil chemotaxis, and comparable attenuations in airspace neutrophilia and capillary leak in the setting of established lung injury (24h). However, these models manifest subtle differences in other aspects of the inflammatory response, possibly attributable to their disparate mechanisms and duration of obesity. Although $\mathrm{db} / \mathrm{db}$ mice are primarily hyperphagic and rapidly develop obesity on normal chow within 4-6 weeks of birth, DIO mice develop obesity as a product of high fat chow over the course of 20 weeks. Thus, full manifestations of the metabolic syndrome such as vascular activation and injury are likely to be greater at baseline in the DIO model compared to the $\mathrm{db} / \mathrm{db}$ model. Such endothelial activation may account for the normal to increased early neutrophil recruitment seen in injured obese DIO compared to lean mice (Figure 3D) (as well as the relatively normal lung MPO content) that occurs in this model despite the demonstrated obesity-associated defects in neutrophil chemotaxis.

Several other notable differences between obesity models exist. Mice with diet-induced obesity appear to have less pronounced alterations in neutrophil recruitment, calcium flux, and CXCR2 expression, compared to the $\mathrm{db} / \mathrm{db}$ model of obesity, while it is also evident that lean mice in the diet-induced model have a blunted response to LPS injury compared to lean heterozygous db mice. Several factors may account for these findings. Lean mice in the diet-induced model are significantly heavier than lean mice in the $\mathrm{db} / \mathrm{db}$ model $(22.2+/-0.9 \mathrm{~g}$ vs. $32.1+/-0.9 \mathrm{~g}, \mathrm{p}<0.0001)$, suggesting that differences in weight might affect BAL neutrophilia even in the 'lean' groups. Diet composition which differs substantially between models also has been shown to alter the inflammatory response (39), and may contribute to the differences seen between models. Although we do not find a significant correlation between airspace neutrophilia and mouse age in our lung injury model, age has been shown to impair neutrophil chemotaxis response in mice and humans, independent of weight, through unclear mechanisms (40-44) and this may augment the defect in DIO neutrophils independent of CXCR2 expression levels. Lastly, the development of spontaneous diabetes in the $\mathrm{db} / \mathrm{db}$ mouse model is well known, and although our experiments were designed to limit the development of frank diabetes in the animals by using mice on a non-diabetogenic background (B6) and examining them at an age prior to the typical onset of diabetes $(45,46)$, we cannot exclude the possibility that early diabetes may have influenced inflammatory response in the obese $\mathrm{db} / \mathrm{db}$ mice to some degree. Thus, we might expect that the multiple differences between the $\mathrm{db} / \mathrm{db}$ 
and DIO obesity models would alter how obesity-associated defects in neutrophil function and recruitment are expressed. Despite this, the shared phenotype of impaired pulmonary inflammatory response and neutrophil dysfunction in both models suggests that the obese state itself has an overarching effect on the pathogenesis of lung injury.

In summary, we show that obesity has an attenuating effect on LPS-induced lung injury and neutrophil trafficking in two mouse models of obesity. This occurs despite an apparently normal early pulmonary cytokine response and with elevated levels of circulating neutrophils. Further examination revealed that the witnessed attenuation on pulmonary neutrophilia in both models may in part be due to obesity-related abnormalities in neutrophil CXCR2 signaling with associated defects in neutrophil chemotaxis. Taken together, these results suggest that neutrophil dysfunction may play a prominent role in what appears to be a complex, multifactorial process underlying the attenuation of lung injury in obesity. Further studies are warranted to better characterize and dissect these obesity-related alterations in neutrophil function.

\section{Acknowledgements}

The authors would like to acknowledge Lawrence Rudel, PhD and Martha Wilson, PhD at the Lipoprotein Analysis Laboratory, Department of Pathology, Wake Forest University School of Medicine for their assistance in determining murine plasma LDL levels. 


\section{References}

1. Suratt, B.T., and Parsons, P.E. 2006. Mechanisms of acute lung injury/acute respiratory distress syndrome. Clinics in chest medicine 27:579-589; abstract viii.

2. Ware, L.B., and Matthay, M.A. 2000. The acute respiratory distress syndrome. The New England journal of medicine 342:1334-1349.

3. Baughman, R.P., Gunther, K.L., Rashkin, M.C., Keeton, D.A., and Pattishall, E.N. 1996. Changes in the inflammatory response of the lung during acute respiratory distress syndrome: prognostic indicators. American journal of respiratory and critical care medicine 154:76-81.

4. Tate, R.M., and Repine, J.E. 1983. Neutrophils and the adult respiratory distress syndrome. The American review of respiratory disease 128:552-559.

5. Meduri, G.U., Headley, S., Kohler, G., Stentz, F., Tolley, E., Umberger, R., and Leeper, K. 1995. Persistent elevation of inflammatory cytokines predicts a poor outcome in ARDS. Plasma IL-1 beta and IL-6 levels are consistent and efficient predictors of outcome over time. Chest 107:1062-1073.

6. Ware, L.B. 2005. Prognostic determinants of acute respiratory distress syndrome in adults: impact on clinical trial design. Critical care medicine 33:S217-222.

7. O'Brien, J.M., Jr., Phillips, G.S., Ali, N.A., Lucarelli, M., Marsh, C.B., and Lemeshow, S. 2006. Body mass index is independently associated with hospital mortality in mechanically ventilated adults with acute lung injury. Critical care medicine 34:738-744.

8. Morris, A.E., Stapleton, R.D., Rubenfeld, G.D., Hudson, L.D., Caldwell, E., and Steinberg, K.P. 2007. The association between body mass index and clinical outcomes in acute lung injury. Chest 131:342-348.

9. O'Brien, J.M., Jr., Welsh, C.H., Fish, R.H., Ancukiewicz, M., and Kramer, A.M. 2004. Excess body weight is not independently associated with outcome in mechanically ventilated patients with acute lung injury. Annals of internal medicine 140:338-345.

10. Aldawood, A., Arabi, Y., and Dabbagh, O. 2006. Association of obesity with increased mortality in the critically ill patient. Anaesthesia and intensive care 34:629-633.

11. Garrouste-Orgeas, M., Troche, G., Azoulay, E., Caubel, A., de Lassence, A., Cheval, C., Montesino, L., Thuong, M., Vincent, F., Cohen, Y., et al. 2004. Body mass index. An additional prognostic factor in ICU patients. Intensive care medicine 30:437-443.

12. Hogue, C.W., Jr., Stearns, J.D., Colantuoni, E., Robinson, K.A., Stierer, T., Mitter, N., Pronovost, P.J., and Needham, D.M. 2009. The impact of obesity on outcomes after critical illness: a meta-analysis. Intensive care medicine 35:1152-1170.

13. Martino, J.L., Stapleton, R.D., Wang, M., Day, A.G., Cahill, N.E., Dixon, A.E., Suratt, B.T., and Heyland, D.K. 2011. Extreme obesity and outcomes in critically ill patients. Chest 140:1198-1206.

14. Nasraway, S.A., Jr., Albert, M., Donnelly, A.M., Ruthazer, R., Shikora, S.A., and Saltzman, E. 2006. Morbid obesity is an independent determinant of death among surgical critically ill patients. Critical care medicine 34:964-970; quiz 971.

15. Oliveros, H., and Villamor, E. 2008. Obesity and mortality in critically ill adults: a systematic review and meta-analysis. Obesity 16:515-521.

16. Tremblay, A., and Bandi, V. 2003. Impact of body mass index on outcomes following critical care. Chest 123:1202-1207.

17. Ramos, E.J., Xu, Y., Romanova, I., Middleton, F., Chen, C., Quinn, R., Inui, A., Das, U., and Meguid, M.M. 2003. Is obesity an inflammatory disease? Surgery 134:329-335.

18. Desai, M.Y., Dalal, D., Santos, R.D., Carvalho, J.A., Nasir, K., and Blumenthal, R.S. 2006. Association of body mass index, metabolic syndrome, and leukocyte count. The American journal of cardiology 97:835-838.

19. Stapleton, R.D., Dixon, A.E., Parsons, P.E., Ware, L.B., Suratt, B.T., and Network, N.A.R.D.S. 2010. The association between BMI and plasma cytokine levels in patients with acute lung injury. Chest 138:568577.

20. Barazzone-Argiroffo, C., Muzzin, P., Donati, Y.R., Kan, C.D., Aubert, M.L., and Piguet, P.F. 2001. Hyperoxia increases leptin production: a mechanism mediated through endogenous elevation of corticosterone. American journal of physiology. Lung cellular and molecular physiology 281:L1150-1156.

21. Bellmeyer, A., Martino, J.M., Chandel, N.S., Scott Budinger, G.R., Dean, D.A., and Mutlu, G.M. 2007. Leptin resistance protects mice from hyperoxia-induced acute lung injury. American journal of respiratory and critical care medicine 175:587-594. 
22. Shore, S.A., Lang, J.E., Kasahara, D.I., Lu, F.L., Verbout, N.G., Si, H., Williams, E.S., Terry, R.D., Lee, A., and Johnston, R.A. 2009. Pulmonary responses to subacute ozone exposure in obese vs. lean mice. Journal of applied physiology 107:1445-1452.

23. Lang, J.E., Williams, E.S., Mizgerd, J.P., and Shore, S.A. 2008. Effect of obesity on pulmonary inflammation induced by acute ozone exposure: role of interleukin-6. American journal of physiology. Lung cellular and molecular physiology 294:L1013-1020.

24. Hsu, A., Aronoff, D.M., Phipps, J., Goel, D., and Mancuso, P. 2007. Leptin improves pulmonary bacterial clearance and survival in ob/ob mice during pneumococcal pneumonia. Clinical and experimental immunology 150:332-339.

25. Mancuso, P., Gottschalk, A., Phare, S.M., Peters-Golden, M., Lukacs, N.W., and Huffnagle, G.B. 2002. Leptin-deficient mice exhibit impaired host defense in Gram-negative pneumonia. Journal of immunology 168:4018-4024.

26. Mancuso, P. 2010. Obesity and lung inflammation. Journal of applied physiology 108:722-728.

27. Suratt, B.T., Young, S.K., Lieber, J., Nick, J.A., Henson, P.M., and Worthen, G.S. 2001. Neutrophil maturation and activation determine anatomic site of clearance from circulation. American journal of physiology. Lung cellular and molecular physiology 281:L913-921.

28. Suratt, B.T., Petty, J.M., Young, S.K., Malcolm, K.C., Lieber, J.G., Nick, J.A., Gonzalo, J.A., Henson, P.M., and Worthen, G.S. 2004. Role of the CXCR4/SDF-1 chemokine axis in circulating neutrophil homeostasis. Blood 104:565-571.

29. Petty, J.M., Sueblinvong, V., Lenox, C.C., Jones, C.C., Cosgrove, G.P., Cool, C.D., Rai, P.R., Brown, K.K., Weiss, D.J., Poynter, M.E., et al. 2007. Pulmonary stromal-derived factor-1 expression and effect on neutrophil recruitment during acute lung injury. Journal of immunology 178:8148-8157.

30. Stapleton, R.D., Dixon, A.E., Parsons, P.E., Ware, L.B., and Suratt, B.T. 2010. The association between BMI and plasma cytokine levels in patients with acute lung injury. Chest 138:568-577.

31. Lu, F.L., Johnston, R.A., Flynt, L., Theman, T.A., Terry, R.D., Schwartzman, I.N., Lee, A., and Shore, S.A. 2006. Increased pulmonary responses to acute ozone exposure in obese $\mathrm{db} / \mathrm{db}$ mice. American journal of physiology. Lung cellular and molecular physiology 290:L856-865.

32. Johnston, R.A., Theman, T.A., Lu, F.L., Terry, R.D., Williams, E.S., and Shore, S.A. 2008. Diet-induced obesity causes innate airway hyperresponsiveness to methacholine and enhances ozone-induced pulmonary inflammation. Journal of applied physiology 104:1727-1735.

33. Marik, P.E. 2006. The paradoxical effect of obesity on outcome in critically ill patients. Critical care medicine 34:1251-1253.

34. McCallister, J.W., Adkins, E.J., and O'Brien, J.M., Jr. 2009. Obesity and acute lung injury. Clinics in chest medicine 30:495-508, viii.

35. Pilewski, J.M., and Albelda, S.M. 1993. Adhesion molecules in the lung. An overview. The American review of respiratory disease 148:S31-37.

36. Madenspacher, J.H., Draper, D.W., Smoak, K.A., Li, H., Griffiths, G.L., Suratt, B.T., Wilson, M.D., Rudel, L.L., and Fessler, M.B. 2010. Dyslipidemia induces opposing effects on intrapulmonary and extrapulmonary host defense through divergent TLR response phenotypes. Journal of immunology 185:1660-1669.

37. Pini, M., Gove, M.E., Sennello, J.A., van Baal, J.W., Chan, L., and Fantuzzi, G. 2008. Role and regulation of adipokines during zymosan-induced peritoneal inflammation in mice. Endocrinology 149:4080-4085.

38. Wolters, P.J., Wray, C., Sutherland, R.E., Kim, S.S., Koff, J., Mao, Y., and Frank, J.A. 2009. Neutrophilderived IL-6 limits alveolar barrier disruption in experimental ventilator-induced lung injury. Journal of immunology 182:8056-8062.

39. Dandona, P., Ghanim, H., Chaudhuri, A., Dhindsa, S., and Kim, S.S. 2010. Macronutrient intake induces oxidative and inflammatory stress: potential relevance to atherosclerosis and insulin resistance. Experimental \& molecular medicine 42:245-253.

40. Biasi, D., Carletto, A., Dell'Agnola, C., Caramaschi, P., Montesanti, F., Zavateri, G., Zeminian, S., Bellavite, P., and Bambara, L.M. 1996. Neutrophil migration, oxidative metabolism, and adhesion in elderly and young subjects. Inflammation 20:673-681.

41. Lord, J.M., Butcher, S., Killampali, V., Lascelles, D., and Salmon, M. 2001. Neutrophil ageing and immunesenescence. Mechanisms of ageing and development 122:1521-1535.

42. Niwa, Y., Kasama, T., Miyachi, Y., and Kanoh, T. 1989. Neutrophil chemotaxis, phagocytosis and parameters of reactive oxygen species in human aging: cross-sectional and longitudinal studies. Life sciences 44:1655-1664. 
43. Wenisch, C., Patruta, S., Daxbock, F., Krause, R., and Horl, W. 2000. Effect of age on human neutrophil function. Journal of leukocyte biology 67:40-45.

44. Panda, A., Arjona, A., Sapey, E., Bai, F., Fikrig, E., Montgomery, R.R., Lord, J.M., and Shaw, A.C. 2009. Human innate immunosenescence: causes and consequences for immunity in old age. Trends in immunology 30:325-333.

45. Svenson, K.L., Von Smith, R., Magnani, P.A., Suetin, H.R., Paigen, B., Naggert, J.K., Li, R., Churchill, G.A., and Peters, L.L. 2007. Multiple trait measurements in 43 inbred mouse strains capture the phenotypic diversity characteristic of human populations. Journal of applied physiology 102:2369-2378.

46. Nishina, P.M., Lowe, S., Wang, J., and Paigen, B. 1994. Characterization of plasma lipids in genetically obese mice: the mutants obese, diabetes, fat, tubby, and lethal yellow. Metabolism: clinical and experimental 43:549-553. 



\section{CHAPTER 35}

\section{Obesity and Neutrophil Dysfunction in Acute Lung Injury}

Supplement 


\section{Materials and Methods}

\section{Lipopolysaccharide-induced lung injury}

Mice were exposed to aerosolized E.coli 0111:B4 lipopolysaccharide (LPS, Sigma, St. Louis, MO) using a $3 \mathrm{mg} / \mathrm{ml}$ solution of LPS in sterile saline nebulized by a Pari LC Plus Reusable Nebulizer with ProNeb Turbo Air Compressor (Pari Respiratory Equipment, Midlothian, VA). The nebulizer was connected, via a central manifold, to a multicompartment pie-shaped Plexiglas aerosol chamber (modified Tepper box) in which groups of mice were exposed individually but simultaneously to the aerosol for 15 minutes. Saline controls were performed using a similar approach. Both lean and obese mice (3-4 each) were exposed simultaneously in the aerosol chamber in each experiment, and each experiment was repeated 2-3 times. The animals were euthanized 2,6 or $24 \mathrm{~h}$ later by pentobarbital overdose. Blood was collected via cardiac puncture into a syringe containing EDTA and $1 x$ protease inhibitor cocktail ( $p-8340$, Sigma). Aliquots were analyzed for cell count and differential using an Advia 120 Hematology Analyzer with veterinary software (Bayer, Tarrytown, NY), and serum from the remaining blood was frozen for later analysis. For bronchoalveolar lavage, a midline neck incision was performed and an $18 \mathrm{G}$ catheter (Baxter Health Care) was inserted into the trachea and secured with suture. Lungs were lavaged with $1 \mathrm{~mL}$ of chilled $0.1 \%$ BSA in PBS with $1 x$ protease inhibitor cocktail. Bronchoalveolar lavage was spun for 6 minutes at $500 \mathrm{~g}$ and the resulting supernatant was aspirated and snap-frozen for later analysis, while the cell pellet was resuspended in 5\% BSA in PBS and analyzed for cell count and differential using the Advia 120. In some experiments, lavaged and exsanguinated lungs were snapfrozen for later analysis by myeloperoxidase assay (Life Technologies, Grand Island, NY). In other experiments whole lungs were fixed for histology in 4\% PFA by gravityinstillation through a tracheal catheter, paraffin-embedded, and 5 um sections were mounted on slides for examination using light microscopy after H\&E staining. Images were obtained by the Olympus BX50 light microscope with an Optronics Magnafire digital camera.

\section{Determination of Cytokine Levels}

Cytokine levels in mouse plasma and bronchoalveolar lavage supernatants were assayed using a Bio-Plex suspension array system (Bio-Rad, Hercules, CA) as follows. Milliplex kits containing beads and antibodies recognizing 4 cytokines/chemokines (IL- 6, KC, TNF- $\alpha$, MIP-2, and MCP-1) were from Millipore (Billerica, MA). All assays were performed in duplicate according to manufacturer's instructions. Briefly, $25 \mu \mathrm{l}$ of undiluted culture supernatant, standard (in culture media), or culture media (background) was added to each well of a pre-wet 96-well vacuum filter plate. $25 \mu \mathrm{l}$ of assay buffer plus $25 \mu \mathrm{l}$ of antibody-conjugated beads were added to each well and the plates were covered, shaken vigorously for 1 minute on an IKA (Wilmington, NC) MTS 2/4 digital microtiter 
plate shaker and then moderately shaken for 2 hours at room temperature. After washing using a Bio-Rad (Hercules, CA) Bio-Plex Pro II wash station, $25 \mu$ l of biotinylated detection antibodies were added to the appropriate wells for 1 hour followed by addition of $25 \mu \mathrm{l}$ of streptavidin-phycoerythrin to all wells for 30 minutes. The wells were washed and the beads were resuspended in $125 \mu$ l sheath fluid. Data were acquired using the Bio-Rad Bio-Plex suspension array system and Bio-Plex Manager 6.0 software. Fluorescence intensity of the background was subtracted from the values for each sample and standard for each specific bead. Standard curves were generated from 4-fold dilutions of standards provided in the Milliplex kits, which were analyzed using 5-place logistic regression from standards within $70-130 \%$ of the expected values. Upper levels of quantitation and lower levels of quantitation were calculated by the Bio-Plex Manager software. Reported concentrations are in $\mathrm{pg} / \mathrm{ml}$.

\section{Determination of Plasma LDL Cholesterol Levels}

Total plasma cholesterol concentration in uninjured mice was first determined by a micro-enzymatic method. Total cholesterol reagent (Cholesterol HP, Roche Diagnostics) was added to dilutions of plasma in a microtiter plate and the OD at $546 \mathrm{~nm}$ was measured using a Genios microtiter plate reader (Tecan). Plasma samples were then diluted with cold phosphate buffered saline, centrifuged at $10,000 \times \mathrm{xg}$ for 2 min at $4^{\circ} \mathrm{C}$, and the supernatant (containing approximately $15 \mu \mathrm{g}$ cholesterol in $60 \mu \mathrm{l}$ ) was analyzed by FPLC with online mixing of the column effluent with enzymatic reagent (Cholesterol Liquid Stable, Thermo Electron) to determine LDL content, as previously described.

\section{Statistical Analysis}

Correlations between weight and bronchoalveolar lavage neutrophil levels, as well as covariates that might affect bronchoalveolar lavage neutrophil levels, including age, and weight, were analyzed by linear regression using STATA 10.0 (College Station, TX). Covariates significant at $<0.1$ by univariate analysis were included in the final model. All other data were analyzed with the Student's or Welch's t-test, using Prism 5 software (GraphPad Sofware, La Jolla, CA). An F-test was used to analyze whether groups exhibited equal variances, and the Welch's t-test was used in lieu of the Student's t-test if the variances were un-equal. Differences between groups were reported as reaching statistical significance when $p<0.05$. Results are reported with SEM in the case of $t$-test analysis, and with $95 \%$ confidence intervals for linear regressions. 


\section{Figures}

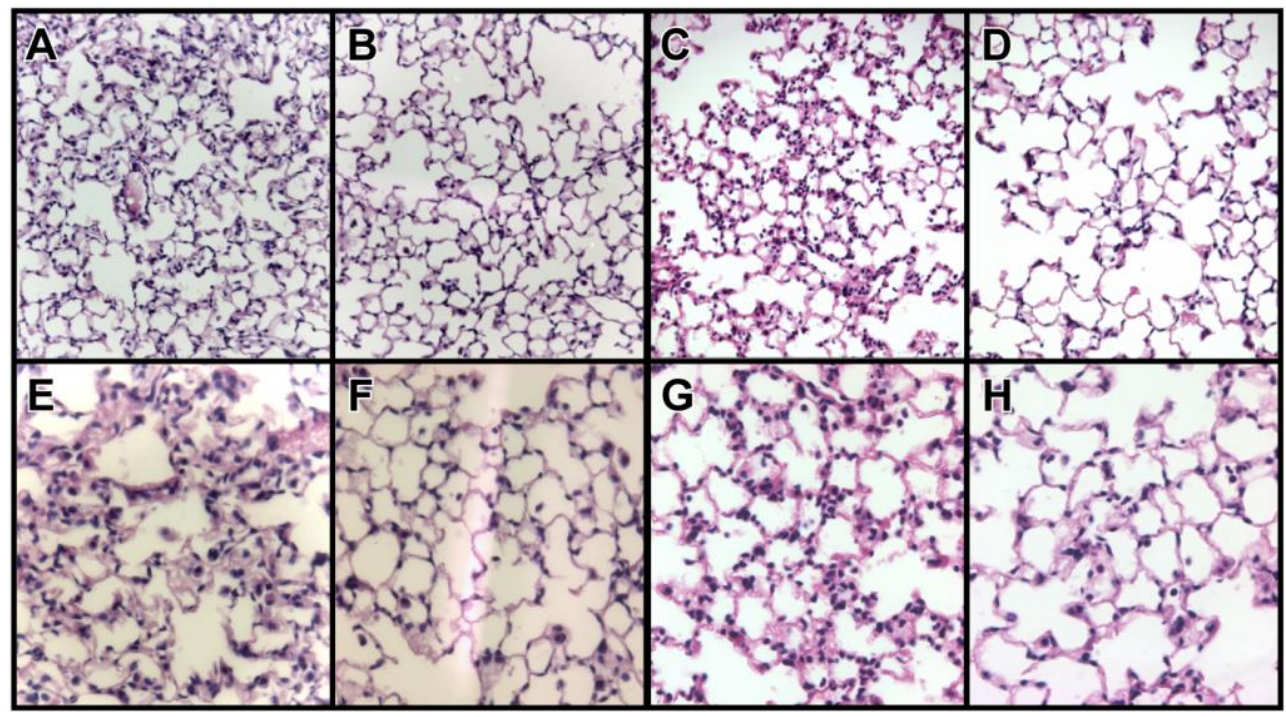

Figure E1: Histological evidence of lung inflammation and injury is reduced in obese mice following LPSexporsure. Shown are LPS-injured mouse lungs (24h) from db/db obese (A/E) and diet-induced obese (C/G) mice, as well as injured lean mice from both obesity models ( $\mathrm{db} / \mathrm{db} \mathbf{B} / \mathbf{F}$; diet induced $\mathbf{D} / \mathbf{H})$. Lower panels represent higher magnification views of the selected areas. Representative images are shown from lean $(n=3)$ and obese mice $(n=3)$. Lungs are 4\% PFA inflation-fixed and H\&E stained before imaging (see Methods). Magnification A-D 200x; E-H 400x.

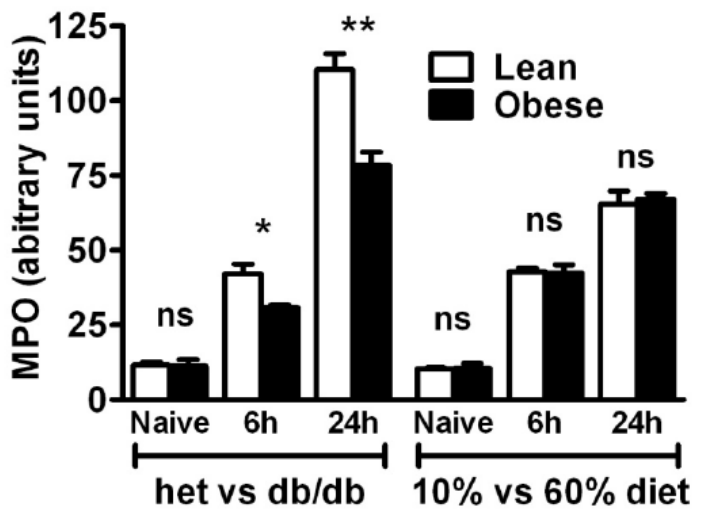

Figure E2: Lung myeloperoxidase content following lung injury is decreased in $\mathrm{db} / \mathrm{db}$ obese mice compared to leans, yet no difference is seen between diet-induced obese and lean mice. Whole lung myeloperoxidase (MPO) content in lean compared to genetically obese $(\mathrm{db} / \mathrm{db})$ and dietinduced obese mice was determined in perfused, lavaged lungs $6 \mathrm{~h}$ and $24 \mathrm{~h}$ after nebulized LPS exposure. Lungs from uninjured mice from all four groups were similarly examined. $\mathrm{n}=3$ mice/condition. ${ }^{*} \mathrm{p}<0.05,{ }^{* *} \mathrm{p}<0.01, \mathrm{~ns}=$ not significant. 

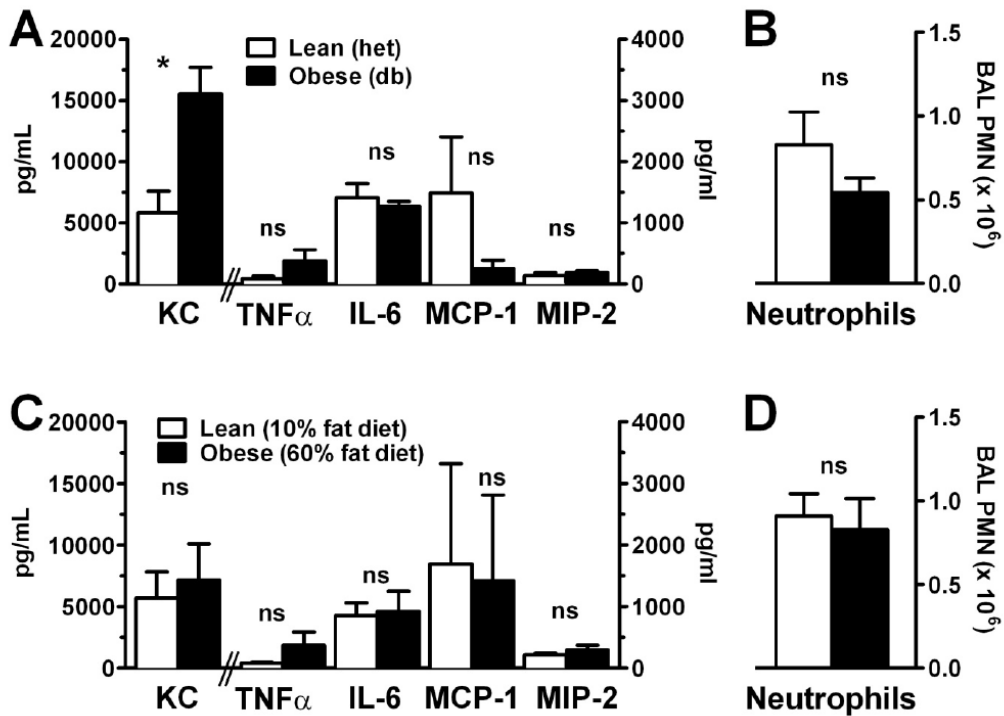

Figure E3: Lung cytokine response $6 \mathrm{~h}$ after LPS injury is normal in obese mice. Bronchoalveolar lavage cytokine $(\mathbf{A} / \mathbf{C})$ and neutrophil (B/D) levels $6 \mathrm{~h}$ after nebulized LPS exposure in lean compared to genetically obese $(\mathrm{db} / \mathrm{db})$ and diet-induced obese mice were determined by Bio-Plex and cell counter, respectively. $n=6$ mice/condition. ${ }^{*} \mathrm{p}<0.05, \mathrm{~ns}=$ not significant.

Figure E4: Obesity impairs neutrophil chemotaxis. Chemotaxis of density centrifugation-isolated mature bone marrow neutrophils from genetically obese $(\mathrm{db} / \mathrm{db})$ (A) and diet-induced obese (B) mice was compared to lean controls using a modified Boyden chamber with varying concentrations of $\mathrm{KC}$. Membrane counts were expressed as total neutrophils migrated per field for each experiment. Three separate experiments were performed on both $\mathrm{db} / \mathrm{db}$ and diet-induced obese mouse isolated neutrophils and respective controls.
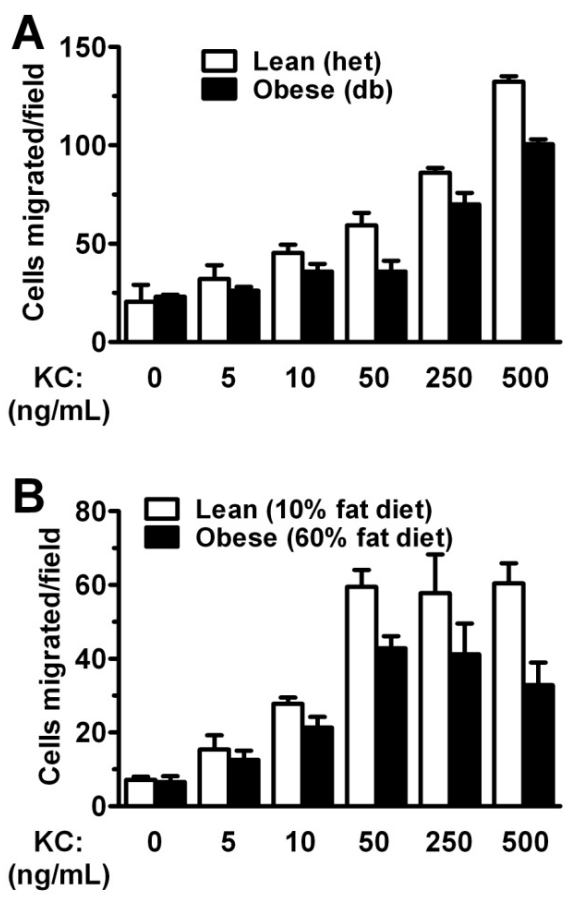

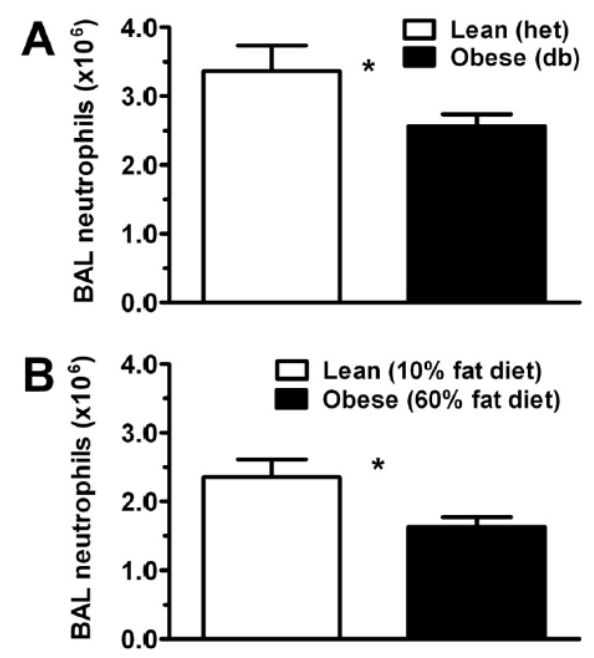

Figure E5: Adoptive transfer of obese versus lean mouse neutrophils leads to reduced airspace neutrophilia following lung injury. Neutrophil adoptive transfer was performed on lean recipient mice using bone marrow neutrophils isolated from genetically obese $(\mathrm{db} / \mathrm{db})$ vs. lean (heterozygous littermate control) mice (A), and diet-induced obese (60\% fat diet) vs. lean (10\% fat diet) mice (B) (see Methods). Following transfer, acute lung injury was induced in the recipient mice by LPS inhalation $24 \mathrm{~h}$ prior to determining bronchoalveolar lavage neutrophil levels by cell counter. $n=8$ mice/condition from 3 separate experiments. ${ }^{*} p<0.05$.
Figure E6: Obesity is associated with decreased neutrophil surface expression of CXCR2. Cell surface levels of CXCR2 were determined on mature bone marrow neutrophils isolated from genetically obese $(\mathrm{db} / \mathrm{db})(\mathbf{A})$ and diet-induced obese (B) mice and compared to lean controls using flow cytometry. Representative cytometric histograms are presented from three separate experiments on both $d b / d b$ and diet-induced obese mice and respective controls.
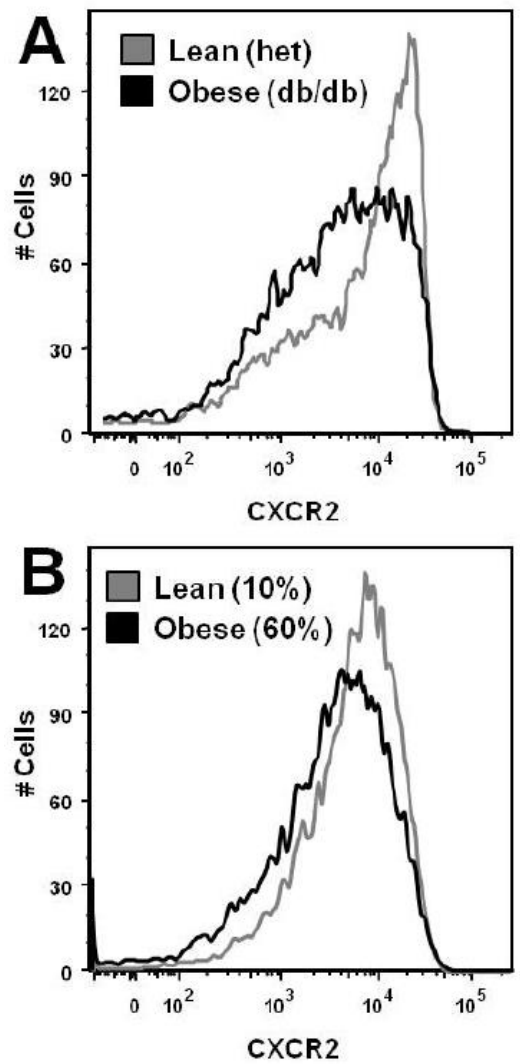

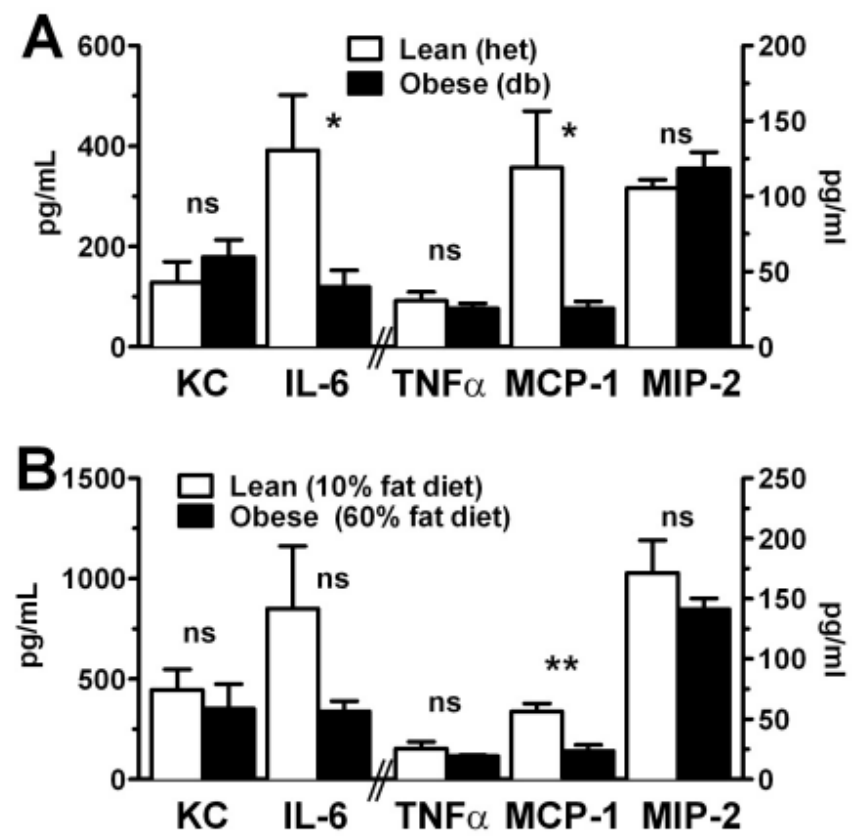

Figure E7: Airspace IL-6 and MCP-1 response $24 \mathrm{~h}$ after LPS injury is impaired in obese mice. Bronchoalveolar lavage cytokine (A/C) and neutrophil (B/D) levels $24 \mathrm{~h}$ after nebulized LPS exposure in lean compared to genetically obese (db/db) and diet-induced obese mice were determined by Bio-Plex and cell counter, respectively. $\mathrm{n}=6$ mice/condition. ${ }^{*} \mathrm{p}<0.05, * *$ $\mathrm{p}<0.01, \mathrm{~ns}=$ not significant.

Figure E8: Baseline plasma cytokine levels are normal in obese mice. Plasma cytokine levels in lean compared to genetically obese $(\mathrm{db} / \mathrm{db})(\mathbf{A})$ and diet-induced obese $(\mathbf{A})$ mice were determined by Bio-Plex. $n=8$ mice/condition. $\mathrm{nd}=$ none detected.
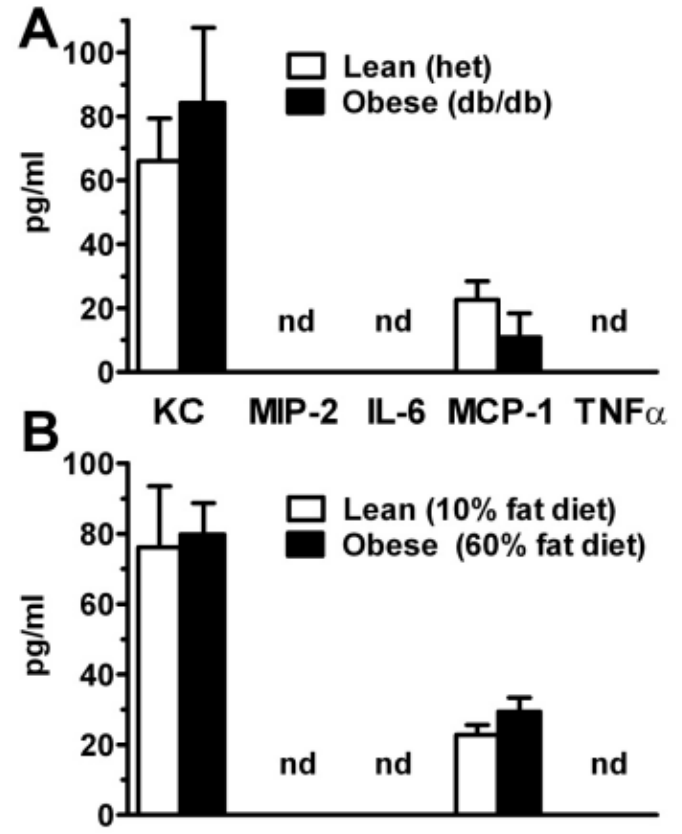

KC MIP-2 IL-6 MCP-1 TNF $\alpha$ 


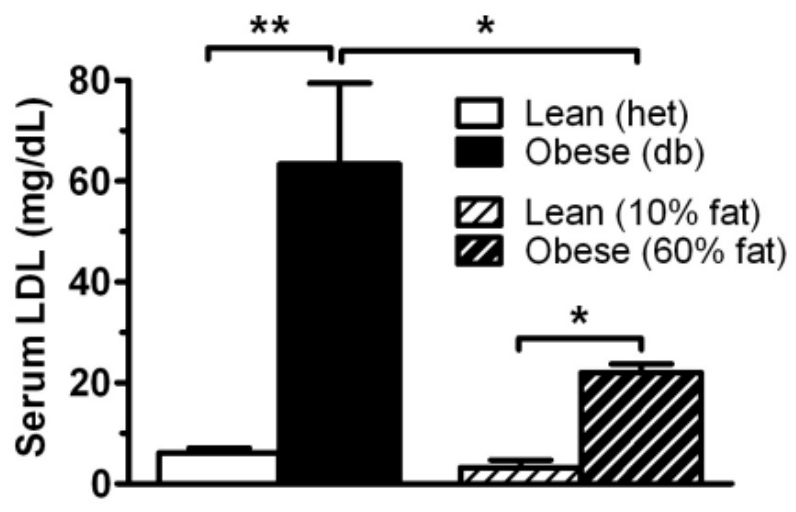

Figure E9: Both $\mathrm{db} / \mathrm{db}$ and dietinduced obese mice demonstrate elevated plasma levels of LDL compared to lean controls. Plasma LDL levels from uninjured genetically obese $(\mathrm{db} / \mathrm{db})$ and diet-induced obese mice and their lean controls were determined by FPLC. $\mathrm{n}=3-5$ /group. ${ }^{*} \mathrm{p}<0.03$; ** $p<0.001$. 




\section{CHAPTER 4}

\section{A Comparative Study of Pulmonary Host Defense in Murine Obesity Models: Important Insights into Neutrophil Function}

Niki D.J. Ubags*, Elianne Burg*, Maryellen Antkowiak, Aaron M. Wallace, Estee Dilli, Jenna Bement, Matthew J. Wargo, Matthew E. Poynter, Emiel F.M. Wouters and Benjamin T. Suratt.

*Authors contributed equally to this work.

\section{Submitted}




\section{Abstract}

Rationale: We recently demonstrated obesity-associated attenuation of murine acute lung injury that appears, in part, to be driven by blunted neutrophil chemotaxis; however, significant differences were noted between the two different models of obesity studied. We hypothesized that obesity-associated impairment of neutrophil function contributes to the increased risk for respiratory infection, yet that significant differences in innate immune response may exist between commonly used murine models of obesity.

Methods: We examined the four most commonly reported murine models of obesity: diet-induced (DIO), db/db, CPE ${ }^{\text {fat/fat }}$, and ob/ob obese mice and matched lean controls using a $K$. pneumoniae model of pneumonia and LPS-induced pneumonitis, and determined bronchoalveolar-lavage neutrophilia, and (in pneumonia) whole-lung CFU, at $24 \mathrm{~h}$ and $48 \mathrm{~h}$. Bone marrow-derived neutrophils from uninjured lean and obese mice were also examined for functional responses including chemotaxis, cytokine transcription, induced apoptosis, and intracellular signaling response to LPS and G-CSF.

Results: All four models of obesity showed impaired clearance of $K$. pneumoniae, but in differing temporal patterns. Failure to contain infection in obese mice was seen in the $\mathrm{db} / \mathrm{db}$ model at both $24 \mathrm{~h}$ and $48 \mathrm{~h}$ post-infection, yet this defect was only evident at $24 \mathrm{~h}$ in $\mathrm{CPE}^{\text {fat/fat }}$ and ob/ob models, and at $48 \mathrm{~h}$ in the DIO model. Airspace neutrophilia following LPS-induced lung injury was decreased in all four models. This was associated with blood neutropenia in the ob/ob model, but leukocytosis in the other three models. Neutrophils isolated from uninjured mice demonstrated impaired chemotaxis and G-CSFmediated survival in all models, whereas cytokine transcription after LPS stimulation was impaired in DIO and db/db neutrophils only. Lastly, both DIO and db/db neutrophils showed impaired signaling through the MAPK and STAT3 pathways in response to LPS and G-CSF, respectively. This response was delayed but normal in $\mathrm{CPE}^{\text {fat/fat }}$ mice and unchanged in ob/ob mice.

Conclusions: Obesity-associated impairment of host response to lung infection is characterized by both defects in neutrophil recruitment and survival, which appear to be part of a broad attenuation of neutrophil function in obesity. Yet, critical differences exist between commonly used mouse models of obesity, suggesting caution be used when studying these models. 


\section{Introduction}

Obesity is a rapidly expanding global epidemic, with a markedly increased prevalence of overweight and obesity for adults (27.5\%) and for children $(47.1 \%)$ in the past 30 years (1). Recent studies have demonstrated that human obesity is associated with increased risk for developing bacterial and viral respiratory infections (2), as well as greater incidence of Acute Respiratory Distress Syndrome (ARDS) (3). Interestingly, however, we and others have shown that, once ARDS has developed, obesity is also associated with rapid attenuation of the inflammatory response and improved outcomes in both patients $(3,4)$, and animal models (5). Recently, using both diet-induced obese (DIO) and hyperphagic mutant obese $(\mathrm{db} / \mathrm{db})$ mice, we showed impaired pulmonary innate immune responses following LPS-induced lung injury, as well as defects in neutrophil chemoattractant response in the obese mice, suggesting that obesity-associated neutrophil dysfunction may, in part, underlie the attenuated inflammatory response seen in these animals (5). Yet, significant differences in the degree of impairment were noted between the two models of obesity studied, despite being of similar weights. Others studying the effects of obesity on hyperoxic and ozone-induced lung injury have shown that obese mice ( $\mathrm{db} / \mathrm{db}$ and ob/ob) have reduced lung injury and mortality, but to varying degrees (6-8).

As a corollary to the impaired inflammatory response seen in obese ARDS models, we and others have shown that pulmonary host defense is impaired following both influenza $(9,10)$ and bacterial pneumonias $(11,12)$, with consequent lung injury and death. Recent clinical studies have demonstrated associations between obesity and risk for both bacterial and viral pneumonias, as well as increased disease severity and mortality (13-15), whereas others have suggested a protective effect of increasing BMI on mortality in this setting $(16,17)$. Similar to these human studies, variable results were also found using mouse models of obesity. Susceptibility to and outcome of bacterial respiratory infection was increased in obese ob/ob mice compared to their lean controls $(11,18)$, whereas no differences were observed between obese $\mathrm{CPE}^{\mathrm{fat} / \mathrm{fat}}$ mice and their lean controls (19). Reasons for this inconsistency may include pathogen-specific defects in the immune response or differences in the metabolic state (lipid-, glucose-, and adipokine levels amongst others) of individual obese subjects. Differences between these and other mouse models of obesity may, in part, determine the effects on the pulmonary immune response and subsequently the susceptibility to and outcome of respiratory infections. However, there are a limited data available comparing different murine models of obesity and their metabolic state on the level of immune cell dysfunction and consequently the effects on host defense.

A variety of mouse models have been used to study obesity. Although it has been suggested that human obesity may be best mimicked by the diet-induced (DIO) mouse model of high fat diet (20-22), three hyperphagic mutant models are also commonly reported, including leptin 'resistant' $\mathrm{db} / \mathrm{db}$ mice (long form of leptin receptor $(O b R b$ ) 
deficient) (23), aleptinemic ob/ob mice (leptin (ob) deficient) (24), and hyperphagic $\mathrm{CPE}^{\text {fat/fat }}$ mice (carboxypeptidase-E deficient) (25). Studies in these models have suggested that obesity-associated defects may exist in both the innate and adaptive immune responses $(5,7,9-11,18,19,26-32)$. However, inconsistencies exist in the published literature, suggesting that these models may display different features/hallmarks of the obese state or the underlying defect leading to obesity. Therefore, important caveats may exist when studying the available obese mouse models, which should be taken into account when extrapolating to human obesity.

In the current study, we examine obesity-associated defects in the innate immune response to bacterial pneumonia, and implicate elements of neutrophil impairment as an underlying mechanism. Furthermore, we detail important differences between commonly used mouse models of obesity related to respiratory infection and the underlying role of neutrophil dysfunction. We present evidence of a consistent failure to contain bacterial growth following respiratory infection in obese mice. However, the temporal course and severity of the infection, as well as the underlying mechanisms, appear to vary significantly with the mouse model used. Furthermore, we show that obesity is associated with numerous defects in neutrophil function including impaired chemotaxis, cytokine transcription, and cell survival, and link these to obesity-associated defects in intracellular signaling responses. 


\section{Materials and methods}

\section{Mice}

For the diet-induced obesity model, C57BL/6J mice (Harlan, Indianapolis, IN) were fed high-fat ( $60 \%$ fat) versus normal-fat ( $10 \%$ fat) chow (Research Diets, New Brunswick, NJ) for 20 weeks. In genetic models of obesity, homozygous B6.BKS(D)-LepR ${ }^{\mathrm{db} / \mathrm{J}}(d b / d b)$ mice (lacking ObRb, the long form of the leptin receptor), homozygous B6.HRS(BKS)-CPE ${ }^{\mathrm{fat} / \mathrm{s}}$ $\left(\mathrm{CPE}^{\text {fat/fat }}\right)$ mice (hyperphagic due to a mutation in the carboxypeptidase-E gene), homozygous B6.Cg-lep ${ }^{\mathrm{ob} / \mathrm{s}}(\mathrm{ob} / \mathrm{ob}$ ) mice (leptin-deficient) (on a C57BL/6 background; obtained from Jackson Labs, Bar Harbor, ME) and their lean heterozygous littermates were examined at 12 to 16 weeks (genetic models of obesity) or 26-30 weeks (dietinduced obesity) of age. Mice were considered 'obese' once the difference between their body weight and that of controls reached at least $20 \mathrm{~g}$ (33). Exposures of the mice as well as the analysis performed on the murine lungs are described in the online supplement. Experiments were performed in accordance with the Animal Welfare Act and the USPHS Policy on Humane Care and Use of Laboratory Animals after review by the Institutional Animal Care and Use Committee of the University of Vermont.

\section{Murine exposures}

Klebsiella pneumoniae infections were induced by oropharyngeal aspiration of $K$. pneumoniae (43816 serotype 2, ATCC, $2 \times 10^{3}$ CFU) following brief anesthesia with isofluorane (35). Lipopolysaccharide (LPS) induced pneumonitis was induced by exposure to nebulized LPS (Escherichia coli 0111:B4 LPS, Sigma, St Louis, MO) (5).

\section{Murine lung analysis}

Blood and bronchoalveolar lavage (BAL) fluid were analyzed for cell count and differential using the Advia 120 (Siemens Healthcare, Malvern PA). Bacterial CFU in lung and spleen, as well as BAL cytokine levels, where appropriate, were determined at $24 \mathrm{~h}$ ( $K$. pneumonia and LPS) and 48h ( $K$. pneumoniae) after exposure, as described (35). Interleukin (IL)-6, IL-1 $\beta$, KC, TNF- $\alpha$, G-CSF, MIP-2, and MCP-1 levels were assessed in BAL supernatant by Bio-Plex suspension-array system (Bio-Rad, Hercules, CA) as previously described (5).

\section{Preparation of morphologically mature murine bone marrow neutrophils}

Mature bone marrow neutrophils were isolated using a 3-step Percoll gradient as previously described (36). 


\section{Neutrophil chemotaxis}

Chemotaxis of bone marrow derived neutrophils was measured in response to KC (R\&D systems, Minneapolis, MN) and fMLP (Sigma, St Louis, MO) using a 48-well modified Boyden chamber with $5 \mu \mathrm{M}$ pore polycarbonate membranes (both NeuroProbe Inc, Gaithersburg, MD), as previously described $(12,37)$.

\section{FasL induced apoptosis survival.}

Bone marrow derived neutrophils were incubated for 6 hours with 200ng/ml of FasLigand (ENZO Life Sciences, Farmingdale, NY) and 400ng/mL monoclonal anti-FLAG M2 antibody (Sigma, St Louis, MO) with or without $25 \mathrm{ng} / \mathrm{ml} \mathrm{rG-CSF}$ (Amgen Mfg Ltd, Thousand Oaks, CA) or with $25 \mathrm{ng} / \mathrm{ml} \mathrm{rG-CSF}$. Cells were counted using a hemocytometer and trypan blue was used for dead cell exclusion.

\section{Neutrophil cytokine transcription}

Bone marrow derived neutrophils were stimulated with LPS $(100 \mathrm{ng} / \mathrm{ml})$ for $4 \mathrm{hr}$ at 37 으 and IL-6, IL-1 $\beta$, KC, TNF- $\alpha$, MIP-2 and MCP-1 expression levels were determined by realtime semi-quantitative RT-PCR using SYBR universal PCR master mix and the ABI PRISM 7700 sequence detection system and analyzed as described in online supplement. Expression levels were analyzed using the cycle threshold $(\Delta \Delta \mathrm{Ct})$ method and normalized to pPia expression. A taqman AOD primer was used for pPia (life technologies, Grand Island, NY, USA). LPS stimulated neutrophil cytokine expression levels were reported as the fold change over unstimulated neutrophil expression levels. The following primer sequences were used for IL-6: CCGGAGAGGAGACTTCACAG and GAGCATTGGAAATTGGGGTA; for IL-1ß: GCCCATCCTCTGTGACTCAT and AGGCCACAGGTATTTTGTCG; for KC: GCTGGGATTCACCTCAAGAA and TGGGGACACCTTTTAGCATC; for TNF $\alpha$ : GAACTGGCAGAAGAGGCACT and AGGGTCTGGGCCATAGAACT; for MIP-2: AGTGAACTGCGCTGTCAATG and TTCAGGGTCAAGGCAAACTT; for MCP-1: AGGTCCCTGTCATGCTTCTG and TCTGGACCCATTCCTTCTTG.

\section{Neutrophil intracellular signaling}

Bone marrow derived neutrophils were isolated as described above, and incubated with LPS $(1 \mu \mathrm{g} / \mathrm{ml})$ or PBS control for 15,30 or 60 minutes. Neutrophils were lysed in Triton Lysis Buffer (20mM Tris pH 7.4, $137 \mathrm{mM} \mathrm{NaCl}, 25 \mathrm{mM} \beta$-glycerolphosphate $\mathrm{pH} 7.4,2 \mathrm{mM}$ PPiNa, $2 \mathrm{mM}$ EDTA pH 7.4, $1 \%$ Triton X-100, $10 \%$ glycerol, $1 \mu \mathrm{M} \mathrm{NaVO}_{3}, 0.5 \mathrm{mM}$ DTT and protease inhibitors) (all chemicals from Sigma-Aldrich, St. Louis, MO). Lysates were incubated on ice for 20 minutes, followed by 10 minutes centrifugation at 14,000 rpm. Total protein concentration of the supernatant was determined by Bradford assay (BioRad, Hercules, CA), according to manufacturer's instructions. Samples were analyzed by 
western blot. Briefly, $20 \mu \mathrm{g}$ of protein was loaded and separated on a polyacrylamide gel, followed by transfer to a $0.45 \mu \mathrm{m}$ nitrocellulose membrane (Bio-Rad) by electroblotting. The membrane was blocked for $1 \mathrm{~h}$ at room temperature in $5 \%(\mathrm{w} / \mathrm{v})$ nonfat, dried milk diluted in TBS-Tween20 (0.1\%). Nitrocellulose blots were washed in TBS-Tween20 (0.1\%) followed by overnight incubation at 4을 with primary antibody (pSTAT3 (Y705): no. 9138; STAT3: no. 9139; pP38 (T180/Y182) no. 9215; P38: no. 9212, all Cell Signaling Technology, Beverly, MA, or $\beta$-actin no. A5441, Sigma Aldrich, St. Louis, MO). After three washes of $5 \mathrm{~min}$ each, the blots were probed with horseradish peroxidase-conjugated anti-mouse (p-STAT3, $\beta$-actin) or anti-rabbit (STAT3, pP38, P38) antibody $(1 / 2,000$; Jackson Immunology Research, West Grove, PA) and visualized by chemiluminesence using Supersignal ${ }^{\circledR}$ West Pico Chemiluminescent Substrate (Pierce Biotechnology, Rockford, IL) according to the manufacturer's instructions and exposed to film.

\section{Metabolic parameters}

Total plasma cholesterol levels were measured from obese mice and their lean controls at baseline as described previously (5). Fasting glucose levels were measured after a $6 \mathrm{~h}$ fast with a glucometer (TrueTrack, Nipro Diagnostics, Fort Lauderdale, FL, USA).

\section{Statistical Analysis}

Data were represented as mean \pm SEM, and analysis of differences between experimental groups was performed by Student $t$ test. Associations between mouse weight and lung CFU levels were analyzed by linear regression. All analyses were performed using Prism 6 software (GraphPad). Results with $P \leq 0.05$ were considered statistically significant. 


\section{Results}

\section{Obesity is associated with impaired clearance of bacteria in mice}

Obesity was found to worsen bacterial pneumonia in all four models. However, differences were observed between bacterial burden and the temporal course of infection. Bacterial counts at $24 \mathrm{~h}$ after infection were increased in $\mathrm{db} / \mathrm{db}, \mathrm{CPE}{ }^{\text {fat } / f a t}$ and ob/ob mice when compared to their lean littermates (Figure 1B-D) and this increase in bacterial burden was significantly associated with increased body weight in these mice (Figure 1F-H). Bacterial dissemination to the blood as indicated by spleen bacterial counts was seen in obese ob/ob mice, which also had the highest lung bacterial counts (Figure 1M-P). Interestingly, DIO mice appeared to be able to contain the infection in the first 24 hours (Figure $1 \mathrm{~A}$ and $\mathrm{E}$ ), yet lung bacterial counts were increased at $48 \mathrm{~h}$ after infection, which were also significantly associated with increased body weight (Figure $2 \mathrm{~A}$ and $E$ ). The observed differences at $24 \mathrm{~h}$ post-infection between obese and lean lung bacterial counts in the $\mathrm{CPE}^{\text {fat/fat }}$ and ob/ob models were no longer evident at $48 \mathrm{~h}$ postinfection (Figure $2 \mathrm{C}$ and $\mathrm{D}$ ): although lung CFU in lean mice increased from $24 \mathrm{~h}-48 \mathrm{~h}$ post-infection, CFU remained similar in the obese mice in these models. Bacterial burden in obese $\mathrm{db} / \mathrm{db}$ mice at $48 \mathrm{~h}$ post-infection, as well as its association with body weight, remained significantly different compared to their lean littermates (Figure 2B, F and J). Taken together, these results suggest that obesity-associated failure to contain bacterial growth following $K$. pneumoniae infection, although common to all four models, differs substantially in its kinetics between models.

\section{Obesity attenuates airspace neutrophilia during LPS-induced pneumonitis.}

To further examine neutrophil recruitment to the airspace in the absence of bacterial expansion, we used a sterile model of pneumonitis using aerosolized LPS. Pulmonary neutrophilia was attenuated in the obese mice at $24 \mathrm{~h}$ after LPS exposure in all models (Figure 3A-D). The reduction in airspace neutrophil levels did not appear to be due to a decrease in neutrophil release from the bone marrow into the periphery in the DIO, $\mathrm{db} / \mathrm{db}$ and $\mathrm{CPE}^{\text {fat/fat }}$ mice (Figure $3 \mathrm{~A}-\mathrm{C}$ ), as indicated by the elevated circulating neutrophil numbers. However, the obese ob/ob mice showed significantly lower peripheral neutrophil numbers compared to their lean littermates (Figure 3D), indicating a different or possibly accompanying mechanism of decreased airspace neutrophilia. In addition, a significant decrease in alveolar cytokine levels (IL-6 and MCP-1) was observed at $24 \mathrm{~h}$ after LPS in obese $\mathrm{db} / \mathrm{db}$ and $\mathrm{CPE}^{\text {fat/fat }}$ mice (Figure $3 \mathrm{~F}$ and $\mathrm{G}$ ), whereas no such differences were observed between lean and obese DIO and ob/ob mice (Figure $3 \mathrm{E}$ and $\mathrm{H})$. 

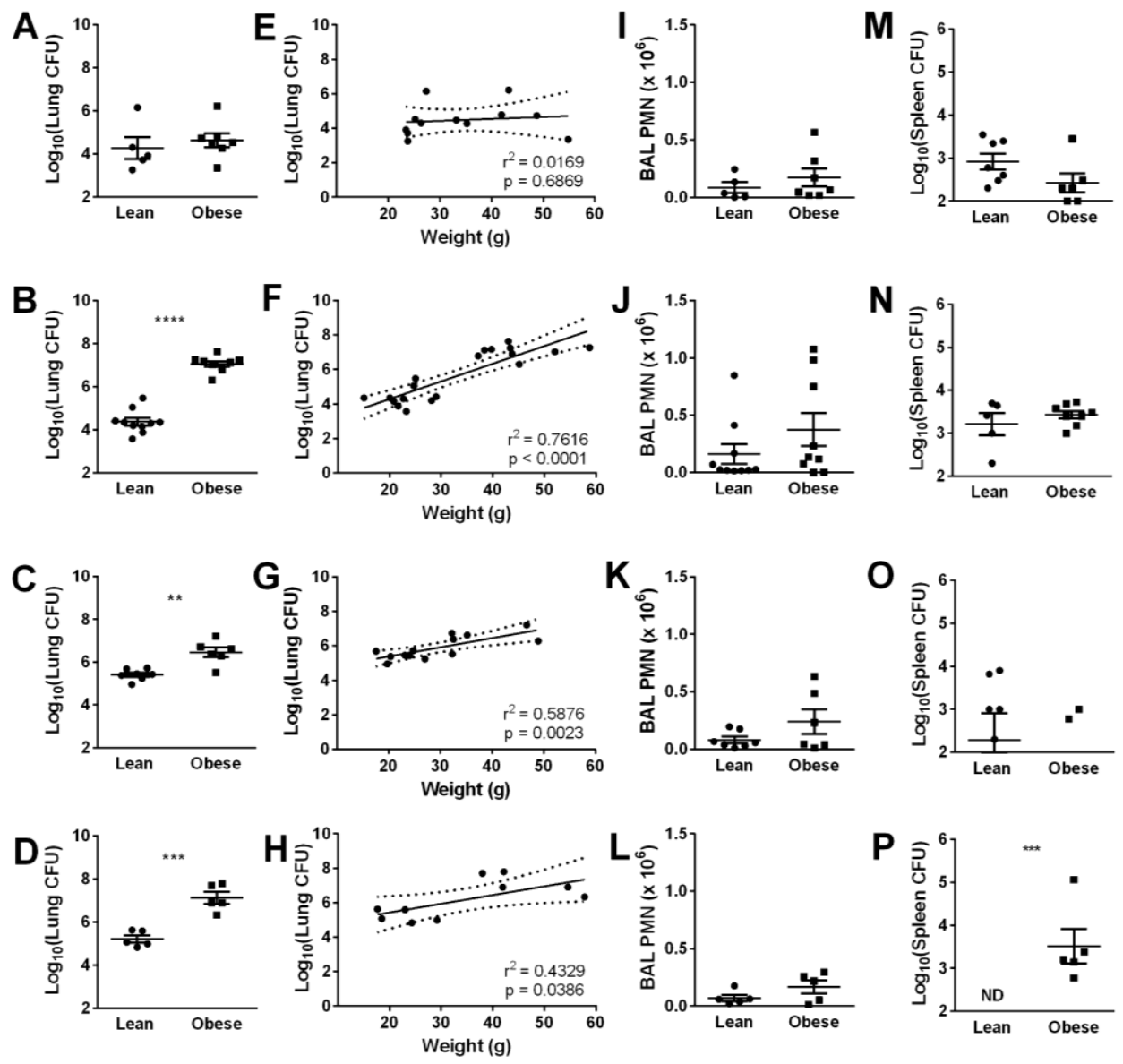

Figure 1 Obesity worsens bacterial pneumonia in mice. Lung colony forming units (CFU) were determined at $24 \mathrm{~h}$ after K. pneumoniae infection in diet-induced obese mice (60\% fat diet vs. $10 \%$ fat diet) (A), db/db mice (B), $C P E^{\text {fat }}$ mice (C), and ob/ob mice (D). Lung CFU was compared with mouse weight by linear regression (E-H). In addition, BAL neutrophil levels (I-L) and spleen CFU (M-P) were determined. $n=5-13$ mice per condition. Dashed lines indicate $95 \%$ confidence intervals. Data are represented as mean \pm SEM. ${ }^{* *} P \leq 0.01 ; * * P \leq 0.001$ compared to lean controls. ND= non-detectable. 

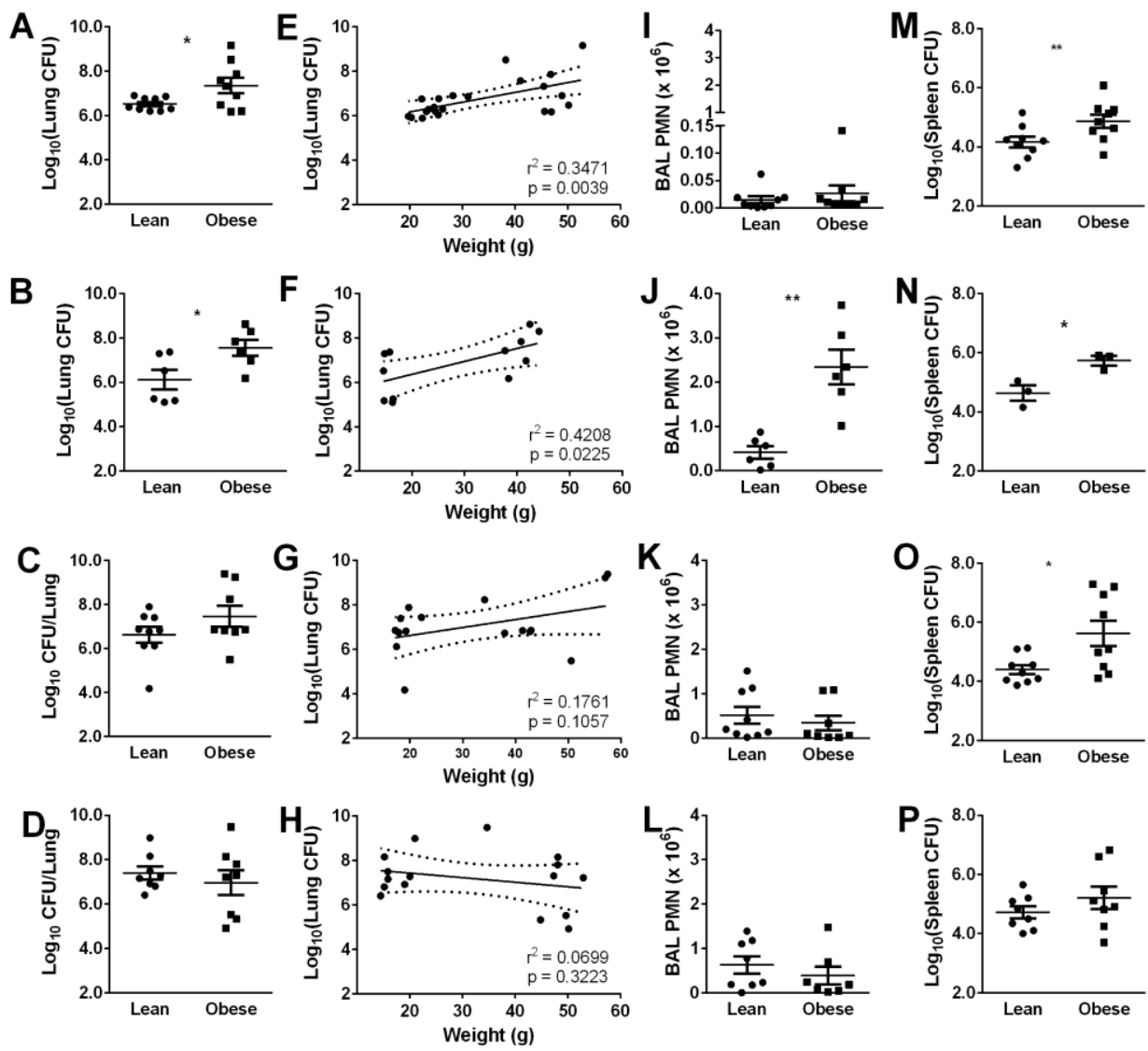

Figure 2 Obesity worsens bacterial pneumonia in mice. Lung colony forming units (CFU) were determined at $48 \mathrm{~h}$ after $K$. pneumoniae infection in diet-induced obese mice (60\% fat diet vs. $10 \%$ fat diet) (A), db/db mice (B), $C P E^{\text {fat }}$ mice (C), and ob/ob mice (D). Lung CFU was compared with mouse weight by linear regression (E-H). In addition, BAL neutrophil levels (I-L) and spleen CFU (M-P) were determined. $n=5-13$ mice per condition. Dashed lines indicate $95 \%$ confidence intervals. Data are represented as mean $\pm \mathrm{SEM}$. ${ }^{*} P \leq 0.05,{ }^{*} P \leq 0.01$ compared to lean controls. 


\section{Obesity impairs neutrophil chemotaxis.}

To determine whether the attenuated pulmonary neutrophilia observed in obese mice may be, at least in part, caused by an intrinsic defect in neutrophil function, we first examined the chemoattractant response of density-isolated, mature bone marrowderived neutrophils from $\mathrm{DIO}, \mathrm{db} / \mathrm{db}, \mathrm{CPE}^{\text {fat/fat }}$ and ob/ob obese mice and their lean littermate controls. Chemotactic responses to KC (a CXCR2 ligand) and FMLP (an FPR1 ligand) were impaired in neutrophils from obese DIO, db/db, CPE ${ }^{\text {fat } / f a t}$, and ob/ob mice (Figure 4A-D) compared to their lean littermates, although in ob/ob mice the difference in chemotaxis response to fMLP did not reach statistical significance. These results indicate that obesity-associated defects in neutrophil chemotaxis are common among the examined obesity models, and suggest that multiple G-protein coupled receptors are affected.
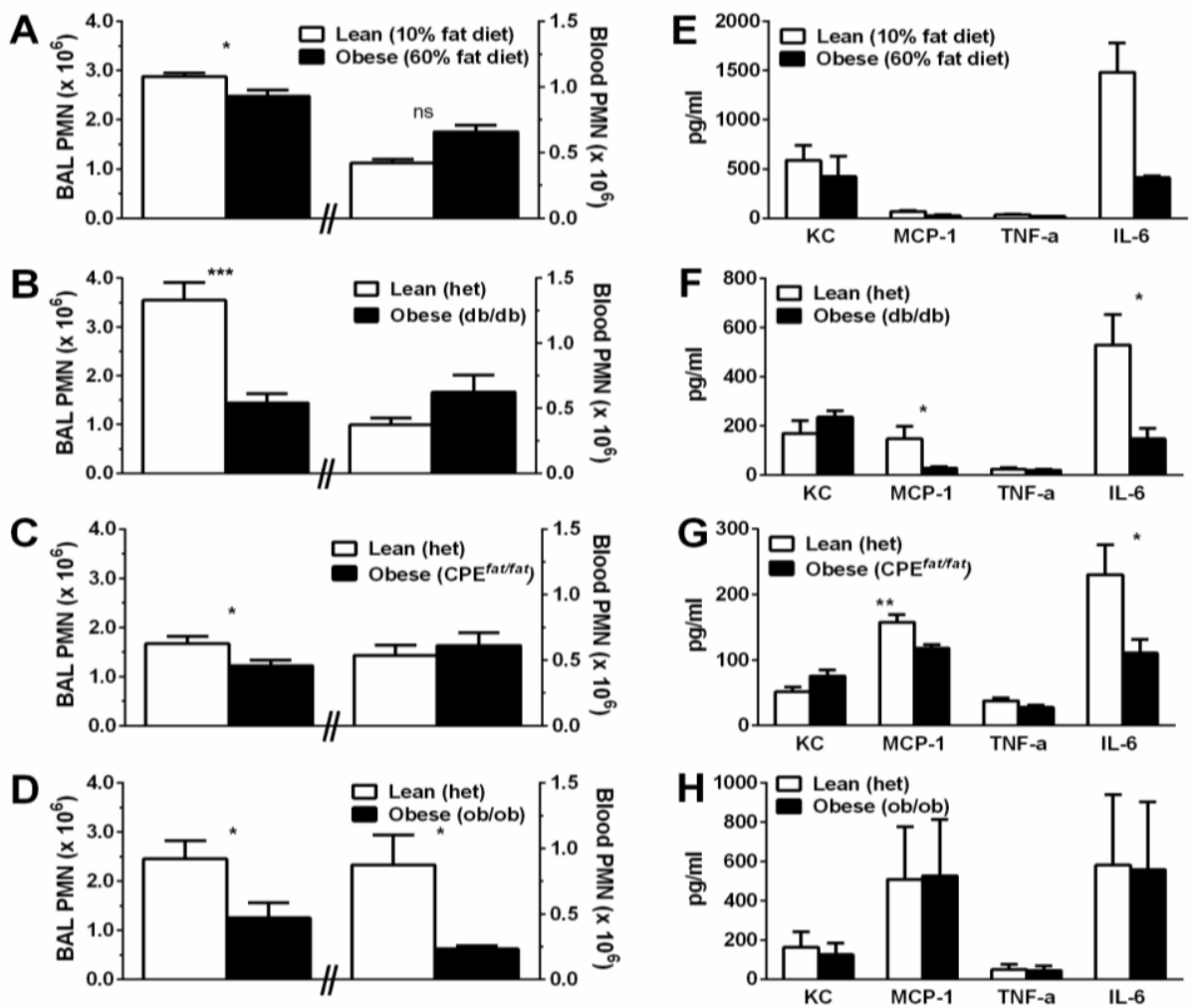

Figure 3 Obesity impairs the pulmonary immune response in mice following LPS induced pneumonitis. BAL and blood neutrophil counts (A-D) and BAL cytokine levels (E-H) were determined in diet-induced obese (DIO) ( $\mathbf{A}$ and $\mathbf{E}), \mathrm{db} / \mathrm{db}$ ( $\mathbf{B}$ and $\mathbf{F}$ ), $\mathrm{CPE}^{\text {fat }}$ (C and $\mathbf{G}$ ) and ob/ob mice ( $\mathbf{D}$ and $\mathbf{H}$ ) and their lean littermates at $24 \mathrm{~h}$ after LPS exposure. $n=8-12$ mice per condition. Data are represented as mean \pm SEM. $* P<0.05, * * p<0.01, * * * p$ $<0.001$ compared to lean control. ns = not significant. 


\section{Obesity variably attenuates the pro-survival effect of G-CSF on FasL- induced apoptotic neutrophils.}

The effects of obesity on neutrophil survival were determined by incubating mature bone marrow-derived neutrophils from each model of obesity with the anti-apoptotic cytokine G-CSF, pro-apoptotic FasL, or a combination of both. Neutrophils from lean mice of all models were susceptible to FasL-induced cell death, and could be rescued by G-CSF stimulation in lean controls from both $\mathrm{DIO}$ and $\mathrm{CPE}^{\text {fat/fat }}$ models (Figure $4 \mathrm{E}-\mathrm{H}$ ). However, neutrophils from obese DIO and $\mathrm{CPE}^{\text {fat/fat }}$ mice demonstrated an attenuated pro-survival effect of G-CSF in the setting of FasL exposure. No differences were found in the number of viable cells between control and G-CSF treated neutrophils from obese $\mathrm{DIO}, \mathrm{CPE}^{\text {fat/fat }}$ or ob/ob mice (Figure 4E, G, and $\mathrm{H}$ ); however, interestingly, G-CSF appeared to induce cell death in obese $\mathrm{db} / \mathrm{db}$ mice (Figure $4 \mathrm{~F}$ ). None of these conditions appeared to have significant effects on neutrophils from obese ob/ob mice. These data suggest that neutrophils from obese $\mathrm{DIO}, \mathrm{db} / \mathrm{db}$, and $\mathrm{CPE}^{\text {fat/fat }}$ mice are not only defective in their chemotactic but may also have defects in survival. Thus, the obesityassociated attenuation of airspace neutrophilia in these models may derive from both impaired neutrophil recruitment and survival.

\section{LPS-induced neutrophil cytokine transcription is variably impaired in obesity.}

To further delineate the effects of obesity on neutrophil function, we examined neutrophil cytokine transcription after LPS exposure. Bone marrow-derived neutrophils from obese mice and lean littermate controls were stimulated with LPS in vitro for $4 \mathrm{~h}$ and mRNA expression levels of the cytokines IL-1 $\beta$, MCP-1, IL-6, TNF $\alpha$ and KC were then determined. An overall decrease in cytokine production was observed in the obese neutrophils from DIO and $\mathrm{db} / \mathrm{db}$ mice (Figure $5 \mathrm{~A}$ and $\mathrm{B}$ ) compared to lean littermate controls. However, no attenuation in cytokine expression was observed in neutrophils from obese ob/ob and CPE ${ }^{\text {fat/fat }}$ mice (Figure 5D), and increased expression of TNF $\alpha$ was seen in obese $\mathrm{CPE}^{\text {fat/fat }}$ neutrophils compared to lean controls (Figure $5 \mathrm{C}$ ). These results suggest that obesity may impair LPS-induced signaling, but that differences exist between the obese models studied. 

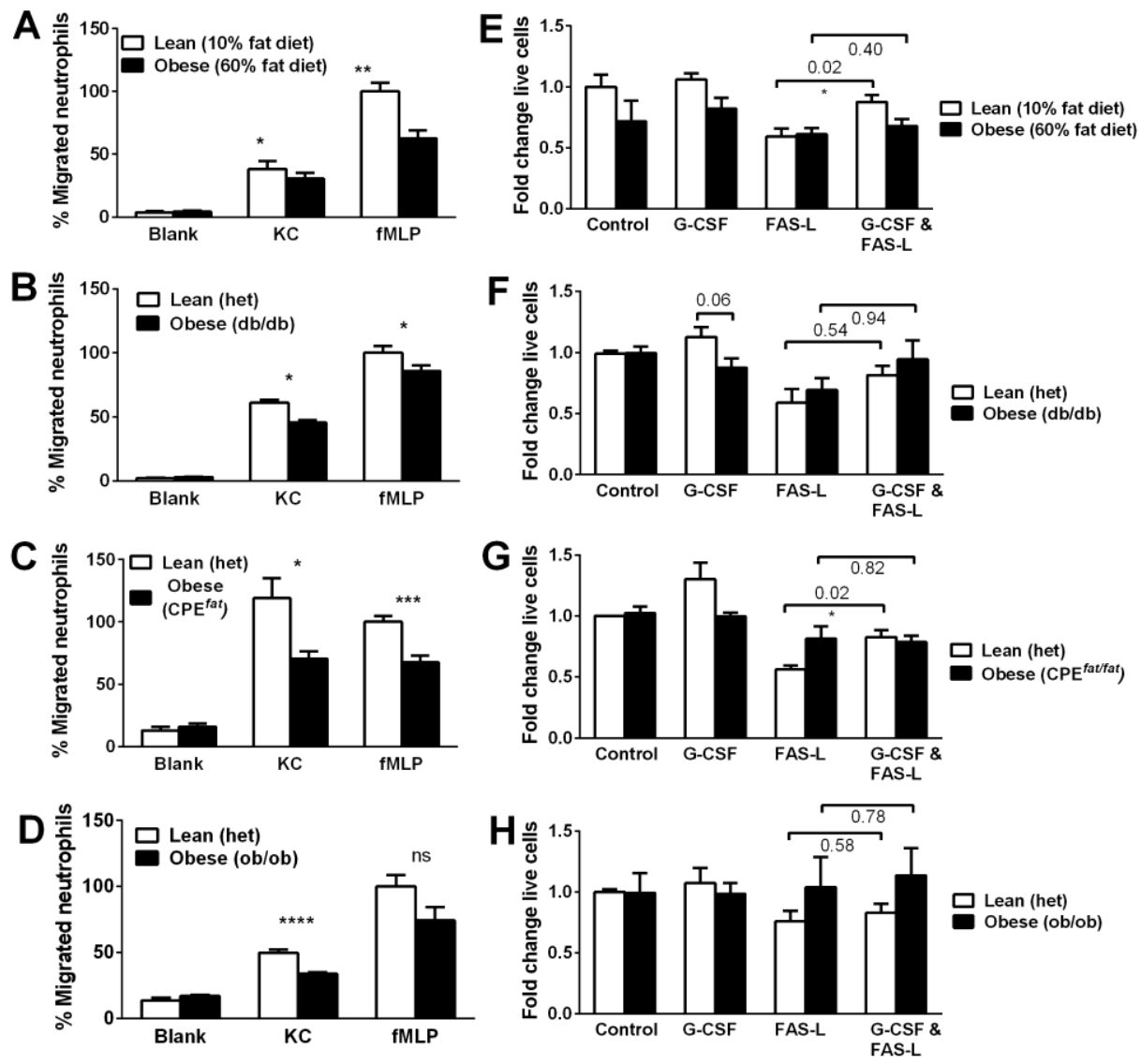

Figure 4 Obesity impairs neutrophil function. Chemotaxis of mature bone marrow neutrophils isolated from (A) diet-induced obese (DIO) mice and (B) mutant obese $\mathrm{db} / \mathrm{db},(C) \mathrm{CPE}^{\text {fat/fat }}$, and (D) ob/ob mice was compared with lean control mice using a modified Boyden chamber with KC $(25 \mathrm{ng} / \mathrm{ml})$ or $\mathrm{fMLP}(1 \mu \mathrm{M})$. Membrane counts were expressed as percentage of lean control neutrophil migration to fMLP for each experiment. Furthermore, the pro-survival effect of G-CSF on FasL-induced neutrophil apoptosis was examined. Mature bone marrow neutrophils isolated from (E) diet-induced obese (DIO) mice and (F) mutant obese $\mathrm{db} / \mathrm{db},(\mathbf{G}) \mathrm{CPE}^{\text {fat/fat }}$, and (H) ob/ob mice were incubated with G-CSF $(25 \mathrm{ng} / \mathrm{ml})$, FasL $(200 \mathrm{ng} / \mathrm{ml})$ or a combination of G-CSF and FasL for $6 \mathrm{~h}$. Live cells were then counted using trypan blue. Three separate experiments were performed on isolated neutrophils from each mouse model and their respective controls. Cell counts were expressed as fold change of lean control live cell count for each experiment. Data are represented as mean $\pm \mathrm{SEM}$. ${ }^{*} P \leq 0.05,{ }^{*} P \leq 0.01$, ${ }^{* * *} P \leq 0.001, * * * * P \leq 0.0001$ compared to lean control (A-D) or compared to G-CSF and Fas-L conditions (E-H). $\mathrm{ns}=$ not significant. 

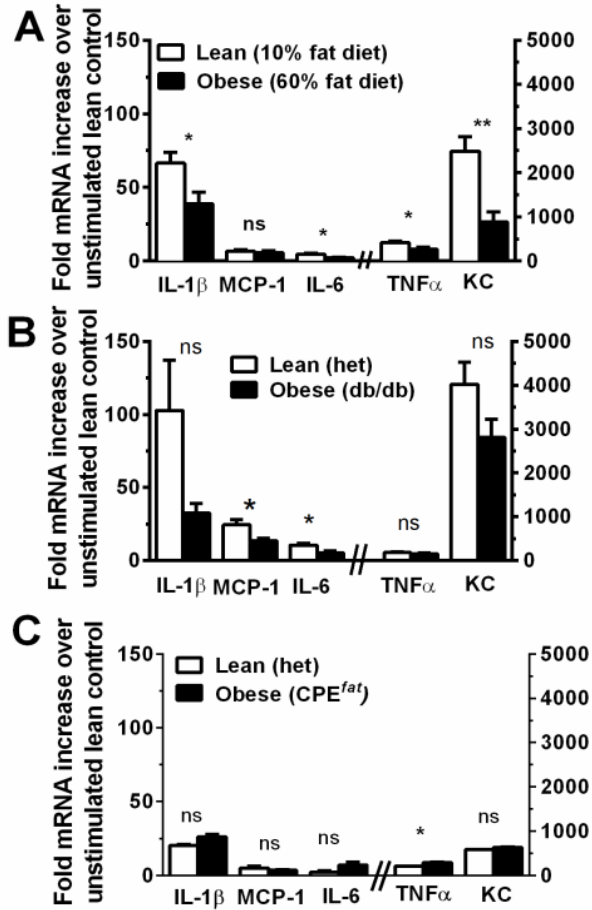

Figure 5 LPS-induced neutrophil cytokine transcription is variably impaired in obesity. Furthermore, gene expression levels of IL-1 $\beta$, MCP-1, IL6, TNF- $\alpha$ and KC levels were measured by qPCR 4 h after in vitro LPS (100ng/ml) stimulation of bone marrow derived neutrophils from $(A)$ dietinduced obese, (B) db/db, (C) CPEfat/fat and (D) ob/ob obese mice and compared with lean control mice. Three separate experiments were performed on isolated neutrophils from each mouse model and their respective controls. Data are represented as mean \pm SEM. $* P \leq 0.05$, $* * \mathrm{P} \leq 0.01, * * * \mathrm{P} \leq 0.001, * * * * \mathrm{P} \leq 0.0001$ compared to lean control. ns= not significant.

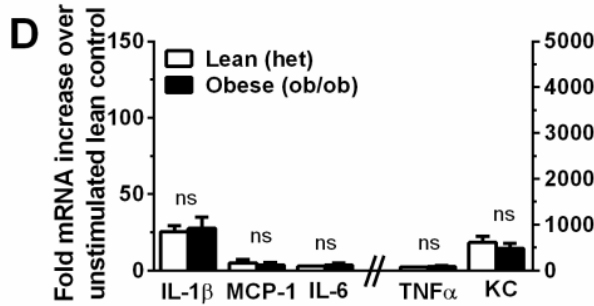

\section{Obesity impairs neutrophil signaling in response to LPS and G-CSF.}

To examine the underlying mechanisms of the observed obesity-related neutrophil dysfunction, we next examined neutrophil intracellular signaling. First, the MAPK signaling pathway was examined after LPS stimulation of bone marrow-derived neutrophils from obese $\mathrm{DIO}, \mathrm{db} / \mathrm{db}, \mathrm{CPE} \mathrm{E}^{\text {fat/fat }}$ and ob/ob mice and their lean littermates. An overall decrease in LPS-induced p38 phosphorylation was observed at various timepoints in neutrophils from obese $\mathrm{DIO}, \mathrm{db} / \mathrm{db}$ and $\mathrm{CPE}^{\text {fat/fat }}$ mice compared to their lean littermate controls (Figure 6A-C). However, no distinct differences were observed between LPS-stimulated neutrophils from obese and lean ob/ob mice (Figure 6D). Next, we determined the downstream signaling response to G-CSF via STAT3 signaling, which is important in directing neutrophilic granulocyte differentiation and cell survival $(38,39)$. 
G-CSF-induced signaling through STAT3 was reduced in obese neutrophils from DIO and $\mathrm{db} / \mathrm{db}$ mice, but appeared to be normal but delayed in obese $\mathrm{CPE}^{\text {fat/fat }}$ mice and normal in ob/ob mice (Figure $6 \mathrm{E}-\mathrm{H}$ ). These results may, in part, explain the impaired neutrophil transcriptional response to LPS, as well as the failure of G-CSF-induced neutrophil survival in several models of obesity.

\section{Metabolic parameters vary between different mouse models of obesity.}

Factors involved in the metabolic syndrome, such as glucose tolerance and dyslipidemia, have been suggested to differ between the diverse murine models of obesity. To examine differences in metabolic parameters between the four different models used in the current study, we measured cholesterol levels as well as fasting (6h) glucose levels in obese $\mathrm{DIO}, \mathrm{db} / \mathrm{db}, \mathrm{CPE} \mathrm{fat}^{\text {ffat }}$ and ob/ob mice and their lean controls. We found significantly increased cholesterol levels in obese mice compared to their lean controls, but the levels varied between the different models (Table 1). Interestingly, fasting glucose levels were significantly increased only in obese $\mathrm{db} / \mathrm{db}$ mice compared to their lean controls, whereas fasting glucose levels were similar between obese and lean DIO, $C P E^{f a t / f a t}$ and ob/ob mice (Table 1). These results suggest that the obesity models used in this study integrate variable degrees of the metabolic syndrome.

Table 1 Baseline metabolic parameters of obese mouse models.

\begin{tabular}{|l|c|c|c|c|}
\hline Mouse model & \multicolumn{2}{|c|}{ Cholesterol (mg/dl) } & \multicolumn{2}{c|}{ Fasting glucose (mg/dl) } \\
\hline & Lean & Obese & Lean & Obese \\
\hline DIO & $88.0 \pm 3.23$ & $139.0 \pm 9.57 * * *$ & $148.2 \pm 18.98$ & $123.8 \pm 6.98$ \\
\hline $\mathbf{d b} / \mathrm{db}$ & $53.60 \pm 2.23$ & $101.0 \pm 14.01 * *$ & $146.2 \pm 18.29$ & $481.8 \pm 56.35^{* * *}$ \\
\hline $\mathrm{CPE}^{\text {fat/fat }}$ & $51.0 \pm 1.0$ & $142.0 \pm 8.41 * * * *$ & $126.3 \pm 34.93$ & $292.3 \pm 75.38$ \\
\hline ob/ob & $50.0 \pm 0.0$ & $63.0 \pm 3.22 *$ & $202.6 \pm 34.93$ & $192.7 \pm 18.39$ \\
\hline
\end{tabular}


A

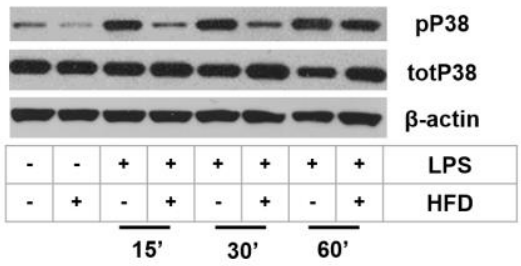

B

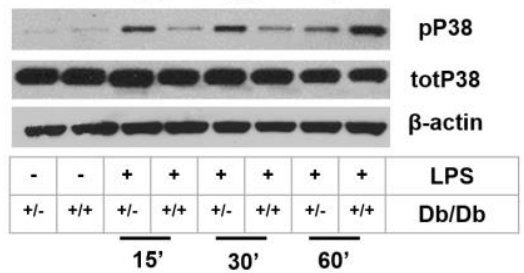

C

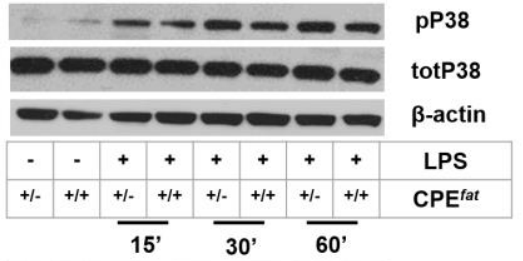

D

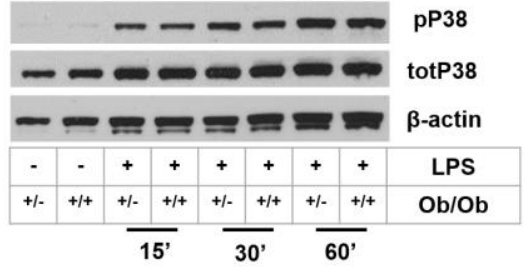

E

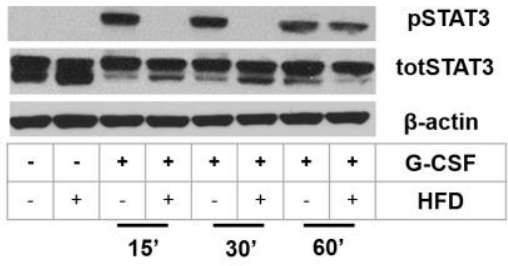

F
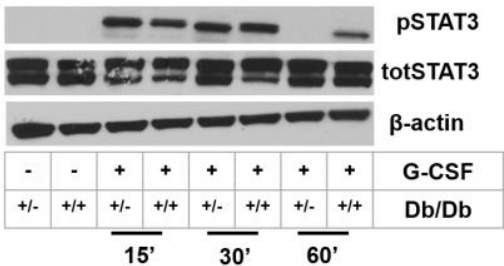

G
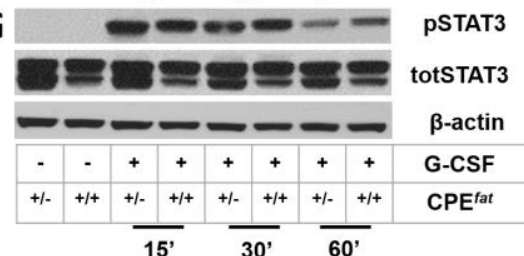

H

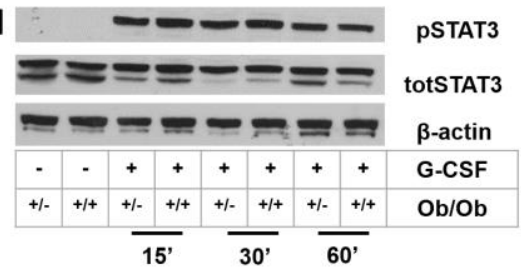

Figure 6 LPS-induced MAPK and G-CSF induced STAT signaling response is attenuated in obese neutrophils. Bone marrow-derived neutrophils were isolated from DIO (10\% vs. $60 \%$ fat diet) mice (A and E), lean (+/-) and obese (+/+) $d b / d b$ mice (B and $\mathbf{F}$ ), lean (+/-) and obese (+/+) $\mathrm{CPE}^{\text {fat }}$ mice (C and $\mathbf{G}$ ) and lean (+/-) and obese (+/+) $o b / o b$ mice (D and $\mathbf{H})$, and subsequently stimulated with PBS (control), lipopolysaccharide (LPS) (1 $\mu \mathrm{g} / \mathrm{ml})$ (A-D) or G-CSF $(25 \mathrm{ng} / \mathrm{ml})(\mathrm{E}-\mathrm{H})$ for 15, 30 or 60 minutes. Protein expression of phosphorylated P38, total P38, pSTAT3, totSTAT3 and $\beta$-actin (loading control) was determined by western blot. Data shown are representative blots out of 3 different experiments. HFD= high fat diet. 


\section{Discussion}

The present study presents evidence of obesity-associated defects in host defense to bacterial pneumonia in mice. However, the course and severity of pulmonary infection appears to be vary with the mouse model used. Furthermore, although the inflammatory response following LPS-induced pneumonitis was attenuated in obese mice from all models; yet, the mechanisms underlying this response appear to differ. We demonstrate that obesity is associated with variable defects in neutrophil functions including chemotaxis, cell survival, and cytokine transcription, as well as impaired intracellular signaling responses.

Several animal models of obesity have been used to investigate the effects of obesity and associated comorbidities on the pulmonary immune response related to both acute and chronic lung diseases, including bacterial $(11,12,18,19,27,29)$ and viral $(9,28,40$, 41) respiratory infections, airway hyperresponsiveness (8, 42-47), ARDS (5, 7, 12, 30), pulmonary fibrosis (26) and COPD (31). The most commonly employed mouse models of obesity include diet-induced obesity (DIO), and the hyperphagic mutant $\mathrm{db} / \mathrm{db}, \mathrm{CPE}^{\text {fat/fat }}$, and ob/ob strains. Diet-induced obesity using high fat containing food in wild-type mice has been suggested to mimic human obesity most closely (20-22). Yet, most published reports use $\mathrm{db} / \mathrm{db}$ mice (spontaneous mutants lacking expression of the long form of the leptin receptor, ObRb), which are typically considered to be a model of leptin 'resistance' and obesity-associated diabetes (23). The obese, aleptinemic ob/ob mouse (a spontaneous mutant lacking expression of leptin) has also been used, particularly to determine the role and importance of leptin (24). Lastly, the CPE ${ }^{\text {fat/fat }}$ mouse has been used as a general model of obesity given its hyperphagic phenotype, which is driven by the lack of carboxypeptidase-E, which cleaves functional hormones regulating satiety (25).

Previous work using these models to investigate the effects of obesity on the susceptibility to and outcomes from bacterial respiratory infection has been inconclusive. Mancuso, et al, showed that obese leptin-deficient (ob/ob) mice exhibit increased susceptibility to infections with both Gram-negative ( $K$. pneumoniae) and Gram-positive (S. pneumonia) organisms, at $24 \mathrm{~h}$ and 24 and $48 \mathrm{~h}$ after inoculation respectively $(11,18)$, and that restoration of leptin levels could reverse the observed defects in bacterial clearance and survival (18). However, pulmonary host defense in hyperphagic $\mathrm{CPE}^{\text {fat/fat }}$ mice (which manifest more modest metabolic abnormalities (25)) appeared to be normal at both $24 \mathrm{~h}$ and $48 \mathrm{~h}$ post-infection with $S$. pneumoniae (19). Here, we report evidence of impaired pulmonary host defense in response to $K$. pneumoniae in both ob/ob and CPE ${ }^{\text {fat/fat }}$, as well as $\mathrm{db} / \mathrm{db}$ and DIO models of obesity, but with temporal variation. Early (24h) lung bacterial burden was elevated in obese compared to lean $\mathrm{db} / \mathrm{db}$, ob/ob, and $\mathrm{CPE}^{\text {fat/fat }}$ mice, but not in DIO mice. However, the effect of obesity was no longer evident at $48 \mathrm{~h}$ in the ob/ob and $\mathrm{CPE}^{\text {fat/fat }}$ models, while only becoming detectable at that time point in the DIO model, and remaining constant in 
the $\mathrm{db} / \mathrm{db}$. The kinetic differences between these models may suggest the presence of either a 'plateau' phenomenon in which lung bacterial burden does not increase above a certain level (perhaps that corresponding to blood dissemination) in the obese mice, and/or differences in pulmonary bacterial handling in the early vs. late phases of infection between the obesity models. These findings, in the context of previous reports, suggest that obesity model, timing of observation, and the strain of bacteria used may lead to significantly different 'outcomes' in obese pneumonia studies, despite a common obesity-associated susceptibility to pulmonary infection.

Our previous work suggests that an attenuated pulmonary inflammatory response may underlie the witnessed increased susceptibility to pulmonary infection in both obese subjects and animals $(4,5)$. In the current study we find decreased pulmonary neutrophilia in all four murine obesity models following LPS-induced lung injury. However, our results also suggest that the underlying mechanisms may differ between these models. In the $\mathrm{DIO}, \mathrm{db} / \mathrm{db}$ and $\mathrm{CPE}^{\text {fat/fat }}$ models, circulating neutrophil counts following injury are similarly elevated between lean and obese mice indicating that the attenuation of pulmonary neutrophilia is not due to a decrease in neutrophil release from the bone marrow to the periphery. However, we observed a decrease in circulating neutrophil levels in obese ob/ob mice, suggesting that a different or possibly accompanying mechanism may account for attenuated pulmonary neutrophilia in this model. In support of this, Claycombe et al. previously reported that obese ob/ob (leptin deficient) mice demonstrate impaired granulopoiesis at baseline, and that leptin replacement can reverse this defect (48). Thus, in the ob/ob model, defective granulopoiesis may, in part, underlie the impaired development of pulmonary neutrophilia following insult. Similar defects in granulopoiesis have not, however, been described in the other models of obesity, and in fact, the opposite has been reported in the other mouse models of obesity and obese humans in which both resting and inflammatory states are associated with elevated blood neutrophil levels, possibly related to the effects of dyslipidemia and lipid overload (49-51).

Subsequent to blood delivery, neutrophil migration from the microvascular beds of the lung to the airspace is a crucial process following a pulmonary inflammatory insult. Previously, we reported obesity-associated impairment of neutrophil chemotaxis in the setting of blunted calcium flux response to the CXC cytokine KC (a homologue of human IL-8) and decreased surface levels of its receptor, CXCR2, on neutrophils in both DIO and $\mathrm{db} / \mathrm{db}$ mice compared to their lean littermates (5). In the current study, we extend these findings to demonstrate defects in neutrophil chemotaxis across all four models of murine obesity and to both chemokines and bacterial peptides, suggesting that multiple G-protein coupled receptors (CXCR2 and FPR1) are affected in the obesity-associated chemotaxis defect.

Another critical neutrophil function regulating levels of airspace neutrophilia and the pulmonary inflammatory response is neutrophil apoptosis. Yet, very little is known regarding the effects of obesity on neutrophil apoptosis. In the current study, we 
examined the effects of obesity on G-CSF-mediated rescue from fasL-induced neutrophil apoptosis and found variably but overall impaired responses in obese mouse models, suggesting obesity-associated defects in neutrophil survival. Perhaps underlying these findings, G-CSF mediated STAT3 signaling response was reduced in obese neutrophils from $\mathrm{DIO}, \mathrm{db} / \mathrm{db}$ and $\mathrm{CPE}^{\text {fat/fat }}$ mice, whereas it appeared to be normal in ob/ob mice. Interestingly, G-CSF, a pro-survival cytokine, appeared to induce cell death in neutrophils isolated from obese $\mathrm{db} / \mathrm{db}$ mice. These mice are bred on a C57BLKS/J (BKS) background, which is a genetic composite between the diabetic resistant $\mathrm{C} 57 \mathrm{BL} / 6 \mathrm{~J}$ and the diabetes susceptible DBA/2J strains (52), whereas the DIO, $\mathrm{CPE}^{\text {fat/fat }}$ and ob/ob mice were bred on a C57BL/6J background. The different background may contribute, in part, to the different response of G-CSF on neutrophil survival. Together, these results suggest that the obesity-associated attenuation of airspace neutrophilia in these models may derive from both impaired neutrophil recruitment and, in some models, survival.

Beyond neutrophil transit to and survival in the lung, impaired neutrophil function may have other detrimental effects on the immune response to pathogens. The transcriptional response of neutrophils is a critical factor in amplifying pulmonary inflammation (25). Our current studies demonstrate an overall decrease in LPS-induced inflammatory cytokine transcription in neutrophils from both DIO and db/db models of obesity, yet little effect was seen in either $\mathrm{CPE}^{\text {fat/fat }}$ or ob/ob models, suggesting that obesity may differentially impair LPS-induced signaling depending on the model used. In support of this, we found that downstream signaling responses to LPS through the MAPK pathway were decreased in neutrophils from obese $\mathrm{DIO}$, and $\mathrm{db} / \mathrm{db}$ mice, whereas no distinct differences were seen when examining neutrophils from ob/ob mice. Subtle attenuation of LPS-induced p38 phosphorylation did not correlate with transcriptional impairment in obese $\mathrm{CPE}^{\text {fat/fat }}$ neutrophils.

Suitable animal models are fundamental to our understanding of the effects of obesity on pulmonary immune function and, through extrapolation, the pathogenesis of pulmonary disease in the obese human population. All obese mouse models integrate variable degrees of different elements of the metabolic syndrome and therefore are imperfect models of individual facets of the metabolic syndrome (e.g. $\mathrm{db} / \mathrm{db}$ mice as a model of simple diabetes). Factors contributing to the metabolic syndrome, including glucose intolerance and dyslipidemia, differ between the four models we examined (Supplemental table E1), likely leading to varying effects on the immune response and host defense. Diabetes and hyperglycemia have been suggested to increase the risk for and severity of infection (53), in line with our current results in the $\mathrm{db} / \mathrm{db}$ model, which demonstrates both the greatest glucose intolerance (Supplemental table E1) and the most impaired ability to contain lung infection. Dyslipidemia has also been shown to impair both neutrophil function and the response to pneumonia $(54,55)$. Thus, the differing levels of hypercholesterolemia manifested in the four mouse obesity models (Supplemental table E1) likely also contribute to the variable degrees of neutrophil functional impairment and responses to pulmonary infection across these four models. 
Other potential factors that may contribute to the observed variability between mouse models in this study include genetic background, adipokine milieu, and the age at which obesity onset of occurs. Obesity develops late in DIO mice (+/- 24-28 weeks), whereas $\mathrm{db} / \mathrm{db}$ and ob/ob mice are obese by 8-10 weeks of age, and it has suggested that older mice may respond differently to bacterial infections compared to younger mice (56). However, multivariate analysis including both sex and age have shown no effect of these variables on airspace neutrophilia following lung injury in previous studies (5). Taken together, it is evident that in order to select appropriate modelling approaches to obesity, a thorough understanding of the presence and degree of metabolic and other relevant factors manifest in each available model is essential to both interpret and maximize the clinical relevance of studies performed in these models.

\section{Conclusion}

We demonstrate that obesity is associated with impaired pulmonary host defense following bacterial infection. However, the course and severity of the infection, as well as the underlying mechanisms, may vary with the mouse model of obesity used, possibly on the basis of variable expression of the metabolic syndrome. Furthermore, we show that obesity is associated with defects in neutrophil function such as impaired cytokine transcription, downstream signaling responses as well as neutrophil chemoattractant response. 


\section{References}

1. Ng, M., Fleming, T., Robinson, M., Thomson, B., Graetz, N., Margono, C., Mullany, E.C., Biryukov, S., Abbafati, C., Abera, S.F., et al. 2014. Global, regional, and national prevalence of overweight and obesity in children and adults during 1980-2013: a systematic analysis for the Global Burden of Disease Study 2013. Lancet 384:766-781.

2. Phung, D.T., Wang, Z., Rutherford, S., Huang, C., and Chu, C. 2013. Body mass index and risk of pneumonia: a systematic review and meta-analysis. Obes Rev 14:839-857.

3. Gong, M.N., Bajwa, E.K., Thompson, B.T., and Christiani, D.C. 2010. Body mass index is associated with the development of acute respiratory distress syndrome. Thorax 65:44-50.

4. Stapleton, R.D., Dixon, A.E., Parsons, P.E., Ware, L.B., Suratt, B.T., and Network, N.A.R.D.S. 2010. The association between BMI and plasma cytokine levels in patients with acute lung injury. Chest 138:568-577.

5. Kordonowy, L.L., Burg, E., Lenox, C.C., Gauthier, L.M., Petty, J.M., Antkowiak, M., Palvinskaya, T., Ubags, N., Rincon, M., Dixon, A.E., et al. 2012. Obesity is associated with neutrophil dysfunction and attenuation of murine acute lung injury. Am J Respir Cell Mol Biol 47:120-127.

6. Barazzone-Argiroffo, C., Muzzin, P., Donati, Y.R., Kan, C.D., Aubert, M.L., and Piguet, P.F. 2001. Hyperoxia increases leptin production: a mechanism mediated through endogenous elevation of corticosterone. Am J Physiol Lung Cell Mol Physiol 281:L1150-1156.

7. Bellmeyer, A., Martino, J.M., Chandel, N.S., Scott Budinger, G.R., Dean, D.A., and Mutlu, G.M. 2007. Leptin resistance protects mice from hyperoxia-induced acute lung injury. Am J Respir Crit Care Med 175:587-594.

8. Shore, S.A., Lang, J.E., Kasahara, D.I., Lu, F.L., Verbout, N.G., Si, H., Williams, E.S., Terry, R.D., Lee, A., and Johnston, R.A. 2009. Pulmonary responses to subacute ozone exposure in obese vs. lean mice. $J$ Appl Physiol (1985) 107:1445-1452.

9. Smith, A.G., Sheridan, P.A., Harp, J.B., and Beck, M.A. 2007. Diet-induced obese mice have increased mortality and altered immune responses when infected with influenza virus. J Nutr 137:1236-1243.

10. Easterbrook, J.D., Dunfee, R.L., Schwartzman, L.M., Jagger, B.W., Sandouk, A., Kash, J.C., Memoli, M.J., and Taubenberger, J.K. 2011. Obese mice have increased morbidity and mortality compared to non-obese mice during infection with the 2009 pandemic H1N1 influenza virus. Influenza Other Respir Viruses 5:418-425.

11. Mancuso, P., Gottschalk, A., Phare, S.M., Peters-Golden, M., Lukacs, N.W., and Huffnagle, G.B. 2002. Leptin-deficient mice exhibit impaired host defense in Gram-negative pneumonia. Journal of immunology 168:4018-4024.

12. Ubags, N.D., Vernooy, J.H., Burg, E., Hayes, C., Bement, J., Dilli, E., Zabeau, L., Abraham, E., Poch, K.R., Nick, J.A., et al. 2014. The Role of Leptin in the Development of Pulmonary Neutrophilia in Infection and Acute Lung Injury. Critical Care Medicine 42:E143-E151.

13. Fezeu, L., Julia, C., Henegar, A., Bitu, J., Hu, F.B., Grobbee, D.E., Kengne, A.P., Hercberg, S., and Czernichow, S. 2011. Obesity is associated with higher risk of intensive care unit admission and death in influenza A (H1N1) patients: a systematic review and meta-analysis. Obesity reviews : an official journal of the International Association for the Study of Obesity 12:653-659.

14. Mertz, D., Kim, T.H., Johnstone, J., Lam, P.P., Science, M., Kuster, S.P., Fadel, S.A., Tran, D., Fernandez, E., Bhatnagar, N., et al. 2013. Populations at risk for severe or complicated influenza illness: systematic review and meta-analysis. BMJ 347:f5061.

15. Phung, D.T., Wang, Z., Rutherford, S., Huang, C., and Chu, C. 2013. Body mass index and risk of pneumonia: a systematic review and meta-analysis. Obesity reviews : an official journal of the International Association for the Study of Obesity 14:839-857.

16. Corrales-Medina, V.F., Valayam, J., Serpa, J.A., Rueda, A.M., and Musher, D.M. 2011. The obesity paradox in community-acquired bacterial pneumonia. Int J Infect Dis 15:e54-57.

17. Singanayagam, A., Singanayagam, A., and Chalmers, J.D. 2013. Obesity is associated with improved survival in community-acquired pneumonia. Eur Respir J 42:180-187.

18. Hsu, A., Aronoff, D.M., Phipps, J., Goel, D., and Mancuso, P. 2007. Leptin improves pulmonary bacterial clearance and survival in ob/ob mice during pneumococcal pneumonia. Clin Exp Immunol 150:332-339. 
19. Mancuso, P., E, O.B., Prano, J., Goel, D., and Aronoff, D.M. 2014. No Impairment in host defense against Streptococcus pneumoniae in obese CPEfat/fat mice. PLoS One 9:e106420.

20. West, D.B., Boozer, C.N., Moody, D.L., and Atkinson, R.L. 1992. Dietary obesity in nine inbred mouse strains. Am J Physiol 262:R1025-1032.

21. Surwit, R.S., Kuhn, C.M., Cochrane, C., McCubbin, J.A., and Feinglos, M.N. 1988. Diet-induced type II diabetes in C57BL/6J mice. Diabetes 37:1163-1167.

22. Belperio, J.A., Keane, M.P., Burdick, M.D., Londhe, V., Xue, Y.Y., Li, K., Phillips, R.J., and Strieter, R.M. 2002. Critical role for CXCR2 and CXCR2 ligands during the pathogenesis of ventilator-induced lung injury. J Clin Invest 110:1703-1716.

23. Hummel, K.P., Dickie, M.M., and Coleman, D.L. 1966. Diabetes, a new mutation in the mouse. Science 153:1127-1128.

24. Ingalls, A.M., Dickie, M.M., and Snell, G.D. 1950. Obese, a new mutation in the house mouse. J Hered 41:317-318.

25. Strieter, R.M., Belperio, J.A., and Keane, M.P. 2002. Cytokines in innate host defense in the lung. $J$ Clin Invest 109:699-705.

26. Jain, M., Budinger, G.R., Lo, A., Urich, D., Rivera, S.E., Ghosh, A.K., Gonzalez, A., Chiarella, S.E., Marks, K., Donnelly, H.K., et al. 2011. Leptin promotes fibroproliferative acute respiratory distress syndrome by inhibiting peroxisome proliferator-activated receptor-gamma. Am J Respir Crit Care Med 183:1490-1498.

27. Mancuso, P., Huffnagle, G.B., Olszewski, M.A., Phipps, J., and Peters-Golden, M. 2006. Leptin corrects host defense defects after acute starvation in murine pneumococcal pneumonia. Am J Respir Crit Care Med 173:212-218.

28. Milner, J.J., Sheridan, P.A., Karlsson, E.A., Schultz-Cherry, S., Shi, Q., and Beck, M.A. 2013. Dietinduced obese mice exhibit altered heterologous immunity during a secondary 2009 pandemic H1N1 infection. J Immunol 191:2474-2485.

29. Park, S., Rich, J., Hanses, F., and Lee, J.C. 2009. Defects in innate immunity predispose C57BL/6JLeprdb/Leprdb mice to infection by Staphylococcus aureus. Infect Immun 77:1008-1014.

30. Tilton, S.C., Waters, K.M., Karin, N.J., Webb-Robertson, B.J., Zangar, R.C., Lee, K.M., Bigelow, D.J., Pounds, J.G., and Corley, R.A. 2013. Diet-induced obesity reprograms the inflammatory response of the murine lung to inhaled endotoxin. Toxicol Appl Pharmacol 267:137-148.

31. Vernooy, J.H., Bracke, K.R., Drummen, N.E., Pauwels, N.S., Zabeau, L., van Suylen, R.J., Tavernier, J., Joos, G.F., Wouters, E.F., and Brusselle, G.G. 2010. Leptin modulates innate and adaptive immune cell recruitment after cigarette smoke exposure in mice. J Immunol 184:7169-7177.

32. Fessler, M.B. 2015. Regulation of Adaptive Immunity in Health and Disease by Cholesterol Metabolism. Curr Allergy Asthma Rep 15:48.

33. Speakman, J., Hambly, C., Mitchell, S., and Krol, E. 2007. Animal models of obesity. Obes Rev 8 Suppl 1:55-61.

34. Wargo, M.J., Gross, M.J., Rajamani, S., Allard, J.L., Lundblad, L.K., Allen, G.B., Vasil, M.L., Leclair, L.W., and Hogan, D.A. 2011. Hemolytic phospholipase $C$ inhibition protects lung function during Pseudomonas aeruginosa infection. Am J Respir Crit Care Med 184:345-354.

35. Ubags, N.D., Vernooy, J.H., Burg, E., Hayes, C., Bement, J., Dilli, E., Zabeau, L., Abraham, E., Poch, K.R., Nick, J.A., et al. 2014. The role of leptin in the development of pulmonary neutrophilia in infection and acute lung injury. Critical care medicine 42:e143-151.

36. Suratt, B.T., Young, S.K., Lieber, J., Nick, J.A., Henson, P.M., and Worthen, G.S. 2001. Neutrophil maturation and activation determine anatomic site of clearance from circulation. Am J Physiol Lung Cell Mol Physiol 281:L913-921.

37. Petty, J.M., Sueblinvong, V., Lenox, C.C., Jones, C.C., Cosgrove, G.P., Cool, C.D., Rai, P.R., Brown, K.K., Weiss, D.J., Poynter, M.E., et al. 2007. Pulmonary stromal-derived factor-1 expression and effect on neutrophil recruitment during acute lung injury. Journal of Immunology 178:8148-8157.

38. Demetri, G.D., and Griffin, J.D. 1991. Granulocyte colony-stimulating factor and its receptor. Blood 78:2791-2808.

39. Nicola, N.A. 1987. Granulocyte colony-stimulating factor and differentiation-induction in myeloid leukemic cells. International journal of cell cloning 5:1-15.

40. Milner, J.J., Rebeles, J., Dhungana, S., Stewart, D.A., Sumner, S.C., Meyers, M.H., Mancuso, P., and Beck, M.A. 2015. Obesity Increases Mortality and Modulates the Lung Metabolome during Pandemic H1N1 Influenza Virus Infection in Mice. J Immunol. 
41. Radigan, K.A., Morales-Nebreda, L., Soberanes, S., Nicholson, T., Nigdelioglu, R., Cho, T., Chi, M., Hamanaka, R.B., Misharin, A.V., Perlman, H., et al. 2014. Impaired clearance of influenza A virus in obese, leptin receptor deficient mice is independent of leptin signaling in the lung epithelium and macrophages. PLoS One 9:e108138.

42. Johnston, R.A., Theman, T.A., and Shore, S.A. 2006. Augmented responses to ozone in obese carboxypeptidase E-deficient mice. Am J Physiol Regul Integr Comp Physiol 290:R126-133.

43. Johnston, R.A., Zhu, M., Hernandez, C.B., Williams, E.S., and Shore, S.A. 2010. Onset of obesity in carboxypeptidase E-deficient mice and effect on airway responsiveness and pulmonary responses to ozone. J Appl Physiol (1985) 108:1812-1819.

44. Lu, F.L., Johnston, R.A., Flynt, L., Theman, T.A., Terry, R.D., Schwartzman, I.N., Lee, A., and Shore, S.A. 2006. Increased pulmonary responses to acute ozone exposure in obese $\mathrm{db} / \mathrm{db}$ mice. Am J Physiol Lung Cell Mol Physiol 290:L856-865.

45. Williams, A.S., Mathews, J.A., Kasahara, D.I., Wurmbrand, A.P., Chen, L., and Shore, S.A. 2015. Innate and ozone-induced airway hyperresponsiveness in obese mice: role of TNF-alpha. Am J Physiol Lung Cell Mol Physiol 308:L1168-1177.

46. Lang, J.E., Williams, E.S., Mizgerd, J.P., and Shore, S.A. 2008. Effect of obesity on pulmonary inflammation induced by acute ozone exposure: role of interleukin-6. Am J Physiol Lung Cell Mol Physiol 294:L1013-1020.

47. Johnston, R.A., Theman, T.A., Lu, F.L., Terry, R.D., Williams, E.S., and Shore, S.A. 2008. Diet-induced obesity causes innate airway hyperresponsiveness to methacholine and enhances ozone-induced pulmonary inflammation. J Appl Physiol (1985) 104:1727-1735.

48. Claycombe, K., King, L.E., and Fraker, P.J. 2008. A role for leptin in sustaining lymphopoiesis and myelopoiesis. Proc Natl Acad Sci U S A 105:2017-2021.

49. Westerterp, M., Gourion-Arsiquaud, S., Murphy, A.J., Shih, A., Cremers, S., Levine, R.L., Tall, A.R., and Yvan-Charvet, L. 2012. Regulation of hematopoietic stem and progenitor cell mobilization by cholesterol efflux pathways. Cell Stem Cell 11:195-206.

50. Tall, A.R., and Yvan-Charvet, L. 2015. Cholesterol, inflammation and innate immunity. Nat Rev Immunol 15:104-116.

51. Gomes, A.L., Carvalho, T., Serpa, J., Torre, C., and Dias, S. 2010. Hypercholesterolemia promotes bone marrow cell mobilization by perturbing the SDF-1:CXCR4 axis. Blood 115:3886-3894.

52. Naggert, J.K., Mu, J.L., Frankel, W., Bailey, D.W., and Paigen, B. 1995. Genomic analysis of the C57BL/Ks mouse strain. Mamm Genome 6:131-133.

53. Valdez, R., Narayan, K.M., Geiss, L.S., and Engelgau, M.M. 1999. Impact of diabetes mellitus on mortality associated with pneumonia and influenza among non-Hispanic black and white US adults. American journal of public health 89:1715-1721.

54. Madenspacher, J.H., Draper, D.W., Smoak, K.A., Li, H., Griffiths, G.L., Suratt, B.T., Wilson, M.D., Rudel, L.L., and Fessler, M.B. 2010. Dyslipidemia induces opposing effects on intrapulmonary and extrapulmonary host defense through divergent TLR response phenotypes. J Immunol 185:16601669.

55. Palvinskaya, T., Antkowiak, M., Burg, E., Lenox, C.C., Ubags, N., Cramer, A., Rincon, M., Dixon, A.E., Fessler, M.B., Poynter, M.E., et al. 2013. Effects of acute and chronic low density lipoprotein exposure on neutrophil function. Pulm Pharmacol Ther 26:405-411.

56. Krone, C.L., Trzcinski, K., Zborowski, T., Sanders, E.A., and Bogaert, D. 2013. Impaired innate mucosal immunity in aged mice permits prolonged Streptococcus pneumoniae colonization. Infection and immunity 81:4615-4625. 



\section{CHAPTER 5}

\section{Paradoxical Modulation of the Pulmonary Innate Immune Response in Murine Obese ARDS}

Niki D.J. Ubags, Aaron M. Wallace, Sebastian B. Ventrone, Estee Dilli, Maryellen Antkowiak, Courtney Frasch, Donna L. Bratton, Emiel F.M. Wouters and Benjamin T. Suratt. 


\section{Abstract}

Background: Alveolar macrophages are key participants in the overexuberant pulmonary inflammatory response that characterizes Acute Respiratory Distress Syndrome (ARDS) both in its initial onset and its protracted course. Obesity, a rapidly increasing prevalence worldwide, is associated with an increased risk for the development of ARDS. However, once ARDS has developed, obesity appears to be associated with a rapid attenuation of the inflammatory response and improved outcomes in both patients and animal models. We hypothesize that alveolar macrophage function and phenotype are abnormally 'skewed' by obesity in opposite directions in the uninjured state compared to that of established ARDS.

Methods: Lean and diet-induced obese C57BL/ 6 mice with or without lipopolysaccharide (LPS)-induced lung injury were examined at $2 \mathrm{~h}, 24 \mathrm{~h}$ or $48 \mathrm{~h}$. Bronchoalveolar lavage (BAL) macrophage and neutrophil counts were determined as well as cytokine and albumin levels, and airspace macrophages were isolated and examined by transmission electron microscopy. Alveolar macrophages from LPS-injured mice $(48 \mathrm{~h})$ or uninjured mice were isolated and exposed to LPS for $4 \mathrm{~h}$ in vitro after which cytokine secretion was determined. In addition, lysophosphatidylserine (lyso-PS) expression on neutrophils was assayed by LC/MS/MS.

Results: We found that obesity increases susceptibility to ARDS in our LPS-injured mice and exaggerates the early inflammatory response in the lung. Alveolar macrophage numbers were increased in uninjured obese mice, and baseline MCP-1 levels were also found to be elevated in BAL of the obese mice. Furthermore, the alveolar macrophage cytokine response from uninjured obese mice to LPS in vitro was exaggerated. Moreover, numerous atypical lysosomes were found in alveolar macrophages from obese mice, which appear to be filled with lipids. In addition, the alveolar macrophage cytokine response was attenuated in alveolar macrophages from injured obese mice, and obese neutrophils were more rapidly cleared by macrophages compared to lean neutrophils, which may be driven by increased neutrophil lyso-PS expression.

Conclusion: Our findings indicate that alveolar macrophage function and phenotype manifests a more pro-inflammatory state at baseline, whereas an anti-inflammatory state is observed after lung injury. These results may, in part, explain the paradoxical effects seen in obese ARDS, and shed further light on the altered pulmonary innate immune response in the obese. 


\section{Introduction}

Acute Respiratory Distress Syndrome (ARDS) affects approximately 150,000 patients a year in the United States alone, accounting for nearly $20 \%$ of all ICU admissions, and results in deaths in up to $40 \%$ of the ARDS patients, due to the lack of effective therapies for this disease $(1,2)$. Alveolar macrophages are key participants in the over-exuberant pulmonary inflammatory response that characterizes ARDS both in its initial onset and its protracted course (3). Obesity, a rapidly increasing prevalence worldwide (4), is a major health problem, in large part due to its associated low-grade systemic inflammatory state that contributes to both cardiovascular disease and diabetes. Recently, it has been shown that obesity is also associated with an increased risk for the development of ARDS (5). Interestingly, however, we and others have shown that, once ARDS has developed, obesity is also associated with rapid attenuation of the inflammatory response and improved outcomes in both patients $(5,6)$ and animal models $(7)$.

Adipose tissue, and more specifically adipose infiltrating macrophages are a major source of the elevated levels of circulating inflammatory cytokines, such as TNF- $\alpha$, IL-1 $\beta$, IL-6, MCP-1 and IL-8, which are seen in obesity $(8,9)$. This 'up-regulation' has diverse effects on immune cells, including activation/ priming of monocytes, macrophages, and neutrophils (10). Furthermore, the dyslipidemia and oxidative stress associated with the metabolic syndrome have been shown to produce additional pro-inflammatory mediators, such as oxidized $\operatorname{LDL}(11,12)$ and to alter other critical lipid species $(13)$. Although these effects are becoming better understood in the pathogenesis of cardiovascular disease, little is known about how obesity and obesity-associated changes in the immune system affect the lungs and lung disease.

The response to pulmonary injury includes the controlled, alveolar macrophage-driven recruitment of neutrophils to the lung, followed by the rapid elimination of these cells through the induction of apoptosis and subsequent clearance by alveolar macrophages during the resolution phase of the inflammatory response (14). Critical to this latter phase of resolution is the process of 'efferocytosis' or the change in macrophage phenotype from inflammatory to anti-inflammatory (also described as ' $\mathrm{M} 1$ ' to ' $\mathrm{M} 2$ ' shift) that is driven by the phagocytosis of the dying neutrophils (14). Recent studies suggest that clearance of apoptotic neutrophils is driven by lysophosphatidylserine (lyso-PS) expression on the surface of neutrophils, thereby enhancing their engulfment by macrophages via the G-protein-coupled receptor G2A (15). Lyso-PS is thus considered to be one of several "eat-me" signals that mark neutrophils entering apoptosis for rapid removal by alveolar macrophages.

Currently, little is known about obesity's effect on lung macrophages in either baseline or acutely inflamed conditions. Given the paradoxical findings of increased risk of developing ARDS, yet improved outcomes from ARDS in obesity, one might predict that 
alveolar macrophage function and phenotype are abnormally 'skewed' by obesity in opposite directions in the baseline (uninjured) state compared to that of established ARDS. In the current study this hypothesis was tested. We present evidence that alveolar macrophage numbers are increased and show baseline activation in obesity, as well as increased lipid deposition in the obese macrophages, which may, in part, explain the baseline activation. Furthermore, a more anti-inflammatory state of the alveolar macrophages was observed in obese mice after established lung injury, suggesting that obesity modulates the alveolar macrophage response in murine ARDS. 


\section{Materials and Methods}

\section{Mice}

For the diet-induced obesity model, female C57BL/6 mice (Harlan, Indianapolis, IN) were fed a high fat $(60 \%$ fat) versus normal-fat $(10 \%$ fat) chow (Research Diets, New Brunswick, NJ) for 20 weeks. Mice were considered obese once the difference between their body weight and that of control mice reached at least $20 \mathrm{~g}$ (16). Experiments were performed in accordance with the Animal elfare Act and the USPHS Policy on Humane Care and Use of Laboratory Animals after review by the Animal Care and Use Committee of the University of Vermont.

\section{Murine exposures}

Lipopolysaccharide (LPS) induced lung injury was induced by exposure to nebulized LPS Escherichia coli 0111:B4 LPS, Sigma, St. Louis, MO), as described previously (7).

\section{Murine lung analysis}

Bronchoalveolar lavage (BAL) fluid was analyzed for cell count and differential using the ADVIA 120 (Siemens Healthcare, Malvern, PA).

\section{Cytokine analysis}

IL-6, keratinocyte cytokine (KC), tumor necrosis factor $\alpha$, (TNF $\alpha$ ), and monocyte chemoattractant protein (MCP)-1 levels were assessed in either BAL- or cell culture supernatant by Bio-Plex suspension array system (Bio-Rad, Hercules, CA) as previously described (7), and macrophage inflammatory protein (MIP)-2 levels were assessed by ELISA (R\&D systems, Minneapolis, MN) according to manufacturer's instructions.

\section{Albumin western blot analysis}

Murine alveolar lavage supernatant (2.5ul) was loaded and separated on a polyacrylamide gel, followed by transfer to a $0.45 \mu \mathrm{m}$ nitrocellulose membrane (Bio-Rad) by electroblotting. The membrane was blocked for $1 \mathrm{~h}$ at room temperature in $5 \%(\mathrm{w} / \mathrm{v})$ nonfat, dried milk diluted in TBS-Tween20 (0.05\%). Nitrocellulose blots were washed in TBS-Tween $20(0.05 \%)$ followed by $1 \mathrm{hr}$ incubation at room temperature, with primary antibody (goat anti-mouse Albumin; 1/5000; Immunology Consultants Laboratory Inc., Portland, OR Immunology Consultants Laboratory Inc). After three washes of $15 \mathrm{~min}$ each, the blots were probed with horseradish peroxidase-conjugated anti-goat antibody (1/10,000; Jackson Immunology Research, West Grove, PA) and visualized by chemiluminesence using Supersignal ${ }^{\circledR}$ West Pico Chemiluminescent Substrate (Pierce 
Biotechnology, Rockford, IL) according to the manufacturer's instructions and exposed to film.

\section{Phagocytosis assay}

Peritoneal lavage was performed with $1 \mathrm{x}$ hanks buffered saline solution (HBSS) containing 10mM HEPES pH 7.2 and 1 mM EDTA (both Sigma-Aldrich, St. Louis, MO). Lavage was spun down and cells were resuspended in DMEM (10\% hiFBS and $1 \mathrm{x} P / \mathrm{S} / \mathrm{G})$ and counted. Next, $2 \times 10^{5}$ cells/well were seeded in an 8-well labtek chamber (Thermo Scientific, Waltham, MA). Macrophages were allowed to adhere for $2 \mathrm{~h}$ at $37^{\circ} \mathrm{C}$ in a $10 \%$ $\mathrm{CO}_{2}$-humidified incubator at which time non-adherent cells were removed, and macrophages were cultured for an additional $48 \mathrm{~h}$ before use in phagocytosis assays. Next, bronchoalveolar lavage neutrophils isolated from lean and obese mice at $24 \mathrm{~h}$ after LPS-exposure were co-cultured $\left(1 \times 10^{6}\right.$ cells/well) with the peritoneal macrophages in culture for $1 \mathrm{~h}$ at $37^{\circ} \mathrm{C}, 10 \% \mathrm{CO}_{2}$. Cells were washed twice with PBS and fixed with $4 \%$ formaldehyde before staining with the DeadEnd TUNEL colorimetric system (Promega, Madison, WI) was performed according to manufacturer's instructions. The phagocytic index was calculated by multiplying the percentage of macrophages that have phagocytosed one or more cells by the average number of engulfed cells per macrophage. A minimum of 200 macrophages were counted blindly.

\section{Lyso-PS measurements}

Bronchoalveolar neutrophils were isolated from lean and obese (DIO mice) or control and hypercholesterolemic mice at $24 \mathrm{~h}$ after LPS-exposure. Neutrophils were washed, counted and stored in methanol after which lipid extraction and derivatization was performed as described by Frasch et al. (17). Analysis of Lyso-PS species was performed by LC/MS, and quantitation of the species was performed using a standard isotope dilution curve (17).

\section{Statistical analysis}

Data were represented as mean \pm SEM, and analysis of differences between experimental groups were performed by Student $t$ test. All analyses were performed using Prism6 software (GraphPad). Results with $\mathrm{p}<0.05$ were considered statistically significant. 


\section{Results}

\section{Obesity attenuates the course of ARDS}

It has been suggested that obesity increases the risk to develop ARDS (5), however, in our previous work we have shown that at $24 \mathrm{~h}$ after LPS-induced lung injury the inflammatory response in attenuated in obese mice (7). We set out to determine the course of lung injury in diet-induced obese (60\% fat diet) and lean ( $10 \%$ fat diet) mice, and determined BAL neutrophil counts as well as cytokine levels at $2 \mathrm{~h}, 6 \mathrm{~h}$ and $24 \mathrm{~h}$ after LPS-induced lung injury. Airspace neutrophil levels are increased in obese mice early after LPS-exposure, whereas a switch in this response occurred at $6 \mathrm{~h}$ and decreased pulmonary neutrophil levels were found in obese mice in established lung injury after $24 \mathrm{~h}$ (Figure 1A). A similar course was observed in lavage IL-6 levels (Figure 1B). These results provide evidence that obese mice are more susceptible to induced ARDS early on, but appear to control pulmonary neutrophilic inflammation better in established ARDS.
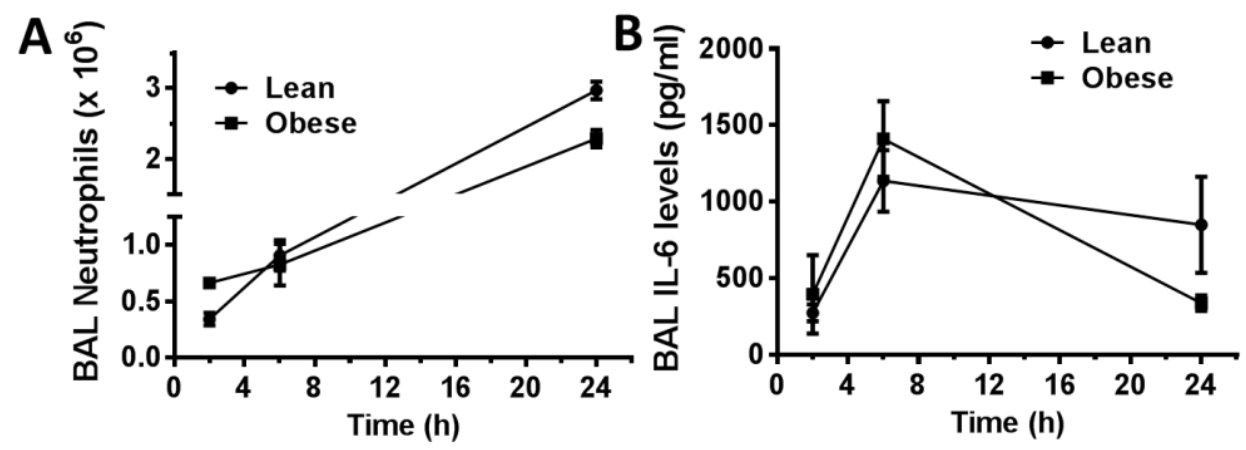

Figure 1 Obesity shifts pulmonary inflammatory response to induced lung injury over time. Diet-induced obese (60\% fat diet) and lean (10\% fat diet) mice were exposed LPS (3mg/ml) and BAL neutrophil (A) and IL-6 levels (B) were determined at $2 \mathrm{~h}, 6 \mathrm{~h}$, and $24 \mathrm{~h}$ after exposure. $\mathrm{n}=6$ mice for each condition. Data is presented as mean \pm SEM.

\section{Obesity increases the susceptibility to induced lung injury in mice.}

We demonstrate that the pulmonary inflammatory response is exaggerated early after LPS ( $3 \mathrm{mg} / \mathrm{ml}$ ) injury in obese compared to lean mice. A LPS dose titration was performed in order to determine the lowest dose of LPS that induced increased total cell counts (Figure 2A) in the lung as well as BAL albumin levels (Figure 2B). Next, we exposed obese and lean mice to our previously established low-dose $(0.3 \mathrm{mg} / \mathrm{ml})$ LPS and determined BAL neutrophil and albumin levels (a marker of capillary leakage and injury) at $24 \mathrm{~h}$ after exposure, in order to determine whether obese mice may indeed be more susceptible to lung injury. Both airspace neutrophil counts (Figure $3 \mathrm{~A}$ ) and albumin levels (Figure 3B) 
were increased in the obese mice compared to normal weight mice, suggesting an increased susceptibility to the development of ARDS.
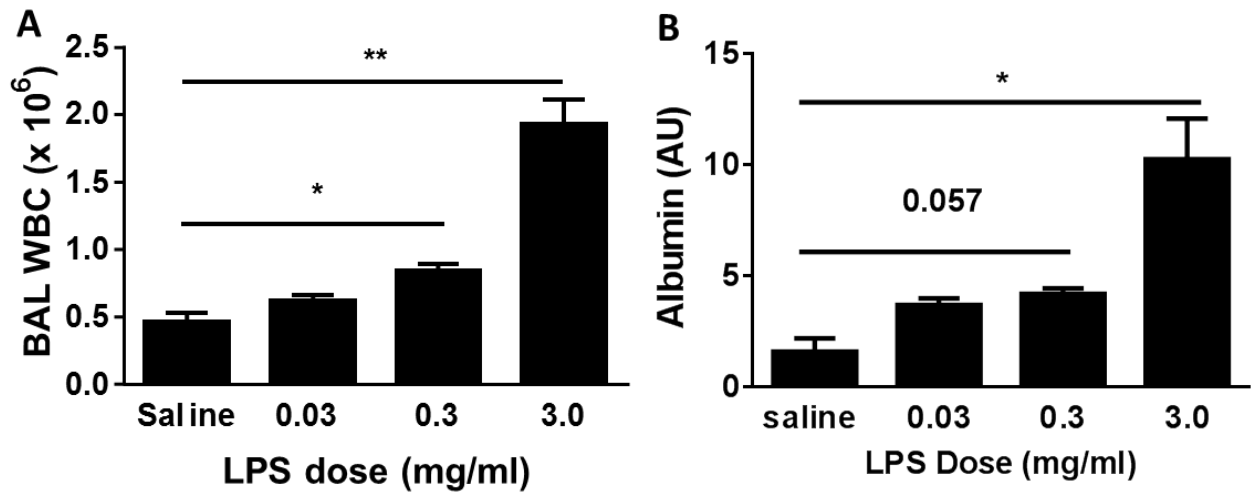

Figure 2 Dose dependent increase of total cell counts and albumin level in BAL following nebulized LPS exposure. BAL total cell counts (A) and albumin levels (B) were determined at $24 \mathrm{~h}$ after nebulized saline or LPS exposures $(0.03 \mathrm{mg} / \mathrm{ml}, 0.3 \mathrm{mg} / \mathrm{ml}$, or $3.0 \mathrm{mg} / \mathrm{ml}) . \mathrm{n}=3$ mice for each condition. Data is presented as mean \pm SEM. * $P \leq 0.05, * * P \leq 0.01$. WBC $=$ white blood cells.

\section{Obesity is associated with increased alveolar macrophage numbers and baseline activation of these cells.}

To determine the effects of obesity on the alveolar macrophage response at baseline, we examined BAL cell counts in uninjured lean and obese mice in the DIO model (7). Alveolar macrophage counts were increased in uninjured obese mice compared to lean littermate controls (Figure 4A). Furthermore, increased levels of MCP-1, a cytokine known to recruit and differentiate blood monocytes into tissue macrophages, were observed in bronchoalveolar lavage fluid from obese mice (Figure 4B). In addition, alveolar macrophages isolated from uninjured obese mice and stimulated for $4 \mathrm{~h}$ with LPS in vitro showed a slight increase in cytokine secretion compared to alveolar macrophages isolated from uninjured lean controls (Figure 4C). Taken together, these results suggest baseline activation of alveolar macrophages in obese mice. 

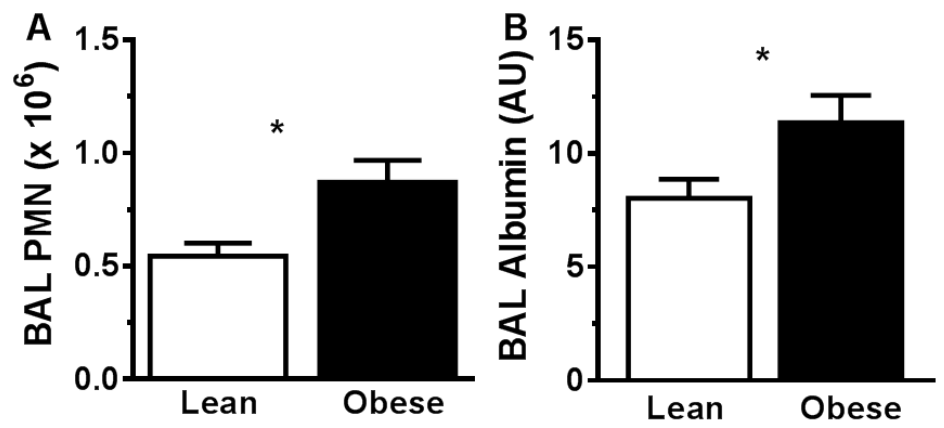

Figure 3 Obesity enhances risk for induced lung injury. Diet-induced obese (60\% fat diet) and lean (10\% fat diet) mice were exposed to a low dose of LPS $(0.3 \mathrm{mg} / \mathrm{ml})$ and BAL neutrophil (A) and albumin (B) levels were determined after $24 \mathrm{~h} . \mathrm{n}=4$ mice for each condition. Data is presented as mean $\pm \mathrm{SEM}$. ${ }^{*} P \leq 0.05$

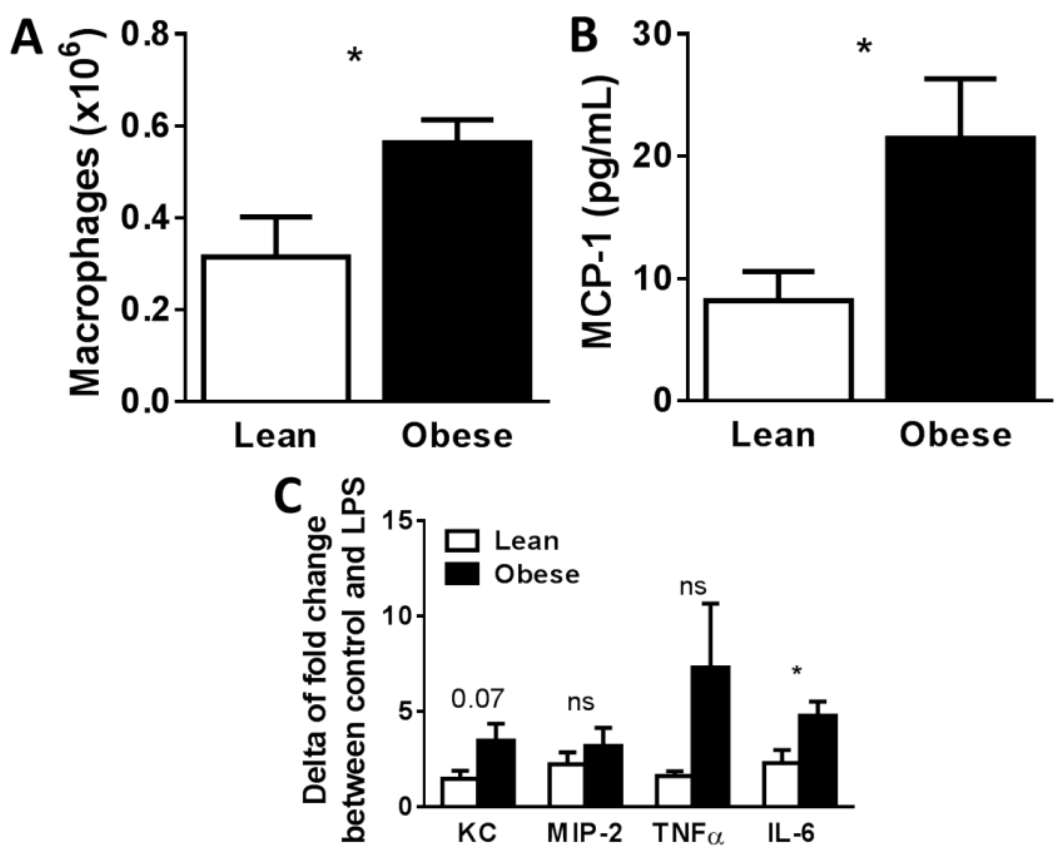

Figure 4 Obesity activates and expands alveolar macrophages. Alveolar macrophage numbers from uninjured lean ( $10 \%$ fat diet) and obese (60\% fat diet) mice were determined by bronchoalveolar lavage (A) and airspace levels of MCP-1 by ELISA (B). Isolated alveolar macrophages from uninjured lean and obese mice were stimulated with LPS $(100 \mathrm{ng} / \mathrm{ml})$ in vitro for $4 \mathrm{~h}$, and cytokine levels were determined in culture supernatants (C). $n=5$ mice per group. Data is presented as mean \pm SEM. ${ }^{*} P \leq 0.05$. 


\section{Alveolar macrophages in obese mice appear to be lipid-laden.}

In order to further investigate the baseline state of alveolar macrophages in obese mice, we examined alveolar macrophages from BAL of resting lean and diet-induced obese mice by transmission electron microscopy (TEM). Alveolar macrophages from lean mice are normal in appearance, with evidence of maturing lysosomes form young (light and granular) to old (dark and homogenous) (Figure $5 \mathrm{~A}$ and $\mathrm{B}$ ). Macrophages from obese mice however, contain numerous atypical lysosomes, in addition to normal ones, filled with lipid, often in an onionskin-like pattern (Figure $5 \mathrm{C}$ and D). These findings suggest that in baseline state, alveolar macrophages in obese mice handle a substantial burden of lipids, likely through scavenger and other receptor binding.

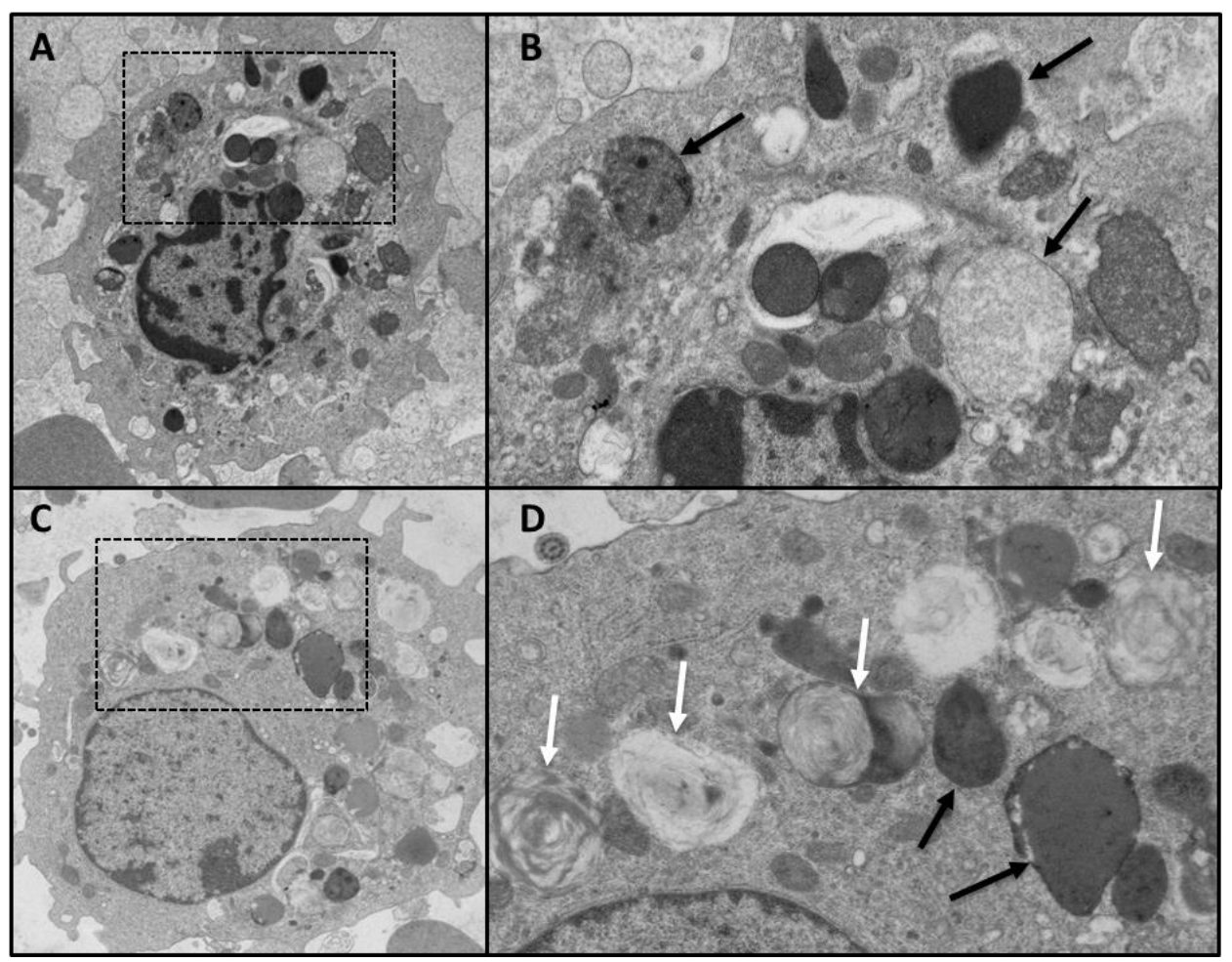

Figure 5 Alveolar macrophages from uninjured obese mice appear to be lipid-laden. Alveolar macrophages were obtained from uninjured lean and obese mice by lavage and then examined using transmission electron microscopy (TEM). Macrophages from lean mice (A) are normal in appearance, with evidence of maturing lysosomes (B; black arrows) from young (light, granular) to old (dark, homogenous). Macrophages from obese mice (C) appear to contain numerous atypical lysosomes (D; white arrows) in addition to normal ones (black arrows). Flocculent and often onion skin-appearing contents of atypical lysosomes appear to be lipid. Representative images from $>50$ cells examined for each condition are shown. Boxes in A \& $C$ indicate areas shown in B \& D. A \& C were imaged at 2000x, B \& D at 4000x. 


\section{Obesity impairs neutrophil survival, but increases neutrophil clearance by macrophages.}

We previously reported a marked attenuation in the pro-survival effect of G-CSF on neutrophils from obese mice. Clearance of apoptotic neutrophils is an important step in the resolution of pulmonary inflammation. To determine the effects of obesity on neutrophil clearance, we assessed in vitro macrophage phagocytosis by examining airspace neutrophils isolated after LPS-exposure (24h) of lean and obese mice, and fed them to peritoneal macrophages isolated from uninjured lean mice. We found a marked increase in the number of phagocytosed obese lavage neutrophils compared to lean lavage neutrophils (Figure 6A). Recent studies suggest that macrophage phagocytosis of neutrophils is driven by lysophosphatidylserine (lyso-PS) expression on neutrophils (17). We examined lyso-PS expression on airspace neutrophils isolated from LPS-exposed lean and obese mice using mass spectroscopy. Lyso-PS levels were found to be increased on neutrophils from obese mice compared to their lean controls (Figure 6B). These data suggest that obesity not only impairs pro-survival effects of G-CSF, but also enhances macrophage clearance of these cells from the lung, presumably driven by increased lysoPS expression on the neutrophils.
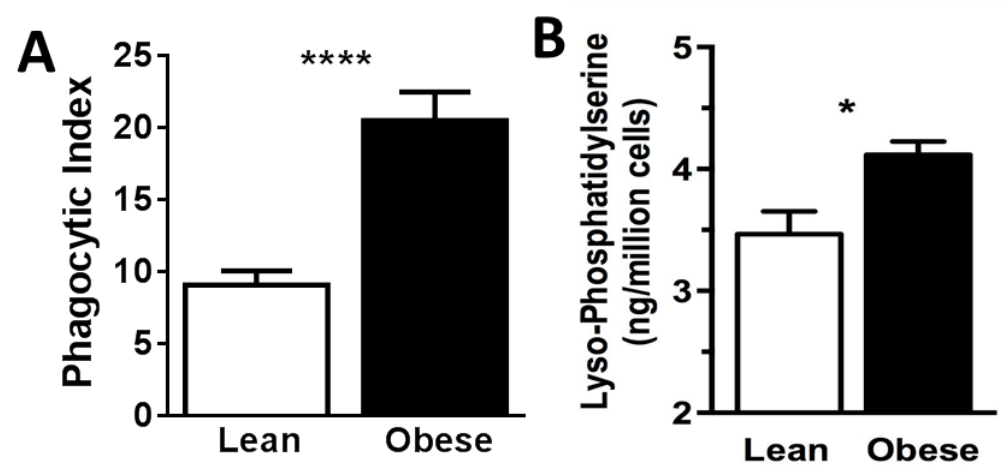

Figure 6 Neutrophil clearance is enhanced in obesity. Diet-induced obese (60\% fat diet) and lean (10\% fat diet) mice were to exposed LPS $(3 \mathrm{mg} / \mathrm{ml})$ and BAL neutrophils were isolated and co-cultured with wild-type peritoneal macrophages $(A)$, after which a TUNEL stain was performed and the phagocytic index was calculated (by multiplying the percentage of macrophages that have phagocytosed one or more cells by the average number of engulfed cells per macrophage). A minimum of 200 cells was counted for each condition. In addition, lyso-PS levels were measured on BAL neutrophils from these lean and obese (diet-induced obesity) mice at $24 \mathrm{~h}$ after LPS-exposure by LC/MS/MS. $\mathrm{n}=3$ mice for each experiment, and experiment was repeated 3 times. Data is presented as mean \pm SEM. ${ }^{*} P \leq 0.05 ; * * * * P \leq 0.0001$. 


\section{The alveolar macrophage cytokine response is decreased following established lung injury.}

We have previously demonstrated defects in neutrophil chemotaxis and delayed survival responses in uninjured obese mice. In addition, our current data suggests that obese alveolar macrophages are activated rather than impaired at baseline. To further delineate the mechanisms underlying the shift seen in the inflammatory response in obese mice following induced lung injury, we determined the alveolar macrophage response after established lung injury. Alveolar macrophages isolated from obese mice at $48 \mathrm{~h}$ after LPS exposure and stimulated for $4 \mathrm{~h}$ with LPS in vitro showed a slight decrease in cytokine secretion when compared to lean controls (Figure 7). Taken together, these results suggest that although the alveolar macrophage response (and hence the pulmonary inflammatory response) is exaggerated at baseline as well as during the initiation phase of ARDS in obesity, it is subsequently rapidly attenuated during the established phase of this disease.

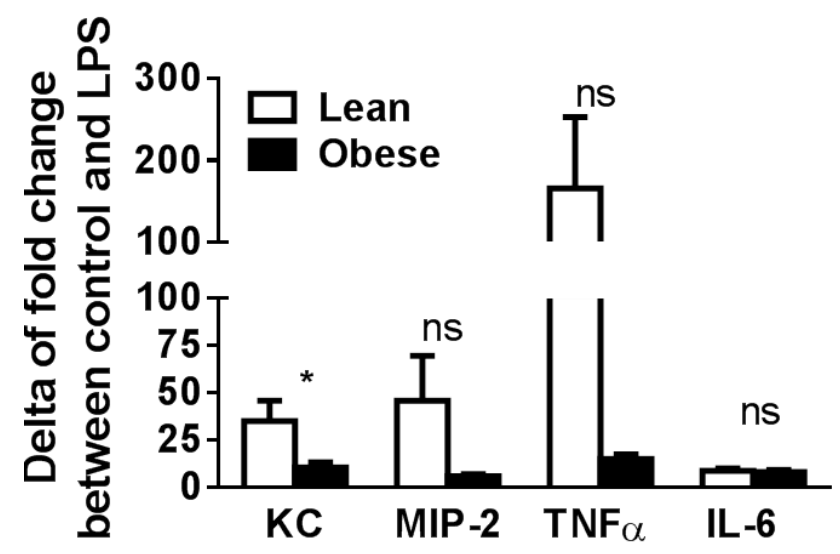

Figure 7 Obesity decreases the alveolar macrophage cytokine response following established lung injury. Alveolar macrophages from diet-induced obese (60\% fat diet) and lean ( $10 \%$ fat diet) mice were isolated at $48 \mathrm{~h}$ after LPS exposure and stimulated with either saline control or LPS $(100 \mathrm{ng} / \mathrm{ml})$ in vitro for $4 \mathrm{~h}$ after which cytokine levels in culture supernatant were measured. $n=5$ mice per condition. Data is presented as mean \pm SEM. ${ }^{*} P \leq 0.05$. 


\section{Discussion}

We present evidence that obesity increases the susceptibility to ARDS in LPS-injured mice and exaggerates the early inflammatory response in the lung. Furthermore, we demonstrate that in the uninjured state alveolar macrophage number is significantly increased in obese mice, and that their ex vivo cytokine response to an inflammatory stimulus is exaggerated, suggesting that the obese lung manifests a macrophage-driven pro-inflammatory state at baseline. However, once lung injury is established, a more anti-inflammatory response is observed. This may be due, in part, to the rapid development of airspace neutrophil apoptosis and down regulation of alveolar macrophage inflammatory cytokine release, inducing a shift to a more anti-inflammatory environment and resolution of the event.

The effects of obesity on pulmonary innate immune function and respiratory disease pathogenesis remain an underinvestigated area of research. Recently, several studies of our group and others have shown that obesity impairs pulmonary host defense $(11,18$ 21 ) as well as neutrophil function and attenuates the pulmonary inflammatory response following induced acute lung injury $(7,22)$. Moreover, studies by Mancuso et al., demonstrate that alveolar macrophage antibacterial effector functions, including phagocytosis, are impaired in leptin-deficient obese (ob/ob) mice and restoration of leptin levels rescued the observed impairment $(19,20)$. The majority of studies on macrophages in obesity are focused on adipose tissue macrophages and they show increased baseline activation (as reviewed in (23)), whereas studies exploring alveolar macrophage function and phenotype in obesity remain scarce. Alveolar macrophages isolated from obese $\left(\mathrm{BMI}>30 \mathrm{~kg} / \mathrm{m}^{2}\right)$ subjects did not show impaired phagocytic and bactericidal activity, however, these macrophages were isolated from subjects requiring mechanical ventilation (24). In addition, a study by Bedoui et al. aimed at determining alveolar macrophage function in rats fed a normal (12.5\% fat) or "cafeteria-diet" (35\% fat) for 2 weeks or 10 weeks, suggests that cytokine secretion following LPS-stimulation ex vivo remained unchanged when compared to controls (25). Our current results show for the first time enhanced baseline activation of alveolar macrophages in diet-induced obese mice. These differences in study findings may be explained by the composition (35\% vs. $60 \%$ fat) and duration (2-10 weeks vs. $16-20$ weeks) of the diet, which influences body weight, but also existence of the metabolic syndrome, which has been shown to play an important role in the immune dysregulation observed in obesity.

Characteristics of the diet-induced obese mouse model are dyslipidemia and oxidative stress, which have been shown to produce additional pro-inflammatory mediators, such as oxidized $\operatorname{LDL}(11,12)$, and to alter other critical lipid species (13). Pulmonary surfactant, which is a lipoprotein complex, reduces surface tension at the air-liquid interface of the lung (surfactant protein B and C (SP-B and SP-C)) (26), but also plays an important role in host defense against infection and inflammation (SP-A and SP-D), by 
enhancing phagocytosis of pathogens by alveolar macrophages and neutrophils (27). SPA or SP-D deficiency in mice increases susceptibility to infection and inflammation induced by various pathogens and inflammatory agents, such as LPS (28). We and our collaborators have previously shown that macrophage interaction with LDL and its oxidized forms may activate macrophages $(11,29,30)$, and we have also shown that LDL levels are elevated in the airspace of dyslipidemic mice (11). Furthermore, it has also been noted that decreased levels of airspace SP-A and SP-D, as might occur with oxidative damage to surfactant and its subsequent removal by alveolar macrophages, may 'prime' these macrophages (31). Thus, in addition to the possibility that alveolar translocation of elevated blood cytokines may activate resident macrophages, these findings raise the interesting possibility that increased lipid handling, either from systemic lipoproteins or from altered surfactant, may contribute to this phenomenon.

Macrophage efferocytosis is an important process in the resolution phase of pulmonary inflammation. We demonstrated attenuated neutrophil recruitment to the lung in obese mice following induction of acute lung injury (7). In addition, spontaneous neutrophil apoptosis is increased in obese mice. So, although there may be less neutrophils present in the lungs of obese mice at the start of the resolution phase, the neutrophils present may be more apoptotic. Clearance of apoptotic neutrophils from the airspace is the first step in resolving pulmonary inflammation, and we provide evidence that lyso-PS expression, which is one of the 'eat-me' signals, is increased on pulmonary neutrophils from obese mice after injury. In addition, our results suggest that these obese neutrophils are more rapidly cleared by macrophages. These results suggest that the neutrophil/macrophage interaction may be dysregulated, and that abrogation of this interaction may restore the attenuated inflammatory response in murine obese ARDS.

It is important to mention that the macrophages used for the phagocytosis assay are not of pulmonary origin (peritoneal macrophages). However, the effects noted, increased phagocytosis of obese pulmonary neutrophils, suggest that although alveolar macrophages are anti-inflammatory following lung injury, the neutrophils also play an important role. Therefore, further studies looking more into the effects of obesity on the neutrophil/macrophage interactions in the lung are needed.

The findings presented in this study indicate that alveolar macrophage function and phenotype manifests a more pro-inflammatory state at baseline, whereas an antiinflammatory state is observed after lung injury. These results may start to explain some of the paradoxical effects seen in obese ARDS, which will lead to a better understanding of the marked effects of obesity on the pulmonary innate immune response following inflammation. This increased understanding may lead to the development of novel therapeutic approaches to both reduce the risk of ARDS in the obese and to improve ARDS outcomes in the non-obese population, and in the end decrease the substantial associated healthcare costs. 


\section{References}

1. Rubenfeld, G.D., Caldwell, E., Peabody, E., Weaver, J., Martin, D.P., Neff, M., Stern, E.J., and Hudson, L.D. 2005. Incidence and outcomes of acute lung injury. N Engl J Med 353:1685-1693.

2. MacCallum, N.S., and Evans, T.W. 2005. Epidemiology of acute lung injury. Current opinion in critical care 11:43-49.

3. Steinberg, K.P., Milberg, J.A., Martin, T.R., Maunder, R.J., Cockrill, B.A., and Hudson, L.D. 1994. Evolution of bronchoalveolar cell populations in the adult respiratory distress syndrome. American journal of respiratory and critical care medicine 150:113-122.

4. Finucane, M.M., Stevens, G.A., Cowan, M.J., Danaei, G., Lin, J.K., Paciorek, C.J., Singh, G.M., Gutierrez, H.R., Lu, Y., Bahalim, A.N., et al. 2011. National, regional, and global trends in body-mass index since 1980: systematic analysis of health examination surveys and epidemiological studies with 960 country-years and 9.1 million participants. Lancet 377:557-567.

5. Gong, M.N., Bajwa, E.K., Thompson, B.T., and Christiani, D.C. 2010. Body mass index is associated with the development of acute respiratory distress syndrome. Thorax 65:44-50.

6. Stapleton, R.D., Dixon, A.E., Parsons, P.E., Ware, L.B., Suratt, B.T., and Network, N.A.R.D.S. 2010. The association between $\mathrm{BMI}$ and plasma cytokine levels in patients with acute lung injury. Chest 138:568-577.

7. Kordonowy, L.L., Burg, E., Lenox, C.C., Gauthier, L.M., Petty, J.M., Antkowiak, M., Palvinskaya, T., Ubags, N., Rincon, M., Dixon, A.E., et al. 2012. Obesity is associated with neutrophil dysfunction and attenuation of murine acute lung injury. American journal of respiratory cell and molecular biology 47:120-127.

8. Park, H.S., Park, J.Y., and Yu, R. 2005. Relationship of obesity and visceral adiposity with serum concentrations of CRP, TNF-alpha and IL-6. Diabetes research and clinical practice 69:29-35.

9. Ramos, E.J., Xu, Y., Romanova, I., Middleton, F., Chen, C., Quinn, R., Inui, A., Das, U., and Meguid, M.M. 2003. Is obesity an inflammatory disease? Surgery 134:329-335.

10. Ghanim, H., Aljada, A., Hofmeyer, D., Syed, T., Mohanty, P., and Dandona, P. 2004. Circulating mononuclear cells in the obese are in a proinflammatory state. Circulation 110:1564-1571.

11. Madenspacher, J.H., Draper, D.W., Smoak, K.A., Li, H., Griffiths, G.L., Suratt, B.T., Wilson, M.D., Rudel, L.L., and Fessler, M.B. 2010. Dyslipidemia induces opposing effects on intrapulmonary and extrapulmonary host defense through divergent TLR response phenotypes. Journal of immunology 185:1660-1669.

12. Palvinskaya, T., Antkowiak, M., Burg, E., Lenox, C.C., Ubags, N., Cramer, A., Rincon, M., Dixon, A.E., Fessler, M.B., Poynter, M.E., et al. 2013. Effects of acute and chronic low density lipoprotein exposure on neutrophil function. Pulmonary pharmacology \& therapeutics 26:405-411.

13. Roberts, C.K., and Sindhu, K.K. 2009. Oxidative stress and metabolic syndrome. Life sciences 84:705712.

14. Vandivier, R.W., Henson, P.M., and Douglas, I.S. 2006. Burying the dead: the impact of failed apoptotic cell removal (efferocytosis) on chronic inflammatory lung disease. Chest 129:1673-1682.

15. Frasch, S.C., Fernandez-Boyanapalli, R.F., Berry, K.Z., Leslie, C.C., Bonventre, J.V., Murphy, R.C., Henson, P.M., and Bratton, D.L. 2011. Signaling via macrophage G2A enhances efferocytosis of dying neutrophils by augmentation of Rac activity. The Journal of biological chemistry 286:12108-12122.

16. Speakman, J., Hambly, C., Mitchell, S., and Krol, E. 2007. Animal models of obesity. Obesity reviews : an official journal of the International Association for the Study of Obesity 8 Suppl 1:55-61.

17. Frasch, S.C., Berry, K.Z., Fernandez-Boyanapalli, R., Jin, H.S., Leslie, C., Henson, P.M., Murphy, R.C., and Bratton, D.L. 2008. NADPH oxidase-dependent generation of lysophosphatidylserine enhances clearance of activated and dying neutrophils via G2A. The Journal of biological chemistry 283:3373633749.

18. Easterbrook, J.D., Dunfee, R.L., Schwartzman, L.M., Jagger, B.W., Sandouk, A., Kash, J.C., Memoli, M.J., and Taubenberger, J.K. 2011. Obese mice have increased morbidity and mortality compared to non-obese mice during infection with the 2009 pandemic H1N1 influenza virus. Influenza and other respiratory viruses 5:418-425. 
19. Hsu, A., Aronoff, D.M., Phipps, J., Goel, D., and Mancuso, P. 2007. Leptin improves pulmonary bacterial clearance and survival in ob/ob mice during pneumococcal pneumonia. Clinical and experimental immunology 150:332-339.

20. Mancuso, P., Gottschalk, A., Phare, S.M., Peters-Golden, M., Lukacs, N.W., and Huffnagle, G.B. 2002. Leptin-deficient mice exhibit impaired host defense in Gram-negative pneumonia. Journal of immunology 168:4018-4024.

21. Smith, A.G., Sheridan, P.A., Harp, J.B., and Beck, M.A. 2007. Diet-induced obese mice have increased mortality and altered immune responses when infected with influenza virus. The Journal of nutrition 137:1236-1243.

22. Stapleton, R.D., Dixon, A.E., Parsons, P.E., Ware, L.B., and Suratt, B.T. 2010. The association between $\mathrm{BMI}$ and plasma cytokine levels in patients with acute lung injury. Chest 138:568-577.

23. Exley, M.A., Hand, L., O'Shea, D., and Lynch, L. 2014. Interplay between the immune system and adipose tissue in obesity. The Journal of endocrinology 223:R41-48.

24. El Solh, A., Porhomayon, J., and Szarpa, K. 2009. Proinflammatory and phagocytic functions of alveolar macrophages in obesity. Obesity research \& clinical practice 3:203-207.

25. Bedoui, S., Velkoska, E., Bozinovski, S., Jones, J.E., Anderson, G.P., and Morris, M.J. 2005. Unaltered TNF-alpha production by macrophages and monocytes in diet-induced obesity in the rat. Journal of inflammation 2:2.

26. Whitsett, J.A., Nogee, L.M., Weaver, T.E., and Horowitz, A.D. 1995. Human surfactant protein B: structure, function, regulation, and genetic disease. Physiological reviews 75:749-757.

27. Wright, J.R. 1997. Immunomodulatory functions of surfactant. Physiological reviews 77:931-962.

28. Lawson, P.R., and Reid, K.B. 2000. The roles of surfactant proteins A and D in innate immunity. Immunological reviews 173:66-78.

29. Bae, Y.S., Lee, J.H., Choi, S.H., Kim, S., Almazan, F., Witztum, J.L., and Miller, Y.I. 2009. Macrophages generate reactive oxygen species in response to minimally oxidized low-density lipoprotein: toll-like receptor 4- and spleen tyrosine kinase-dependent activation of NADPH oxidase 2. Circulation research 104:210-218, 221p following 218.

30. Wiesner, P., Choi, S.H., Almazan, F., Benner, C., Huang, W., Diehl, C.J., Gonen, A., Butler, S., Witztum, J.L., Glass, C.K., et al. 2010. Low doses of lipopolysaccharide and minimally oxidized low-density lipoprotein cooperatively activate macrophages via nuclear factor kappa B and activator protein-1: possible mechanism for acceleration of atherosclerosis by subclinical endotoxemia. Circulation research 107:56-65.

31. Atochina-Vasserman, E.N., Beers, M.F., and Gow, A.J. 2010. Review: Chemical and structural modifications of pulmonary collectins and their functional consequences. Innate immunity 16:175182. 




\section{CHAPTER 6}

\section{Leptin as a Regulator of Pulmonary Immune Responses: Involvement in Respiratory Diseases}

Juanita H.J. Vernooy, Niki D.J. Ubags, Guy G. Brusselle, Jan Tavernier, Benjamin T. Suratt, Guy F. Joos, Emiel F.M. Wouters and Ken R. Bracke. 


\section{Abstract}

Leptin is an adipocyte-derived hormone, recognized as a critical mediator of the balance between food intake and energy expenditure by signalling through its functional receptor (Ob-Rb) in the hypothalamus. Structurally, leptin belongs to the long-chain helical cytokine family, and is now known to have pleiotropic functions in both innate and adaptive immunity. The presence of the functional leptin receptor in the lung together with evidence of increased airspace leptin levels arising during pulmonary inflammation, suggests an important role for leptin in lung development, respiratory immune responses and eventually pathogenesis of inflammatory respiratory diseases. The purpose of this article is to review our current understanding of leptin and its functional role on the different resident cell types of the lung in health as well as in the context of three major respiratory conditions being chronic obstructive pulmonary disease (COPD), asthma, and pneumonia. 


\section{Introduction}

Leptin is a $16 \mathrm{kDa}$ non-glycosylated polypeptide encoded by the 'obese' (ob) gene (1). Originally described as a hormone secreted by adipocytes in proportion to total fat mass, leptin was implicated in early studies as a critical mediator of the balance between food intake and energy expenditure by signalling through its functional receptor $(\mathrm{Ob}-\mathrm{Rb})$ in the hypothalamus $(2,3)$. However, leptin belongs structurally to the long-chain helical cytokine family, which includes interleukin-6 (IL-6), G-CSF, and oncostatin M amongst others, and shares an extreme functional pleiotropy with many other members of this family. The near universal distribution of leptin receptors, including in the respiratory system, reflects a multiplicity of biological effects. Leptin has been reported to participate in diverse physiological functions in both the central nervous system and the periphery, including appetite and body mass control, metabolism, endocrine function, immune response, wound healing, reproduction, cardiovascular pathophysiology, and respiratory tissue development, remodelling, and function.

Adipocytes located in various fat depots are a major, but not sole source of leptin. Cells of the placenta (4), gastric mucosa (5), colon (6), mammary epithelium (7), pituitary, hypothalamus (8), skeletal muscle $(9,10)$, bone (11) and bone marrow (12) have also been shown to produce leptin in certain circumstances (2). Leptin expression has also been described in the lung tissues of humans (13), baboons (14), mice (15), seals (16), and even Xenopus (17). Recent studies have shown leptin secretion by human lung epithelial cell types, including bronchial epithelial cells $(B E C)(13,18)$, type II pneumocytes (13), and lipofibroblasts (19).

Leptin expression in adipocytes is regulated by food intake and circulating leptin levels have been shown to positively correlate with insulin levels. In addition, glucocorticoids appear to be potent regulators of leptin expression based on in vitro studies of isolated adipocytes (20), while a gender-related leptin regulation is suggested by the findings that leptin expression is increased by ovarian sex steroids and inhibited by testosterone (2123). Other modulators of leptin expression include a wide range of pro-inflammatory cytokines - including TNF $\alpha$ - which are known to acutely increase leptin synthesis in adipocytes $(24,25)$, whereas chronic stimulation with such cytokines appears to lead to a suppression of leptin synthesis $(26,27)$. In the normal lung, numerous cell types display high levels of $\mathrm{Ob}-\mathrm{Rb}(28,29)$, and specific leptin-binding sites have been identified in both bronchial and alveolar epithelial cells (30-32), airway smooth muscle cells, and (infiltrating) inflammatory cells. Multiple observations that leptin is actually present in induced sputum (33-35), proximal airway biopsies (18), bronchoalveolar lavage (BAL) fluid $(36,37)$, and peripheral lung tissue $(13)$ of patients with lung disease, strongly suggest the lung as a peripheral site of action for leptin. The present review aims to summarize our current understanding on leptin and its functional role in the respiratory system in homeostasis and inflammatory lung diseases. 


\section{Leptin Signal Transduction}

Leptin acts via the Ob-R transmembrane receptor, which shares structural similarities with the class I cytokine receptor superfamily $(38,39)$. Members of this family have signature extracellular domains (so-called cytokine receptor homology or CRH domains) characterised by a set of four cysteine residues and the highly conserved Trp-Ser-XaaTrp-Ser motif. Several alternative splice isoforms of Ob-R exist in humans and rodents, designated Ob-Ra, Ob-Rb, Ob-Rc, Ob-Rd, Ob-Re (only in rats and mice) and Ob-Rf (only in rats). All isoforms contain the same extracellular domain of over 800 amino acids consisting of two $\mathrm{CRH}$ domains, separated by an immunoglobulin (Ig)-like domain and followed by two membrane-proximal fibronectin type III domains $(38,39,40)$. With the exception of Ob-Re which is a secreted receptor variant, they all share a similar transmembrane and juxtamembrane JAK-binding domain of 34 and 29 amino acids respectively, followed by a variable intracellular domain. The isoforms can thus be classified into short isoforms (Ob-Ra, Ob-Rc, Ob-Rd and Ob-Rf), a full-length long isoform $\mathrm{Ob}-\mathrm{Rb}$, and a secreted isoform Ob-Re. Of note, the latter only exists in rodents. In man, a secreted Ob-R ectodomain is generated by proteolytic cleavage by the ADAM10 and ADAM17 metalloproteases (41). Ob-Rb was initially considered to be the only functional isoform of the leptin receptor, based on its extended intracellular domain of approximately 300 residues containing various motifs required for activation of multiple signalling pathways (38). Although signalling functions have been ascribed to short $\mathrm{Ob}-\mathrm{R}$ isoforms in over-expression studies (42), their role in physiological leptin-mediated effects remains to be established.

The early recognition of $O b-R$ as a class I cytokine receptor rapidly led to the identification of the JAK/STAT pathway as the primary signalling route. Leptin-induced JAK-2 activation results in the rapid phosphorylation of three, conserved, cytoplasmic tyrosine-based motifs that act as binding sites for different signalling molecules, including STAT-1, STAT-3, STAT-5 and STAT-6. In addition to signalling through the JAK/STAT pathway, leptin is also able to induce alternative pathways, including the MAPK cascade, the PI3K/PDE3B/CAMP pathway, AMPK and mTOR. These different signalling cascades activated by leptin have extensively been reviewed by Wauman and Tavernier (2). Given the multitude of signalling pathways activated via the Ob-R, leptin's effects on different cell types can be expected to be highly cell-specific. A very well studied, direct target of leptin-induced STAT-3 is SOCS-3, a key negative feedback regulator of Ob-R signalling (43). Changes in SOCS-3 expression have been postulated to underlie the phenomenon of leptin resistance in the context of obesity (44). Another negative regulator of leptin signalling is PTP1B, which acts primarily via dephosphorylation of JAK-2 $(45,46)$.

To summarize, leptin signal transduction, especially the pathways that are activated upon Ob-R activation, how Ob-R expression is controlled and the molecular mechanisms 
leading to leptin resistance, are all well-characterized. However, it is not currently known whether these individual signaling routes can indeed be activated in the respiratory system.

\section{Role of Leptin in Respiration and Lung Development}

Multiple studies have shown that leptin participates in the regulation of pulmonary development and remodelling. Huang et al. characterized the effect of leptin deficiency on postnatal lung development in leptin-deficient (ob/ob) mice (47) and showed that the lung volume and alveolar surface area were lower in obese mice compared with wild-type and heterozygote $(o b /+)$ mice, and that the alveolar size did not increase with age. Leptin replacement in $o b / o b$ mice resulted in increased lung volume, enlarged alveolar size and surface area, suggesting a role for leptin in remodelling of lung parenchyma. Leptin receptor-deficient $(d b / d b)$ mice (29) exhibit a $75 \%$ decreased rate of tracheal epithelial proliferation compared with wild-type littermates, emphasizing a potential role for leptin in pulmonary growth. Along these lines, leptin treatment was shown to increase the weight of the lungs in relation to the total body weight $(48,49)$. Insufficient maturation of the fetal lungs, a condition that can be characterized by the production of inadequate amounts of pulmonary surfactant by epithelial type II cells, is a leading cause of human neonatal morbidity and mortality following premature birth. In this light, Torday, et al reported that leptin was expressed by fibroblasts and that the leptin receptor was expressed by type II cells in fetal rat lung (19), suggesting a paracrine signalling mechanism in developing pulmonary tissue. Leptin receptor was also identified in fetal rabbit type II cells (31) and additional evidence supported correlations between leptin, maturation of the pulmonary epithelium and surfactant production. Furthermore, leptin is present in the fetal baboon lung and its receptor is enhanced during late gestation in type II cells responsible for the synthesis of pulmonary surfactant (14). A mechanistically integrated link between leptin and its function in respiration and lung development was recently provided by the finding that leptin stimulates Xenopus laevis tadpole lung development (17). However, a recent study by Sato, et al. shows that neither leptin deficiency in $o b / o b$ mice nor treatment with exogenous leptin in sheep and wild type mice influenced fetal lung maturation or surfactant production (50). An explanation for these paradoxical results can be found in the different models that were used in these two studies. In addition, the responses of fetal lung to the leptin treatment might vary by dose, duration, dosing interval, route, and gestation age.

Gnanalingham investigated the impact of chronic leptin administration on the abundance of UCP2 in the neonatal lung (49). UCP2, a recently discovered member of the inner mitochondrial membrane carrier subfamily, is highly abundant in the lung (51, 
52) and has postulated roles in energy regulation, reactive oxygen species production, and apoptosis, but its exact role and function in the neonatal lung have yet to be determined. Chronic leptin administration was shown to decrease the abundance of UCP2 protein in the lung, which might promote reactive oxygen species production and maintain host immunity through augmentation of alveolar macrophage phagocytosis and leukotriene synthesis (49). The decrease in UCP2 with leptin administration on later lung function needs further study.

Leptin also has also been shown to participate in the regulation of respiratory function. In the $o b / o b$ mouse, respiratory abnormalities including tachypnea, decreased lung compliance, and aberrant respiratory muscle adaptations, such as alterations in diaphragmatic muscle MHC composition, are common with the obese phenotype (53). Tankersley, et al showed that these respiratory abnormalities were attenuated following prolonged leptin administration (53). Similarly, in wild-type mice that were obese due to a high-fat diet, respiratory depression was reversed by leptin treatment (54), suggesting a significant role of leptin as a neurohumoral modulator of central respiration, and in general pulmonary health as well.

Collectively, these findings suggest a modulatory role for leptin in pulmonary development and identify leptin receptor as a physiological marker of fetal lung maturity. In addition, there is increasing evidence showing that leptin is an important player in respiration, but additional research is needed in order to unravel the underlying mechanisms.

\section{Role of Leptin in Inflammatory Lung Diseases}

Numerous studies demonstrate that leptin has a potentiating role in the function of both innate and adaptive immunity (55), making it an ideal candidate for a central role in inflammatory respiratory diseases such as COPD, asthma, and pneumonia. Leptin is known to stimulate neutrophil and macrophage chemotaxis and enhance functional responses such as oxidative burst $(56)$, phagocytosis $(57)$ and cytokine secretion $(58,59)$. Neutrophil chemotaxis response was shown to be blunted in leptin-resistant $\mathrm{db} / \mathrm{db}$ mice as well as in mice with diet-induced obesity (60), which may indicate a crucial role for leptin signaling these cells. In addition, leptin promotes differentiation, survival, and immunostimulatory functions of dendritic cells (DCs), resulting in stronger heterologous T cell responses. Furthermore, leptin exerts proliferative (61) and anti-apoptotic effects (62) on T-lymphocytes and promotes Th1 cell differentiation (63). The possible effects of leptin on the different (resident) cell types of the lung during inflammation will be discussed in the context of three major respiratory conditions: chronic obstructive pulmonary disease (COPD), asthma, and pneumonia. 


\section{COPD}

Chronic obstructive pulmonary disease (COPD) is a leading and increasing cause of morbidity and mortality worldwide. COPD is recognized as a multi-organ disease (64), manifest by airflow limitation associated with both structural changes and an abnormal pulmonary inflammatory response to noxious particles or gases, including tobacco smoke (65), accompanied by various extra-pulmonary manifestations such as low-grade systemic inflammation (66) and an increased prevalence of cardiovascular co-morbidity (67).

\section{Circulating Leptin}

The role of circulating leptin in the systemic manifestation of COPD is poorly understood and has in the past mainly been examined in male COPD patients with a low BMI $1<21$ $\mathrm{kg} / \mathrm{m}^{2}$ ) (68-70). In women with COPD, serum leptin concentrations are increased compared to normal healthy women (71). In addition, circulating leptin levels are higher in women with COPD than men with COPD, and increase with rising fat mass to a greater extent in women with COPD than in their male counterparts (71). Moreover, Breyer et al recently showed that there is a complex relationship between adipokine metabolism and low-grade systemic inflammation in COPD, with a significant relationship between circulating leptin and CRP and fibrinogen (72).

Both the BODE index (the body-mass index (B), the degree of airflow obstruction (O) and dyspnea (D), and exercise capacity (E), measured by the six-minute-walk test) (73) and fat-free mass index (FFMI) have been shown to be associated (positively and negatively, respectively) with circulating levels of leptin in COPD patients. In addition, leptin is the most significant predictor of low FFMI in those patients (74). To date, however, longitudinal studies investigating the relationship between increased circulating leptin concentrations and clinical outcomes in COPD are lacking.

\section{Pulmonary Leptin}

As the lung is highly vascularized, increased circulating levels of leptin may also contribute to the pathogenesis of lung inflammation and injury in COPD. Different types of inflammatory cells such as macrophages, neutrophils, dendritic cells, CD8+ Tlymphocytes have been implicated in the chronic inflammation associated with COPD, and a distinct inflammatory pattern has been described in each lung compartment (75). In light of the immunomodulating effects of leptin, leptin may be a good candidate for the regulation of pulmonary immune function in COPD. Indeed, Broekhuizen and colleagues demonstrated that leptin is present in induced sputum samples of mild-tomoderate COPD patients, and showed a strong correlation between sputum levels of leptin and both CRP and TNF $\alpha$ (33). A more recent study on the expression of leptin in peripheral lung tissue of COPD patients, asymptomatic smokers, and never-smokers 
suggested that bronchial epithelial cells, type II pneumocytes, and alveolar macrophages are significant sources of pulmonary leptin (13). Numbers of leptin-expressing bronchial epithelial cells and alveolar macrophages were markedly higher in smokers with and without COPD versus never-smokers, indicating that tobacco smoke may be a trigger for pulmonary leptin expression. This was confirmed by air-liquid interface cultures of primary epithelial cells, which demonstrated a dose-dependent increase in leptin mRNA expression and protein production after cigarette smoke concentrate stimulation (13). Bruno, et al(18) also reported positive immunostaining for leptin protein in central airway epithelium from human bronchial biopsies, but found a decrease in leptinpositive epithelial cell counts in smokers and COPD patients compared to never-smokers. This difference may, however, be explained by different tissue specimens used in the two studies. Furthermore, in a more recent study, Bruno et al (35) suggests that leptin plays a role in both pulmonary and systemic inflammation in current and former smokers with COPD. The leptin/Ob-R pathway may contribute to the improvement in host defence seen in COPD patients after smoking cessation, by augmenting neutrophil function. Lastly, associations between genetic polymorphisms in leptin and Ob-R genes and (severity of) COPD were investigated. Hansel et al (76) examined the association between genetic variants in the $\mathrm{Ob}-\mathrm{R}$ gene and lung function decline in European Americans selected from the National Heart Lung and Blood Institute Lung Health Study. Significant associations between multiple SNPs in the Ob-R gene and lung function decline were identified and confirmed by haplotype analyses in a population of smokers with COPD. In addition, Ye et al (77) recently showed a significant association between the polymorphism - $2548 \mathrm{G} / \mathrm{A}$ in the leptin gene (linked to enhanced gene expression and increased circulating leptin levels (78) and the severity of COPD in a Chinese population.

In summary, increasing data suggest that leptin is present in induced sputum and lung tissue of COPD patients. Pulmonary leptin may be associated with greater disease severity in COPD.

\section{Smoke-Induced Lung Inflammation}

Cigarette smoke is a profound stimulus of the innate immune response leading to inflammation that drives COPD pathogenesis. Subsequent host defence mechanisms appear to be altered, rather than suppressed. The functional role of leptin in smokeinduced lung inflammation and pathology is still under investigation. Specific leptinbinding sites have been identified in BEC and type II pneumocytes (30-32), suggesting a potential autocrine and/or paracrine pathway for leptin to activate epithelial cells in COPD. Indeed, leptin was shown to activate several intracellular signal transduction pathways in bronchial epithelial cells $(13,79,80)$, including JAK/STAT and MAPK pathways. Interestingly, Woo et al showed that leptin upregulates mucin production in human airway epithelial cells (79), hereby suggesting that leptin may contribute to mucus hypersecretion in inflammatory lung diseases. Further studies are clearly needed to determine additional effects of leptin on airway epithelial cells. 
An interesting study published by Hansel and co-workers (76) showed a reduction in the expression of Ob-R receptor isoforms in the airspace and airway wall after 4 months of smoke exposure in AKR/J mice. It has yet to be determined whether these findings correspond to reduced leptin signalling in the lung. In another smoking mouse model, characterized by increased accumulation of neutrophils, DCs, macrophages, and lymphocytes in the lung, leptin expression in BEC and pneumocytes was significantly increased in cigarette smoke-exposed wild-type mice compared to air-exposed controls. Evidence that leptin is in fact involved in innate and adaptive immune cell recruitment is provided by studies of mice deficient in leptin signalling (ob/ob and $d b / d b$ mice), which show significantly higher numbers of neutrophils and lower numbers of CD4+, CD8+ and dendritic cells compared to cigarette smoke-exposed wild-type mice(15). Increases in neutrophil and monocyte chemoattractants CXCL1 and CCL2 seen in this model were significantly enhanced in the BALF of cigarette smoke-exposed $o b / o b$ and $d b / d b$ mice compared to wild-type mice.

To summarize, there is increasing literature showing the presence of the functional leptin receptor in the lung together with evidence of local leptin production in the respiratory compartment. Together, this supports the concept of autocrine and/or paracrine cross-talk between resident pulmonary epithelial cells and immune cells in response to inhaled noxious particles or gases. Further validation of this hypothesis by additional experimental and clinical studies is obviously needed to better understand the immunomodulating role of leptin in the pathogenesis of smoking-related COPD.

\section{Asthma}

Asthma is a prevalent and complex disorder that can occur in genetically predisposed individuals through a series of gene-environment interactions (81). Acute and chronic inflammation of the bronchi and the conducting airways plays a central role in the pathogenesis of asthma, and lead to airflow obstruction and the respiratory symptoms of the disease, such a wheezing, coughing, chest tightness, and dyspnea. Inflammation is also important in the development of the airway hyperresponsiveness observed in asthmatics, as well as in the emergence of more permanent structural alterations to the airway walls, termed 'airway remodelling'. Originally, a $T_{H} 1 / T_{H} 2$ imbalance was proposed to explain the $\mathrm{T}_{\mathrm{H}} 2$ mediated allergic airway inflammation in asthmatics. However, recent research has focused increasingly on the failure of endogenous tolerance mechanisms, including impaired function of regulatory T-cells (Tregs) (82) and airway epithelial cells (81).

\section{Obesity and Asthma}

Over the past decade, the interaction between obesity and asthma pathogenesis has become apparent. Several epidemiological studies reported a higher prevalence and incidence of asthma in obese versus lean individuals (83-87). Moreover, obesity appears 
to increase asthma severity and impair effective treatment and control of the disease $(88,89)$. However, the underlying mechanisms of this obesity-asthma relationship have not yet been elucidated. Several possibilities have been postulated (90), including common genetic and environmental factors (91), reduced lung volume and airway diameter in obese individuals (92), comorbidities of obesity such as sleeping-disordered breathing (93) and last but not least, the chronic low-grade systemic inflammation that accompanies obesity (94). The latter includes increased serum levels of cytokines, chemokines, acute phase proteins and energy regulating hormones such as leptin (95, 96).

\section{Mouse Models}

The possible role of leptin in allergic airways disease has been studied extensively in mouse models. Mice sensitized to and challenged with ovalbumin (OVA) exhibit many features of asthma, including increased airway hyperresponsiveness (AHR) to methacholine, increased airspace eosinophils, neutrophils and lymphocytes, and $\mathrm{T}_{\mathrm{H}} 2$ cytokine expression, and increases in serum IgE. Interestingly, OVA-treated mice show increased serum levels of leptin, while exogenous administration of leptin augments OVA-induced AHR and serum IgE levels (97). These augmenting effects of leptin on AHR may be due to a direct effect of leptin on airway smooth muscle (ASM) cells or may be related to the effects of leptin on IgE production. Cross-linking of high-affinity IgE receptors (Fc\&RI) on mast cells upon binding of allergen to IgE results in degranulation of these cells and subsequent release of mediators such as histamine, prostaglandin $D_{2}$ and cysteinyl leukotrienes, which are all powerful bronchoconstricting agents (98). Importantly, exogenous administration of leptin has no apparent effects on the OVAinduced eosinophil recruitment to or $\mathrm{T}_{\mathrm{H}} 2$ cytokine expression in the airways, suggesting that leptin is capable of augmenting AHR independently of $T_{H} 2$ inflammation. This supports the hypothesis that leptin may instead be acting on the innate immune system. Along these lines, studies have shown that exogenous leptin increases the pulmonary inflammatory response following acute exposure to ozone $\left(\mathrm{O}_{3}\right)(99)$, a common trigger for asthmatic episodes, known to act through activation of Toll-like receptors (100). These augmented responses to $\mathrm{O}_{3}$ have also been observed in obese Cpe ${ }^{\text {fat }}$ mice (101) and in mice with diet-induced obesity (102), both of which manifest high circulating levels of leptin. However, as similar responses to $\mathrm{O}_{3}$ are also observed in ob/ob (99) and $d b / d b(101)$ mice, which lack leptin signalling, additional factors appear to be involved in the augmented response to $\mathrm{O}_{3}$ in obese mice.

In conclusion, experimental mouse studies support an augmenting role for the leptin-axis in airway hyperresponsiveness, possibly independently of $\mathrm{T}_{\mathrm{H}} 2$ inflammation but via a direct effect of leptin on airway smooth muscle.

\section{Circulating Leptin}


Several human studies have reported on the relationship between serum leptin levels and the occurrence of asthma. Guler et al. found that serum leptin levels of asthmatic children and especially of asthmatic boys were increased compared to healthy controls, in spite of no difference in BMI levels (103). In adult asthmatics, increased serum leptin levels compared to non-asthmatics have been described, however this association appeared stronger in women than in men (104). Jartti et al. studied the link between leptin and asthma in individuals who were followed 21 years from childhood to adulthood. They found high serum leptin levels to be associated with asthma only in adulthood. However, this association did not persist when clinical data, such as age, parental asthma and active smoking status, were included in the statistical model (105). Other studies have found no correlation between serum leptin levels and asthma (106, 107). Altogether, evidence of a link between asthma and serum leptin remains unclear and further studies are needed to elucidate whether leptin directly participates in the pathogenesis of asthma, perhaps in certain subsets of this heterogeneous disease, or whether increased serum leptin levels are merely the result of the systemic inflammation that accompanies both asthma and obesity.

\section{Pulmonary Leptin}

Although several studies have reported on the possible relationship between asthma and systemic levels of leptin, less is known regarding the presence and role of leptin in the pulmonary compartment. Expression of both leptin and its receptor have been described in the lung, especially in bronchial epithelial cells (BECs) and type II pneumocytes $(13,29,108)$, but how these may be affected by obesity or allergic airway inflammation remains unclear. In mice, it has been shown that obese $d b / d b$ mice, which lack the leptin receptor and show innate AHR, have higher leptin levels in bronchoalveolar lavage (BAL) fluid (109). Moreover, these levels are modulated by PPAR $\gamma$ ligands, which have been shown to reduce allergic inflammation and AHR. In humans, preliminary studies show increased BAL leptin levels in obese individuals compared to lean individuals, with positive correlations between BAL leptin levels and $B M I$, lung function, and BAL levels of TNF $\alpha$, nitrates, and 8-isoprostanes, particularly in asthmatics (110-112). In addition, Lugogo et al recently demonstrated that primary alveolar macrophages derived from overweight/obese subjects with asthma are uniquely sensitive to leptin (110-112). Ex vivo studies indicated that leptin alone was sufficient to induce production of proinflammatory cytokines from primary macrophages derived from overweight/obese subjects with asthma and pre-exposure to high-dose leptin enhanced the LPS-induced proinflammatory response (110-112). This leptin-sensitive macrophage phenotype, in the context of higher levels of soluble leptin in the pulmonary compartment, may contribute to the pathogenesis of airway diseases associated with obesity.

On the other hand, Holguin et al (36) showed that BAL adipokine levels (leptin and adiponectin) were not associated with the airway biomarkers of oxidation and 
inflammation. In addition, Bruno et al. reported a decreased expression of leptin and its receptor in BECs isolated from patients with mild or severe, uncontrolled asthma, compared to healthy individuals (108). Moreover, these investigators found leptin and leptin receptor expression in isolated BECs to be inversely related to features of airway remodelling such as basement membrane thickening and TGF- $\beta$ expression.

In summary, leptin is present in the pulmonary compartment of asthmatics. There is developing - but conflicting - literature suggesting a potential role for pulmonary leptin in inflammatory asthma. More studies are warranted to investigate mechanisms of leptin action in asthma and to determine whether modulation of pulmonary leptin may be helpful in asthma prevention or treatment.

\section{Leptin and Eosinophils}

Important to review with respect to asthma pathogenesis are the effects of leptin on eosinophils as one of the major effector cells in asthma. Human eosinophils are known to express the leptin receptor $\mathrm{Ob}-\mathrm{Rb}(113)$ and several studies investigated the role of leptin in the functioning of eosinophils. Leptin was shown to be a direct chemoattractant factor for eosinophils $(114,115)$, possibly through the activation of the ERK1/2 and p38 MAPK signalling pathways. In addition, leptin has a priming effect on eotaxin-induced eosinophil migration $(114,116)$. Other studies suggest that leptin is an activating factor for human eosinophils and may prolong eosinophil survival by suppressing eosinophil apoptosis $(113,115)$.

However, as discussed previously, exogenous administration of leptin in mice has no apparent effects on the OVA-induced eosinophil recruitment to the airways (97). Furthermore, leptin deficiency has recently been suggested to potentiate eosinophilopoiesis and the accumulation of eosinophils in the lung following OVA (117). These apparent conflicting data may be explained by the fact that there are key differences between murine asthma and human asthma, and that human studies are limited by the greater heterogeneity among subjects while murine studies are controlled experiments.

In conclusion, current studies indicate a strong association between asthma and obesity, however the direction of causality is yet unclear. Adequately powered longitudinal and interventional studies are needed to establish a clear direction in association. The current evidence supports an emerging central immune modulating role for leptin in the pulmonary compartment. Further studies targeting leptin signalling are currently under way to clarify the role of pulmonary leptin in asthma pathogenesis.

\section{Pulmonary Infections}

Pneumonia is most commonly caused by bacteria, viruses, or - less frequently - fungi or parasites. The associated symptoms, such as cough, chest pain, fever and dyspnea, are 
accompanied by an inflammatory response in the lungs. Malnutrition, which is often seen in patients with chronic diseases such as COPD or cancer, greatly increases the susceptibility to pulmonary infections $(118,119)$. The mechanisms responsible for this impaired host defence against infections are poorly understood, but may be related to reduced leptin levels. Furthermore, growing evidence suggests an effect of high BMI, and hence leptin resistance, on susceptibility to both bacterial and viral pulmonary infections (120-122), as highlighted by the recent H1N1 influenza epidemic $(123,124)$.

\section{Bacterial Infections}

The possible role of leptin in the immune response to pulmonary infections has mainly been studied in experimental murine models. Mice infected by intratracheal challenge with Klebsiella pneumoniae, a gram-negative bacteria, show increased leptin levels in serum, BAL fluid, and whole lung homogenates (125). It is not clear whether increases in leptin in the pulmonary compartment are due to increased synthesis of leptin in the lung itself, or rather due to leakage of leptin from the circulation that may accompany pulmonary inflammation. Interestingly, leptin deficient ob/ob mice show impaired survival following administration of Klebsiella pneumoniae, Streptococcus pneumoniae, and Mycobacterium abscessus, suggesting that the presence of leptin is required for an effective immune response against diverse bacterial challenges (125-127). The reduced bacterial clearance witnessed in leptin-deficient $(o b / o b)$ mice does not appear to be due to impaired recruitment of inflammatory cells, but rather to result from defective macrophage and neutrophil phagocytosis of bacteria $(57,125,126)$. Moreover, macrophages from leptin-deficient mice show diminished leukotriene synthesis in vitro. Leukotrienes have been shown to enhance macrophage phagocytosis, and impaired leukotriene synthesis has been found in some individuals found to be particularly susceptible to pulmonary infections $(128,129)$. Both the phagocytic response of macrophages and neutrophils and the synthesis of leukotrienes can be restored by exogenous administration of leptin in leptin-deficient mice $(57,125,126)$.

More recently, Kordonowy et al studied the effect of leptin on neutrophil trafficking in a sterile model of lipopolysaccharide (LPS)-induced lung injury (60). Early airspace recruitment (2-6h) was reduced in $d b / d b$ mice, and neutrophils of uninjured mice demonstrated diminished chemotaxis towards the chemokine $\mathrm{KC}$ compared with control mice. In addition, adoptive transfer of $d b / d b$ mouse neutrophils into injured control mice revealed a defect in airspace migration in these cells, suggesting that leptin is effective in driving alveolar airspace neutrophilia (60). Herewith in line, Ubags and colleagues recently showed that pulmonary leptin is induced in injured lungs and that this cytokine is effective in driving alveolar airspace neutrophilia via a direct effect on neutrophils (130). Further studies are warranted to better characterize and dissect the role of leptin in neutrophil recruitment and function in pneumonia and acute lung injury. 
Experiments in lean mice fasted for 48 hours, a physiological stimulus that reduces circulating leptin levels, show a 20-fold increase in Streptococcus pneumoniae burden compared to ad libitum fed mice (131). Similar to leptin-deficient mice, macrophages from fasted animals exhibit defective phagocytosis of Streptococcus pneumoniae, while treatment with exogenous leptin restored bacterial clearance in fasted mice (131). In recent studies, Mancuso and colleagues convincingly showed by means of mutant $s / s$ and $I / I$ mice deficient in leptin receptor-mediated STAT3 activation and ERK activation, respectively, that both signalling routes play an essential role in host defence against bacterial pneumonia and in leukocyte antibacterial effector functions $(132,133)$. In contrast to the above mentioned reports, Wieland et al. failed to detect differences between wild type and leptin deficient $o b / o b$ mice in host response to both Klebsiella pneumoniae and Streptococcus pneumoniae (134). This may be due to differing routes of bacterial administration (intratracheal versus intranasal) or to differences in mouse gender or age (with older, male mice being less susceptible to infections). However, the same group has also reported an increased susceptibility to infection with Mycobacterium tuberculosis in these mice (135). Interestingly, the pulmonary response to Mycobacterium tuberculosis was recently suggested to be affected by the host's nutritional status via the regulation on non-bone marrow-derived cells, and not through direct action of leptin on Th1 immunity (136). Future studies are needed to better understand the role of non-bone marrow-derived cell like pulmonary epithelium involved in leptin-mediated immune regulation in bacterial infections.

\section{Viral Infections}

To date, only a few studies report on the effects of obesity, and thus increased leptin levels and leptin resistance, on the immune response to viral infections. Diet-induced obese mice showed a higher mortality rate upon infection with influenza virus $(137,138)$ and along with this increased mortality rate an altered immune response, including diminished NK-cell cytotoxicity and delayed pro-inflammatory cytokine expression (137). The chronic leptin elevation in these mice appears to cause a state of leptin resistance (139), which may lead to an inadequate immune response and increased mortality upon viral infection. Zhang et al recently suggested that leptin has no effect on viral replication itself (140). Furthermore, it has been shown that diet induced obesity results in selective impairment of DC functions and that obesity leads to delayed recruitment of mononuclear cells to the infected lung during influenza infection. In addition, while migration of antigen-loaded DCs to the lymph node appears to be normal in obese mice, the ability of DCs to present antigens to $C D 8^{+}$T-cells is impaired, and this may be caused by a lack of co-stimulation by DCs (141). Karlsson et al. showed that increased morbidity and mortality during a secondary influenza infection is due to impairment in the ability to generate and maintain functional influenza specific memory T-cells (142). Furthermore, it has also been shown that diet-induced obesity can affect the maintenance of influenza-specific memory T-cell populations in the lung and this may be 
due to peripheral leptin resistance in the obese lung microenvironment affecting IL-15 function (143). These studies highlight potentially different effects on the host's immune system seen in diet-induced obesity and obesity that arises from a leptin-deficient state.

In conclusion, there is a lack of - particularly clinical and translational - research, which is necessary to gain a more comprehensive understanding concerning the possible role of leptin in the human immune responses against bacterial or viral pulmonary infections.

\section{Conclusions}

The pleiotropic functions of leptin are of growing interest, and significant progress has been made in understanding leptin's role in inflammatory respiratory diseases and the underlying immune response. As a type-I cytokine, leptin appears to serve as far more than a satiety hormone for the regulation of food intake and energy expenditure. The presence of the functional leptin receptor in the lung on both leukocytes and lung epithelial cells together with evidence of local leptin production in the respiratory compartment, supports the concept that leptin plays an important role in respiration, lung development and the pathogenesis of diverse respiratory diseases.

Further studies are however needed to elucidate the functional - possibly autocrine and/or paracrine - targets and effects of leptin signalling in the respiratory system in homeostasis and disease. It will be critical to distinguish the effects of leptin signalling in both acute and chronic respiratory diseases, as it appears that leptin may have dichotomous effects depending on the acuity of the disease process. Furthermore, in order to fully understand the role of leptin in clinical disease, more longitudinal or weight-intervention studies are required that focus on the mechanisms by which human obesity - and hence leptin resistance - influences respiratory diseases, and in particular respiratory immunity. Future investigations that reveal the mechanisms by which leptin influences pulmonary inflammation may eventually contribute to the development of novel therapeutic interventions in respiratory diseases.

\section{Acknowledgements}

This study was supported by an unrestricted grant from De Weijerhorst Foundation, Maastricht, The Netherlands and a Concerted Research Action of the University of Ghent (BOF/GOA 01251504 and 01G01009), Ghent, Belgium. K.R. Bracke is a post-doctoral researcher of the Fund for Scientific Research in Flanders (FWO Vlaanderen). 


\section{References}

1. Zhang, Y., Proenca, R., Maffei, M., Barone, M., Leopold, L., and Friedman, J.M. 1994. Positional cloning of the mouse obese gene and its human homologue. Nature 372:425-432.

2. Wauman, J., and Tavernier, J. 2011. Leptin receptor signaling: pathways to leptin resistance. Front Biosci 17:2771-2793.

3. Otero, M., Lago, R., Gomez, R., Dieguez, C., Lago, F., Gomez-Reino, J., and Gualillo, O. 2006. Towards a pro-inflammatory and immunomodulatory emerging role of leptin. Rheumatology (Oxford) 45:944-950.

4. Masuzaki, H., Ogawa, Y., Sagawa, N., Hosoda, K., Matsumoto, T., Mise, H., Nishimura, H., Yoshimasa, Y., Tanaka, I., Mori, T., et al. 1997. Nonadipose tissue production of leptin: leptin as a novel placenta-derived hormone in humans. Nat Med 3:1029-1033.

5. Mix, H., Widjaja, A., Jandl, O., Cornberg, M., Kaul, A., Goke, M., Beil, W., Kuske, M., Brabant, G., Manns, M.P., et al. 2000. Expression of leptin and leptin receptor isoforms in the human stomach. Gut 47:481-486.

6. Sitaraman, S., Liu, X., Charrier, L., Gu, L.H., Ziegler, T.R., Gewirtz, A., and Merlin, D. 2004. Colonic leptin: source of a novel proinflammatory cytokine involved in IBD. Faseb J 18:696-698.

7. Smith-Kirwin, S.M., O'Connor, D.M., De Johnston, J., Lancey, E.D., Hassink, S.G., and Funanage, V.L. 1998. Leptin expression in human mammary epithelial cells and breast milk. J Clin Endocrinol Metab 83:1810-1813.

8. Morash, B., Li, A., Murphy, P.R., Wilkinson, M., and Ur, E. 1999. Leptin gene expression in the brain and pituitary gland. Endocrinology 140:5995-5998.

9. Wang, J., Liu, R., Hawkins, M., Barzilai, N., and Rossetti, L. 1998. A nutrient-sensing pathway regulates leptin gene expression in muscle and fat. Nature 393:684-688.

10. Wang, J., Liu, R., Liu, L., Chowdhury, R., Barzilai, N., Tan, J., and Rossetti, L. 1999. The effect of leptin on Lep expression is tissue-specific and nutritionally regulated. Nat Med 5:895-899.

11. Reseland, J.E., Syversen, U., Bakke, I., Qvigstad, G., Eide, L.G., Hjertner, O., Gordeladze, J.O., and Drevon, C.A. 2001. Leptin is expressed in and secreted from primary cultures of human osteoblasts and promotes bone mineralization. J Bone Miner Res 16:1426-1433.

12. Laharrague, P., Larrouy, D., Fontanilles, A.M., Truel, N., Campfield, A., Tenenbaum, R., Galitzky, J., Corberand, J.X., Penicaud, L., and Casteilla, L. 1998. High expression of leptin by human bone marrow adipocytes in primary culture. Faseb $J$ 12:747-752.

13. Vernooy, J.H., Drummen, N.E., van Suylen, R.J., Cloots, R.H., Moller, G.M., Bracke, K.R., Zuyderduyn, S., Dentener, M.A., Brusselle, G.G., Hiemstra, P.S., et al. 2009. Enhanced pulmonary leptin expression in patients with severe COPD and asymptomatic smokers. Thorax 64:26-32.

14. Henson, M.C., Swan, K.F., Edwards, D.E., Hoyle, G.W., Purcell, J., and Castracane, V.D. 2004. Leptin receptor expression in fetal lung increases in late gestation in the baboon: a model for human pregnancy. Reproduction 127:87-94.

15. Vernooy, J.H., Bracke, K.R., Drummen, N.E., Pauwels, N.S., Zabeau, L., van Suylen, R.J., Tavernier, J., Joos, G.F., Wouters, E.F., and Brusselle, G.G. 2010. Leptin modulates innate and adaptive immune cell recruitment after cigarette smoke exposure in mice. Journal of immunology 184:7169-7177.

16. Hammond, J.A., Bennett, K.A., Walton, M.J., and Hall, A.J. 2005. Molecular cloning and expression of leptin in gray and harbor seal blubber, bone marrow, and lung and its potential role in marine mammal respiratory physiology. Am J Physiol Regul Integr Comp Physiol 289:R545-R553.

17. Torday, J.S., Ihida-Stansbury, K., and Rehan, V.K. 2009. Leptin stimulates Xenopus lung development: evolution in a dish. Evol Dev 11:219-224.

18. Bruno, A., Chanez, P., Chiappara, G., Siena, L., Giammanco, S., Gjomarkaj, M., Bonsignore, G., Bousquet, J., and Vignola, A.M. 2005. Does leptin play a cytokine-like role within the airways of COPD patients? Eur Respir J 26:398-405.

19. Torday, J.S., Sun, H., Wang, L., Torres, E., Sunday, M.E., and Rubin, L.P. 2002. Leptin mediates the parathyroid hormone-related protein paracrine stimulation of fetal lung maturation. Am J Physiol Lung Cell Mol Physiol 282:L405-410. 
20. Wabitsch, M., Jensen, P.B., Blum, W.F., Christoffersen, C.T., Englaro, P., Heinze, E., Rascher, W., Teller, W., Tornqvist, H., and Hauner, H. 1996. Insulin and cortisol promote leptin production in cultured human fat cells. Diabetes 45:1435-1438.

21. Machinal, F., Dieudonne, M.N., Leneveu, M.C., Pecquery, R., and Giudicelli, Y. 1999. In vivo and in vitro ob gene expression and leptin secretion in rat adipocytes: evidence for a regional specific regulation by sex steroid hormones. Endocrinology 140:1567-1574.

22. Mattsson, C., and Olsson, T. 2007. Estrogens and glucocorticoid hormones in adipose tissue metabolism. Curr Med Chem 14:2918-2924.

23. De Pergola, G. 2000. The adipose tissue metabolism: role of testosterone and dehydroepiandrosterone. Int J Obes Relat Metab Disord 24 Suppl 2:S59-63.

24. Sarraf, P., Frederich, R.C., Turner, E.M., Ma, G., Jaskowiak, N.T., Rivet, D.J., 3rd, Flier, J.S., Lowell, B.B., Fraker, D.L., and Alexander, H.R. 1997. Multiple cytokines and acute inflammation raise mouse leptin levels: potential role in inflammatory anorexia. J Exp Med 185:171-175.

25. Gualillo, O., Eiras, S., Lago, F., Dieguez, C., and Casanueva, F.F. 2000. Elevated serum leptin concentrations induced by experimental acute inflammation. Life Sci 67:2433-2441.

26. Popa, C., Netea, M.G., Radstake, T.R., van Riel, P.L., Barrera, P., and van der Meer, J.W. 2005. Markers of inflammation are negatively correlated with serum leptin in rheumatoid arthritis. Annals of the rheumatic diseases 64:1195-1198.

27. Zhang, H.H., Kumar, S., Barnett, A.H., and Eggo, M.C. 2000. Tumour necrosis factor-alpha exerts dual effects on human adipose leptin synthesis and release. Mol Cell Endocrinol 159:79-88.

28. Lollmann, B., Gruninger, S., Stricker-Krongrad, A., and Chiesi, M. 1997. Detection and quantification of the leptin receptor splice variants $\mathrm{Ob}-\mathrm{Ra}, \mathrm{b}$, and, e in different mouse tissues. Biochem Biophys Res Commun 238:648-652.

29. Tsuchiya, T., Shimizu, H., Horie, T., and Mori, M. 1999. Expression of leptin receptor in lung: leptin as a growth factor. Eur J Pharmacol 365:273-279.

30. Dal Farra, C., Zsurger, N., Vincent, J.P., and Cupo, A. 2000. Binding of a pure 125I-monoiodoleptin analog to mouse tissues: a developmental study. Peptides 21:577-587.

31. Bergen, H.T., Cherlet, T.C., Manuel, P., and Scott, J.E. 2002. Identification of leptin receptors in lung and isolated fetal type II cells. Am J Respir Cell Mol Biol 27:71-77.

32. Bellmeyer, A., Martino, J.M., Chandel, N.S., Scott Budinger, G.R., Dean, D.A., and Mutlu, G.M. 2007. Leptin resistance protects mice from hyperoxia-induced acute lung injury. American journal of respiratory and critical care medicine 175:587-594.

33. Broekhuizen, R., Vernooy, J.H., Schols, A.M., Dentener, M.A., and Wouters, E.F. 2005. Leptin as local inflammatory marker in COPD. Respir Med 99:70-74.

34. Carpagnano, G.E., Spanevello, A., Curci, C., Salerno, F., Palladino, G.P., Resta, O., Di Gioia, G., Carpagnano, F., and Foschino Barbaro, M.P. 2007. IL-2, TNF-alpha, and leptin: local versus systemic concentrations in NSCLC patients. Oncol Res 16:375-381.

35. Bruno, A., Alessi, M., Soresi, S., Bonanno, A., Riccobono, L., Montalbano, A.M., Albano, G.D., Gjomarkaj, M., and Profita, M. 2011. Increased leptin/leptin receptor pathway affects systemic and airway inflammation in COPD former smokers. J Inflamm Res 4:51-59.

36. Holguin, F., Rojas, M., Brown, L.A., and Fitzpatrick, A.M. 2011. Airway and plasma leptin and adiponectin in lean and obese asthmatics and controls. J Asthma 48:217-223.

37. Jain, M., Budinger, G.R., Lo, A., Urich, D., Rivera, S.E., Ghosh, A.K., Gonzalez, A., Chiarella, S.E., Marks, K., Donnelly, H.K., et al. 2011. Leptin promotes fibroproliferative acute respiratory distress syndrome by inhibiting peroxisome proliferator-activated receptor-gamma. American journal of respiratory and critical care medicine 183:1490-1498.

38. Tartaglia, L.A., Dembski, M., Weng, X., Deng, N., Culpepper, J., Devos, R., Richards, G.J., Campfield, L.A., Clark, F.T., Deeds, J., et al. 1995. Identification and expression cloning of a leptin receptor, OBR. Cell 83:1263-1271.

39. Tartaglia, L.A. 1997. The leptin receptor. J Biol Chem 272:6093-6096.

40. Myers, M.G., Jr. 2004. Leptin receptor signaling and the regulation of mammalian physiology. Recent Prog Horm Res 59:287-304.

41. Wauman, J., De Ceuninck, L., Vanderroost, N., Lievens, S., and Tavernier, J. 2011. RNF41 (Nrdp1) controls type 1 cytokine receptor degradation and ectodomain shedding. J Cell Sci 124:921-932. 
42. Uotani, S., Bjorbaek, C., Tornoe, J., and Flier, J.S. 1999. Functional properties of leptin receptor isoforms: internalization and degradation of leptin and ligand-induced receptor downregulation. Diabetes 48:279-286.

43. Bjorbak, C., Lavery, H.J., Bates, S.H., Olson, R.K., Davis, S.M., Flier, J.S., and Myers, M.G., Jr. 2000. SOCS3 mediates feedback inhibition of the leptin receptor via Tyr985. J Biol Chem 275:40649-40657.

44. Munzberg, H., and Myers, M.G., Jr. 2005. Molecular and anatomical determinants of central leptin resistance. Nat Neurosci 8:566-570.

45. Cook, W.S., and Unger, R.H. 2002. Protein tyrosine phosphatase 1B: a potential leptin resistance factor of obesity. Dev Cell 2:385-387.

46. Zabolotny, J.M., Bence-Hanulec, K.K., Stricker-Krongrad, A., Haj, F., Wang, Y., Minokoshi, Y., Kim, Y.B., Elmquist, J.K., Tartaglia, L.A., Kahn, B.B., et al. 2002. PTP1B regulates leptin signal transduction in vivo. Dev Cell 2:489-495.

47. Huang, K., Rabold, R., Abston, E., Schofield, B., Misra, V., Galdzicka, E., Lee, H., Biswal, S., Mitzner, W., and Tankersley, C.G. 2008. Effects of leptin deficiency on postnatal lung development in mice. J Appl Physiol 105:249-259.

48. Kirwin, S.M., Bhandari, V., Dimatteo, D., Barone, C., Johnson, L., Paul, S., Spitzer, A.R., Chander, A., Hassink, S.G., and Funanage, V.L. 2006. Leptin enhances lung maturity in the fetal rat. Pediatr Res 60:200-204.

49. Gnanalingham, M.G., Mostyn, A., Webb, R., Keisler, D.H., Raver, N., Alves-Guerra, M.C., Pecqueur, C., Miroux, B., Symonds, M.E., and Stephenson, T. 2005. Differential effects of leptin administration on the abundance of UCP2 and glucocorticoid action during neonatal development. Am J Physiol Endocrinol Metab 289:E1093-1100.

50. Sato, A., Schehr, A., and Ikegami, M. 2011. Leptin does not influence surfactant synthesis in fetal sheep and mice lungs. Am J Physiol Lung Cell Mol Physiol 300:L498-505.

51. Gnanalingham, M.G., Mostyn, A., Dandrea, J., Yakubu, D.P., Symonds, M.E., and Stephenson, T. 2005. Ontogeny and nutritional programming of uncoupling protein-2 and glucocorticoid receptor mRNA in the ovine lung. J Physiol 565:159-169.

52. Pecqueur, C., Alves-Guerra, M.C., Gelly, C., Levi-Meyrueis, C., Couplan, E., Collins, S., Ricquier, D., Bouillaud, F., and Miroux, B. 2001. Uncoupling protein 2, in vivo distribution, induction upon oxidative stress, and evidence for translational regulation. J Biol Chem 276:8705-8712.

53. Tankersley, C.G., O'Donnell, C., Daood, M.J., Watchko, J.F., Mitzner, W., Schwartz, A., and Smith, P. 1998. Leptin attenuates respiratory complications associated with the obese phenotype. J Appl Physiol 85:2261-2269.

54. O'Donnell C, P., Schaub, C.D., Haines, A.S., Berkowitz, D.E., Tankersley, C.G., Schwartz, A.R., and Smith, P.L. 1999. Leptin prevents respiratory depression in obesity. Am J Respir Crit Care Med 159:1477-1484.

55. La Cava, A., and Matarese, G. 2004. The weight of leptin in immunity. Nat Rev Immunol 4:371-379.

56. Caldefie-Chezet, F., Poulin, A., and Vasson, M.P. 2003. Leptin regulates functional capacities of polymorphonuclear neutrophils. Free Radic Res 37:809-814.

57. Moore, S.I., Huffnagle, G.B., Chen, G.H., White, E.S., and Mancuso, P. 2003. Leptin modulates neutrophil phagocytosis of Klebsiella pneumoniae. Infect Immun 71:4182-4185.

58. Loffreda, S., Yang, S.Q., Lin, H.Z., Karp, C.L., Brengman, M.L., Wang, D.J., Klein, A.S., Bulkley, G.B., Bao, C., Noble, P.W., et al. 1998. Leptin regulates proinflammatory immune responses. Faseb J 12:57-65.

59. Santos-Alvarez, J., Goberna, R., and Sanchez-Margalet, V. 1999. Human leptin stimulates proliferation and activation of human circulating monocytes. Cell Immunol 194:6-11.

60. Kordonowy, L.L., Burg, E., Lenox, C.C., Gauthier, L.M., Petty, J.M., Antkowiak, M., Palvinskaya, T., Ubags, N., Rincon, M., Dixon, A.E., et al. 2012. Obesity is associated with neutrophil dysfunction and attenuation of murine acute lung injury. American journal of respiratory cell and molecular biology 47:120-127.

61. Martin-Romero, C., Santos-Alvarez, J., Goberna, R., and Sanchez-Margalet, V. 2000. Human leptin enhances activation and proliferation of human circulating T lymphocytes. Cell Immunol 199:15-24.

62. Fujita, Y., Murakami, M., Ogawa, Y., Masuzaki, H., Tanaka, M., Ozaki, S., Nakao, K., and Mimori, T. 2002. Leptin inhibits stress-induced apoptosis of T lymphocytes. Clin Exp Immunol 128:21-26. 
63. Lord, G.M., Matarese, G., Howard, J.K., Baker, R.J., Bloom, S.R., and Lechler, R.I. 1998. Leptin modulates the T-cell immune response and reverses starvation-induced immunosuppression. Nature 394:897-901.

64. Wouters, E.F. 2008. COPD: from an organ- to a disease-oriented approach. Copd 5:73-74.

65. Rabe, K.F., Hurd, S., Anzueto, A., Barnes, P.J., Buist, S.A., Calverley, P., Fukuchi, Y., Jenkins, C., Rodriguez-Roisin, R., van Weel, C., et al. 2007. Global strategy for the diagnosis, management, and prevention of chronic obstructive pulmonary disease: GOLD executive summary. Am J Respir Crit Care Med 176:532-555.

66. Gan, W.Q., Man, S.F., Senthilselvan, A., and Sin, D.D. 2004. Association between chronic obstructive pulmonary disease and systemic inflammation: a systematic review and a meta-analysis. Thorax 59:574-580.

67. Sin, D.D., and Man, S.F. 2003. Why are patients with chronic obstructive pulmonary disease at increased risk of cardiovascular diseases? The potential role of systemic inflammation in chronic obstructive pulmonary disease. Circulation 107:1514-1519.

68. Schols, A.M., Creutzberg, E.C., Buurman, W.A., Campfield, L.A., Saris, W.H., and Wouters, E.F. 1999. Plasma leptin is related to proinflammatory status and dietary intake in patients with chronic obstructive pulmonary disease. Am J Respir Crit Care Med 160:1220-1226.

69. Takabatake, N., Nakamura, H., Abe, S., Hino, T., Saito, H., Yuki, H., Kato, S., and Tomoike, H. 1999. Circulating leptin in patients with chronic obstructive pulmonary disease. Am J Respir Crit Care Med 159:1215-1219.

70. Yang, Y.M., Sun, T.Y., and Liu, X.M. 2006. The role of serum leptin and tumor necrosis factor-alpha in malnutrition of male chronic obstructive pulmonary disease patients. Chin Med J (Engl) 119:628633.

71. Breyer, M.K., Rutten, E.P., Vernooy, J.H., Spruit, M.A., Dentener, M.A., van der Kallen, C., vanGreevenbroek, M.M., and Wouters, E.F. 2011. Gender differences in the adipose secretome system in chronic obstructive pulmonary disease (COPD): a pivotal role of leptin. Respiratory medicine 105:1046-1053.

72. Breyer, M.K., Rutten, E.P., Locantore, N.W., Watkins, M.L., Miller, B.E., and Wouters, E.F. 2012. Dysregulated adipokine metabolism in chronic obstructive pulmonary disease. European journal of clinical investigation 42:983-991.

73. Celli, B.R., Cote, C.G., Marin, J.M., Casanova, C., Montes de Oca, M., Mendez, R.A., Pinto Plata, V., and Cabral, H.J. 2004. The body-mass index, airflow obstruction, dyspnea, and exercise capacity index in chronic obstructive pulmonary disease. N Engl J Med 350:1005-1012.

74. Gaki, E., Kontogianni, K., Papaioannou, A.I., Bakakos, P., Gourgoulianis, K.I., Kostikas, K., Alchanatis, M., Papiris, S., and Loukides, S. 2011. Associations between BODE index and systemic inflammatory biomarkers in COPD. COPD 8:408-413.

75. Hogg, J.C. 2004. Pathophysiology of airflow limitation in chronic obstructive pulmonary disease. Lancet 364:709-721.

76. Hansel, N.N., Gao, L., Rafaels, N.M., Mathias, R.A., Neptune, E.R., Tankersley, C., Grant, A.V., Connett, J., Beaty, T.H., Wise, R.A., et al. 2009. Leptin receptor polymorphisms and lung function decline in COPD. The European respiratory journal : official journal of the European Society for Clinical Respiratory Physiology 34:103-110.

77. Ye, X.W., Xiao, M., Ye, J., Zhang, X.Y., Xiao, J., Feng, Y.L., and Wen, F.Q. 2011. The polymorphism 2548G/A in leptin and severity of chronic obstructive pulmonary disease. Int J Immunogenet 38:4550.

78. Hoffstedt, J., Eriksson, P., Mottagui-Tabar, S., and Arner, P. 2002. A polymorphism in the leptin promoter region (-2548 G/A) influences gene expression and adipose tissue secretion of leptin. Horm Metab Res 34:355-359.

79. Woo, H.J., Yoo, W.J., Bae, C.H., Song, S.Y., Kim, Y.W., Park, S.Y., and Kim, Y.D. 2010. Leptin upregulates $\mathrm{MUC5B}$ expression in human airway epithelial cells via mitogen-activated protein kinase pathway. Experimental lung research 36:262-269.

80. Vernooy, J.H.J., Haegens, A., Van Opbergen, D., Cloots, R.H.E., and Wouters, E.F.M. 2006. Leptin activates the JAK/STAT signaling pathway in bronchial and alveolar epithelial cells. Eur Respir J 2006; 28: Suppl. 50, S338. 
81. Holgate, S.T. 2011. Pathophysiology of asthma: what has our current understanding taught us about new therapeutic approaches? J Allergy Clin Immunol 128:495-505.

82. Larche, M. 2007. Regulatory T cells in allergy and asthma. Chest 132:1007-1014.

83. Ford, E.S. 2005. The epidemiology of obesity and asthma. J Allergy Clin.Immunol 115:897-909.

84. Taylor, B., Mannino, D., Brown, C., Crocker, D., Twum-Baah, N., and Holguin, F. 2008. Body mass index and asthma severity in the National Asthma Survey. Thorax 63:14-20.

85. Camargo, C.A., Jr., Weiss, S.T., Zhang, S., Willett, W.C., and Speizer, F.E. 1999. Prospective study of body mass index, weight change, and risk of adult-onset asthma in women. Arch.Intern.Med. 159:2582-2588.

86. Castro-Rodriguez, J.A., Holberg, C.J., Morgan, W.J., Wright, A.L., and Martinez, F.D. 2001. Increased incidence of asthmalike symptoms in girls who become overweight or obese during the school years. Am.J Respir.Crit Care Med. 163:1344-1349.

87. Ronmark, E., Andersson, C., Nystrom, L., Forsberg, B., Jarvholm, B., and Lundback, B. 2005. Obesity increases the risk of incident asthma among adults. Eur.Respir.J 25:282-288.

88. Lavoie, K.L., Bacon, S.L., Labrecque, M., Cartier, A., and Ditto, B. 2006. Higher BMI is associated with worse asthma control and quality of life but not asthma severity. Respir.Med. 100:648-657.

89. Saint-Pierre, P., Bourdin, A., Chanez, P., Daures, J.P., and Godard, P. 2006. Are overweight asthmatics more difficult to control? Allergy 61:79-84.

90. Shore, S.A. 2008. Obesity and asthma: possible mechanisms. J Allergy Clin.Immunol 121:1087-1093.

91. Hallstrand, T.S., Fischer, M.E., Wurfel, M.M., Afari, N., Buchwald, D., and Goldberg, J. 2005. Genetic pleiotropy between asthma and obesity in a community-based sample of twins. J Allergy Clin.Immunol 116:1235-1241.

92. Biring, M.S., Lewis, M.I., Liu, J.T., and Mohsenifar, Z. 1999. Pulmonary physiologic changes of morbid obesity. Am.J Med.Sci. 318:293-297.

93. Sulit, L.G., Storfer-Isser, A., Rosen, C.L., Kirchner, H.L., and Redline, S. 2005. Associations of obesity, sleep-disordered breathing, and wheezing in children. Am.J Respir.Crit Care Med. 171:659-664.

94. Fantuzzi, G. 2005. Adipose tissue, adipokines, and inflammation. J Allergy Clin.Immunol 115:911919.

95. Berg, A.H., and Scherer, P.E. 2005. Adipose tissue, inflammation, and cardiovascular disease. Circ.Res. 96:939-949.

96. Scherer, P.E. 2006. Adipose tissue: from lipid storage compartment to endocrine organ. Diabetes 55:1537-1545.

97. Shore, S.A., Schwartzman, I.N., Mellema, M.S., Flynt, L., Imrich, A., and Johnston, R.A. 2005. Effect of leptin on allergic airway responses in mice. J Allergy Clin.Immunol 115:103-109.

98. Barnes, P.J. 2008. Immunology of asthma and chronic obstructive pulmonary disease. Nat.Rev Immunol 8:183-192.

99. Shore, S.A., Rivera-Sanchez, Y.M., Schwartzman, I.N., and Johnston, R.A. 2003. Responses to ozone are increased in obese mice. J Appl.Physiol 95:938-945.

100. Williams, A.S., Leung, S.Y., Nath, P., Khorasani, N.M., Bhavsar, P., Issa, R., Mitchell, J.A., Adcock, I.M., and Chung, K.F. 2007. Role of TLR2, TLR4, and MyD88 in murine ozone-induced airway hyperresponsiveness and neutrophilia. J Appl.Physiol 103:1189-1195.

101. Lu, F.L., Johnston, R.A., Flynt, L., Theman, T.A., Terry, R.D., Schwartzman, I.N., Lee, A., and Shore, S.A. 2006. Increased pulmonary responses to acute ozone exposure in obese $\mathrm{db} / \mathrm{db}$ mice. Am.J Physiol Lung Cell Mol.Physiol 290:L856-L865.

102. Johnston, R.A., Theman, T.A., Lu, F.L., Terry, R.D., Williams, E.S., and Shore, S.A. 2008. Diet-induced obesity causes innate airway hyperresponsiveness to methacholine and enhances ozone-induced pulmonary inflammation. J Appl.Physiol 104:1727-1735.

103. Guler, N., Kirerleri, E., Ones, U., Tamay, Z., Salmayenli, N., and Darendeliler, F. 2004. Leptin: does it have any role in childhood asthma? J Allergy Clin.Immunol 114:254-259.

104. Sood, A., Ford, E.S., and Camargo, C.A., Jr. 2006. Association between leptin and asthma in adults. Thorax 61:300-305.

105. Jartti, T., Saarikoski, L., Jartti, L., Lisinen, I., Jula, A., Huupponen, R., Viikari, J., and Raitakari, O.T. 2009. Obesity, adipokines and asthma. Allergy 64:770-777. 
106. Erel, F., Gulec, M., Kartal, O., Caliskaner, Z., Ozturk, S., Yaman, H., Kurt, Y., Gocgeldic, E., Ors, F., and Karaayvaz, M. 2007. Serum leptin levels and lipid profiles in patients with allergic rhinitis and mild asthma. Allergol Immunopathol.(Madr.) 35:232-238.

107. Jang, A.S., Kim, T.H., Park, J.S., Kim, K.U., Uh, S.T., Seo, K.H., Kim, Y.H., Lim, G.I., and Park, C.S. 2009. Association of serum leptin and adiponectin with obesity in asthmatics. J Asthma 46:59-63.

108. Bruno, A., Pace, E., Chanez, P., Gras, D., Vachier, I., Chiappara, G., La Guardia, M., Gerbino, S., Profita, M., and Gjomarkaj, M. 2009. Leptin and leptin receptor expression in asthma. The Journal of allergy and clinical immunology 124:230-237, 237 e231-234.

109. Holguin, F., Rojas, M., and Hart, C.M. 2007. The peroxisome proliferator activated receptor gamma (PPARgamma) ligand rosiglitazone modulates bronchoalveolar lavage levels of leptin, adiponectin, and inflammatory cytokines in lean and obese mice. Lung 185:367-372.

110. Lugogo, N.L., Hollingsworth, J.W., Howell, D.L., Que, L.G., Francisco, D., Church, T.D., Potts-Kant, E.N., Ingram, J.L., Wang, Y., Jung, S.H., et al. 2012. Alveolar macrophages from overweight/obese subjects with asthma demonstrate a proinflammatory phenotype. American journal of respiratory and critical care medicine 186:404-411.

111. Lessard, A., St-Laurent, J., Turcotte, H., and Boulet, L.P. 2011. Leptin and adiponectin in obese and non-obese subjects with asthma. Biomarkers : biochemical indicators of exposure, response, and susceptibility to chemicals 16:271-273.

112. Holguin, F., Rojas, M., Brown, L.A., and Fitzpatrick, A.M. 2011. Airway and plasma leptin and adiponectin in lean and obese asthmatics and controls. The Journal of asthma: official journal of the Association for the Care of Asthma 48:217-223.

113. Conus, S., Bruno, A., and Simon, H.U. 2005. Leptin is an eosinophil survival factor. J Allergy Clin.Immunol 116:1228-1234.

114. Kato, H., Ueki, S., Kamada, R., Kihara, J., Yamauchi, Y., Suzuki, T., Takeda, M., Itoga, M., Chihara, M., Ito, W., et al. 2011. Leptin has a priming effect on eotaxin-induced human eosinophil chemotaxis. Int Arch Allergy Immunol 155:335-344.

115. Wong, C.K., Cheung, P.F., and Lam, C.W. 2007. Leptin-mediated cytokine release and migration of eosinophils: implications for immunopathophysiology of allergic inflammation. Eur J Immunol 37:2337-2348.

116. Takeda, M., Ueki, S., Kato, H., Konno, Y., Chihara, M., Itoga, M., Kobayashi, Y., Moritoki, Y., Ito, W., Kayaba, H., et al. 2012. Obesity and eosinophilic inflammation: does leptin play a role. Int Arch Allergy Immunol 158 Suppl 1:87-91.

117. Lintomen, L., Calixto, M.C., Schenka, A., and Antunes, E. 2012. Allergen-induced bone marrow eosinophilopoiesis and airways eosinophilic inflammation in leptin-deficient ob/ob mice. Obesity 20:1959-1965.

118. Piitulainen, E., Areberg, J., Linden, M., Eriksson, S., Mattsson, S., and Wollmer, P. 2002. Nutritional status and muscle strength in patients with emphysema and severe alpha(1)-antitrypsin deficiency. Chest 122:1240-1246.

119. Schattner, M. 2003. Enteral nutritional support of the patient with cancer: route and role. J Clin.Gastroenterol. 36:297-302.

120. Jedrychowski, W., Maugeri, U., Flak, E., Mroz, E., and Bianchi, I. 1998. Predisposition to acute respiratory infections among overweight preadolescent children: an epidemiologic study in Poland. Public health 112:189-195.

121. LaCroix, A.Z., Lipson, S., Miles, T.P., and White, L. 1989. Prospective study of pneumonia hospitalizations and mortality of U.S. older people: the role of chronic conditions, health behaviors, and nutritional status. Public health reports 104:350-360.

122. Baik, I., Curhan, G.C., Rimm, E.B., Bendich, A., Willett, W.C., and Fawzi, W.W. 2000. A prospective study of age and lifestyle factors in relation to community-acquired pneumonia in US men and women. Arch Intern Med 160:3082-3088.

123. Van Kerkhove, M.D., Vandemaele, K.A., Shinde, V., Jaramillo-Gutierrez, G., Koukounari, A., Donnelly, C.A., Carlino, L.O., Owen, R., Paterson, B., Pelletier, L., et al. 2011. Risk factors for severe outcomes following 2009 influenza A (H1N1) infection: a global pooled analysis. PLoS Med 8:e1001053.

124. Kwong, J.C., Campitelli, M.A., and Rosella, L.C. 2011. Obesity and respiratory hospitalizations during influenza seasons in Ontario, Canada: a cohort study. Clin Infect Dis 53:413-421. 
125. Mancuso, P., Gottschalk, A., Phare, S.M., Peters-Golden, M., Lukacs, N.W., and Huffnagle, G.B. 2002. Leptin-deficient mice exhibit impaired host defense in Gram-negative pneumonia. J Immunol 168:4018-4024.

126. Hsu, A., Aronoff, D.M., Phipps, J., Goel, D., and Mancuso, P. 2007. Leptin improves pulmonary bacterial clearance and survival in ob/ob mice during pneumococcal pneumonia. Clin.Exp.Immunol 150:332-339.

127. Ordway, D., Henao-Tamayo, M., Smith, E., Shanley, C., Harton, M., Troudt, J., Bai, X., Basaraba, R.J., Orme, I.M., and Chan, E.D. 2008. Animal model of Mycobacterium abscessus lung infection. J Leukoc.Biol. 83:1502-1511.

128. Cederholm, T., Lindgren, J.A., and Palmblad, J. 2000. Impaired leukotriene C4 generation in granulocytes from protein-energy malnourished chronically ill elderly. J Intern.Med. 247:715-722.

129. Jubiz, W., Draper, R.E., Gale, J., and Nolan, G. 1984. Decreased leukotriene B4 synthesis by polymorphonuclear leukocytes from male patients with diabetes mellitus. Prostaglandins Leukot.Med. 14:305-311.

130. Ubags, N., Vernooy, J.H., Burg, E., Nick, J.A., Abraham, E., Tavernier, J., Wouters, E.F., and Suratt, B.T. 2012. Obesity And The Role Of Leptin In Human And Murine Acute Lung Injury/ARDS Am. J. Respir. Crit. Care Med. May 2012; 185: A4112

131. Mancuso, P., Huffnagle, G.B., Olszewski, M.A., Phipps, J., and Peters-Golden, M. 2006. Leptin corrects host defense defects after acute starvation in murine pneumococcal pneumonia. Am.J Respir.Crit Care Med. 173:212-218.

132. Mancuso, P., Peters-Golden, M., Goel, D., Goldberg, J., Brock, T.G., Greenwald-Yarnell, M., and Myers, M.G., Jr. 2011. Disruption of leptin receptor-STAT3 signaling enhances leukotriene production and pulmonary host defense against pneumococcal pneumonia. J Immunol 186:10811090.

133. Mancuso, P., Myers, M.G., Jr., Goel, D., Serezani, C.H., O'Brien, E., Goldberg, J., Aronoff, D.M., and Peters-Golden, M. 2012. Ablation of leptin receptor-mediated ERK activation impairs host defense against Gram-negative pneumonia. J Immunol 189:867-875.

134. Wieland, C.W., Stegenga, M.E., Florquin, S., Fantuzzi, G., and van der, P.T. 2006. Leptin and host defense against Gram-positive and Gram-negative pneumonia in mice. Shock 25:414-419.

135. Wieland, C.W., Florquin, S., Chan, E.D., Leemans, J.C., Weijer, S., Verbon, A., Fantuzzi, G., and van der, P.T. 2005. Pulmonary Mycobacterium tuberculosis infection in leptin-deficient ob/ob mice. Int.Immunol 17:1399-1408.

136. Lemos, M.P., Rhee, K.Y., and McKinney, J.D. 2011. Expression of the leptin receptor outside of bone marrow-derived cells regulates tuberculosis control and lung macrophage MHC expression. $J$ Immunol 187:3776-3784.

137. Smith, A.G., Sheridan, P.A., Harp, J.B., and Beck, M.A. 2007. Diet-induced obese mice have increased mortality and altered immune responses when infected with influenza virus. J Nutr. 137:1236-1243.

138. Easterbrook, J.D., Dunfee, R.L., Schwartzman, L.M., Jagger, B.W., Sandouk, A., Kash, J.C., Memoli, M.J., and Taubenberger, J.K. 2011. Obese mice have increased morbidity and mortality compared to non-obese mice during infection with the 2009 pandemic H1N1 influenza virus. Influenza Other Respi Viruses 5:418-425.

139. Lin, S., Thomas, T.C., Storlien, L.H., and Huang, X.F. 2000. Development of high fat diet-induced obesity and leptin resistance in C57BI/6J mice. Int.J Obes. Relat Metab Disord. 24:639-646.

140. Zhang, A.J., To, K.K., Li, C., Lau, C.C., Poon, V.K., Chan, C.C., Zheng, B.J., Hung, I.F., Lam, K.S., Xu, A., et al. 2013. Leptin mediates the pathogenesis of severe influenza $A(H 1 N 1) p d m 09$ associated with cytokine dysregulation is preventable by anti-leptin antibody in diet-induced obese mice. The Journal of infectious diseases.

141. Smith, A.G., Sheridan, P.A., Tseng, R.J., Sheridan, J.F., and Beck, M.A. 2009. Selective impairment in dendritic cell function and altered antigen-specific CD8+ T-cell responses in diet-induced obese mice infected with influenza virus. Immunology 126:268-279.

142. Karlsson, E.A., Sheridan, P.A., and Beck, M.A. 2010. Diet-induced obesity impairs the T cell memory response to influenza virus infection. J Immunol 184:3127-3133.

143. Karlsson, E.A., Sheridan, P.A., and Beck, M.A. 2010. Diet-induced obesity in mice reduces the maintenance of influenza-specific CD8+ memory T cells. J Nutr 140:1691-1697. 




\section{CHAPTER 7}

\section{The Role of Leptin in the Development of Pulmonary Neutrophilia in Infection and Acute Lung Injury}

Niki D.J. Ubags, Juanita H.J. Vernooy, Elianne Burg, Catherine M. Hayes, Jenna Bement, Estee Dilli, Lennart Zabeau, Edward Abraham, Katie R. Poch, Jerry A. Nick, Oliver Dienz, Joaquin Zuñiga, Matthew J. Wargo, Joseph P. Mizgerd, Jan Tavernier, Mercedes Rincón, Matthew E. Poynter, Emiel F.M. Wouters and Benjamin T. Suratt. 


\section{Abstract}

Objective: One of the hallmarks of severe pneumonia and associated Acute Lung Injury (ALI) is neutrophil recruitment to the lung. Leptin is thought to be up-regulated in the lung following injury and to exert diverse effects on leukocytes, influencing both chemotaxis and survival. We hypothesized that pulmonary leptin contributes directly to the development of pulmonary neutrophilia during pneumonia and ALI.

Design: Controlled human and murine in vivo and ex vivo experimental studies.

Settings: Research laboratory of a university hospital.

Subjects: Healthy human volunteers and subjects hospitalized with bacterial and H1N1 pneumonia. C57BI/6 and $d b / d b$ mice were also used.

Interventions: Lung samples from patients and mice with either bacterial or H1N1 pneumonia and associated ALI were immunostained for leptin. Human bronchoalveolarlavage (BAL) samples obtained after lipopolysaccharide (LPS)-induced lung injury were assayed for leptin. C57BI/6 mice were examined after oropharyngeal aspiration of recombinant leptin alone or in combination with E.coli- or K.pneumonia-induced pneumonia. Leptin-resistant $(d b / d b)$ mice were also examined using the $E$.coli model. BAL neutrophilia and cytokine levels were measured. Leptin-induced chemotaxis was examined in human blood- and murine marrow-derived neutrophils in vitro.

Measurements and Main Results: Injured human and murine lung tissue showed leptin induction compared to normal lung, as did human BAL following LPS instillation. BAL neutrophilia in uninjured and infected mice was increased and lung bacterial-load decreased by airway leptin administration, whereas BAL neutrophilia in infected leptinresistant mice was decreased. In sterile lung injury by LPS, leptin also appeared to decrease airspace neutrophil apoptosis. Both human and murine neutrophils migrated towards leptin in vitro, and this required intact signaling through the JAK2/PI3K pathway.

Conclusion: We demonstrate that pulmonary leptin is induced in injured human and murine lungs and that this cytokine is effective in driving alveolar airspace neutrophilia. This action appears to be caused by direct effects of leptin on neutrophils. 


\section{Introduction}

Acute Lung Injury (ALI) affects approximately 200,000 patients a year in the United States alone, with an associated mortality rate of between $37 \%$ and $60 \%$ (1). Severe infection, particularly pneumonia, is the most frequent risk factor for ALI (2), and this syndrome is seen in response to a variety of bacterial and viral pulmonary pathogens. Neutrophils are key participants in the alveolar epithelial and endothelial injury that characterizes ALI, and are the predominant cells in alveolar edema fluid obtained from affected patients (3). The normal response to pulmonary infection or injury induces the controlled recruitment of neutrophils to the lung, which are then rapidly eliminated through the induction of apoptosis and subsequent clearance by alveolar macrophages during the resolution phase of the inflammatory response (4). In ALI, however, neutrophil recruitment is both exaggerated and persistent, and neutrophil apoptosis is delayed as a consequence of alveolar cytokines and growth factors, including IL-8 and GCSF $(5,6)$. This prolonged neutrophil life-span contributes significantly to the protracted lung injury seen in ALI patients (7). Thus, the key neutrophil processes in ALI are: 1) cytokine-mediated neutrophil recruitment to the lung and 2) prolonged neutrophil survival in the lung leading to sustained inflammation and increased tissue damage (810).

Although traditionally considered a mediator of metabolic homeostasis (11), the adipokine and IL-6 family member leptin also appears to be released into the blood in the setting of systemic inflammation (12). However, leptin's overall role in inflammation remains unclear. Monocyte and macrophage activation, phagocytosis, and release of pro-inflammatory cytokines appear to be promoted by leptin during the innate immune response (13-15), and leptin may be required for these cells to clear bacterial pathogens (16). In the case of neutrophils, surface expression of leptin receptor has been reported and it has been suggested that leptin may augment the functional responses of these cells, including chemotaxis (17), and may delay spontaneous neutrophil apoptosis (18).

Recent studies have shown up-regulated leptin expression in bronchial epithelial cells and alveolar macrophages in both human and murine lungs following chronic smokinginduced lung injury $(19,20)$, and that leptin is increased in BAL from ARDS patients $(21)$. Furthermore, it has been suggested that leptin receptor activation is important in the innate immune response to pneumonia $(17,18)$, as well as in the development of hyperoxia-induced $\mathrm{ALI}$ in mice (22).

Given the proposed effects of leptin on neutrophil function, we hypothesized that pulmonary leptin is an important factor during both pulmonary inflammatory response and $A L I$ pathogenesis. In this study, we show for the first time that leptin expression is up-regulated in both human and murine lung tissues in response to bacterial and viralinduced lung injury, and further, present evidence that leptin is an important mediator 
of pulmonary neutrophilia in ALI that functions via leptin-augmented neutrophil chemotaxis to and possibly delayed clearance from the alveolar space.

\section{Materials and Methods}

\section{Animals}

Eight to twelve week old female C57BI/6 mice (Harlan, Indianapolis, IN), and homozygous female leptin receptor-deficient mice (BKS $d b / d b$ ) and heterozygous littermates (Jackson Labs, Bar Harbor, ME), were housed in the animal facilities at the University of Vermont. All experimental animal procedures were approved by the University of Vermont Institutional Animal Care and Use Committee.

\section{Human immunohistochemistry}

Banked human lung specimens were analyzed from patients who died of bacterial $(n=3)$ or influenza $A(H 1 N 1)(n=3)$ pneumonias with ALI/ARDS and compared to histologically normal lung tissue $(n=3)$. A previously validated protocol for leptin-immunostaining using a rabbit-anti-human leptin antibody (Santa Cruz, Dallas, TX) was used to identify leptinpositive cells in both human and murine tissue (20).

\section{Human pulmonary endotoxin injury}

To determine human alveolar production of leptin in response to injury, alveolar lavage samples banked from a previous study of normal healthy volunteers $(n=14)$ exposed to bronchoscopically-instilled endotoxin (LPS) versus saline were analyzed (23). Briefly, subjects were exposed to endotoxin via bronchoscopic subsegmental-instillation $(4 \mathrm{ng} / \mathrm{kg}$ subject body weight in $10 \mathrm{~mL}$ saline; E. coli strain $\mathrm{O}: 113, \mathrm{NIH}$, Bethesda, MD) randomized to either the lingula or right middle lobe of the lung, which was immediately followed by instillation of $10 \mathrm{~mL}$ sterile saline into a contralateral lung-subsegment. A second bronchoscopy was performed $16 \mathrm{~h}$ later, and both the LPS- and saline-instilled subsegments were lavaged with $150 \mathrm{~mL}$ saline. Previously reported lavage cell counts, and IgM and protein concentrations (23) were compared to lavage leptin levels, as determined by ELISA (R\&D Systems), of the stored samples.

\section{Murine exposures}

Mice treated with pegylated recombinant murine leptin (19) were instilled (50 $\mathrm{g}$ in $100 \mu \mathrm{l}$ sterile PBS or vehicle-control) by oropharyngeal (o.p.) aspiration under isoflurane anesthesia. Murine influenza A (A/California/7/2009 H1N1, 3x10 $\left.{ }^{3} \mathrm{EIU}\right)$, E. coli (O6:K2:H1 ATCC, $1 \times 10^{7} \mathrm{CFU}$ ), and Klebsiella pneumonia (43816 serotype 2, ATCC, $2 \times 10^{3} \mathrm{CFU}$ ) 
infections were performed by either o.p. aspiration (E.coli and K.pneumoniae) or nasalinstillation (H1N1), as described (24-26). LPS lung injury was induced by nebulized LPS, as described (27).

\section{Murine lung analysis and immunohistochemistry}

Airspace lavage cell counts and cytokine levels, as well as whole-lung leptin mRNA levels and bacterial CFU where appropriate were determined at $24 \mathrm{~h}$ (E.coli, K.pneumoniae) or $4 \mathrm{~d}(\mathrm{H} 1 \mathrm{~N} 1)$ after exposure as described in the online supplement. Leptin immunostaining was performed on unlavaged, paraffin-embedded lungs from mice exposed to either E.coli $(n=3)$ or H1N1 pneumonia $(n=3)$, as well as matched saline-instilled control mice ( $n=3$ for each condition), as described for human lung samples.

\section{Neutrophil isolation}

Human blood neutrophils were isolated by dextran sedimentation and discontinuous density-gradient centrifugation (28), and re-suspended in Krebs-Ringer-phosphatedextrose buffer. Morphologically-mature murine bone marrow neutrophils were isolated by discontinuous density-gradient $(29,30)$.

\section{Neutrophil chemotaxis}

Neutrophil chemoattractant response to IL-8, KC (R\&D), or recombinant human (R\&D) or murine (19) leptin was examined using a modified Boyden chamber (Neuroprobe) (31) with or without pre-incubation of the neutrophils for $30 \mathrm{~min}$ at $37^{\circ} \mathrm{C}$ with PI3K- or JAK2inhibitor (Calbiochem).

\section{Neutrophil apoptosis}

Murine airspace neutrophil apoptosis was examined using TUNEL (R\&D) and flow cytometry of lavaged mice, $6 \mathrm{~h}$ after the induction of sterile lung injury by inhaled LPS (31).

\section{Statistical analysis}

Data were represented as mean \pm SEM, and analysis of differences between experimental groups was performed by Student $t$ test. Wilcoxon signed-rank test was used to analyze differences between lavage levels of leptin in subject-matched LPS- and saline-exposed lung subsegments. Spearman rank correlation was used to determine correlations between subjects' lavage leptin, neutrophil, IgM, and protein levels using 'delta' values (LPS-treated lung subsegment minus saline-treated lung subsegment 
levels) for each subject (23). One-way ANOVA was used for analysis of differences between conditions in chemotaxis assays of human and murine neutrophils. All analyses were performed using Prism5 software (GraphPad). Results with $\mathrm{p}<0.05$ were considered statistically significant. 


\section{Results}

\section{Immunohistologically-detected leptin is increased in human lung tissues following infection and injury}

To determine whether alveolar leptin content is increased in the human lung following infection and injury, lung tissue from patients with pneumonia and ALI due to either bacterial or viral (H1N1) infection, was examined by immunohistochemistry for leptin and compared to similarly-stained uninjured human lung samples. Limited leptin staining (blue) was present in the uninjured lung (Figure $1 \mathrm{~A}$ ), whereas diffuse leptin staining was observed in lungs with bacterial and viral pneumonias (Figure $1 \mathrm{~B}$ and $\mathrm{C}$ ). In particular, intense staining of airspace macrophages was detected following acute lung injury, a finding which has previously only been shown in response to chronic lung injury $(19,20)$.

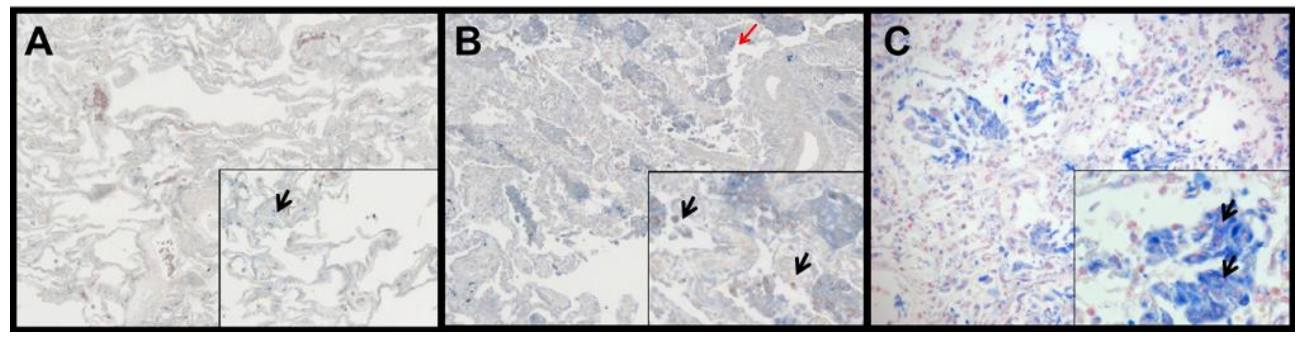

Figure 1 Leptin expression is augmented in the lung during ALI. Immunohistochemical examination was performed for leptin in normal human lung tissue (A), human lung tissue from an ALI patient (B), human lung tissue from an H1N1-infected patient (C). Leptin is indicated by blue staining and nuclei are counterstained in red. Limited leptin staining was observed in normal human lung tissue and was localized in alveolar macrophages. Increased leptin expression in airway macrophages (black arrows) and alveolar epithelium (red arrows) in lung tissue of both ALI and H1N1 infected lung tissue was observed. Original magnification $\times 200$ (inserts $x$ 400).

\section{Airspace leptin levels increase following endotoxin-induced lung injury in humans}

To further examine human alveolar leptin induction, we measured leptin protein levels in BAL samples from a previous study of bronchoscopic subsegmental LPS instillation in healthy volunteers $(n=14)$ (23). BAL samples obtained $16 \mathrm{~h}$ after instillation of LPS showed significantly increased leptin levels in the LPS-exposed lung segments compared to saline-exposed contralateral lung segments of the same subject (Figure 2A). Furthermore, a significant correlation was observed between airspace neutrophil accumulation and leptin levels (Figure 2B). Total BAL protein concentrations, a measurement of both lung injury and capillary leak, also correlated with leptin release (Figure 2C). Yet, BAL IgM levels, a more specific marker for capillary leak, did not 
correlate with leptin levels (Figure 2D), suggesting that increased airspace leptin levels correlate with alveolar injury and not leakage of serum leptin into the airspace.
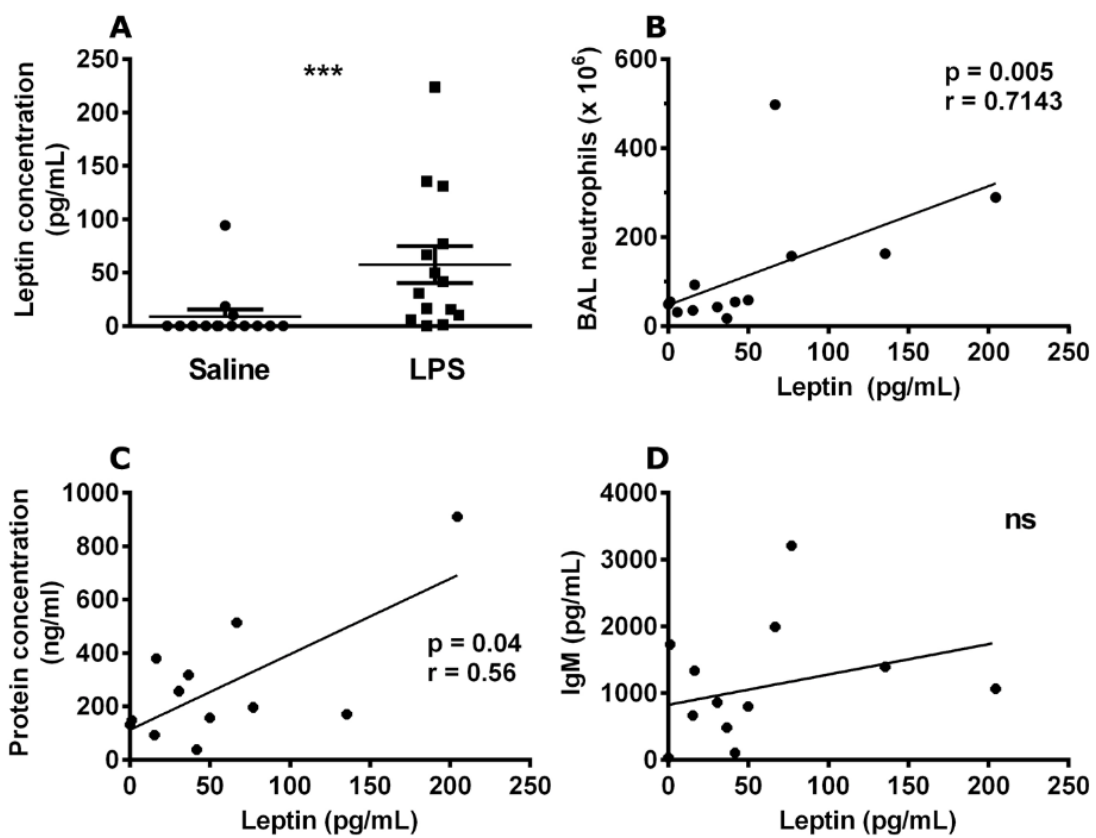

Figure 2 Airspace leptin levels are increased by LPS exposure in humans. Human leptin was quantified in brochoalveolar lavage fluid from lung segments exposed to either saline $(10 \mathrm{~mL})$ or LPS ( $4 \mathrm{ng} / \mathrm{kg}$ in $10 \mathrm{~mL}$ saline) $16 \mathrm{~h}$ after instillation (A). The increase in leptin expression was compared to the levels of brochoalveolar lavage neutrophils (B), total brochoalveolar lavage protein concentration (C), and IgM levels (D). $n=14$ in all groups. Data are presented as mean $\pm \mathrm{SEM}, * \mathrm{p} \leq 0.05$ compared to control. Wilcoxon signed rank test was used to analyze differences between paired LPS and saline instilled subsegments from each subject (A), and Spearman rank correlation was used to analyze the relationship between LPS-treated subsegment lavage leptin, neutrophil, protein, and IgM levels, which were adjusted for the matched control subsegment in each subject (LPS-instilled subgement minus saline instilled subsegment).

\section{Pulmonary leptin expression increases in murine models of both E. coli and influenza A pneumonia}

To further examine the induction of leptin within the lung during infection, we determined leptin immunostaining in lung tissue as well as airspace leptin protein levels and whole lung leptin mRNA expression in mice. Limited leptin staining (blue) was present in the uninjured lung (Figure $3 A$ ), whereas diffuse leptin staining was observed in lungs with bacterial and viral pneumonias (Figure $3 B$ and $C$ ) with intense staining of alveolar macrophages as well as epithelium, similar to the findings in human lung tissue. BAL leptin protein levels were significantly increased at both $24 \mathrm{~h}$ after E.coli infection and $4 \mathrm{~d}$ after H1N1 infection, compared to saline treated control mice (Figure 3D). A 
similar effect was seen on relative leptin mRNA expression in lung tissue of these mice (Figure $3 \mathrm{E}$ ). Analysis of BAL leptin and BAL albumin levels (an indicator of the degree of serum leakage) showed no correlation in these experiments (data not shown), suggesting that airspace leptin is of pulmonary origin and does not reflect serum leptin leakage to a significant degree.

\section{Recombinant leptin augments airspace neutrophilia in injured and uninjured mice}

We next investigated the effect of airspace leptin augmentation in models of E.coli- and K.pneumoniae-induced pneumonia. Pulmonary neutrophilia was significantly increased at $24 \mathrm{~h}$ after E.coli infection with instilled leptin compared to $E$. coli infection without (Figure 4A), and whole lung E.coli CFU were lower in the leptin-treated mice compared to controls (Figure 4B). However, the latter difference did not reach statistical significance, likely related to the limited severity of the E.coli model. Using the more aggressive pulmonary pathogen K.pneumoniae $(32,33)$, leptin instillation significantly augmented bacterial clearance (Figure 4D), while BAL neutrophil levels (Figure 4C) were similar, possibly due to compensatory recruitment signals in the (sicker) control mice. To investigate whether the leptin-associated increase in BAL neutrophilia requires the induction of lung injury, we examined the effect of leptin airway-instillation on pulmonary neutrophil recruitment in uninjured mice. Leptin treatment led to a significant increase in total BAL neutrophil counts at both $6 \mathrm{~h}$ and $24 \mathrm{~h}$ compared to control (Figure 4E), as well as increased albumin levels, indicative of injury and capillary leak (Figure S1A). A similar trend was seen in E. coli and $K$. pneumoniae treated mice (Figure S1B and C), despite decreased bacterial burden in the leptin-treated lungs (Figure $4 B$ and $D)$.

\section{Leptin does not induce alveolar release of inflammatory cytokines}

To distinguish whether the effects of o.p.-instilled leptin on pulmonary neutrophilia were direct (i.e. acting on neutrophils themselves) or indirect (mediated through the induction of inflammatory cytokines), levels of inflammatory cytokines in BAL fluid from leptin- and control-treated uninjured and E.coli-infected mice were measured. No differences were observed in airspace cytokine levels between PBS- and leptin-treated animals in either uninjured (Figure S2A and B) or E.coli-infected mice (Figure S2C). These results suggest that leptin-associated augmentation of airspace neutrophilia may represent a direct effect of leptin on neutrophils themselves. 


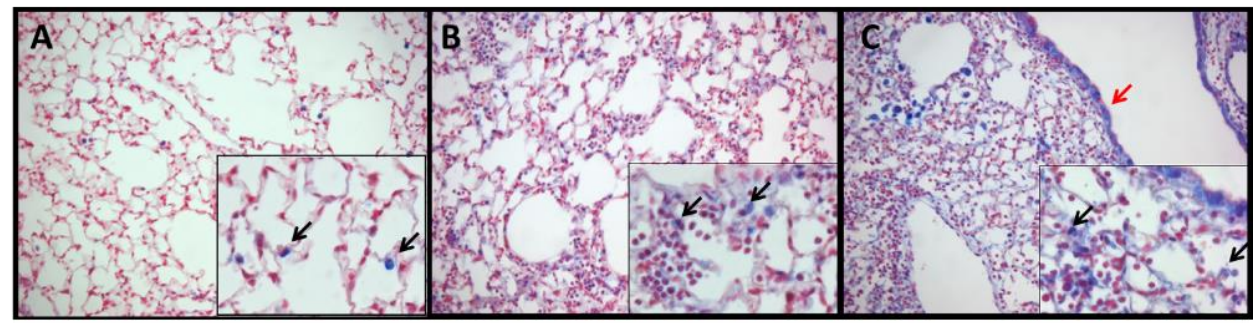

D

E
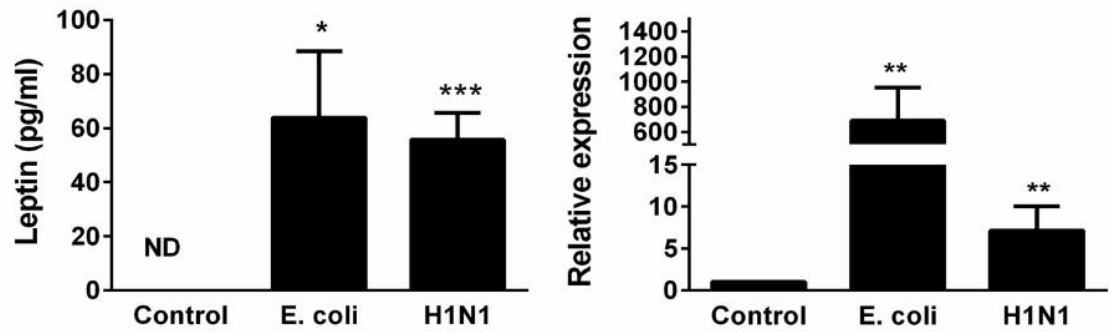

Figure 3 Leptin levels are increased in murine lungs after bacterial or viral infection. Immunohistochemical examination was performed for leptin in normal murine lung tissue $(n=5)(A)$, murine lung tissue infected with E. coli $(n=5)(B)$, and murine H1N1 infected lung tissue $(n=5)(C)$. Leptin is indicated by blue staining and nuclei are counterstained in red. Leptin staining was localized in alveolar macrophages (black arrows) and alveolar epithelium (red arrows). Original magnification x 200 (inserts x 400). Leptin levels were determined in either brochoalveolar lavage by ELISA (D) or lung tissue by qPCR (E) from mice exposed to either saline control $(n=4)$, E. coli for $24 \mathrm{~h}(\mathrm{n}=8)$ or $\mathrm{H} 1 \mathrm{~N} 1$ for $4 \mathrm{~d}(\mathrm{n}=4)$. Data are presented as mean \pm SEM, $* \mathrm{p} \leq 0.05, * * p \leq 0.01$ and $* * * p \leq 0.001$ compared to control.

\section{Defective leptin signaling is associated with decreased pulmonary neutrophilia following murine bacterial pneumonia}

To determine whether leptin was not only sufficient but necessary for the development of pulmonary neutrophilia during infection and injury, we examined the effects of defective leptin signaling in E.coli- or K.pneumoniae-induced pneumonia in mice lacking leptin receptor $(d b / d b)$. In contrast to our findings in wild type mice (Figure 4E), leptin instillation alone in $d b / d b$ mice did not result in significant airspace neutrophilia (Figure S3). Pulmonary neutrophilia was significantly decreased at $24 \mathrm{~h}$ after E. coli infection in $d b / d b$ mice compared to their heterozygous littermates (Figure 5A), and although whole lung $E$. coli CFU were higher in the $d b / d b$ mice compared to controls (Figure $5 \mathrm{~B}$ ), this difference did not reach statistical significance. In addition, BAL neutrophilic cytokine levels (IL-6, KC, G-CSF, TNF- $\alpha$ ) were the same in $d b / d b$ mice compared to littermate controls (Figure $5 C$ ), suggesting that despite lower levels of neutrophils recruited to the airspace of $d b / d b$ mice, the animals were still capable of handling this non-lethal pneumonia model. In the Klebsiella model, leptin receptor-deficiency led to significant impairment of bacterial clearance compared to littermate controls (Figure 5E). Although the difference between BAL neutrophil levels in $d b / d b$ compared littermate control mice 
was not significant, we found markedly increased levels of BAL cytokines in the $d b / d b$ mice compared to control (Figure 5F), suggesting that in the Klebsiella model, unlike the self-limited $E$. coli model, as infection worsens in the absence of leptin signaling it leads to the release of additional neutrophil recruitment signals.
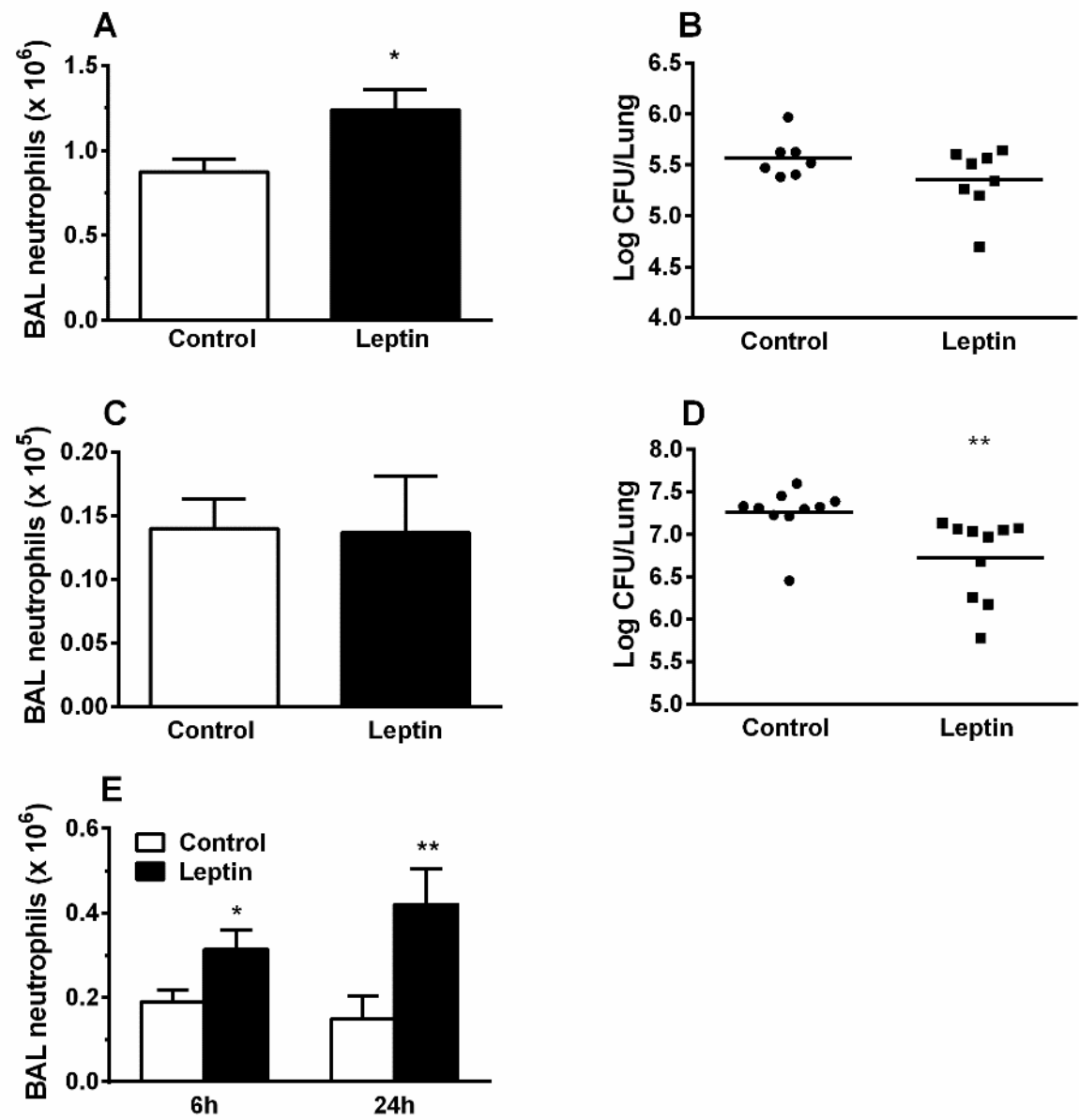

Figure 4 Leptin increases pulmonary neutrophilia in E. coli pneumonia injured as well as in uninjured mice. Total neutrophil counts in brocho-alveolar lavage fluid were determined at $24 \mathrm{~h}$ after o.p. aspiration of control (PBS) or recombinant pegylated leptin $(50 \mu \mathrm{g})$ in $E$. coli (A) and $K$. pneumoniae (C) infected mice, and at 6 and $24 \mathrm{~h}$ after o.p. aspiration of vehicle (PBS) or recombinant pegylated leptin $(50 \mu \mathrm{g})$ in uninjured mice (E). In addition, whole lung CFU were determined in the E.coli (B) and K.pneumoniae (D) infected mice. $n=5$ in all groups of uninjured mice; $n=7$ in the control group and $n=8$ in the pegylated-leptin treated group of $E$. coli pneumonia infected mice; $\mathrm{n}=10$ in all groups of $K$. pneumonia infected mice. Data are presented as mean \pm SEM, * $p \leq 0.05$ and $* * p \leq 0.01$ compared to vehicle-exposed mice. 


\section{Defective leptin signaling is associated with decreased pulmonary neutrophilia following murine bacterial pneumonia}

To determine whether leptin was not only sufficient but necessary for the development of pulmonary neutrophilia during infection and injury, we examined the effects of defective leptin signaling in E.coli- or K.pneumoniae-induced pneumonia in mice lacking leptin receptor $(d b / d b)$. In contrast to our findings in wild type mice (Figure 4E), leptin instillation alone in $d b / d b$ mice did not result in significant airspace neutrophilia (Figure S3). Pulmonary neutrophilia was significantly decreased at $24 \mathrm{~h}$ after $E$. coli infection in $d b / d b$ mice compared to their heterozygous littermates (Figure $5 \mathrm{~A}$ ), and although whole lung $E$. coli CFU were higher in the $d b / d b$ mice compared to controls (Figure 5B), this difference did not reach statistical significance. In addition, BAL neutrophilic cytokine levels (IL-6, KC, G-CSF, TNF- $\alpha$ ) were the same in $d b / d b$ mice compared to littermate controls (Figure $5 \mathrm{C}$ ), suggesting that despite lower levels of neutrophils recruited to the airspace of $d b / d b$ mice, the animals were still capable of handling this non-lethal pneumonia model. In the Klebsiella model, leptin receptor-deficiency led to significant impairment of bacterial clearance compared to littermate controls (Figure 5E). Although the difference between BAL neutrophil levels in $d b / d b$ compared littermate control mice was not significant, we found markedly increased levels of BAL cytokines in the $d b / d b$ mice compared to control (Figure 5F), suggesting that in the Klebsiella model, unlike the self-limited $E$. coli model, as infection worsens in the absence of leptin signaling it leads to the release of additional neutrophil recruitment signals.

\section{Leptin effects human and murine neutrophil chemotaxis in a dose- dependent manner}

To establish whether a direct chemoattractant effect of leptin on neutrophils might contribute to its in vivo effects, we examined both murine and human neutrophil chemotaxis in vitro. A dose-dependent chemotaxis response to leptin was observed in both human and murine neutrophils (Figure $6 \mathrm{~A}$ and $\mathrm{B}$ ). This effect appears to be greater in human neutrophils than mouse, although this may reflect the source and relative maturity of these cells (blood vs. bone marrow). 
A
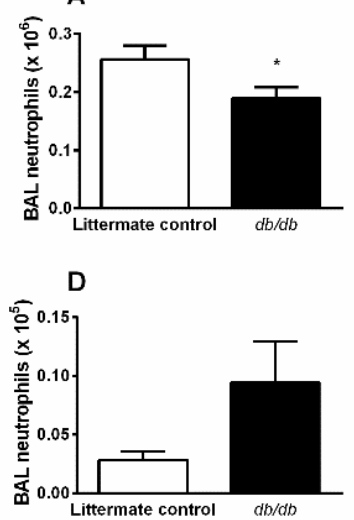

B
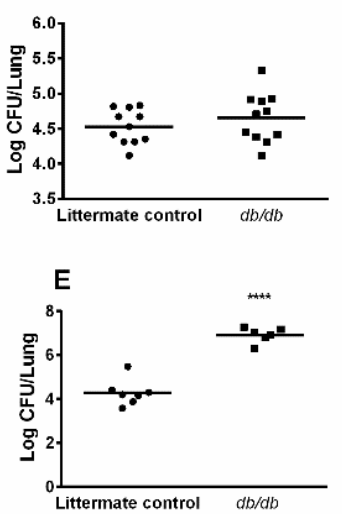

C

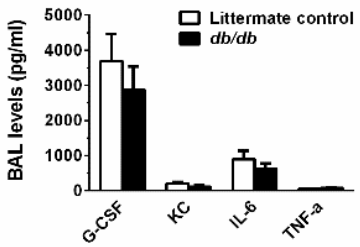

$\mathbf{F}$

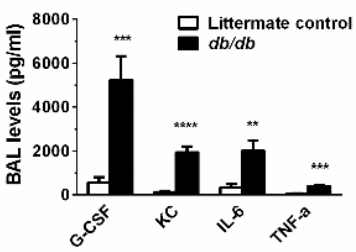

Figure 5 Defective leptin signaling decreases pulmonary neutrophilia in murine $E$. coli pneumonia and increases lung CFU levels in murine $K$. pneumoniae infection. Total neutrophil counts in brochoalveolar lavage fluid and whole lung CFU were determined at $24 \mathrm{~h}$ after $E$. coli (A, B) or $K$. pneumonia (D, E) infection in leptin receptor-deficient $(d b / d b)$ mice and heterozygote littermate controls. In addition, BAL cytokine levels were determined in $d b / d b$ and control mice after E.coli (C) or $K$. pneumoniae (F) infections. $n=11$ in all groups of E.coli infected mice; $\mathrm{n}=7$ in the control mice and $\mathrm{n}=6$ in the $d b / d b$ mice infected with $K$. pneumonia. Data are presented as mean $\pm \mathrm{SEM}, * \mathrm{p} \leq 0.05,{ }^{* *} \mathrm{p} \leq 0.01,{ }^{* * *} \mathrm{p} \leq 0.001$ and $* * * * \mathrm{p} \leq 0.0001$ compared to control mice.
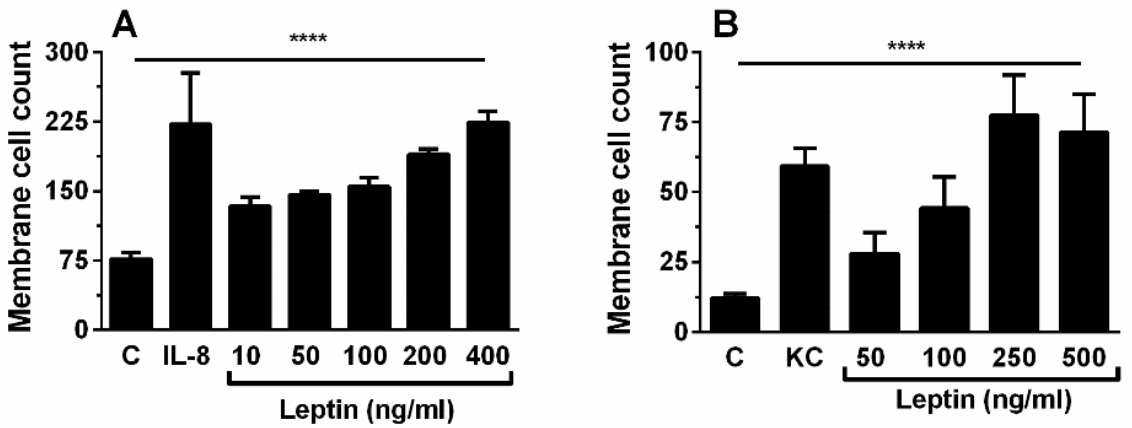

Figure 6 Leptin has a dose-dependent effect on both human and murine neutrophil migration. Human peripheral blood derived neutrophils (A) and murine isolated bone marrow-derived neutrophils (B) were exposed to control (C), IL-8 (100ng/mL) (human), KC (50ng/mL) (murine), and different concentrations of human and murine leptin in a modified Boyden chamber ( $n=4$ for each condition). Data are presented as mean \pm SEM. $* * * * p \leq 0.0001$ as performed with One-way ANOVA. 
Signaling molecules Janus kinase 2 (JAK2) and phosphatidylinositol-4,5bisphosphate 3-kinase (PI3K) are critical for leptin-mediated neutrophil chemotaxis

To further dissect the leptin-induced chemotaxis response, we examined downstream targets of leptin signaling in isolated murine neutrophils. Inhibition of JAK2 and PI3K effectively abolished neutrophil chemotaxis towards leptin (Figure 7), suggesting that neutrophil chemotaxis to leptin requires JAK2/PI3K signaling. Neutrophil response to the CXC chemokine KC did not require JAK2 signaling but was dependent on PI3K activation (Figure 7), as has previously been demonstrated (34.).

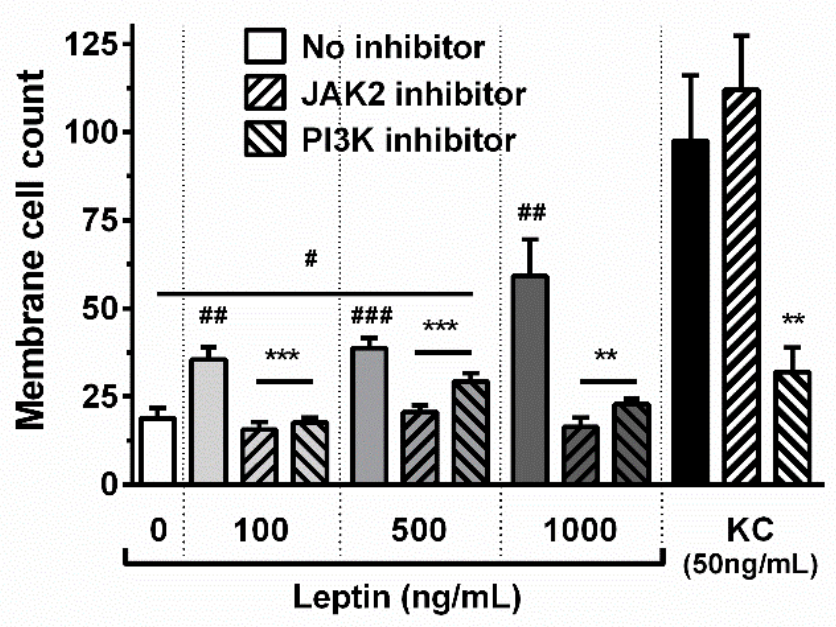

${ }^{* *} p \leq 0.01, * * * p \leq 0.001$ compared to no inhibitor control.
Figure 7 JAK2 and PI3K inhibition abolish leptinmediated neutrophil chemotaxis. Murine bonemarrow derived neutrophils were pre-incubated with control, JAK2 $(100 \mu \mathrm{M})$ or PI3K $(50 \mu \mathrm{M})$ inhibitor $(\mathrm{n}=4$ for each condition) and were exposed to buffer control, $\mathrm{KC}$ $(50 \mathrm{ng} / \mathrm{mL})$ or different concentrations of murine leptin in a modified Boyden Chamber. Data are presented as mean \pm SEM. \# $\mathrm{p} \leq 0.05$, \#\# $\mathrm{p} \leq \mathrm{0.01}$, \#\#\# $\mathrm{p} \leq 0.001$ compared to buffer control;

\section{Leptin delays murine airspace neutrophil apoptosis in vivo}

As previous work has suggested that leptin may have an anti-apoptotic effect on neutrophils in vitro $(18,35)$, we examined whether it might also serve to increase airspace neutrophilia by delaying airspace neutrophil apoptosis in vivo. To address this possibility, we examined a less complex, sterile lung injury model using nebulized lipopolysaccharide to induce rapid recruitment of neutrophils to the lung. Detectable apoptotic neutrophils, which are typically scarce in the airspace due to their rapid clearance (36), were found at low levels in both groups but were significantly reduced in lung-injured mice treated with o.p. leptin compared to those treated with vehicle alone (Figure 8). 


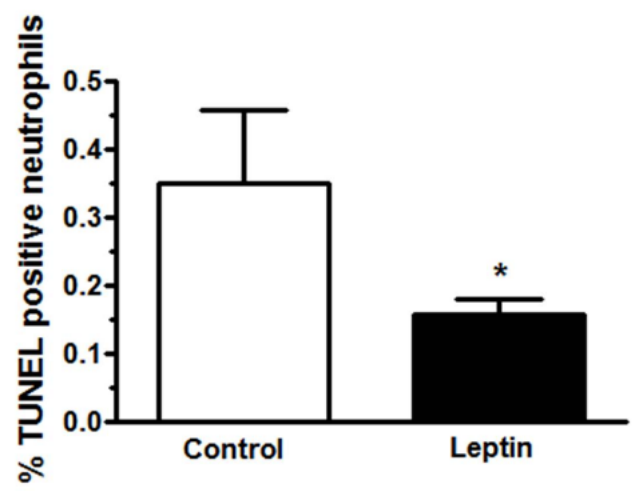

Figure 8 Leptin decreases murine neutrophil apoptosis in vivo. Apoptosis was determined in BAL neutrophils at $6 \mathrm{~h}$ after LPS exposure and o.p. pegylated-leptin $(50 \mu \mathrm{g})$ or control (PBS) instillation by TUNEL staining ( $n=3$ for control and $n=9$ for leptin treatment). Data are presented as mean \pm SEM, * $\mathrm{p} \leq 0.05$ compared to control treated mice.

\section{Discussion}

In this study we demonstrate the induction of leptin expression and release in both human and murine lung during pneumonia and acute lung injury. Furthermore, we describe leptin-mediated effects on neutrophil recruitment and potentially survival, suggesting a novel role for pulmonary leptin in the development and persistence of airspace neutrophilia in severe pneumonia and ALI.

Among its many effects, the adipokine leptin has recently been suggested to act as a neutrophil chemoattractant and an anti-apoptotic molecule in humans $(17,18)$. Yet, the role of leptin in neutrophil recruitment in pneumonia and ALI has not previously been examined. Circulating leptin levels are increased in critical illness, and evidence suggests leptin expression increases is human lung tissue during chronic injury and inflammation $(20,37,38)$, while leptin levels have been found to be elevated in BAL from hyperoxiaexposed mice and patients with acute lung injury $(21,22,39)$. Using immunohistochemistry, we observed intense leptin staining of both alveolar epithelium and macrophages in human subjects with either viral or bacterial-induced lung injury. We found similar leptin staining patterns in mouse models of both H1N1 and E. coli pneumonia, and levels of both leptin transcription and airspace release were increased. Furthermore, we found that endotoxin-induced lung injury in healthy human subjects leads to increased leptin content in BAL fluid, and that these increased leptin concentrations appear to correlate with both the degree of lung injury and levels of airspace neutrophilia. Thus, we show for the first time that pulmonary leptin upregulation a nd airspace release is a response to infection and acute lung injury in both murine models and human disease. 
The effects of leptin on pulmonary inflammatory responses remain poorly understood. Most relevant studies have examined mouse models of leptin- or leptin receptordeficiency. Mancuso et al. demonstrated an impaired host defense in leptin deficient mice, and restoration of circulating leptin levels in these mice led to improved pulmonary bacterial clearance and survival $(15,16)$. Others have shown that leptin infusion or instillation into wild type mice augments lung inflammation in models of allergic sensitization (40) and hyperoxia (22). Furthermore, in recent studies of human $A L I$, high BAL leptin levels were reported to be associated with greater morbidity and mortality in patients with a normal BMI (21), suggesting a pathophysiological role for leptin in this disease.

Leptin has previously been suggested to act as a neutrophil chemoattractant $(17,41,42)$ and anti-apoptotic $(18,35)$ in vitro, yet little has been reported on leptin's effects on neutrophil behavior in vivo. In the present study, we show leptin to be an effective neutrophil chemoattractant not only in vitro but also in vivo. We also find in vivo evidence that leptin may further augment airspace neutrophilia in the context of injury through anti-apoptotic effects, similar to $\operatorname{G-CSF}(6,7)$. In this setting, we note that pneumonia-associated airspace neutrophilia is diminished in mice with impaired leptin signaling, while clearance of bacteria is significantly impaired. Mancuso et al. previously reported impaired bacterial clearance after $K$. pneumoniae infection in leptin-deficient $(o b / o b)$ mice, suggesting an important role for leptin in the pulmonary antibacterial host defense (15). Our data are in agreement with these findings; however, we show that not only the presence of leptin, but also intact leptin signaling is critical in the pulmonary host defense.

The signaling pathways underlying leptin-induced neutrophil chemotaxis have been poorly defined. In our work, signaling through the 'canonical' ObR/JAK2/STAT pathway was not detected (43). We find instead that the 'alternate' JAK2/IRS-1 and the MAPK pathways (34) are required for leptin-induced neutrophil chemotaxis. Furthermore, this process requires $\mathrm{PI} 3 \mathrm{~K}$, suggesting that JAK2 instead activates IRS1/2, which has been shown to activate PI3K in this context (44). Further investigation will be required to fully delineate this process.

It has previously been suggested that increased airspace leptin levels following lung injury may be caused by increased capillary leak and consequent serum leptin extravasation into the airspace $(40,45)$. In our examination of human airspace leptin response we used BAL IgM as a marker of capillary leak (Figure 2 ) in order to avoid the confounding effects of using total protein, which reflects not only vascular leak, but is also an indicator of tissue injury. However, IgM is a larger protein compared to leptin, potentially allowing leptin to cross the alveolar/capillary membrane more readily than IgM following injury. Thus, although we present additional data that a pulmonary source of leptin exists (including immunohistology and whole lung quantitative PCR), our findings must be interpreted with caution. It should also be noted that, given unclear dilution factors related to airspace lavage and the critical role of microanatomical 
cytokine compartmentalization in the lung, the relevant airspace dosing of leptin is unknown.

Our findings not only suggest that leptin participates in the host response to pneumonia and the pathogenesis of ARDS, but may also shed light on the apparent effects of obesity and the accompanying leptin-resistance on both of these diseases. Obesity has been shown in both clinical studies and animal models to be associated with greater susceptibility to and poorer outcomes from pneumonia $(46,47)$. Conversely, in the case of ALI/ARDS, we and others have shown that rising BMI reduces clinical mortality from this syndrome $(48,49)$, and have implicated a blunted inflammatory response during ALI in the obese (50). Furthermore, we have recently reported that diet-induced obese mice have attenuated airspace neutrophilia in response to LPS-induced lung injury (27), which appears to be multifactorial in origin. In light of our current findings, we propose that the altered pulmonary innate immune response seen in obesity could in part reflect impairment of neutrophil leptin-response.

\section{Conclusion}

We demonstrate up-regulation of pulmonary leptin levels in both humans and mice following bacterial- and viral-induced pneumonia and ALI. Leptin enhances airspace neutrophilia, an effect that appears to be independent of secondary cytokine induction. This effect is in part mediated through leptin's action as a neutrophil chemoattractant, but may also include leptin-driven effects on neutrophil survival. Taken together, the present study suggests an important role for leptin in the development of pulmonary neutrophilia following a wide range of insults. Further studies are needed to better understand the effects of leptin and its signaling cascades on both neutrophil development and neutrophil function in pulmonary inflammation. 


\section{References}

1. Rubenfeld, G.D., Caldwell, E., Peabody, E., Weaver, J., Martin, D.P., Neff, M., Stern, E.J., and Hudson, L.D. 2005. Incidence and outcomes of acute lung injury. N Engl J Med 353:1685-1693.

2. Sheu, C.C., Gong, M.N., Zhai, R., Bajwa, E.K., Chen, F., Thompson, B.T., and Christiani, D.C. 2010. The influence of infection sites on development and mortality of ARDS. Intensive Care Med 36:963-970.

3. Steinberg, K.P., Milberg, J.A., Martin, T.R., Maunder, R.J., Cockrill, B.A., and Hudson, L.D. 1994. Evolution of bronchoalveolar cell populations in the adult respiratory distress syndrome. Am J Respir Crit Care Med 150:113-122.

4. Vandivier, R.W., Henson, P.M., and Douglas, I.S. 2006. Burying the dead: the impact of failed apoptotic cell removal (efferocytosis) on chronic inflammatory lung disease. Chest 129:1673-1682.

5. Droemann, D., Aries, S.P., Hansen, F., Moellers, M., Braun, J., Katus, H.A., and Dalhoff, K. 2000. Decreased apoptosis and increased activation of alveolar neutrophils in bacterial pneumonia. Chest 117:1679-1684.

6. Matute-Bello, G., Liles, W.C., Radella, F., 2nd, Steinberg, K.P., Ruzinski, J.T., Hudson, L.D., and Martin, T.R. 2000. Modulation of neutrophil apoptosis by granulocyte colony-stimulating factor and granulocyte/macrophage colony-stimulating factor during the course of acute respiratory distress syndrome. Crit Care Med 28:1-7.

7. Matute-Bello, G., Liles, W.C., Radella, F., 2nd, Steinberg, K.P., Ruzinski, J.T., Jonas, M., Chi, E.Y., Hudson, L.D., and Martin, T.R. 1997. Neutrophil apoptosis in the acute respiratory distress syndrome. Am J Respir Crit Care Med 156:1969-1977.

8. Matute-Bello, G., and Martin, T.R. 2003. Science review: apoptosis in acute lung injury. Crit Care 7:355-358

9. Lee, W.L., and Downey, G.P. 2001. Neutrophil activation and acute lung injury. Curr Opin Crit Care 7:1-7.

10. Suratt, B.T., and Parsons, P.E. 2006. Mechanisms of acute lung injury/acute respiratory distress syndrome. Clin Chest Med 27:579-589; abstract viii.

11. Muoio, D.M., and Lynis Dohm, G. 2002. Peripheral metabolic actions of leptin. Best Pract Res Clin Endocrinol Metab 16:653-666.

12. La Cava, A., and Matarese, G. 2004. The weight of leptin in immunity. Nat Rev Immunol 4:371-379.

13. Zarkesh-Esfahani, H., Pockley, G., Metcalfe, R.A., Bidlingmaier, M., Wu, Z., Ajami, A., Weetman, A.P., Strasburger, C.J., and Ross, R.J. 2001. High-dose leptin activates human leukocytes via receptor expression on monocytes. J Immunol 167:4593-4599.

14. Dixit, V.D., Mielenz, M., Taub, D.D., and Parvizi, N. 2003. Leptin induces growth hormone secretion from peripheral blood mononuclear cells via a protein kinase C- and nitric oxide-dependent mechanism. Endocrinology 144:5595-5603.

15. Mancuso, P., Gottschalk, A., Phare, S.M., Peters-Golden, M., Lukacs, N.W., and Huffnagle, G.B. 2002. Leptin-deficient mice exhibit impaired host defense in Gram-negative pneumonia. Journal of immunology 168:4018-4024.

16. Hsu, A., Aronoff, D.M., Phipps, J., Goel, D., and Mancuso, P. 2007. Leptin improves pulmonary bacterial clearance and survival in ob/ob mice during pneumococcal pneumonia. Clin Exp Immunol 150:332-339.

17. Caldefie-Chezet, F., Poulin, A., and Vasson, M.P. 2003. Leptin regulates functional capacities of polymorphonuclear neutrophils. Free Radic Res 37:809-814.

18. Bruno, A., Conus, S., Schmid, I., and Simon, H.U. 2005. Apoptotic pathways are inhibited by leptin receptor activation in neutrophils. J Immunol 174:8090-8096.

19. Vernooy, J.H., Bracke, K.R., Drummen, N.E., Pauwels, N.S., Zabeau, L., van Suylen, R.J., Tavernier, J., Joos, G.F., Wouters, E.F., and Brusselle, G.G. 2010. Leptin modulates innate and adaptive immune cell recruitment after cigarette smoke exposure in mice. Journal of immunology 184:7169-7177.

20. Vernooy, J.H., Drummen, N.E., van Suylen, R.J., Cloots, R.H., Moller, G.M., Bracke, K.R., Zuyderduyn, S., Dentener, M.A., Brusselle, G.G., Hiemstra, P.S., et al. 2009. Enhanced pulmonary leptin expression in patients with severe COPD and asymptomatic smokers. Thorax 64:26-32.

21. Jain, M., Budinger, G.R., Lo, A., Urich, D., Rivera, S.E., Ghosh, A.K., Gonzalez, A., Chiarella, S.E., Marks, K., Donnelly, H.K., et al. 2011. Leptin promotes fibroproliferative acute respiratory distress 
syndrome by inhibiting peroxisome proliferator-activated receptor-gamma. Am J Respir Crit Care Med 183:1490-1498.

22. Bellmeyer, A., Martino, J.M., Chandel, N.S., Scott Budinger, G.R., Dean, D.A., and Mutlu, G.M. 2007. Leptin resistance protects mice from hyperoxia-induced acute lung injury. Am J Respir Crit Care Med 175:587-594.

23. Nick, J.A., Coldren, C.D., Geraci, M.W., Poch, K.R., Fouty, B.W., O'Brien, J., Gruber, M., Zarini, S., Murphy, R.C., Kuhn, K., et al. 2004. Recombinant human activated protein C reduces human endotoxin-induced pulmonary inflammation via inhibition of neutrophil chemotaxis. Blood 104:3878-3885.

24. Dienz, O., Rud, J.G., Eaton, S.M., Lanthier, P.A., Burg, E., Drew, A., Bunn, J., Suratt, B.T., Haynes, L., and Rincon, M. 2012. Essential role of IL- 6 in protection against H1N1 influenza virus by promoting neutrophil survival in the lung. Mucosal Immunol 5:258-266.

25. Mizgerd, J.P., Lupa, M.M., Kogan, M.S., Warren, H.B., Kobzik, L., and Topulos, G.P. 2003. Nuclear factor-kappaB p50 limits inflammation and prevents lung injury during Escherichia coli pneumonia. Am J Respir Crit Care Med 168:810-817.

26. Wargo, M.J., Gross, M.J., Rajamani, S., Allard, J.L., Lundblad, L.K., Allen, G.B., Vasil, M.L., Leclair, L.W., and Hogan, D.A. 2011. Hemolytic phospholipase C inhibition protects lung function during Pseudomonas aeruginosa infection. Am J Respir Crit Care Med 184:345-354.

27. Kordonowy, L.L., Burg, E., Lenox, C.C., Gauthier, L.M., Petty, J.M., Antkowiak, M., Palvinskaya, T., Ubags, N., Rincon, M., Dixon, A.E., et al. 2012. Obesity is associated with neutrophil dysfunction and attenuation of murine acute lung injury. Am J Respir Cell Mol Biol.

28. Haslett, C., Guthrie, L.A., Kopaniak, M.M., Johnston, R.B., Jr., and Henson, P.M. 1985. Modulation of multiple neutrophil functions by preparative methods or trace concentrations of bacterial lipopolysaccharide. Am J Pathol 119:101-110.

29. Suratt, B.T., Petty, J.M., Young, S.K., Malcolm, K.C., Lieber, J.G., Nick, J.A., Gonzalo, J.A., Henson, P.M., and Worthen, G.S. 2004. Role of the CXCR4/SDF-1 chemokine axis in circulating neutrophil homeostasis. Blood 104:565-571.

30. Suratt, B.T., Young, S.K., Lieber, J., Nick, J.A., Henson, P.M., and Worthen, G.S. 2001. Neutrophil maturation and activation determine anatomic site of clearance from circulation. Am J Physiol Lung Cell Mol Physiol 281:L913-921.

31. Petty, J.M., Sueblinvong, V., Lenox, C.C., Jones, C.C., Cosgrove, G.P., Cool, C.D., Rai, P.R., Brown, K.K., Weiss, D.J., Poynter, M.E., et al. 2007. Pulmonary stromal-derived factor-1 expression and effect on neutrophil recruitment during acute lung injury. Journal of Immunology 178:8148-8157.

32. Standiford, T.J., Kunkel, S.L., Greenberger, M.J., Laichalk, L.L., and Strieter, R.M. 1996. Expression and regulation of chemokines in bacterial pneumonia. J Leukoc Biol 59:24-28.

33. Sordi, R., Menezes-de-Lima, O., Della-Justina, A.M., Rezende, E., and Assreuy, J. 2013. Pneumoniainduced sepsis in mice: temporal study of inflammatory and cardiovascular parameters. Int J Exp Pathol.

34. Bjorbaek, C., Uotani, S., da Silva, B., and Flier, J.S. 1997. Divergent signaling capacities of the long and short isoforms of the leptin receptor. The Journal of biological chemistry 272:32686-32695.

35. Claycombe, K., King, L.E., and Fraker, P.J. 2008. A role for leptin in sustaining lymphopoiesis and myelopoiesis. Proc Natl Acad Sci U S A 105:2017-2021.

36. Aldawood, A., Arabi, Y., and Dabbagh, O. 2006. Association of obesity with increased mortality in the critically ill patient. Anaesth Intensive Care 34:629-633.

37. Koc, E., Ustundag, G., Aliefendioglu, D., Ergenekon, E., Bideci, A., and Atalay, Y. 2003. Serum leptin levels and their relationship to tumor necrosis factor-alpha and interleukin- 6 in neonatal sepsis. $J$ Pediatr Endocrinol Metab 16:1283-1287.

38. Bruno, A., Pace, E., Chanez, P., Gras, D., Vachier, I., Chiappara, G., La Guardia, M., Gerbino, S., Profita, M., and Gjomarkaj, M. 2009. Leptin and leptin receptor expression in asthma. J Allergy Clin Immunol 124:230-237, 237 e231-234.

39. Barazzone-Argiroffo, C., Muzzin, P., Donati, Y.R., Kan, C.D., Aubert, M.L., and Piguet, P.F. 2001. Hyperoxia increases leptin production: a mechanism mediated through endogenous elevation of corticosterone. Am J Physiol Lung Cell Mol Physiol 281:L1150-1156.

40. Shore, S.A., Schwartzman, I.N., Mellema, M.S., Flynt, L., Imrich, A., and Johnston, R.A. 2005. Effect of leptin on allergic airway responses in mice. J Allergy Clin Immunol 115:103-109. 
41. Montecucco, F., Bianchi, G., Gnerre, P., Bertolotto, M., Dallegri, F., and Ottonello, L. 2006. Induction of neutrophil chemotaxis by leptin: crucial role for p38 and Src kinases. Ann N Y Acad Sci 1069:463471.

42. Ottonello, L., Gnerre, P., Bertolotto, M., Mancini, M., Dapino, P., Russo, R., Garibotto, G., Barreca, T., and Dallegri, F. 2004. Leptin as a uremic toxin interferes with neutrophil chemotaxis. J Am Soc Nephrol 15:2366-2372.

43. Zarkesh-Esfahani, H., Pockley, A.G., Wu, Z., Hellewell, P.G., Weetman, A.P., and Ross, R.J. 2004. Leptin indirectly activates human neutrophils via induction of TNF-alpha. Journal of immunology 172:1809-1814.

44. Lakatos, H.F., Burgess, H.A., Thatcher, T.H., Redonnet, M.R., Hernady, E., Williams, J.P., and Sime, P.J. 2006. Oropharyngeal aspiration of a silica suspension produces a superior model of silicosis in the mouse when compared to intratracheal instillation. Experimental lung research 32:181-199.

45. Mancuso, P. 2010. Obesity and lung inflammation. J Appl Physiol 108:722-728.

46. Baik, I., Curhan, G.C., Rimm, E.B., Bendich, A., Willett, W.C., and Fawzi, W.W. 2000. A prospective study of age and lifestyle factors in relation to community-acquired pneumonia in US men and women. Arch Intern Med 160:3082-3088.

47. Mancuso, P. 2012. Obesity and respiratory infections: Does excess adiposity weigh down host defense? Pulm Pharmacol Ther.

48. O'Brien, J.M., Jr., Phillips, G.S., Ali, N.A., Lucarelli, M., Marsh, C.B., and Lemeshow, S. 2006. Body mass index is independently associated with hospital mortality in mechanically ventilated adults with acute lung injury. Crit Care Med 34:738-744.

49. Martino, J.L., Stapleton, R.D., Wang, M., Day, A.G., Cahill, N.E., Dixon, A.E., Suratt, B.T., and Heyland, D.K. 2011. Extreme obesity and outcomes in critically ill patients. Chest 140:1198-1206.

50. Stapleton, R.D., Dixon, A.E., Parsons, P.E., Ware, L.B., Suratt, B.T., and Network, N.A.R.D.S. 2010. The association between $\mathrm{BMI}$ and plasma cytokine levels in patients with acute lung injury. Chest 138:568-577.

51. Vernooy, J.H., Bracke, K.R., Drummen, N.E., Pauwels, N.S., Zabeau, L., van Suylen, R.J., Tavernier, J., Joos, G.F., Wouters, E.F., and Brusselle, G.G. 2010. Leptin modulates innate and adaptive immune cell recruitment after cigarette smoke exposure in mice. J Immunol 184:7169-7177.

52. Rudmann, D.G., Moore, M.W., Tepper, J.S., Aldrich, M.C., Pfeiffer, J.W., Hogenesch, H., and Tumas, D.B. 2000. Modulation of allergic inflammation in mice deficient in TNF receptors. Am J Physiol Lung Cell Mol Physiol 279:L1047-1057.

53. Petty, J.M., Sueblinvong, V., Lenox, C.C., Jones, C.C., Cosgrove, G.P., Cool, C.D., Rai, P.R., Brown, K.K., Weiss, D.J., Poynter, M.E., et al. 2007. Pulmonary stromal-derived factor-1 expression and effect on neutrophil recruitment during acute lung injury. J Immunol 178:8148-8157.

54. Fruhbeck, G., Jebb, S.A., and Prentice, A.M. 1998. Leptin: physiology and pathophysiology. Clinical physiology 18:399-419. 




\section{CHAPTER 7S}

The Role of Leptin in the Development of Pulmonary Neutrophilia in Infection and Acute Lung Injury

Supplement 


\section{Supplement}

\section{Human immunohistochemistry}

Banked human lung specimens obtained during autopsy were analyzed from patients who died off bacterial $(n=3)$ or influenza $A(H 1 N 1)(n=3)$ pneumonias with ALI/ARDS. Specimens from patients with histologically normal lung tissue without evidence of injury, infection or malignancy $(n=3)$ served as controls. A previously validated protocol for leptin immunostaining was used to identify leptin-positive cells, as we have previously described (20). Briefly, deparaffinized fixed lung sections $(5 \mu \mathrm{m})$ were stained using a rabbit anti-leptin antibody (1:300; SC-842; Santa Cruz Biotechnology, Santa Cruz, California) and blue substrate kit III (Vector Laboratories, Burlingame, California) Sections were counterstained with Nuclear Fast Red (Vector Laboratories) and mounted. All patient specimens were examined in accordance with an approved Institutional Review Board (IRB) protocol.

\section{Human BAL}

Previously reported lavage cell counts, and IgM and protein concentrations (23) were compared to lavage leptin levels, as determined by ELISA (R\&D Systems) of the stored samples. IgM levels in BAL fluid samples were determined by ELISA (R\&D Systems), and total protein levels by Bradford assay. Differential cell counts were performed on MayGrünwald-Giemsa-stained cytocentrifuged preparations (23). As a subset of subjects in the original study were treated with activated protein $C$, we examined only subjects in the control arm of the study who received placebo (IV saline) $(n=14)$.

\section{Murine exposures}

Naïve C57BI/6 mice were anesthetized with inhaled isoflurane (Webster Veterinary, Devens, MA) and received either $50 \mu \mathrm{g}$ pegylated recombinant murine leptin (less than $2 \mathrm{EU} / \mathrm{ml}$ endotoxin) (51) in $100 \mu \mathrm{l}$ sterile PBS or $100 \mu \mathrm{l}$ vehicle control (PBS) by oropharyngeal (o.p.) aspiration. This aspiration technique was modified from Lakatos et al (44). In brief, the anesthetized mouse was placed in an upright position and the tongue was gently extracted from the mouth using blunt forceps. The liquid was pipetted onto the back of the tongue. Respiration was monitored to ensure that the suspension was fully aspirated. The animals were euthanized 6 or $24 \mathrm{~h}$ after leptin or PBS instillation by pentobarbital (Vortech pharmaceuticals, Dearborn, MI) overdose and exsanguination. Blood, BAL fluid and lung tissue of these mice was collected and processed for analysis of cell counts, cytokine, gene, and protein expression.

Murine influenza A infection was performed as described by Rincon et al (24). Briefly, mice were infected intranasally with sublethal doses $\left(3 \times 10^{3}\right.$ EIU) of the A/California/7/2009 H1N1 isolate of the 2009 pandemic H1N1 influenza virus or vehicle (saline) control. Mice were euthanized and examined as above at day 4 post-infection. 
Murine bacterial pneumonia infection was performed as previously described $(25,26)$. Briefly, mice were inoculated with $\sim 1 \times 10^{7} \mathrm{CFU}$ of E.coli 06:K2:H1 (ATCC) or vehicle (saline) control with or without $50 \mu \mathrm{g}$ pegylated recombinant murine leptin (51) via o.p. aspiration following brief anesthesia with isoflurane. Mice were euthanized and examined after $24 \mathrm{~h}$ as described above. Klebsiella pneumoniae infection was performed by o.p. instillation of $K$. pneumonia (43816 serotype 2, ATCC, $2 \times 10^{3} \mathrm{CFU}$ ) or vehicle (saline) control with or without $50 \mu$ g pegylated recombinant murine leptin (51). Mice were euthanized and examined after $24 \mathrm{~h}$ as described above.

Murine LPS-induced lung injury was performed as previously described (27). Briefly, Mice were exposed to aerosolized E. coli 0111:B4 lipopolysaccharide (LPS; Sigma, St. Louis, MO) using a $3 \mathrm{mg} / \mathrm{ml}$ solution of LPS in sterile saline nebulized by a Pari LC Plus Reusable Nebulizer with ProNeb Turbo Air Compressor (Pari Respiratory Equipment, Midlothian, VA). The nebulizer was connected, via a central manifold, to a multi-compartment pieshaped Plexiglas aerosol chamber (modified Tepper box (52)) in which groups of mice were exposed individually but simultaneously to the aerosol for $15 \mathrm{~min}$.

\section{Murine immunohistochemistry}

Paraffin imbedded murine lungs were cut in $4 \mu \mathrm{m}$ sections and processed for immunohistochemical leptin staining according to Vernooy et al. (20). Immunoreactive epitopes of leptin were exposed by treatment with $0.05 \%$ Pronase $E$ in $0.5 \mathrm{M} \mathrm{Tris} / \mathrm{HCl}(\mathrm{pH}$ 7.6), and nonspecific binding was blocked with 5\% BSA in TBS. Leptin was detected using a rabbit anti-leptin polyclonal Ab (SC-842, Santa Cruz Biotechnology, Santa Cruz, CA). After application of biotin-conjugated goat anti-rabbit IgG Ab (E-0431, DakoCytomation, Glostrup, Denmark) and alkaline phosphatase-labeled avidin-biotin complex (ABC-AP, K0376, DakoCytomation), enzymatic reactivity was visualized using Blue Substrate Kit III (SK-5300, Vector Laboratories, Burlingame, CA). Sections were counterstained with Nuclear Fast Red (Vector Laboratories) and mounted. Negative controls for nonspecific binding by omitting the primary detecting $A b$ revealed only nuclear staining in red and no blue staining was observed.

\section{Neutrophil chemotaxis}

Neutrophil chemoattractant response to IL-8, KC (both R\&D Systems), or recombinant leptin (51) was examined using a 48-well modified Boyden chamber (Neuroprobe Gaithersburg, MD) as previously described (53) with or without pre-incubation of the neutrophils for 30 minutes at 37으 with PI3K- $(50 \mu \mathrm{M})$ or JAK2-inhibitor $(100 \mu \mathrm{M})$ (Calbiochem). Briefly, isolated human peripheral blood neutrophils and murine bone marrow neutrophils were isolated as described above, and resuspended at $3.0 \times 10^{6}$ cells/ml in $\mathrm{H} / \mathrm{H}$ buffer ( $1 \mathrm{x} \mathrm{HBSS}, 2 \mathrm{mg} / \mathrm{ml} \mathrm{BSA}, 10 \mathrm{mM}$ HEPES, $1 \mathrm{mM} \mathrm{CaCl} 2$ and $1 \mathrm{mM} \mathrm{MgCl}$ ) (murine neutrophils) or $1 x \mathrm{HBSS}$ supplemented with $1 \mathrm{mM} \mathrm{CaCl}$ and $1 \mathrm{mM} \mathrm{MgCl}$ (human neutrophils). Chemoattractants in the appropriate buffer were added to the lower 
chambers of the apparatus. Polycarbonate membranes with $8 \mu \mathrm{m}$ (in the case of human neutrophils) or $5 \mu \mathrm{m}$ (in the case of murine neutrophils) pores (Neuroprobe, Gaithersburg, MD) were placed between the upper and lower chambers, and $50 \mu \mathrm{l}$ of cells were then added to the upper chambers. Cells were allowed to migrate for $30 \mathrm{~min}$ at $37^{\circ} \mathrm{C}$ with $5 \% \mathrm{CO}_{2}$, before the membrane was removed, gently scraped, and stained using the Diff-Quik system (Hema3, Fisher Scientific, Middletown, VA). Three random fields of each well were scored using light microscopy (40x) to count the membrane bound intact cells. It is worth noting that pegylated leptin (MW $56 \mathrm{kDa}$ ) was used in our experiments in place of native leptin (MW $16 \mathrm{kDa}$ ) in order to improve the cytokine's stability. Thus, the concentrations used in this experiment (10 to $1000 \mathrm{ng} / \mathrm{mL}$ ) correspond to significantly lower levels of native leptin $(2.9$ to $285.7 \mathrm{ng} / \mathrm{mL}$ or $0.179 \mathrm{nM}$ - $17.9 \mathrm{nM}$ ), which are well within physiologically relevant range of this cytokine (54).

\section{Murine albumin western blot analysis}

Murine alveolar lavage supernatant (2.5ul) was loaded and separated on a polyacrylamide gel, followed by transfer to a $0.45 \mu \mathrm{m}$ nitrocellulose membrane (Bio-Rad) by electroblotting. The membrane was blocked for 1 h at room temperature in $5 \%(\mathrm{w} / \mathrm{v})$ nonfat, dried milk diluted in TBS-Tween20 (0.05\%). Nitrocellulose blots were washed in TBS-Tween $20(0.05 \%)$ followed by $1 \mathrm{hr}$ incubation at room temperature, with primary antibody (goat anti-mouse Albumin; 1/5000; Immunology Consultants Laboratory Inc., Portland, OR Immunology Consultants Laboratory Inc). After three washes of $15 \mathrm{~min}$ each, the blots were probed with horseradish peroxidase-conjugated anti-goat antibody (1/10,000; Jackson Immunology Research, West Grove, PA) and visualized by chemiluminesence using Supersignal ${ }^{\circledR}$ West Pico Chemiluminescent Substrate (Pierce Biotechnology, Rockford, IL) according to the manufacturer's instructions and exposed to film.

\section{Murine cytokine analysis}

Macrophage Inflammatory Protein (MIP)-2 concentrations in BAL were analyzed by ELISA (CXCL-2/MIP-2 DuoSet, R\&D Systems), performed according to manufacturer's protocol. Murine IL-1 $\beta$, IL-6, KC, MCP-1, G-CSF and TNF- $\alpha$ levels in BAL supernatants were assessed using a Bio-Plex suspension array system (Bio-Rad, Hercules, CA), as previously described (27). BAL leptin concentrations were measured with a murine leptin ELISA (Quantikine, R\&D Systems) according to manufacturer's protocol.

\section{Quantitative RT-PCR}

Frozen mouse lung samples, obtained as detailed above, were pulverized using chilled mortars and pestles. Transcription of leptin and GAPDH was assessed using a Bio-Rad quantitative PCR system following mRNA isolation and cDNA preparation, as described previously (53). The following primer sequences were used: for leptin TGCACACCAAAACCCTCATCA and TCATTGGCTATCTGCAGCAC; and GAPDH TaqMan Gene expression assay, AOD, (Applied Biosystems). Leptin levels were analyzed using the cycle 
threshold $(\triangle \Delta \mathrm{Ct})$ method and normalized to GAPDH. Tissue leptin mRNA expression for injured lungs was reported as the fold increase over uninjured mouse lung tissue expression.

\section{Figures}
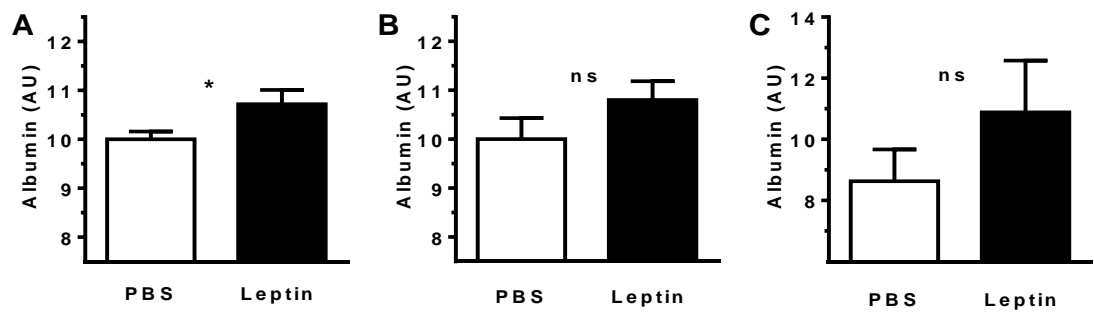

Figure S1. Airspace albumin levels are increased following leptin instillation. Albumin levels were determined in BAL samples at $24 \mathrm{~h}$ after o.p. aspiration of control (PBS) or recombinant pegylated leptin $(50 \mu \mathrm{g})$ in uninjured mice (A) and in E. coli pneumonia (B) and K. pneumoniae (C) infected mice. $n=3$ in both groups of uninfected mice. $n=4$ in the control group and pegylated leptin treated group of $E$. coli pneumonia infected mice. $n=8$ in both groups of $K$. pneumoniae infected mice. Data are presented as mean $\pm \mathrm{SEM}$. ${ }^{*} p \leq 0.05$ compared to PBS instilled controls.

A

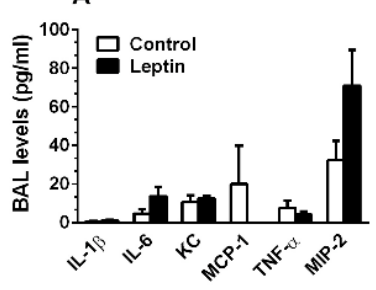

B

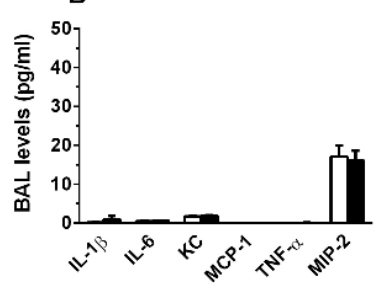

C

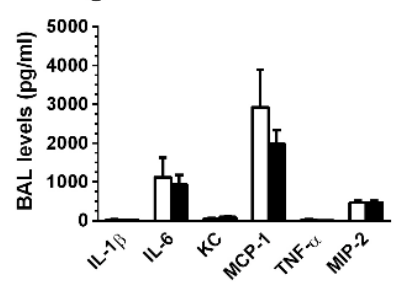

Figure S2. BAL inflammatory cytokine levels remain unchanged after leptin aspiration in uninjured mice as well as in mice with $E$. coli pneumonia. Brochoalveolar lavage cytokine levels were determined in response to leptin airway instillation in uninjured mice at $6 \mathrm{~h}(\mathrm{~A})$ and $24 \mathrm{~h}(\mathrm{~B})$ after leptin instillation, as well as $24 \mathrm{~h}$ after $E$. coli infection and leptin instillation (C). No significant differences were observed between control and leptintreated mice. $n=5$ in all groups. Data are presented as mean \pm SEM. 


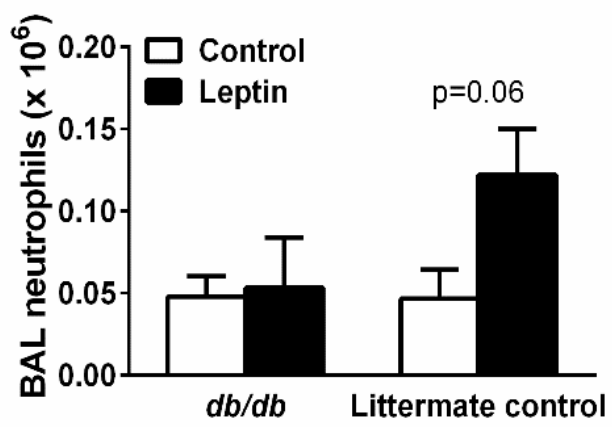

Figure S3. Oropharygeal instillation of leptin fails to recruit neutrophils to the airspace in leptin receptor-deficient mice. Total neutrophil counts in brochoalveolar lavage fluid were determined at $24 \mathrm{~h}$ after o.p. aspiration of control (PBS) or recombinant pegylated leptin $(50 \mu \mathrm{g})$ in leptin receptor-deficient $(d b / d b)$ mice and their heterozygous littermates. While no difference in BAL neutrophil levels were found between leptin and PBS treated mice, a trend $(p=0.06)$ toward higher neutrophils was noted in leptin-treated heterozygous littermates. $n=5$ in all groups. Data are presented as mean \pm SEM. 




\section{CHAPTER 8}

\section{Hyperleptinemia Impairs Pulmonary Host Defense}

Niki D.J. Ubags, Renee D. Stapleton, Juanita H.J. Vernooy, Elianne Burg, Jenna Bement, Catherine M. Hayes, Lennart Zabeau, Jan Tavernier, Matthew J. Wargo, Benjamin Littenberg, Matthew E. Poynter, Emiel F.M. Wouters, Polly E. Parsons, Anne E. Dixon and Benjamin T. Suratt. 


\section{Abstract}

Rationale: We have previously reported that obesity attenuates pulmonary inflammation in both patients with Acute Respiratory Distress Syndrome (ARDS) and in mouse models of the disease. We hypothesized that obesity-associated hyperleptinemia and not body mass per se drives attenuation of the pulmonary inflammatory response, and that this effect could also impair the host response to pneumonia.

Methods: We examined the correlation between circulating leptin levels and risk, severity, and outcome of pneumonia in two patient cohorts (NHANES III and ARDSNetALVEOLI) and in mouse models of diet-induced obesity and lean hyperleptinemia.

Results and conclusion: Plasma leptin levels in ambulatory subjects (NHANES) correlated positively with annual risk of respiratory infection independent of BMI. In patients with severe pneumonia resulting in ARDS (ARDSNet-ALVEOLI), plasma leptin levels were found to correlate positively with subsequent mortality. In obese mice with pneumonia, plasma leptin levels were associated with pneumonia severity, and in obese mice with sterile lung injury, leptin levels were inversely related to bronchoalveolar lavage neutrophilia as well as to plasma IL-6 and G-CSF levels. These results were recapitulated in lean mice with experimentally-induced hyperleptinemia. Our findings suggest that the association between obesity and elevated risk of pulmonary infection may be driven by hyperleptinemia. 


\section{Introduction}

Pulmonary infection is the ninth leading cause of death (1), and accounts for greater than $\$ 40$ billion/year in direct and associated costs in the U.S. alone (2). Despite initial gains in the late 19th through mid-20th centuries, recent efforts to further reduce the morbidity and mortality associated with bacterial and viral infection have been largely ineffective (3). Recent epidemics, such as the pandemic ( $\mathrm{HH} 1 \mathrm{~N} 1)$ influenza outbreaks, have highlighted the continued threat of emerging pathogens for which we have few if any effective treatments.

Epidemiological studies suggest that in addition to pathogen prevalence and virulence, host factors play a critical role in determining both susceptibility to and outcome from pulmonary infections (4-6). Yet, our understanding of these factors remains limited. In this era of increased antibiotic resistance and novel pathogens, there is a pressing need to identify therapeutic approaches that may restore or enhance host defenses in at-risk populations. Several well-described immunocompromised states (e.g., chemotherapyinduced neutropenia, AIDS), the presence of underlying lung disease, smoking, alcoholism, and the extremes of age $(4,7-9)$ are associated with elevated risk for pneumonia. Some recent studies have demonstrated associations between obesity and risk for both bacterial and viral pneumonias, as well as, increased disease severity and mortality $(6,10,11)$. However, others have suggested a protective effect of increasing $\mathrm{BMI}$ on mortality in this setting $(12,13)$. Reasons for this inconsistency remain unclear. Studies in murine models of obesity have shown failure to contain both influenza $(14,15)$ and bacterial $(16,17)$ pneumonias with consequent lung injury and death. Subsequent work examining influenza has focused on the role of altered adaptive immune response in obesity (18-21). Our previous studies have revealed obesity-associated defects in the immune response to lung injury in patients with ARDS (22), and we have replicated these findings in obese mouse models of lung injury, in which both the inflammatory cytokine response and development of airspace neutrophilia are attenuated (23). Many of the effects of obesity have previously been ascribed to the development of a baseline proinflammatory state, yet levels of circulating inflammatory cytokines are only mildly elevated (24) compared to the levels typically thought to induce immune paralysis states such as seen with sepsis (25). The dysregulation of adipokines in obesity, however, can be quite severe. The adipokine leptin, for which leukocytes express receptors, is found in extremely high levels in obesity (10-50 fold increase compared to lean individuals (26, 27)). Interestingly, several host factors that have also been inconsistently associated with pneumonia risk, including pregnancy (6), diabetes (28), and chronic renal failure (29), are also associated with hyperleptinemia (30-38). The inconsistency of these associations may reflect the variability of leptin levels in these conditions as studied, raising the possibility that chronic hyperleptinemia may impair immune function.

We hypothesized that obesity-associated hyperleptinemia and not body mass per se, is linked to an impaired response to pulmonary pathogens and an increased susceptibility 
to infections. In this study, we present evidence that elevated circulating leptin levels are correlated with an increased risk and severity of respiratory infection regardless of BMI in both humans and mouse models.

\section{Materials and Methods}

\section{Human data analysis}

\section{NHANES}

The National Health and Nutrition Examination Survey (NHANES III) database was used to test the association of serum leptin levels to self-reported infections in a representative sample of non-institutionalized adults. NHANES is an ongoing data collection of the US Centers for Disease Control (http://www.cdc.gov/nchs/nhanes.htm). Each sample is comprised of subjects randomly selected form the US population using a stratified sampling scheme. Consenting subjects submit to an extensive interview, examination and collection of blood (Centers for Disease Control and Prevention).

NHANES III subjects were interviewed between 1988 and 1994. Eligible subjects included adults aged 18 years or older at the time of the interview that provided data for all the outcomes and potential confounders and had leptin measures reported.

Upper Respiratory Infection (URI) was coded as the answer to "In the past three weeks have you had any respiratory infections, such as flu, pneumonia, bronchitis, or a severe cold?" Pneumonia was coded as the answer to "During the past 12 months, have you had...Pneumonia?" The primary outcome measure Respiratory Infection, was created by combining the responses to URI and Pneumonia. Subjects who reported one or more pneumonias in the last year, or one or more URIs in the past three weeks, or both, were coded as positive.

Variables with the theoretical ability to confound the relationship between leptin and infection because of their known or suspected association with leptin were selected (age, sex, race (white or non-white), education (number of years of school), income (above or below $\$ 20,000$ per year), marital status (currently married or living as married), body mass index (measured by trained research staff), smoking status (current smoker vs. former or never smoker), diabetes ("other than during pregnancy, has a doctor ever told you that you have diabetes or sugar diabetes?"), glycated hemoglobin A1C, and estimated creatinine clearance (Cockcroft and Gault 1976).

\section{$\underline{\text { ALVEOLI }}$}

Patients with ARDS in our study participated in an RCT of lower versus higher positive end-respiratory pressure, and these patients also received $6 \mathrm{cc} / \mathrm{kg}$ tidal volume. Details of 
this RCT are described elsewhere (39). Briefly, patients were eligible if they required mechanical ventilation and met criteria for acute lung injury according to the AmericanEuropean Consensus Conference (AECC) definition (40). Patients with body weight greater than one kilogram per centimeter of height were excluded. For each participant, Acute Physiology and Chronic Health Evaluation (APACHE) score during the 24 hours following ICU admission was calculated, and the physician investigator identified the primary risk factor for the development of ALI (sepsis, trauma, pneumonia, aspiration, multiple transfusions, or other) as previously described (41).

\section{Human cytokine analysis}

In the NHANES study human serum leptin levels (after an overnight fast) were determined by radioimmunoassay with a polyclonal antibody raised in rabbits against highly purified recombinant leptin (US Department of Health and Human Services (DHHS) National Center for Health Statistics 2001). Serum IL-6 and leptin levels in samples from the ALVEOLI study were determined by ELISA (both Quantikine, R\&D systems, Minneapolis, MN) according to manufacturer's protocol.

\section{Animals}

Eight to twelve week old female C57BI/6 mice (Harlan, Indianapolis, IN) were fed high vs. normal fat chow (60\% vs. $10 \%$ fat; Research Diets, New Brunswick, NJ) for 20 weeks or intraperitoneally (i.p.) injected with PEGylated leptin (2 $\mu \mathrm{g}$ in $200 \mu \mathrm{l} \mathrm{PBS}$ ) (42) or PBS control $(200 \mu \mathrm{l})$ daily for 14 days. Mouse weights and food intake were monitored and daily and average food intake was calculated per mouse. Animals were housed in the animal facilities at the University of Vermont and all experimental animal procedures were approved by the University of Vermont Institutional Animal Care and Use Committee.

\section{Murine exposures}

Murine Klebsiella pneumoniae (43816 serotype 2, ATCC, $2 \times 10^{3} \mathrm{CFU}$ ) infections were performed by oropharyngeal (o.p.) aspiration, as described (43) . Lipopolysaccharide lung injury was induced by nebulized LPS (E. coli 0111:B4, Sigma, St. Louis, MO), as described (23).

\section{Murine lung analysis}

Airspace lavage cell counts and cytokine levels, as well as bacterial CFU where appropriate were determined at 48h (K. pneumoniae) and 24h (LPS) after exposure (17).

\section{Murine cytokine analysis}

Murine IL-1 $\beta$, IL-6, KC, MCP-1, TNF $\alpha$ and G-CSF levels in plasma and BAL were assessed using a Bio-Plex suspension array system (Bio-Rad, Hercules, CA), as previously described 
(23). Plasma and BAL leptin concentrations were measured by ELISA (mouse leptin Quantikine, R\&D Systems) according to manufacturer's protocol.

\section{Murine blood glucose and cholesterol determination}

Fasting blood glucose levels were determined after an overnight fast by a glucometer (Nipro diagnostics, Fort Lauerdale, FL). In addition, plasma LDL and cholesterol levels were assayed using an Advia Chemistry System (Siemens, Tarrytown, NY) (44).

\section{Statistical analysis}

Analyses of the data derived from the NHANES III database were performed by univariate linear regression in order to confirm that each of the potential confounders was associated with the independent variable (serum leptin level). Thereafter, univariate logistic regression analysis was used to assess the relationships between the potential confounders and respiratory infection. Those that were associated with both the predictor and the outcome with $P<0.1$ were retained in an adjusted multivariate logistic model. The adjusted odds ratio (OR), 95\% confidence interval $(\mathrm{Cl})$ and $P$-value was calculated for each retained variable and accepted a $P$-value $<0.05$ on the OR for leptin as evidence of statistical significance. NHANES analyses were performed with SAS software (Cary, NC).

When analyzing ARDSNet data, leptin data were natural log-transformed due to nonnormal distribution. Univariate analysis were performed with linear or logistic regression for continuous and categorical variables, respectively. Multivariable linear and logistic regressions with robust standard errors were used to evaluate the associations between leptin and our dependent variable of interest (IL-6) with adjustment for confounders. In our multivariable models, BMI and APACHE score were fit as a linear continuous variable. Inflammatory biomarker levels were natural log-transformed due to non-normality. Gender and comorbid diabetes were dichotomous, and risk factor for ALI was fit as an indicator variable. All analyses were performed with Stata 9.0 or greater (College Station, TX). Statistical significance was defined as a two-sided $P$-value $\leq 0.05$.

Murine data were represented as mean, and analysis of differences between experimental groups was performed by Student $t$ test. Differences between mouse weights and food intake over time between two groups were analyzed by repeated measures ANOVA. Correlations between murine plasma leptin levels or weight and lung CFU levels, BAL neutrophil counts and plasma cytokine levels, were analyzed by linear regression. All analyses were performed using Prism 6 software (GraphPad). Results with $P \leq 0.05$ were considered statistically significant.

\section{Study approval}

The study protocol for the ARDSNet/ALVEOLI study was previously approved by Institutional Review Boards of the University of Vermont and was conducted in 
accordance with the Declaration of Helsinki. All participants provided written informed consent prior to their participation in the study. All animal experiments were performed in accordance with and approved by the University of Vermont Institutional Animal Care and Use Committee.

\section{Results}

\section{Hyperleptinemia is independently associated with increased risk of respiratory infection in the general population.}

The National Health and Nutrition Examination Survey III (NHANES III) database was used to test the association between host factors and annual risk of pulmonary infection. In univariate logistic regression on subjects with complete data $(n=30,818)$, age $(p<0.0001)$, gender $(p<0.0001)$, race $(p=0.0003)$, and smoking status $(p=0.0003)$ were found to correlate significantly with the annual risk of infection (Table 1), concordant with previous studies $(4,45)$. Similar examination of metabolic variables showed associations between pulmonary infection and BMI $(\mathrm{p}<0.0001)$, glycosylated hemoglobin $(\mathrm{HbA} 1 \mathrm{c}$, $\mathrm{p}<0.0001$ ), and renal function (creatinine clearance, $\mathrm{p}<0.0001$ ) (Table 1), but neither diabetic status per se nor lipid profile (triglycerides, total cholesterol, LDL, or HDL) were found to be associated.

Table 1 The annual risk for respiratory infection is significantly correlated with age, gender, race, body mass index, smoking status, glycosylated hemoglobin and renal function. 30,818 subjects from NHANES III. $P \leq 0.05$ is considered significant.

\begin{tabular}{|c|c|c|c|}
\hline Respiratory tract infection $(n=30,818)$ & $\begin{array}{l}\text { Odds } \\
\text { Ratio }\end{array}$ & $95 \% \mathrm{Cl}$ & $\boldsymbol{P}$ \\
\hline \multicolumn{4}{|l|}{ Univariate Analysis } \\
\hline Age (years) & 1.015 & {$[1.01,1.02]$} & $<0.0001$ \\
\hline Gender & 0.678 & {$[0.58,0.79]$} & $<0.0001$ \\
\hline White Race & 1.474 & {$[1.21,1.80]$} & 0.0003 \\
\hline Education (0-17 years of school) & 0.992 & {$[0.97,1.02]$} & 0.5045 \\
\hline Income $<\$ 20,000$ & 1.133 & {$[0.91,1.41]$} & 0.2501 \\
\hline Married (or living as married) & 1.089 & {$[0.87,1.36]$} & 0.4427 \\
\hline Body Mass Index $\left(\mathrm{kg} / \mathrm{m}^{2}\right)$ & 1.042 & {$[1.03,1.06]$} & $<0.0001$ \\
\hline Current Smoker & 1.718 & {$[1.30,2.27]$} & 0.0003 \\
\hline Diabetes Mellitus & 1.237 & {$[0.85,1.80]$} & 0.2614 \\
\hline Glycated Hgb A1C (\%) & 1.153 & {$[1.09,1.22]$} & $<0.0001$ \\
\hline Creatinine clearance $\left(\mathrm{ml} / \mathrm{min} / 1.74 \mathrm{~m}^{2}\right)$ & 0.988 & {$[0.99,0.99]$} & $<0.0001$ \\
\hline
\end{tabular}


Further analysis of a smaller subset of this cohort in which plasma leptin levels were measured $(n=6,252)$ revealed a significant association between leptin and respiratory infection (OR=1.109 per $\mathrm{ng} / \mathrm{ml} ; 95 \% \mathrm{Cl} 1.003,1.034 ; P=0.019$ ) while controlling for age, sex, BMI, social status, smoking, diabetes and renal function (Table 2). Several metabolic variables were positively associated with leptin levels in this cohort, including BMI $(p<0.0001), \operatorname{HbA} 1 \mathrm{c}(p<0.0001)$, and renal function $(p<0.0001)$, as has been reported in previous studies. Interestingly, these same metabolic variables were associated with respiratory infection in the larger cohort, but not in the smaller cohort which controlled for leptin. These same associations have previously been shown to be variable in other small cohorts $(11,28,29)$. Together these findings suggest that possibility that the effects of these variables on respiratory infection are mediated by leptin.

We also examined the incidence of urinary tract infections in the cohort in which leptin levels were measured. Although the risk for urinary tract infection was associated with serum leptin levels in univariate analysis (Supplemental Table S1), it was not in multivariate analysis, suggesting that high leptin levels may be associated specifically with respiratory infection but not other infections.

Table 2. The annual risk for respiratory infection is significantly correlated with serum leptin level, gender and smoking status. 6,252 subjects from NHANES III. $P \leq 0.05$ is considered significant.

\begin{tabular}{lccc} 
Respiratory infection $(\mathrm{n}=396)$ & $\begin{array}{c}\text { Odds } \\
\text { Ratio }\end{array}$ & $95 \% \mathrm{Cl}$ & $P$ \\
\hline Univariate Analysis & & & \\
\hline Leptin $(\mathrm{ng} / \mathrm{mL})$ & 1.019 & {$[1.003,1.034]$} & 0.019 * \\
Age (years) & 1.003 & {$[0.994,1.012]$} & 0.51 \\
Male & 0.622 & {$[0.433,0.894]$} & $0.011^{*}$ \\
White Race & 0.975 & {$[0.655,1.453]$} & 0.90 \\
Education $(0-17$ years of school) & 0.987 & {$[0.935,1.042]$} & 0.62 \\
Income<\$20, 000 & 1.004 & {$[0.687,1.465]$} & 0.99 \\
Married (or living as married) & 1.051 & {$[0.670,1.647]$} & 0.83 \\
Body Mass Index $\left(\mathrm{kg} / \mathrm{m}^{2}\right)$ & 1.017 & {$[0.988,1.048]$} & 0.25 \\
Current Smoker & 1.950 & {$[1.352,2.812]$} & 0.0006 * \\
Diabetes Mellitus & 1.383 & {$[0.788,2.429]$} & 0.25 \\
Glycated Hgb A1C $(\%)$ & 1.116 & {$[0.963,1.293]$} & 0.14 \\
Creatinine clearance $\left(\mathrm{ml} / \mathrm{min} / 1.74 \mathrm{~m}^{2}\right)$ & 1.004 & {$[0.995,1.013]$} & 0.34 \\
Multivariate Analysis & & & \\
\hline Leptin $(\mathrm{ng} / \mathrm{mL})$ & 1.016 & {$[1.000,1.032]$} & 0.049 \\
Male & 0.692 & {$[0.481,0.995]$} & 0.047 \\
Current Smoker & 2.139 & {$[1.482,3.086]$} & 0.0001
\end{tabular}




\section{Hyperleptinemia is associated with increased risk of death in patients with severe pneumonia.}

We next examined whether leptin levels might be associated with outcomes in critically ill patients with pneumonia. We determined plasma leptin levels in banked samples of critically ill patients with ARDS due to pneumonia ( $n=147)$, that had been enrolled in the ARDSnet/ALVEOLI study of high vs. low PEEP ventilation strategy (39). High circulating leptin levels at day 1 of enrollment were associated with increased mortality (OR= 1.3142 per log leptin; $95 \% \mathrm{Cl}=1.0163,1.6996 ; P=0.037$ ) when adjusted for $\mathrm{BMI}$, gender, disease severity (APACHE II) and diabetic status. Interestingly, when analyzing the entire cohort including patients without pneumonia $(n=385)$, no association was found. Furthermore, elevated leptin levels at enrollment were found to correlate with the diagnosis of pneumonia as the identified risk factor for developing ARDS in the cohort as a whole $(\mathrm{OR}=0.616 ; 95 \% \mathrm{Cl}=0.0875,1.1447 ; P=0.022 ; \mathrm{n}=385)$.

\section{Plasma leptin levels and not body weight correlate with bacterial burden in a mouse model of obesity.}

We next investigated whether the observed associations between hyperleptinemia and pneumonia risk and severity could be replicated in animal models of obese pneumonia. We examined Klebsiella pneumoniae infection in a diet-induced obesity (DIO) mouse model (23) to mimic human obesity and pneumonia. Although pneumonia severity, as measured by whole lung bacterial colony-forming units (CFU) at $48 \mathrm{~h}$, was increased in the obese mice as a group (Figure $1 \mathrm{~A}$ ), there was no association between bacterial burden and mouse weight in regression analysis (Figure 1B). However, a positive association was found with plasma leptin levels (Figure 1C).

\section{Hyperleptinemia, and not body weight, is independently associated with impairment of pulmonary neutrophilia in response to inhaled LPS exposure in obese mice.}

We have previously reported an inverse association between body weight and airspace neutrophilia following LPS-induced lung injury in mouse models of obesity $\left(r^{2}=0.32, P=\right.$ 0.02 ) (23). To determine the relationship between obesity-associated hyperleptinemia and the neutrophil response following lung injury in this model, lavage neutrophil levels were compared to plasma leptin levels $24 \mathrm{~h}$ after injury in obese and lean mice. We found a strong inverse association between bronchoalveolar lavage (BAL) neutrophil counts and plasma leptin levels $(P=0.0002)$ (Figure 2). Furthermore, in multivariate analysis, including both weight and plasma leptin levels, leptin remained significant $(P=$ $0.021)$, whereas weight was not $(P=0.796)$. These results suggest that the previously reported defects in the pulmonary neutrophil response to LPS challenge in obese mice (23) may be driven by obesity-associated hyperleptinemia, and not obesity per se. 

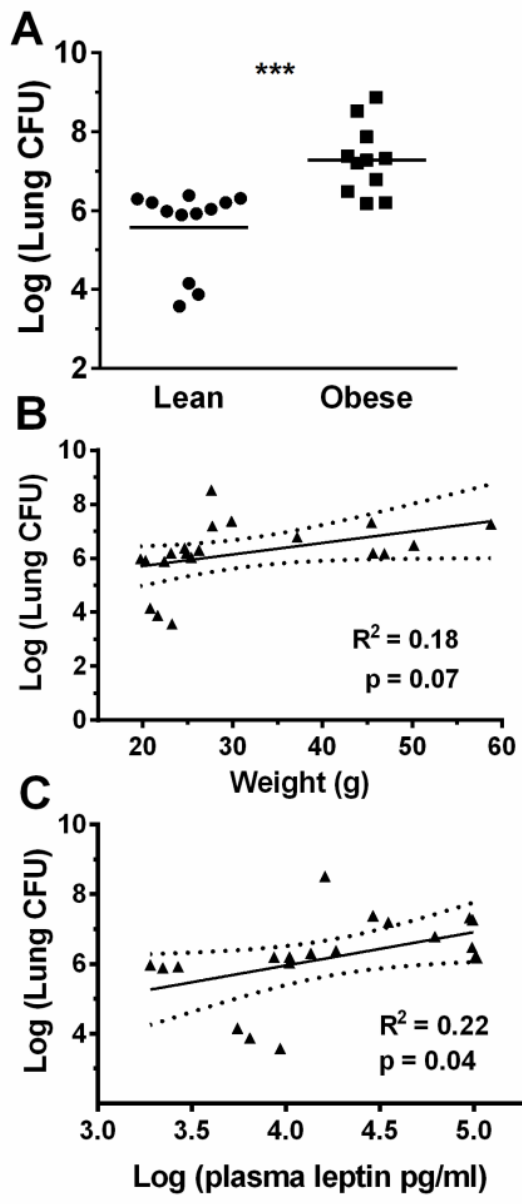

Figure 1 Pneumonia severity as measured by bacterial burden correlates with plasma leptin levels in $K$. pneumoniae-infected lean and obese mice. (A) Lung bacterial colony forming units (CFU) were determined at $48 \mathrm{~h}$ after $K$. pneumoniae infection in lean ( $10 \%$ fat diet) and diet-induced obese (60\% fat diet) mice. In addition, (B) lung CFU was compared with mouse weight and (C) plasma leptin levels by linear regression. $n=11$ (10\% diet) and $n=9$ (60\% diet) animals. Dashed lines indicate $95 \%$ confidence intervals. $* * * P \leq 0.001$ as determined by an unpaired Student's $t$-test (two-tailed).

Figure 2 Plasma leptin levels inversely correlate with airspace neutrophilia in LPSinjured lean and obese mice. Previously we have reported that BAL neutrophil counts and mouse body weight are inversely associated $\left(r^{2}=0.32, P=0.02\right)$ following LPS-induced lung injury in diet-induced obese mice (23). We now compared BAL neutrophil counts and plasma leptin levels at $24 \mathrm{~h}$ after LPS-induced lung injury in diet-induced obese $(60 \%$ fat diet, $n=6$ ) and lean ( $10 \%$ fat diet, $n=5$ ) mice by linear regression. Dashed lines indicate 95\% confidence interval.

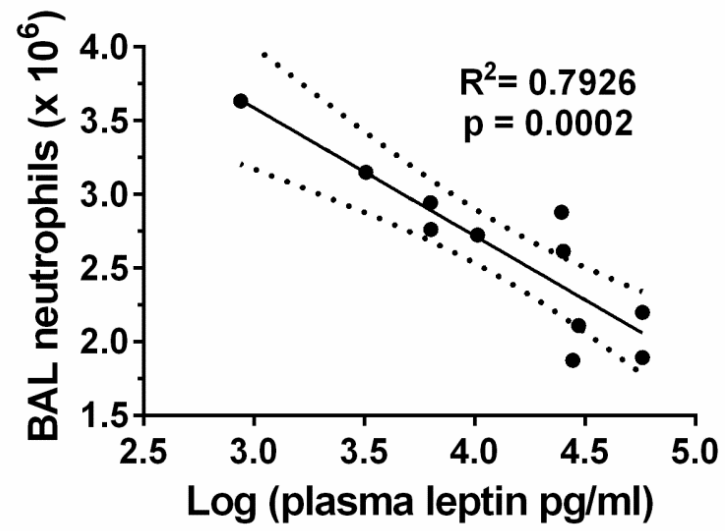




\section{Hyperleptinemia is associated with decreased plasma cytokine levels independent of body weight in both ARDS patients and obese mice following LPS-induced lung injury.}

As in obese patients with ARDS (22), murine obesity is associated with an attenuated release of inflammatory cytokines following LPS-induced acute lung injury (23). To determine whether these relationships might reflect associations between hyperleptinemia and impaired cytokine response, we examined inflammatory cytokine levels in both the ALVEOLI cohort and our murine model of acute of acute lung injury. We found that plasma IL- 6 levels were inversely associated with circulating leptin levels independent of BMI $(P=0.047 ; n=359)$ in the ALVEOLI cohort of ARDS patients, whereas IL-8 levels were not associated $(P=0.499 ; n=362)$. In our obese mouse model of acute lung injury, an inverse association was found between plasma leptin levels and plasma IL-6 levels ( $P=0.01$ ) (Figure 3A), whereas KC (a murine homologue of human IL-8) was not associated $\left(r^{2}=0.0025 ; P=0.88\right)$. Given the changes observed in airspace neutrophil counts in this mouse model following injury, we also examined the neutrophilic cytokine G-CSF, and found it to be inversely associated with plasma leptin levels ( $P=0.04)$ (Figure 3B). However, no association was found between body weight and IL-6 or G-CSF in this model (Figure $3 \mathrm{C}$ and D). These results suggest that obesity-associated hyperleptinemia underlies the previously established associations between obesity and impaired cytokine response following lung injury.
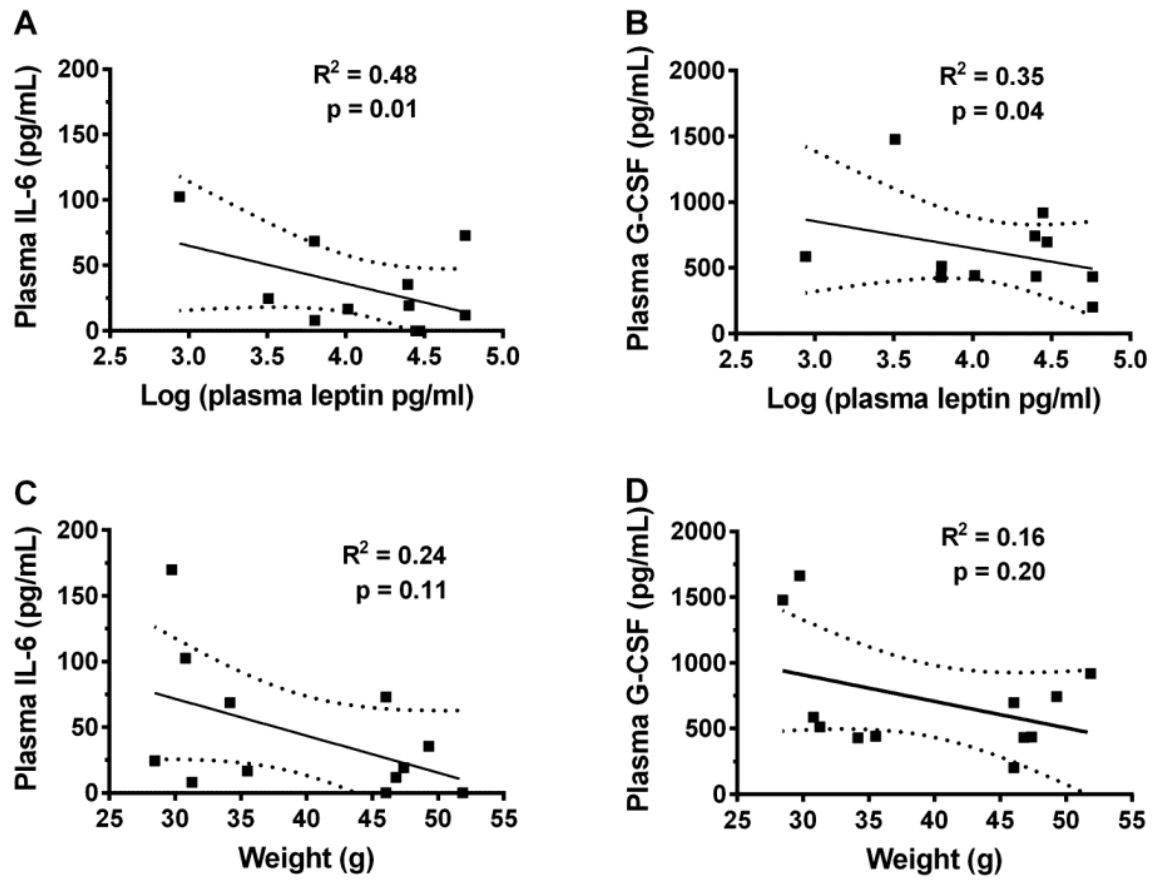
Figure 3 Plasma leptin levels are inversely associated with plasma neutrophilic cytokine levels following LPSinduced lung injury in lean and obese mice. Plasma IL-6 and G-CSF levels were compared with either (A, B) plasma leptin levels or (C, D) body weight at $24 \mathrm{~h}$ after LPS-induced lung injury in diet-induced obese $(60 \%$ fat diet) and lean ( $10 \%$ fat diet) mice by linear regression. Dashed lines indicate $95 \%$ confidence intervals.

\section{A novel mouse model of isolated hyperleptinemia}

To determine whether the association between hyperleptinemia and impaired pulmonary immune response could be causal, we developed a model of induced hyperleptinemia in the absence of obesity and other elements of the metabolic syndrome. In this model, lean mice received daily intraperitoneal injections of PEGylated leptin, at a dose we previously titrated not to alter weight $(2 \mu \mathrm{g})$, or PBS control for 14 days. Although plasma leptin levels were markedly elevated in leptin-treated mice compared to controls $(123.54 \pm 26.69 \mathrm{ng} / \mathrm{ml}$ vs. $5.07 \pm 0.44 \mathrm{ng} / \mathrm{ml}$ at $14 \mathrm{~d} ; P=0.0022)$, similar to those in uninjured obese vs. lean mice $(98.39 \pm 13.52 \mathrm{ng} / \mathrm{ml}$ vs. $23.71 \pm 5.75$ $\mathrm{ng} / \mathrm{ml} ; P=0.0066)$, no differences in mouse body weights nor food consumption were observed between these two groups during or after 14 days of treatment (Figure $4 \mathrm{~A}-\mathrm{C}$ ). Furthermore, both fasting glucose levels and cholesterol levels were decreased in the hyperleptinemic mice at baseline, whereas LDL levels were unchanged compared to control mice (Figure $4 \mathrm{D}-\mathrm{F}$ ), demonstrating that this model of induced hyperleptinemia does not cause glucose intolerance or hypercholesterolemia and may actually enhance metabolic control in these mice. These results are in line with previously published findings with leptin replacement therapy in hypoleptinemic lipodystrophy patients, in which it was demonstrated that administration of leptin not only leads to restoration of leptin levels, but also substantially reduces hyperglycemia and hyperlipidemia in these patients (46). To determine whether this model of lean hyperleptinemia might have a pro-inflammatory effect, we assessed airspace and blood leukocyte counts as well as inflammatory cytokine levels (KC, MCP-1, MIP-2, G-CSF, TNF $\alpha$, IL-1 $\beta$ and IL-6) in uninjured leptin-treated and control mice. No differences were observed in blood or BAL leukocyte counts (Supplemental Figure S1) or cytokine levels (data not shown) between conditions. 
A
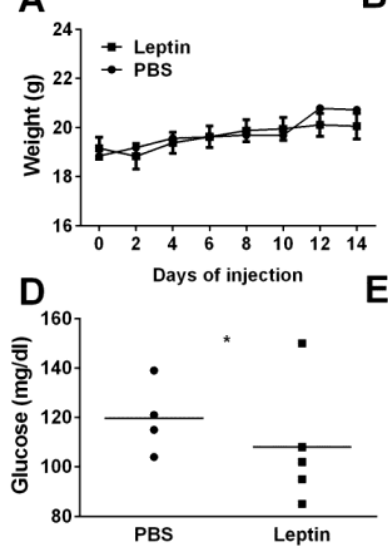

B
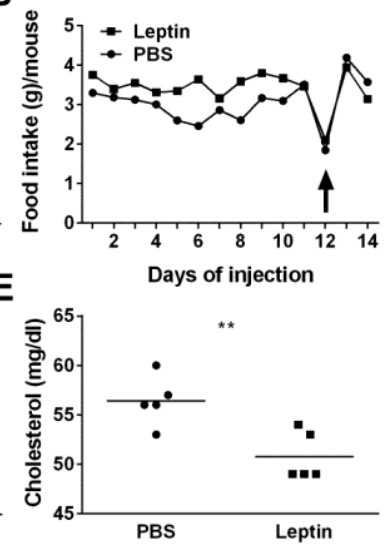

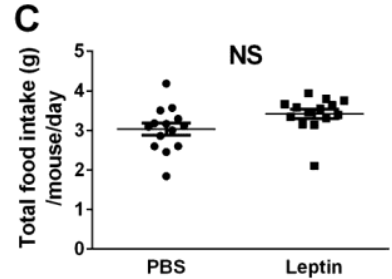

$\mathbf{F}$

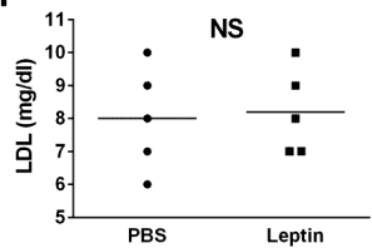

Figure 4 Mouse weight remained unchanged and plasma leptin levels are increased in hyperleptinemic mice at baseline. (A) Body weight and (B) food intake/mouse were monitored for 14 days in HL and control mice. Differences between mouse weights and food intake over time between two groups were analyzed by repeated measures ANOVA. A drop in food intake after overnight fast for blood glucose measurement on day 12 is indicated with a black arrow. (C) Average daily food intake/mouse/day over 14 days was calculated in HL and control mice. (D) Fasting blood glucose levels were measured on day 12. (E) Plasma cholesterol and (F) LDL levels were measured on day 14 . $n=4 / 5$ per group. NS= not significant, $* P \leq 0.05, * * P \leq 0.01$ as determined by an unpaired Student's $t$-test (two-tailed).

\section{Pneumonia severity is increased in mice with isolated hyperleptinemia.}

To further determine whether the association between plasma leptin levels and pneumonia severity in the diet-induced obese mouse model represents causality and not the effects of other obesity-related factors, we next examined $K$. pneumoniae infection in our lean mouse model of hyperleptinemia. Whole lung bacterial CFU were significantly increased in the lungs of hyperleptinemic compared to control mice $48 \mathrm{~h}$ after infection (Figure 5), suggesting that pneumonia severity is increased in this model of lean hyperleptinemia, and recapitulating our findings in obese mice. Interestingly, however, plasma leptin levels were found to be similar between leptin-treated and control mice at the time of euthanasia, $48 \mathrm{~h}$ after the last leptin dose was given $(6.37 \pm 1.89 \mathrm{ng} / \mathrm{ml} \mathrm{vs}$. $10.71 \pm 3.12 \mathrm{ng} / \mathrm{ml}, P=0.2665$ ), suggesting that chronic hyperleptinemia may have a lasting effect on pulmonary host defense, even after circulating leptin levels fall to normal range. 


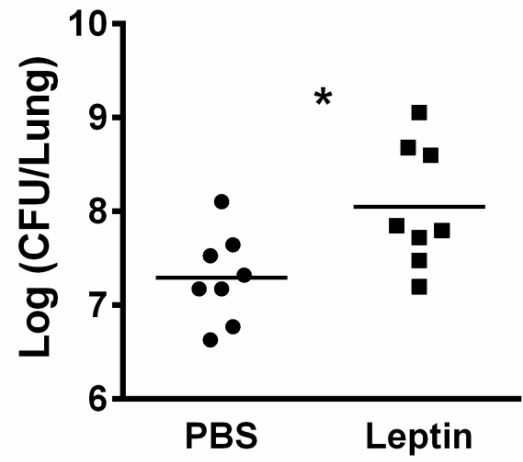

Figure 5 Pneumonia severity is increased in a mouse model of isolated hyperleptinemia. Whole lung $K$. pneumoniae CFU were determined in leptin-treated (2ug i.p. x 14 days) mice compared to i.p. PBS treated controls at $48 \mathrm{~h}$ after $K$. pneumoniae-induced respiratory infection. $\mathrm{n}=8$ per group. $* P \leq$ 0.05 as determined by an unpaired Student's $t$-test (two-tailed).

\section{LPS-induced airspace neutrophilia is attenuated in isolated hyperleptinemia.}

To determine whether the previously described effects of diet-induced obesity on pulmonary neutrophil recruitment and cytokine response seen in our mice might be conferrable by isolated hyperleptinemia, we examined the inflammatory response to inhaled LPS in lean hyperleptinemic mice. BAL neutrophil counts were decreased in hyperleptinemic mice compared to control mice at $24 \mathrm{~h}$ after lung injury (Figure 6A), and linear regression analysis showed a significant inverse correlation between BAL neutrophil counts and plasma leptin levels in these lung-injured mice (Figure 6B). In addition, BAL IL-6 levels were significantly decreased in the hyperleptinemic mice (Supplemental Figure S2). Unfortunately, plasma IL-6 and G-CSF levels were undetectable in both control and hyperleptinemic mice. These results are in line with our observations in the DIO mouse model, suggesting that leptin itself plays an important role in suppressing the pulmonary inflammatory response in the obese state. 


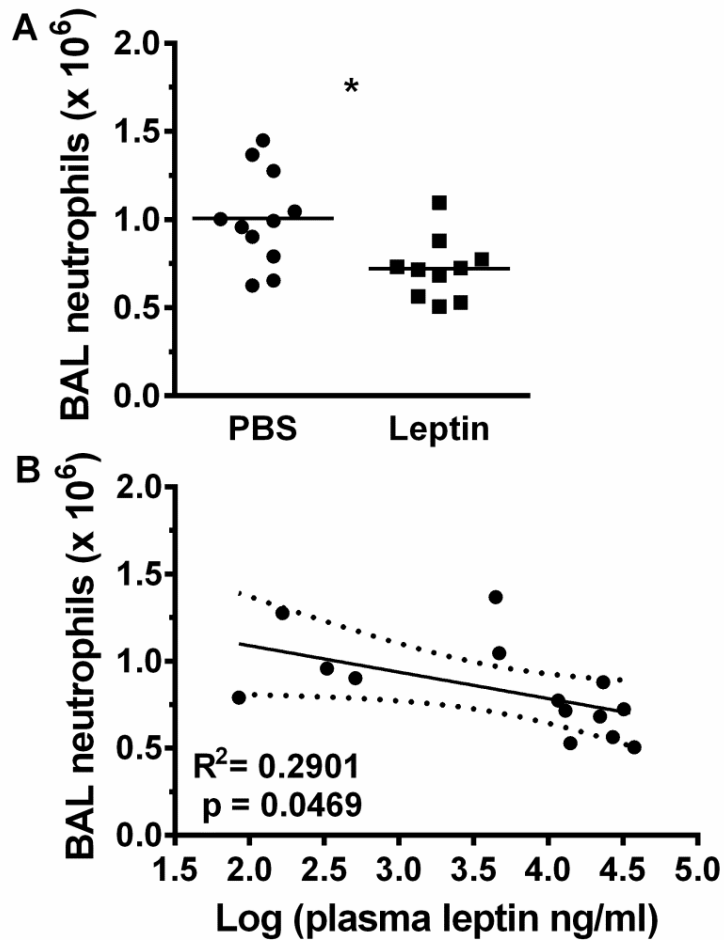

Figure 6 LPS-induced lung injury is attenuated in a mouse model of isolated hyperleptinemia. BAL neutrophil counts ( $n=6$ (control) and $n=8(H L)$ (A) were determined in i.p. leptin treated (14 days) C57BI/6 WT mice compared to i.p. PBS treated controls at $24 \mathrm{~h}$ after LPS-induced lung injury and compared to plasma leptin levels by linear regression ( $n=6$ (control) and $n=8(H L)$ ) (B). Dashed lines indicate 95\% confidence interval. $* * P \leq 0.01$ as determined by an unpaired Student's $t$ test (two-tailed). 


\section{Discussion}

These analyses demonstrate a significant association between elevated circulating plasma leptin levels and increased risk and severity of respiratory infection in humans, independent of BMI and other established risk factors. These findings can be recapitulated in a mouse model of obesity, in which hyperleptinemia is associated with not only impaired pulmonary bacterial clearance, but also suppression of plasma inflammatory cytokines and attenuated pulmonary neutrophilia following LPS-induced inflammation. Finally, using a novel model of induced hyperleptinemia, these hyperleptinemia-associated effects can be replicated in the absence of obesity and other associated metabolic defects in mice.

A recent meta-analysis has confirmed the clinical association between increased BMI and risk of both bacterial and viral pneumonias in humans (11). Studies in murine models of obesity and the metabolic syndrome have also shown that the defense against both bacterial and viral respiratory infections is profoundly attenuated $(47,48)$. Evidence of obesity-associated impairment of the pulmonary innate immune response has recently been demonstrated in the context of acute lung injury as well (49). Although obesity is associated with baseline increases in the same inflammatory cytokines that drive ARDS, counterintuitively, obese patients have better survival from $\operatorname{ARDS}(50,51)$. Although discrete elements of the metabolic syndrome, including both diabetes and hypercholesterolemia, may contribute to obesity's effects on the pulmonary immune response $(47,52)$, human and murine studies controlling for these comorbid conditions show that much of obesity's effects may be independent of the effects of diabetes and hypercholesterolemia $(19,20)$, leaving the underlying mechanisms of this impairment poorly defined.

One of the hallmarks of obesity and the metabolic syndrome is a state of leptinresistance with persistent, markedly increased circulating leptin-levels compared to lean subjects (27). High leptin levels have also been observed in several non-obese conditions, including diabetes, pregnancy, and renal failure $(28,29)$, making hyperleptinemia far more prevalent than obesity. Several studies have shown that leptin-deficient mice have impaired host defenses, and that restoration of leptin levels in these mice can reverse this impaired response, indicating that leptin may be an important mediator of the pulmonary immunity $(47,52)$. However, our data suggest that not only leptin deficiency, but also extremely elevated leptin levels, can impair the pulmonary host defense in both obesity-associated hyperleptinemia as well as in isolated hyperleptinemia.

The effects of increased leptin levels on the immune response appear to be, in part, dependent on the acute or chronic nature of the exposure. In addition to states of chronic hyperleptinemia, such as obesity, leptin may also be elevated as an acute phase reactant (53). Acute in vitro exposure to leptin has been shown to enhance immune cell 
function, such as monocyte and macrophage activation, phagocytosis, and cytokine secretion $(47,54,55)$. Additional work has shown that leptin acts as a neutrophil chemoattractant and an anti-apoptotic $(17,56,57)$, and that not only the presence of leptin, but also intact leptin signaling, is important to maintain pulmonary host defense (17). However, in multiple studies using mouse models of obesity, and thus presumed chronic hyperleptinemia, the obese milieu has a protective and anti-inflammatory effect in induced acute lung injury, leading to an attenuated pulmonary inflammatory response $(23,58)$. Furthermore, in studies of the association between lavage leptin levels in ARDS patients, the associations between high leptin levels and clinical outcomes appear to differ based on the context (59). In non-obese patients (BMI<30), high leptin levels (presumably acute) are associated with poor outcomes, whereas in the obese, high levels (most likely reflecting preceding, baseline hyperleptinemia) have no such association.

The attenuated inflammatory response that we report in both human ARDS patients and murine models of lung injury with hyperleptinemia suggests that such defects underlie the demonstrated associations between high leptin levels and risk for and severity of pulmonary infections. Such associations have not previously been described and appear to be independent of comorbid conditions such as obesity and the metabolic syndrome, given our ability to recapitulate our findings in obese mice using a lean model of hyperleptinemia.

Potential mechanisms underlying the associations between hyperleptinemia and blunted pulmonary immune response remain unclear. We have previously reported that obese ARDS patients have lower plasma levels of both IL-6 and IL-8 compared to lean patients with ARDS (22), and our current study demonstrates that such associations likely reflect the presence of obesity-associated hyperleptinemia in these patients, not obesity itself or other elements of the metabolic syndrome. This suggests that the hyperleptinemic state may underlie the impaired inflammatory response. Such an inverse association between leptin and IL-6 has been previously demonstrated in patients with sepsis (60), and we describe similar effects in our mouse models of obesity and LPS-induced lung injury, in which not only circulating leptin levels were inversely associated with plasma IL-6 levels independent of weight, but also with plasma G-CSF and airspace neutrophil levels as well. These results suggest for the first time that the impaired inflammatory response seen in obese ARDS patients and obese mouse models of lung injury is driven, at least in part, by the effects of obesity-associated hyperleptinemia, and further, that these effects may increase the susceptibility to and severity of pulmonary infection in the general population.

There are potential limitations of our approach worth noting. Although standard for a large cohort health survey study, NHANES III relied on self-reported incidents of respiratory infection, which may introduce some inaccuracy to the dataset. Despite this potential limitation, we found expected associations for previously reported risk factors of respiratory infection (e.g. smoking), suggesting that the cohort is sufficiently robust 
for such analyses. Both the NHANES and ALVEOLI study cohorts are historic datasets (enrolled 1988-1994 and 1999-2002) and are thus likely to underrepresent obesity in the general population and the ICU respectively compared to its contemporary incidence in the US. Although we have worked to exclude other, confounding effects of leptin treatment that might account for the witnessed impairment of pulmonary immune response in our animal model of lean hyperleptinemia, it remains possible that such an indirect mechanism is present. Given the concordance of our findings across both observational human studies and obese mouse models, however, it appears less likely that such an effect could account for our findings.

In summary, the data presented provide evidence that the observed effects of obesity on respiratory infection might be attributable to increased systemic leptin levels independent of other metabolic and mechanical factors. The finding that obesityassociated hyperleptinemia, and not body mass per se, is an important factor in maintenance of pulmonary host defenses is a critical step towards understanding the complex mechanisms underlying increased susceptibility to and mortality from respiratory infections in the obese and other hyperleptinemic populations.

\section{Acknowledgements}

This work was supported, in part, by grants from the Weijerhorst Foundation (NDJU), an ERS Advanced Grant (№340941) (JT), and K23 HL105654 (RDS), R01 Al103003 (MJW), R01 HL107291 (MEP, BTS), P20 GM103496 (MEP, BTS), and R01 HL084200 (BTS) from the National Institutes of Health. Samples from the ALVEOLI trial were provided by the NHLBI Acute Respiratory Distress Syndrome Network. 


\section{References}

1. Prevention, C.f.D.C.a. 2013. Deaths: Final Data for 2010

2. Broulette, J., Yu, H., Pyenson, B., Iwasaki, K., and Sato, R. 2013. The incidence rate and economic burden of community-acquired pneumonia in a working-age population. American health \& drug benefits 6:494-503.

3. Armstrong, G.L., Conn, L.A., and Pinner, R.W. 1999. Trends in infectious disease mortality in the United States during the 20th century. JAMA : the journal of the American Medical Association 281:61-66.

4. Almirall, J., Bolibar, I., Serra-Prat, M., Roig, J., Hospital, I., Carandell, E., Agusti, M., Ayuso, P., Estela, A., and Torres, A. 2008. New evidence of risk factors for community-acquired pneumonia: a population-based study. The European respiratory journal 31:1274-1284.

5. Fine, M.J., Smith, M.A., Carson, C.A., Mutha, S.S., Sankey, S.S., Weissfeld, L.A., and Kapoor, W.N. 1996. Prognosis and outcomes of patients with community-acquired pneumonia. A meta-analysis. JAMA : the journal of the American Medical Association 275:134-141.

6. Mertz, D., Kim, T.H., Johnstone, J., Lam, P.P., Science, M., Kuster, S.P., Fadel, S.A., Tran, D., Fernandez, E., Bhatnagar, N., et al. 2013. Populations at risk for severe or complicated influenza illness: systematic review and meta-analysis. BMJ 347:f5061.

7. Almirall, J., Gonzalez, C.A., Balanzo, X., and Bolibar, I. 1999. Proportion of community-acquired pneumonia cases attributable to tobacco smoking. Chest 116:375-379.

8. Baik, I., Curhan, G.C., Rimm, E.B., Bendich, A., Willett, W.C., and Fawzi, W.W. 2000. A prospective study of age and lifestyle factors in relation to community-acquired pneumonia in US men and women. Arch Intern Med 160:3082-3088.

9. Samokhvalov, A.V., Irving, H.M., and Rehm, J. 2010. Alcohol consumption as a risk factor for pneumonia: a systematic review and meta-analysis. Epidemiology and infection 138:1789-1795.

10. Fezeu, L., Julia, C., Henegar, A., Bitu, J., Hu, F.B., Grobbee, D.E., Kengne, A.P., Hercberg, S., and Czernichow, S. 2011. Obesity is associated with higher risk of intensive care unit admission and death in influenza A (H1N1) patients: a systematic review and meta-analysis. Obesity reviews : an official journal of the International Association for the Study of Obesity 12:653-659.

11. Phung, D.T., Wang, Z., Rutherford, S., Huang, C., and Chu, C. 2013. Body mass index and risk of pneumonia: a systematic review and meta-analysis. Obesity reviews : an official journal of the International Association for the Study of Obesity 14:839-857.

12. Corrales-Medina, V.F., Valayam, J., Serpa, J.A., Rueda, A.M., and Musher, D.M. 2011. The obesity paradox in community-acquired bacterial pneumonia. Int J Infect Dis 15:e54-57.

13. Singanayagam, A., Singanayagam, A., and Chalmers, J.D. 2013. Obesity is associated with improved survival in community-acquired pneumonia. Eur Respir J 42:180-187.

14. Easterbrook, J.D., Dunfee, R.L., Schwartzman, L.M., Jagger, B.W., Sandouk, A., Kash, J.C., Memoli, M.J., and Taubenberger, J.K. 2011. Obese mice have increased morbidity and mortality compared to non-obese mice during infection with the 2009 pandemic H1N1 influenza virus. Influenza Other Respir Viruses 5:418-425.

15. Smith, A.G., Sheridan, P.A., Harp, J.B., and Beck, M.A. 2007. Diet-induced obese mice have increased mortality and altered immune responses when infected with influenza virus. The Journal of nutrition 137:1236-1243.

16. Conge, G.A., Gouache, P., Joyeux, Y., Goichot, J., and Fournier, J.M. 1988. [Influence of different types of experimental obesity on resistance of the mouse to infection by Salmonella typhimurium and Klebsiella pneumoniae]. Ann Nutr Metab 32:113-120.

17. Ubags, N.D., Vernooy, J.H., Burg, E., Hayes, C., Bement, J., Dilli, E., Zabeau, L., Abraham, E., Poch, K.R., Nick, J.A., et al. 2014. The role of leptin in the development of pulmonary neutrophilia in infection and acute lung injury. Crit Care Med 42:e143-151.

18. Karlsson, E.A., Sheridan, P.A., and Beck, M.A. 2010. Diet-induced obesity in mice reduces the maintenance of influenza-specific CD8+ memory T cells. J Nutr 140:1691-1697.

19. Karlsson, E.A., Sheridan, P.A., and Beck, M.A. 2010. Diet-induced obesity impairs the T cell memory response to influenza virus infection. J Immunol 184:3127-3133. 
20. Paich, H.A., Sheridan, P.A., Handy, J., Karlsson, E.A., Schultz-Cherry, S., Hudgens, M.G., Noah, T.L., Weir, S.S., and Beck, M.A. 2013. Overweight and obese adult humans have a defective cellular immune response to pandemic H1N1 influenza A virus. Obesity (Silver Spring) 21:2377-2386.

21. Smith, A.G., Sheridan, P.A., Tseng, R.J., Sheridan, J.F., and Beck, M.A. 2009. Selective impairment in dendritic cell function and altered antigen-specific $C D 8+T$-cell responses in diet-induced obese mice infected with influenza virus. Immunology 126:268-279.

22. Stapleton, R.D., Dixon, A.E., Parsons, P.E., Ware, L.B., Suratt, B.T., and Network, N.A.R.D.S. 2010. The association between $\mathrm{BMI}$ and plasma cytokine levels in patients with acute lung injury. Chest 138:568-577.

23. Kordonowy, L.L., Burg, E., Lenox, C.C., Gauthier, L.M., Petty, J.M., Antkowiak, M., Palvinskaya, T., Ubags, N., Rincon, M., Dixon, A.E., et al. 2012. Obesity is associated with neutrophil dysfunction and attenuation of murine acute lung injury. Am J Respir Cell Mol Biol 47:120-127.

24. Park, H.S., Park, J.Y., and Yu, R. 2005. Relationship of obesity and visceral adiposity with serum concentrations of CRP, TNF-alpha and IL-6. Diabetes research and clinical practice 69:29-35.

25. Reddy, R.C., Chen, G.H., Tekchandani, P.K., and Standiford, T.J. 2001. Sepsis-induced immunosuppression: from bad to worse. Immunologic research 24:273-287.

26. Sideleva, O., Suratt, B.T., Black, K.E., Tharp, W.G., Pratley, R.E., Forgione, P., Dienz, O., Irvin, C.G., and Dixon, A.E. 2012. Obesity and asthma: an inflammatory disease of adipose tissue not the airway. American journal of respiratory and critical care medicine 186:598-605.

27. Sinha, M.K., Opentanova, I., Ohannesian, J.P., Kolaczynski, J.W., Heiman, M.L., Hale, J., Becker, G.W., Bowsher, R.R., Stephens, T.W., and Caro, J.F. 1996. Evidence of free and bound leptin in human circulation. Studies in lean and obese subjects and during short-term fasting. The Journal of clinical investigation 98:1277-1282.

28. Valdez, R., Narayan, K.M., Geiss, L.S., and Engelgau, M.M. 1999. Impact of diabetes mellitus on mortality associated with pneumonia and influenza among non-Hispanic black and white US adults. American journal of public health 89:1715-1721.

29. Sarnak, M.J., and Jaber, B.L. 2001. Pulmonary infectious mortality among patients with end-stage renal disease. Chest 120:1883-1887.

30. Abate, N., Chandalia, M., Snell, P.G., and Grundy, S.M. 2004. Adipose tissue metabolites and insulin resistance in nondiabetic Asian Indian men. The Journal of clinical endocrinology and metabolism 89:2750-2755.

31. Castellano Filho, D.S., do Amaral Correa, J.O., Dos Santos Ramos, P., de Oliveira Montessi, M., Aarestrup, B.J., and Aarestrup, F.M. 2013. Body weight gain and serum leptin levels of nonoverweight and overweight/obese pregnant women. Medical science monitor : international medical journal of experimental and clinical research 19:1043-1049.

32. Huang, K.C., Lin, R.C., Kormas, N., Lee, L.T., Chen, C.Y., Gill, T.P., and Caterson, I.D. 2004. Plasma leptin is associated with insulin resistance independent of age, body mass index, fat mass, lipids, and pubertal development in nondiabetic adolescents. International journal of obesity and related metabolic disorders : journal of the International Association for the Study of Obesity 28:470-475.

33. Menon, V., Wang, X., Greene, T., Beck, G.J., Kusek, J.W., Marcovina, S.M., Levey, A.S., and Sarnak, M.J. 2004. Factors associated with serum leptin in patients with chronic kidney disease. Clinical nephrology 61:163-169.

34. Molvarec, A., Szarka, A., Walentin, S., Beko, G., Karadi, I., Prohaszka, Z., and Rigo, J., Jr. 2011. Serum leptin levels in relation to circulating cytokines, chemokines, adhesion molecules and angiogenic factors in normal pregnancy and preeclampsia. Reproductive biology and endocrinology : RB\&E 9:124.

35. Nordfors, L., Lonnqvist, F., Heimburger, O., Danielsson, A., Schalling, M., and Stenvinkel, P. 1998. Low leptin gene expression and hyperleptinemia in chronic renal failure. Kidney international 54:1267-1275.

36. Schubring, C., Englaro, P., Siebler, T., Blum, W.F., Demirakca, T., Kratzsch, J., and Kiess, W. 1998. Longitudinal analysis of maternal serum leptin levels during pregnancy, at birth and up to six weeks after birth: relation to body mass index, skinfolds, sex steroids and umbilical cord blood leptin levels. Hormone research 50:276-283.

37. Silha, J.V., Krsek, M., Skrha, J.V., Sucharda, P., Nyomba, B.L., and Murphy, L.J. 2003. Plasma resistin, adiponectin and leptin levels in lean and obese subjects: correlations with insulin resistance. European journal of endocrinology / European Federation of Endocrine Societies 149:331-335. 
38. Beberashvili, I., Sinuani, I., Azar, A., Yasur, H., Feldman, L., Averbukh, Z., and Weissgarten, J. 2011. Longitudinal study of leptin levels in chronic hemodialysis patients. Nutrition journal 10:68.

39. Brower, R.G., Lanken, P.N., Maclntyre, N., Matthay, M.A., Morris, A., Ancukiewicz, M., Schoenfeld, D., Thompson, B.T., National Heart, L., and Blood Institute, A.C.T.N. 2004. Higher versus lower positive end-expiratory pressures in patients with the acute respiratory distress syndrome. $\mathrm{N} \mathrm{Engl} \mathrm{J}$ Med 351:327-336.

40. Bernard, G.R., Artigas, A., Brigham, K.L., Carlet, J., Falke, K., Hudson, L., Lamy, M., Legall, J.R., Morris, A., and Spragg, R. 1994. The American-European Consensus Conference on ARDS. Definitions, mechanisms, relevant outcomes, and clinical trial coordination. Am J Respir Crit Care Med 149:818824.

41. Eisner, M.D., Thompson, T., Hudson, L.D., Luce, J.M., Hayden, D., Schoenfeld, D., Matthay, M.A., and Acute Respiratory Distress Syndrome, N. 2001. Efficacy of low tidal volume ventilation in patients with different clinical risk factors for acute lung injury and the acute respiratory distress syndrome. Am J Respir Crit Care Med 164:231-236.

42. Vernooy, J.H., Bracke, K.R., Drummen, N.E., Pauwels, N.S., Zabeau, L., van Suylen, R.J., Tavernier, J., Joos, G.F., Wouters, E.F., and Brusselle, G.G. 2010. Leptin modulates innate and adaptive immune cell recruitment after cigarette smoke exposure in mice. J Immunol 184:7169-7177.

43. Wargo, M.J., Gross, M.J., Rajamani, S., Allard, J.L., Lundblad, L.K., Allen, G.B., Vasil, M.L., Leclair, L.W., and Hogan, D.A. 2011. Hemolytic phospholipase C inhibition protects lung function during Pseudomonas aeruginosa infection. Am J Respir Crit Care Med 184:345-354.

44. Palvinskaya, T., Antkowiak, M., Burg, E., Lenox, C.C., Ubags, N., Cramer, A., Rincon, M., Dixon, A.E., Fessler, M.B., Poynter, M.E., et al. 2013. Effects of acute and chronic low density lipoprotein exposure on neutrophil function. Pulm Pharmacol Ther 26:405-411.

45. Almirall, J., Bolibar, I., Balanzo, X., and Gonzalez, C.A. 1999. Risk factors for community-acquired pneumonia in adults: a population-based case-control study. Eur Respir J 13:349-355.

46. Oral, E.A., Simha, V., Ruiz, E., Andewelt, A., Premkumar, A., Snell, P., Wagner, A.J., DePaoli, A.M., Reitman, M.L., Taylor, S.I., et al. 2002. Leptin-replacement therapy for lipodystrophy. N Engl J Med 346:570-578.

47. Mancuso, P., Gottschalk, A., Phare, S.M., Peters-Golden, M., Lukacs, N.W., and Huffnagle, G.B. 2002. Leptin-deficient mice exhibit impaired host defense in Gram-negative pneumonia. J Immunol 168:4018-4024.

48. Milner, J.J., Sheridan, P.A., Karlsson, E.A., Schultz-Cherry, S., Shi, Q., and Beck, M.A. 2013. Dietinduced obese mice exhibit altered heterologous immunity during a secondary 2009 pandemic H1N1 infection. J Immunol 191:2474-2485.

49. Stapleton, R.D., and Suratt, B.T. 2014. Obesity and nutrition in acute respiratory distress syndrome. Clin Chest Med 35:655-671.

50. Gong, M.N., Bajwa, E.K., Thompson, B.T., and Christiani, D.C. 2010. Body mass index is associated with the development of acute respiratory distress syndrome. Thorax 65:44-50.

51. Martino, J.L., Stapleton, R.D., Wang, M., Day, A.G., Cahill, N.E., Dixon, A.E., Suratt, B.T., and Heyland, D.K. 2011. Extreme obesity and outcomes in critically ill patients. Chest 140:1198-1206.

52. Hsu, A., Aronoff, D.M., Phipps, J., Goel, D., and Mancuso, P. 2007. Leptin improves pulmonary bacterial clearance and survival in ob/ob mice during pneumococcal pneumonia. Clinical and experimental immunology 150:332-339.

53. La Cava, A., and Matarese, G. 2004. The weight of leptin in immunity. Nat Rev Immunol 4:371-379.

54. Dixit, V.D., Mielenz, M., Taub, D.D., and Parvizi, N. 2003. Leptin induces growth hormone secretion from peripheral blood mononuclear cells via a protein kinase $C$ - and nitric oxide-dependent mechanism. Endocrinology 144:5595-5603.

55. Zarkesh-Esfahani, H., Pockley, G., Metcalfe, R.A., Bidlingmaier, M., Wu, Z., Ajami, A., Weetman, A.P., Strasburger, C.J., and Ross, R.J. 2001. High-dose leptin activates human leukocytes via receptor expression on monocytes. J Immunol 167:4593-4599.

56. Caldefie-Chezet, F., Poulin, A., and Vasson, M.P. 2003. Leptin regulates functional capacities of polymorphonuclear neutrophils. Free Radic Res 37:809-814.

57. Bruno, A., Conus, S., Schmid, I., and Simon, H.U. 2005. Apoptotic pathways are inhibited by leptin receptor activation in neutrophils. J Immunol 174:8090-8096. 
58. Bellmeyer, A., Martino, J.M., Chandel, N.S., Scott Budinger, G.R., Dean, D.A., and Mutlu, G.M. 2007. Leptin resistance protects mice from hyperoxia-induced acute lung injury. Am J Respir Crit Care Med 175:587-594.

59. Jain, M., Budinger, G.R., Lo, A., Urich, D., Rivera, S.E., Ghosh, A.K., Gonzalez, A., Chiarella, S.E., Marks, K., Donnelly, H.K., et al. 2011. Leptin promotes fibroproliferative acute respiratory distress syndrome by inhibiting peroxisome proliferator-activated receptor-gamma. Am J Respir Crit Care Med 183:1490-1498.

60. Torpy, D.J., Bornstein, S.R., and Chrousos, G.P. 1998. Leptin and interleukin-6 in sepsis. Horm Metab Res 30:726-729. 


\section{CHAPTER 8S}

\section{Hyperleptinemia Impairs Pulmonary Host \\ Defense}

Supplement 


\section{Figures}

Table S1 The annual risk for urinary tract infection is significantly correlated with serum leptin level, gender and diabetic status. 6,415 subjects from NHANES III. $P \leq 0.05$ is considered significant.

\begin{tabular}{|c|c|c|c|}
\hline Urinary tract infection $(n=520)$ & $\begin{array}{l}\text { Odds } \\
\text { Ratio }\end{array}$ & $95 \% \mathrm{Cl}$ & $P$ \\
\hline \multicolumn{4}{|l|}{ Univariate Analysis } \\
\hline Leptin (ng/ml) & 1.028 & {$[1.017,1.039]$} & $<0.0001^{* * *}$ \\
\hline Age (years) & 0.994 & {$[0.984,1.005]$} & 0.26 \\
\hline Gender & 0.178 & {$[0.136,0.232]$} & $<0.0001^{* * *}$ \\
\hline White Race & 0.863 & {$[0.642,1.161]$} & 0.32 \\
\hline Education (0-17 years of school) & 0.933 & {$[0.900,0.964]$} & $0.0001 * * *$ \\
\hline Income $<\$ 20,000$ & 1.370 & {$[1.063,1.764]$} & 0.016 * \\
\hline Married (or living as married) & 1.113 & {$[0.860,1.440]$} & 0.41 \\
\hline Body Mass Index $\left(\mathrm{kg} / \mathrm{m}^{2}\right)$ & 0.996 & {$[0.963,1.030]$} & 0.81 \\
\hline Current Smoker & 1.111 & {$[0.804,1.535]$} & 0.52 \\
\hline Diabetes Mellitus & 1.569 & {$[1.019,2.415]$} & 0.041 \\
\hline Glycated Hgb A1C (\%) & 0.961 & {$[0.771,1.199]$} & 0.72 \\
\hline Creatinine clearance $\left(\mathrm{ml} / \mathrm{min} / 1.74 \mathrm{~m}^{2}\right)$ & 1.004 & {$[0.995,1.012]$} & 0.29 \\
\hline Used non-steroidal anti-inflammatory in last month & 1.007 & {$[0.798,1.271]$} & 0.95 \\
\hline \multicolumn{4}{|l|}{ Multivariate Analysis } \\
\hline Leptin (ng/ml) & 1.003 & {$[0.991,1.015]$} & 0.63 \\
\hline Male & 0.184 & {$[0.135,0.252]$} & $<0.0001^{\star * *}$ \\
\hline Education (0-17 years of school) & 0.941 & {$[0.906,0.977]$} & $0.0023 * *$ \\
\hline Income $<\$ 20,000$ & 1.045 & {$[0.795,1.374]$} & 0.75 \\
\hline Diabetes Mellitus & 1.467 & {$[0.943,2.284]$} & 0.088 \\
\hline
\end{tabular}


A

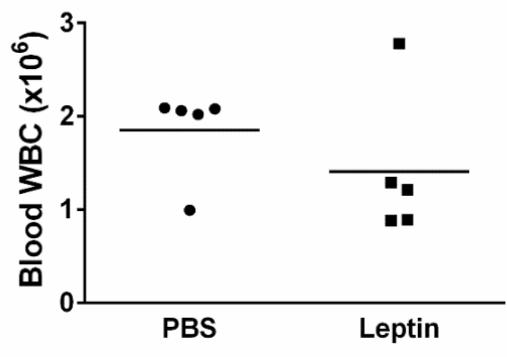

C

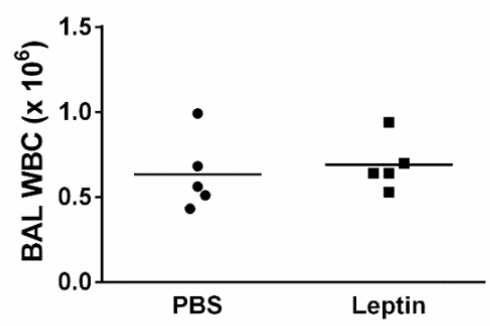

B

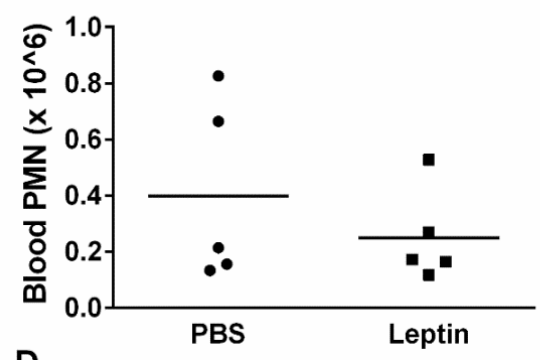

D

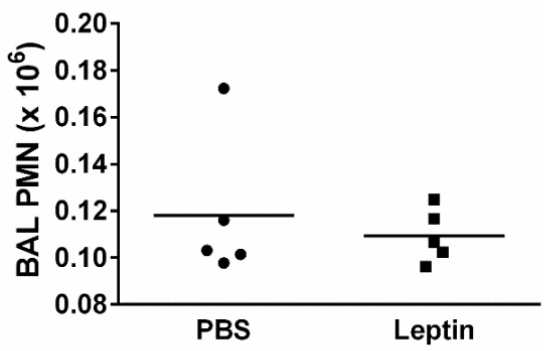

Figure S1. Total and neutrophil cell counts in blood and BAL remain unchanged in hyperleptinemic mice. Baseline blood and BAL total cell counts (A, C) and neutrophil counts (B, D) were determined after 14 days of pbs or leptin $(2 \mu \mathrm{g})$ i.p. injections. $n=5$ per group.

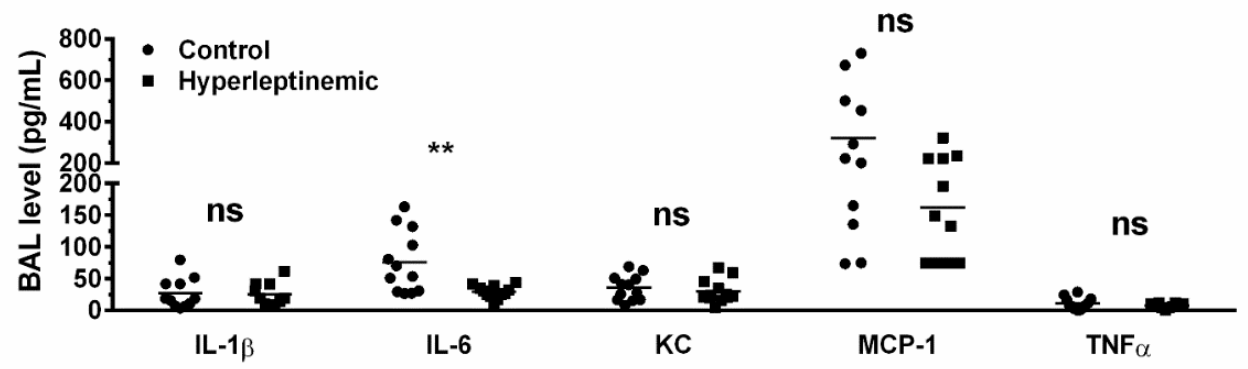

Figure S2. BAL cytokines tend to be lower in hyperleptinemic mice following LPS exposure. BAL cytokine levels were determined at $24 \mathrm{~h}$ after LPS exposure in mice that received PBS or leptin $(2 \mu \mathrm{g})$ i.p. injections for 14 days. $\mathrm{n}=11$ per group. ${ }^{* *} P \leq 0.01$ as determined by an unpaired Student's $t$-test (two-tailed). 



\section{CHAPTER 9}

General Discussion and Future Perspectives 
Host defense includes both physical barriers and the immune system, and is the body's natural protection system which guards against infection. Although appropriate immune responses to infection, persistent and exuberant immune responses may lead to progressive lung injury and the Acute Respiratory Distress Syndrome (ARDS). Obesity is associated with increased risk for the development of respiratory infections, and yet appears to have opposing effects on ARDS risk and severity $(1,2)$. It has been demonstrated that subjects with high Body Mass Index (BMI) are more likely to develop ARDS, whereas high BMI in patients with established ARDS is associated with decreasing mortality (1) and attenuated inflammatory response in such patients (3). However, the extent to which obesity-associated alterations in the immune response may contribute to these paradoxically effects remain unclear. The studies presented in this dissertation contribute to our understanding of obesity's effects on the innate immune response in the lung, and shed light on the effects of obesity-associated factors, such as dysregulation of the adipokine leptin, on pulmonary host defense and the pathogenesis of respiratory infections and ARDS.

\section{Obesity: From Metabolic Fitness to Metabolic Illness}

Obesity is the primary risk factor for the metabolic syndrome, which is a cluster of conditions including hypertension, glucose intolerance, excess visceral adipose tissue, and hypercholesterolemia. The metabolic syndrome is an important risk factor for cardiovascular disease and diabetes $(4,5)$. Over the past 20 years, a sub-population of obese individuals has been described who are thought to exhibit metabolically healthy obesity (MHO), which is an obese phenotype (BMI $30-35 \mathrm{~kg} / \mathrm{m}^{2}$ ) free of any metabolic abnormalities (6). However, no unique criteria have been set to define $\mathrm{MHO}$, and therefore the implications of this obese phenotype are still under debate. It has been suggested that $\mathrm{MHO}$ may represent an intermediate, rather than a permanent obesity sub-phenotype, since the diagnosis of $\mathrm{MHO}$ at one time-point does not always translate into a life-long reduced cardio-metabolic risk, although maintained $\mathrm{MHO}$ is clearly beneficial in terms of cardiovascular risk $(7,8)$. However, the biology behind the transition from metabolic fitness to metabolic illness in obese subjects remains underinvestigated. This concept may contribute to further grasp the variability in immune dysregulation and impaired host defense seen in diverse obese populations.

The plasticity of adipose tissue, which allows for the storage of excess calories in the form of fat accumulation in obese individuals, may be the primary factor that discriminates healthy obesity from unhealthy obesity. In addition, gene-environment interactions likely also contribute to the development of $\mathrm{MHO}$. Genes account for a large part of the observed variability of fat mass, fat distribution, and the number of adipocytes within individuals (9). By using BMI classification as an indicator of obesity and the risk of presenting complications, we rely on the assumption that adipose tissue 
is distributed evenly over the body in each individual. However, it has become evident that it is important to consider regional fat distribution in assigning the risk for complications, as for example visceral adipose tissue is more closely related to metabolic complications of obesity and produces more pro-inflammatory mediators than subcutaneous adipose tissue $(10,11)$. Furthermore, in obesity, adipocytes become hypertrophic and exhibit modified metabolic properties such as insulin resistance and increased adipokine secretion, and a strong correlation that has been observed between adipocyte dysfunction and systemic cholesterol imbalance.

In Chapter 3 and Chapter 4 the differences in pulmonary host defense between commonly used mouse models of obesity were highlighted. Although the differences in body weight were similar between lean and obese mice $(>20 \mathrm{~g})$ from all four models, variability was observed in lung bacterial burden following $K$. pneumoniae infection, as well as the extent to which neutrophil function was impaired across the models. The observed variability within the different mouse models may be, in part, due to the age at which the onset of obesity occurs. Furthermore, since three out of four models used were obese mutant mice, differences in their genetic environment should be taken into account. Ob/ob mice (12) are leptin-deficient and leptin has been shown to play an important role in postnatal development of the lung, as lung volume and alveolar surface area are lower in obese ob/ob mice compared to wild-type littermates, and leptin replacement ameliorates these defects (13). Myelopoiesis and lymphopoiesis are decreased in ob/ob mice (14), suggesting that leptin is an important mediator of immune cell development. Mice lacking the long isoform of the leptin receptor (ObRb) ( $d b / d b$ mice) are hyperleptinemic and lack leptin signaling in cells which primarily express ObRb (15). In addition, db/db mice develop diabetes at an early age. Another model of obesity, the $\mathrm{CPE}^{\text {fat/fat }}$ mouse, has a point-mutation in carboxypeptidase $\mathrm{E}$ leading to inactivation of this gene and consequent failure to activate peptide-hormones such as $\alpha$-melanocytestimulating hormone $(\alpha M S H)$, which impairs satiety signaling (16). Aspects of the metabolic syndrome, including dysregulation of glucose, lipid, and adipokine levels, differ between the models, which may contribute to the variability of their effects on the immune response and host defense. Diabetes and hyperglycemia are suggested to be associated with increased risk for and severity of infection $(17,18)$, which is in line with our results in the $\mathrm{db} / \mathrm{db}$ model. Furthermore, dyslipidemia has been demonstrated to impair neutrophil function $(19,20)$, and the varying levels of cholesterol in our models may begin to explain why neutrophil function is variably impaired when comparing these four different models. These results are in line with the concept of 'metabolically healthy obesity', where obesity is not always accompanied by the metabolic syndrome.

To our knowledge, no studies have been performed looking at the effects of MHO on susceptibility to and outcome of infections thus far. In our analyses of the NHANES database in Chapter 8, we noted that although BMI was found to correlate with risk of infection in univariate logistic regression, other metabolic variables, such as diabetic status and lipid profile, which have previously been associated with increased risk for 
and severity of infection, were not associated in these analyses. Furthermore, the association of BMI itself disappears when considering other factors associated with the metabolic syndrome, such as hyperleptinemia. The NHANES study cohort used was a historic dataset (enrolled between 1988 and 1994) and is thus likely to underrepresent obesity in the general population compared to its contemporary incidence in the US.

\section{Obesity Modulates the Pulmonary Inflammatory Response}

A continuous positive caloric intake leads to obesity. As mentioned previously, a focus on BMI to define obesity as a disease is inadequate since body composition, and in particular regional fat distribution, differs between individuals. Several studies suggest that evaluation of the pathogenic potential of excessive body fat is a more informative approach to use in obesity research. 'Adiposopathy' (or sick fat disease) is the term used to describe the adverse anatomical and pathophysiological effects on adipose tissue that accompany the inflammatory and metabolic consequences of obesity (21). Excessive caloric intake leads to adipocyte hypertrophy as well as the recruitment, proliferation and differentiation of additional adipocytes to store energy in the form of fat. If excessive enlargement of fat cells occurs, then derangement of adipocytes and adipose tissue metabolic and immune responses may lead to metabolic disease $(22,23)$. In addition, visceral adipose tissue deposition and impaired crosstalk of adipose tissue with other organ systems may contribute to pathogenic, endocrinologic, and immune responses that contribute to metabolic disease (22). To summarize, weight gain in the form of increased adipose tissue leading to metabolic disease is dependent on how the fat is stored (adipocyte hypertrophy vs. adipocyte proliferation), where the fat is stored (visceral vs. subcutaneous), and adipose tissue signaling and interactions with other organs.

Adipose tissue consists not only of adipocytes but also of infiltrating macrophages that produce a variety of mediators, including cytokines, which are thought to contribute to many of the metabolic consequences of obesity (24). These cytokines include many of the same pro-inflammatory mediators associated with worse outcomes in ARDS patients, such as IL- 6 and IL- 8 , and are believed to partially drive ARDS pathogenesis. High BMI has been associated with decreased levels these same cytokines in patients with ARDS, suggesting that obese patients may have an attenuated inflammatory response in the setting of ARDS (3). It has been shown that increasing BMI is associated with higher risk for the development of ARDS, and longer length of stay but improved survival from ARDS (1). The observed increased susceptibility to develop ARDS may be, in part, explained by the mild elevations in baseline systemic pro-inflammatory cytokine levels observed in healthy obese subjects. However, in Chapter 5, we describe increased baseline activation of alveolar macrophages from obese mice, leading to a pro-inflammatory lung environment. The proposed mechanisms underlying the increased susceptibility to ARDS 
and infection in the obese is that obesity-associated low-grade systemic inflammation at baseline activates alveolar macrophages, which than drives the release of airspace MCP1 levels (which were found to be increased at baseline) and consequently leads to recruitment and differentiation of blood monocytes into alveolar macrophages. Furthermore, in Chapter $\mathbf{3}$ and Chapter $\mathbf{4}$ we observed an attenuation of the pulmonary inflammatory response following established ARDS in our models of obese ARDS, and this may be due to a dysfunctional neutrophil response. In addition, the alveolar macrophages of obese mice appear to make an early transition to a more antiinflammatory phenotype during the inflammatory response to injury (Chapter 5), and may enhance clearance of apoptotic neutrophils in the airspace. Together, these findings suggest that obese mice are more susceptible to the onset of ARDS, but appear to dampen pulmonary inflammation during ARDS progression. These observations may begin to explain some of the witnessed paradoxical effects of obesity on ARDS.

\section{Leptin and Leptin Signaling}

Obesity is associated with adipokine dysregulation, and studies identifying a role for the adipokine leptin in a variety of diseases emphasize the importance of leptin as a key mediator which participates in many physiological processes, but may also contribute to the pathogenesis of ARDS and respiratory infections. Yet, many pieces of the pathogenic puzzle linking leptin to the development and progression of disease are missing, and thus further research is needed.

Initially described as a satiety hormone, leptin has been shown to influence basal metabolism, angiogenesis, thermogenesis, reproduction and hematopoiesis. In addition, leptin also plays an important role in the regulation of the innate and adaptive immune response. The mechanisms by which leptin mediates its effects are initiated by its binding to one or more forms of the leptin receptor (ObR). In Chapter 6 we reviewed the different isoforms of the leptin receptor and described leptin signaling through the long isoform of the receptor, ObRb. The primary signaling cascade initiated with ObRb binding is the JAK/STAT pathway. In addition, several alternate pathways have been described, including signaling through MAPK, PI3K/PDE3B/CAMP, AMPK and mTOR (25). Most immune cells (monocytes, macrophages, dendritic cells, B cells, T cells) have been shown to express the long form of the leptin receptor. However, which isoform neutrophils express (or even if they express any isoform) has remained unclear. In Chapter 7 we suggest that the signaling pathways underlying leptin-induced neutrophil migration do not require the 'canonical' ObRb/JAK2/STAT pathway, and indicate that the 'alternate' IRS/PI3K and MAPK pathways are involved (26). There has been an ongoing debate about whether ObRb is the only isoform of the leptin receptor through which leptin can signal. Although the short form of ObR, ObRa (in mice), was originally thought to lack signaling capabilities, subsequent studies suggested that it induces both MAPK and 
Insulin Receptor Substrate (IRS)-PI3K pathways via JAK2 in response to leptin (27-29). Our preliminary findings suggest that murine bone-marrow derived neutrophils express only ObRa, and not ObRb (Figure 1A), and thus the lack of STAT3 activation upon leptin stimulation (the hallmark of signaling via ObRb) further suggests that ObRb is not present in these cells (Figure 1B).

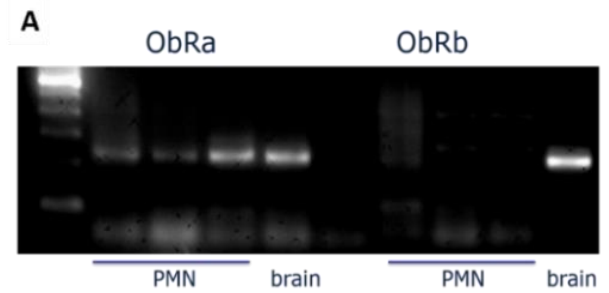

B

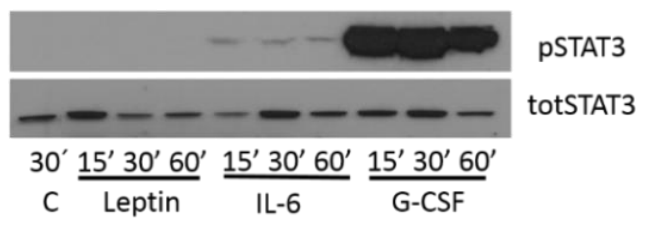

Figure 1 Leptin signals through ObRa in neutrophils. Bone-marrow derived neutrophils from wild-type mice were examined for ObRa and ObRb expression by PCR (A), or stimulated with leptin ( $30 \mathrm{ng} / \mathrm{ml})$, IL-6 (20 ng/ml) or G-CSF (25 ng/ml) or PBS control for 15,30 or 60 minutes and STAT3 phosphorylation and total protein expression was determined by western blot (B).

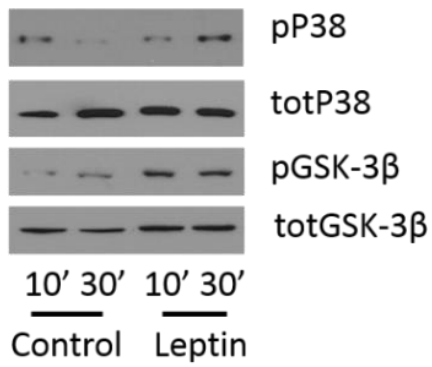

Figure 2 Leptin signaling in neutrophils through MAPK and IRS/ $\mathbf{P I}_{3} \mathbf{K}$. Bone-marrow derived neutrophils from wild-type mice were stimulated with leptin $(30 \mathrm{ng} / \mathrm{ml})$, or PBS control for 10,30 or 60 minutes. P38 and GSK3 $\beta$ phosphorylation and total protein content was determined by western blot.

Additionally, in preliminary work we have examined leptin-induced MAPK and PI3K pathway activation in neutrophils. An important down-stream target of both these

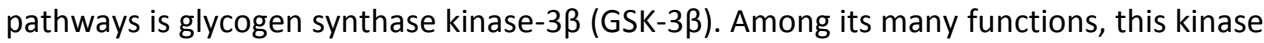
is an important regulator of inflammatory signaling $(30,31)$. In its active form, GSK-3 $\beta$ promotes multiple pro-inflammatory and survival pathways, and upon inactivation by serine phosphorylation it serves as a feedback inhibitor for TLR- and GPCR-induced cell activation. Inhibition of GSK-3 $\beta$ has also been shown to suppress JAK-mediated STAT activation in monocytes and macrophages (32). Furthermore, pharmacologic inhibition of GSK-3 $\beta$ in animal models leads to marked reduction in the inflammatory response to LPS and other injuries (33-36). We found induction of both p38 and GSK-3 $\beta$ phosphorylation following leptin stimulation of bone-marrow derived neutrophils (Figure 2 ), further suggesting that leptin signals through ObRa on murine neutrophils and activates the MAPK and IRS/PI3K pathways (Figure 3). 


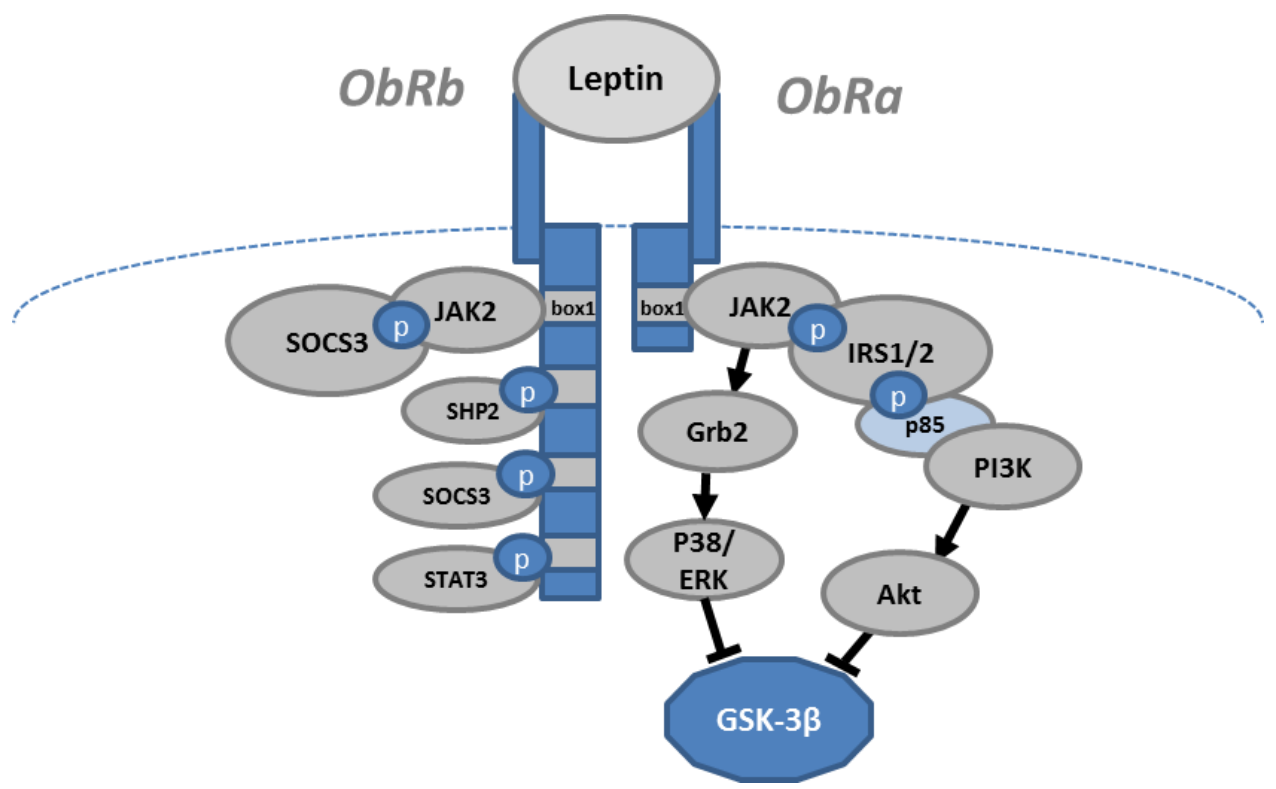

Figure 3 Proposed leptin signaling pathway in neutrophils through ObRa, and classical leptin signaling through ObRb, as found on a variety of other immune cells.

\section{Leptin and Respiratory Infections: Finding a Balance}

The increasing numbers of antibiotic-resistant bacteria causing infections in the hospital and the community are alarming (37-39). These gram-positive and gram-negative bacteria have recently been reported as the "ESKAPE" pathogens: Enterococcus faecium, Staphylococcus Aureus, Klebsiella pneumoniae, Acinetobacter baumanii, Pseudomonas aeruginosa and Enterobacter species (38). They are capable of 'escaping' the biocidal action of antibiotics and represent new paradigms in pathogenesis, transmission and resistance (40). In addition, recent epidemics, such as the pandemic ( $\mathrm{pH} 1 \mathrm{N1}$ ) influenza outbreaks, have highlighted the continued threat of emerging pathogens for which we have few if any effective treatments. Few treatments that are currently in the late stage of development will augment our ability to treat infection due to resistant pathogens. Therefore, there is a pressing need to identify therapeutic approaches that may restore or enhance host defenses in at-risk populations.

Conflicting evidence exists on the effects of obesity on the risk for and severity of respiratory. Several studies have demonstrated associations between obesity and risk for both bacterial and viral pneumonias, as well as increased disease severity and subsequent mortality (41-43). However, others have suggested a protective effect of increasing BMI on mortality in these settings $(44,45)$. Reasons for this inconsistency 
remain unclear. Studies in murine models of obesity have shown that obese mice fail to contain both influenza $(46,47)$ and bacterial $(26,48)$ pneumonias, which consequently lead to increased disease severity and death. Furthermore, the impaired adaptive immune response following influenza infection in obese mice also appears to be impaired (49-52). The studies described in Chapter 3 and Chapter 4 demonstrate obesity-associated defects in the immune response to both respiratory infections and lung injury.

One of the hallmarks of obesity is a state of leptin-resistance with markedly increased circulating leptin levels. In Chapter $\mathbf{8}$ of this thesis we provide evidence that decreased bacterial clearance following infection in the obese may be attributable to increased systemic leptin levels (hyperleptinemia), independent of other metabolic and mechanical factors. Although we only examined the effects of lean hyperleptinemia on pulmonary host defense in a model of bacterial infection, our recent preliminary data shows that mortality from pH1N1 influenza is increased in lean hyperleptinemic mice (Figure 4), suggesting that not only the host response to bacterial infections, but also to viral infections, can be influenced by hyperleptinemia. This adds further insight into the mechanisms which underlie the reported effects of obesity on H1N1 infection $(53,54)$, and may also start to explain why non-obese hyperleptinemic populations, including pregnant women and diabetic subjects, were more susceptible to H1N1 influenza (55). These findings, in aggregate, represent an initial step in understanding the complex mechanisms underlying the increased susceptibility to and mortality from respiratory infection in the obese and other hyperleptinemic populations.

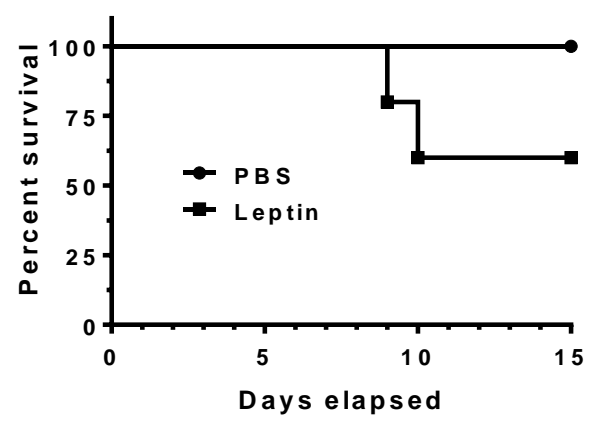

Figure 4 Hyperleptinemic mice have decreased survival following H1N1 infection. Lean hyperleptinemic and control mice were infected intranasally with a sub-lethal dose of A/California/7/2009 H1N1 $\left(3 * 10^{3}\right.$ EU) and followed for 15 days. Leptin was given for 14 days prior to infection and at day 3 post infection.

Interestingly, in contrast to our work in the diet-induced obesity model which manifests high circulating leptin levels, pneumonia studies of obese leptin-deficient (ob/ob) mice these mice also exhibited increased susceptibility to Gram-negative K. pneumoniae (56). Obese leptin-deficient (ob/ob) as well as starved, hypoleptinemic mice have been shown to have impaired host defenses, and restoration of leptin levels in both conditions can reverse the defective response to bacterial infections $(57,58)$. Furthermore, circulating leptin levels are low in malnourished or severely underweight humans, and are associated with an immune-compromised state of increased susceptibility to infection, 
and this can be partially reversed with leptin replacement $(2,58)$. Taken together, these observations suggest that leptin is critical to maintain the pulmonary host defense. Yet, hyperleptinemia also impairs the pulmonary host defense (Chapter 8). Phung et al. recently published a review in which a U-shaped association between BMI and both bacterial and viral respiratory infections are presented (2). We can speculate that the association between circulating leptin levels and the risk for developing respiratory infections may have a similar $U$-shape, suggesting that balancing leptin levels in populations at risk for respiratory infections and thus decreasing the burden of disease may be a possible therapeutic implication of our findings.

Furthermore, the effects of increased leptin levels on the immune response appear to be, in part, dependent on the acuity versus chronicity of the exposure. In addition to states of chronic hyperleptinemia, such as obesity, leptin may also be elevated as an acute phase reactant (59). Acute in vitro exposure to leptin has been shown to enhance immune cell function, such as monocyte and macrophage activation, phagocytosis, and cytokine secretion (60-62). Our work described in Chapter 7 as well as studies from other groups showed that leptin can act as a neutrophil chemoattractant and an anti-apoptotic $(26,63,64)$. In addition, we demonstrated that not only the presence of leptin, but also intact leptin signaling, is important to maintain pulmonary host defense (Chapter 7). However, in multiple studies using mouse models of obesity, and thus chronic hyperleptinemia, the obese milieu has a protective and anti-inflammatory effect in induced acute lung injury, leading to an attenuated pulmonary inflammatory response, which we describe in Chapter $3(65,66)$. Furthermore, in studies determining the association between lavage leptin levels in ARDS patients, the associations between high leptin levels and clinical outcomes appear to differ based on the context (67). In nonobese patients (BMI<30), high leptin levels (presumably acute) are associated with poor outcomes, whereas in the obese (BMI>30), high levels (most likely reflecting preceding, baseline hyperleptinemia) have no such association. Although we provide possible mechanisms which may start to explain the different effects of leptin on the pulmonary immune response in this dissertation, further research delineating the exact role of leptin in host defense is needed in order to develop suitable therapeutics down the road.

\section{Future Directions}

Since the obesity epidemic is still increasing worldwide and the threat of infections with drug-resistant pathogens is high, multiple challenges and opportunities lie ahead in the research field of obesity and pulmonary host defense. Although valuable new insights have emerged from the work presented in this dissertation, a number of issues remain unresolved and new questions arise.

Our comparison of four commonly used mouse models of obesity demonstrated the variability in response to bacterial pneumonia, LPS-induced pneumonitis, and impaired 
neutrophil function in similarly obese mice. The differences in these models may, in part, be due to variations in their metabolic abnormalities, such as the degree of dyslipidemia, hyperglycemia, or adipokine dysregulation. Further research into the effects of these obesity-associated factors on pulmonary host defense may help to identify subjects at risk for developing respiratory infections and ARDS or worse outcome of infection. Furthermore, since the genetic abnormalities modeled in the $\mathrm{db} / \mathrm{db}$ and ob/ob model are extremely rare in humans, caution is recommended when extrapolating data generated in these particular obese animal models to the human condition.

Our finding that obesity-associated hyperleptinemia, and not body mass per se, is an important factor in the impairment of pulmonary host defense is a critical step towards understanding the complex mechanisms underlying increased susceptibility to and mortality from respiratory infections in the obese and other hyperleptinemic populations. Further understanding of host defense and the specific mechanisms underlying its impairment in hyperleptinemic conditions such as obesity, pregnancy, and diabetes, is critical to further develop improved identification and treatment of populations at risk for pneumonia.

To increase our understanding of the role of obesity-associated and lean hyperleptinemia on the pulmonary host defense, there is a crucial need to develop effective tools which can either inhibit or overexpress leptin in any given context. As such, we have already developed an animal model to study the effects of lean hyperleptinemia (Chapter 7). The ability to also inhibit obesity-associated hyperleptinemia would allow us to confirm whether hyperleptinemia is causing the observed impairment of pulmonary host defense in our animal models of obesity and provide us with a critical proof of approach for decreasing the risk of respiratory infections and ARDS in hyperleptinemic subjects. Furthermore, the effect of local inhibition of leptin's actions, such as on neutrophils, can be determined in genetically manipulated mice which lack ObR (all isoforms) on neutrophils. Similarly, the effects of local leptin overexpression (in for example the lung or bone-marrow) can be examined by using genetically modified mice in which leptin (over)expression can be induced. Generating these tools will allow us to take this research area to the next level and gain more insight into the underlying mechanisms.

The observed clinical dichotomy between the risk of and outcomes from ARDS in obese patients was further investigated in this dissertation, and our results suggest that modulation of the alveolar macrophage response plays an important role. Alveolar macrophage function and phenotype manifests a more pro-inflammatory state at baseline, whereas an anti-inflammatory state is observed after lung injury. These findings may start to explain some of the paradoxical effects seen in obese ARDS, and lead to a better understanding of the marked effects of obesity on the pulmonary innate immune response following inflammation. Although we demonstrate that alveolar macrophages are "primed" at baseline in obese mice and we suggest that this may be due to alveolar translocation of elevated circulating cytokines, we also find evidence that 
increased lipid handling may, in part, contribute to this effect. Studies discerning the effects of increased lipid levels, in for example a mouse model of lean hypercholesterolemia using a high cholesterol containing diet, on alveolar macrophage function and phenotype will be a first step to further examine the underlying mechanisms. Furthermore, it is suggested that surfactant proteins are dysregulated in obesity and may thus contribute to the modulation of the alveolar macrophage response. Therefore, expression levels of surfactant proteins should be examined in the lung tissue and bronchoalveolar lavage fluid of obese and lean mice. Consequently, increased understanding of the described mechanisms underlying this dichotomy may lead to the development of novel therapeutic approaches to both reduce the risk of ARDS in the obese and to improve ARDS outcomes in the non-obese population, and in the end decrease the substantial associated healthcare costs.

\section{Concluding Remarks}

The research described in this dissertation has shown that obesity impairs pulmonary host defense and that obesity-associated factors, including dysregulation of the adipokine leptin, may underlie this effect. The incidence of obesity is still rising and additional research concerning pulmonary host defense in this population is necessary to identify therapeutic targets and effective therapies for the prevention and treatment of lung infection. In addition, dissecting the effects of several factors involved in obesity and the metabolic syndrome on the pulmonary host defense independent of increased weight are crucial to gain a more complete understanding of the mechanisms involved in this complex environment. Better insight into the pathogenesis of both respiratory infection and ARDS in obese subjects may direct future treatment strategies and may, especially in case of respiratory infections, avoid progression of the disease to a more severe state and eventually decrease mortality. 


\section{References}

1. Gong, M.N., Bajwa, E.K., Thompson, B.T., and Christiani, D.C. 2010. Body mass index is associated with the development of acute respiratory distress syndrome. Thorax 65:44-50.

2. Phung, D.T., Wang, Z., Rutherford, S., Huang, C., and Chu, C. 2013. Body mass index and risk of pneumonia: a systematic review and meta-analysis. Obes Rev 14:839-857.

3. Stapleton, R.D., Dixon, A.E., Parsons, P.E., Ware, L.B., and Suratt, B.T. 2010. The association between $\mathrm{BMI}$ and plasma cytokine levels in patients with acute lung injury. Chest 138:568-577.

4. Mottillo, S., Filion, K.B., Genest, J., Joseph, L., Pilote, L., Poirier, P., Rinfret, S., Schiffrin, E.L., and Eisenberg, M.J. 2010. The metabolic syndrome and cardiovascular risk a systematic review and meta-analysis. J Am Coll Cardiol 56:1113-1132.

5. Ma, X., and Zhu, S. 2013. Metabolic syndrome in the prevention of cardiovascular diseases and diabetes--still a matter of debate? Eur J Clin Nutr 67:518-521.

6. Ruderman, N.B., Schneider, S.H., and Berchtold, P. 1981. The "metabolically-obese," normal-weight individual. The American journal of clinical nutrition 34:1617-1621.

7. Morkedal, B., Vatten, L.J., Romundstad, P.R., Laugsand, L.E., and Janszky, I. 2014. Risk of myocardial infarction and heart failure among metabolically healthy but obese individuals: HUNT (NordTrondelag Health Study), Norway. Journal of the American College of Cardiology 63:1071-1078.

8. Stefan, N., Fritsche, A., and Haring, H.U. 2014. Mechanisms explaining the relationship between metabolically healthy obesity and cardiovascular risk. Journal of the American College of Cardiology 63:2748-2749.

9. Bluher, M. 2010. The distinction of metabolically 'healthy' from 'unhealthy' obese individuals. Current opinion in lipidology 21:38-43.

10. Dixon, A.E., and Suratt, B.T. 2014. Active lifestyle: the next "smoking cessation"? American journal of respiratory and critical care medicine 189:1155-1156.

11. Tchernof, A., and Despres, J.P. 2013. Pathophysiology of human visceral obesity: an update. Physiological reviews 93:359-404.

12. Ingalls, A.M., Dickie, M.M., and Snell, G.D. 1950. Obese, a new mutation in the house mouse. J Hered 41:317-318.

13. Huang, K., Rabold, R., Abston, E., Schofield, B., Misra, V., Galdzicka, E., Lee, H., Biswal, S., Mitzner, W., and Tankersley, C.G. 2008. Effects of leptin deficiency on postnatal lung development in mice. $J$ Appl Physiol (1985) 105:249-259.

14. Claycombe, K., King, L.E., and Fraker, P.J. 2008. A role for leptin in sustaining lymphopoiesis and myelopoiesis. Proceedings of the National Academy of Sciences of the United States of America 105:2017-2021.

15. Hummel, K.P., Dickie, M.M., and Coleman, D.L. 1966. Diabetes, a new mutation in the mouse. Science 153:1127-1128.

16. Coleman, D.L., and Eicher, E.M. 1990. Fat (fat) and tubby (tub): two autosomal recessive mutations causing obesity syndromes in the mouse. J Hered 81:424-427.

17. Park, S., Rich, J., Hanses, F., and Lee, J.C. 2009. Defects in innate immunity predispose C57BL/6JLeprdb/Leprdb mice to infection by Staphylococcus aureus. Infect Immun 77:1008-1014.

18. Kraft, R., Herndon, D.N., Mlcak, R.P., Finnerty, C.C., Cox, R.A., Williams, F.N., and Jeschke, M.G. 2014. Bacterial respiratory tract infections are promoted by systemic hyperglycemia after severe burn injury in pediatric patients. Burns 40:428-435.

19. Madenspacher, J.H., Draper, D.W., Smoak, K.A., Li, H., Griffiths, G.L., Suratt, B.T., Wilson, M.D., Rudel, L.L., and Fessler, M.B. 2010. Dyslipidemia induces opposing effects on intrapulmonary and extrapulmonary host defense through divergent TLR response phenotypes. J Immunol 185:16601669.

20. Palvinskaya, T., Antkowiak, M., Burg, E., Lenox, C.C., Ubags, N., Cramer, A., Rincon, M., Dixon, A.E., Fessler, M.B., Poynter, M.E., et al. 2013. Effects of acute and chronic low density lipoprotein exposure on neutrophil function. Pulmonary pharmacology \& therapeutics 26:405-411.

21. Bays, H., Abate, N., and Chandalia, M. 2005. Adiposopathy: sick fat causes high blood sugar, high blood pressure and dyslipidemia. Future Cardiol 1:39-59. 
22. Bays, H.E., Gonzalez-Campoy, J.M., Bray, G.A., Kitabchi, A.E., Bergman, D.A., Schorr, A.B., Rodbard, H.W., and Henry, R.R. 2008. Pathogenic potential of adipose tissue and metabolic consequences of adipocyte hypertrophy and increased visceral adiposity. Expert Rev Cardiovasc Ther 6:343-368.

23. Bray, G.A., Glennon, J.A., Salans, L.B., Horton, E.S., Danforth, E., Jr., and Sims, E.A. 1977. Spontaneous and experimental human obesity: effects of diet and adipose cell size on lipolysis and lipogenesis. Metabolism 26:739-747.

24. Chawla, A., Nguyen, K.D., and Goh, Y.P. 2011. Macrophage-mediated inflammation in metabolic disease. Nature reviews. Immunology 11:738-749.

25. Wauman, J., and Tavernier, J. 2011. Leptin receptor signaling: pathways to leptin resistance. Front Biosci (Landmark Ed) 16:2771-2793.

26. Ubags, N.D., Vernooy, J.H., Burg, E., Hayes, C., Bement, J., Dilli, E., Zabeau, L., Abraham, E., Poch, K.R., Nick, J.A., et al. 2014. The role of leptin in the development of pulmonary neutrophilia in infection and acute lung injury*. Crit Care Med 42:e143-151.

27. Bjorbaek, C., Uotani, S., da Silva, B., and Flier, J.S. 1997. Divergent signaling capacities of the long and short isoforms of the leptin receptor. The Journal of biological chemistry 272:32686-32695.

28. Murakami, T., Yamashita, T., lida, M., Kuwajima, M., and Shima, K. 1997. A short form of leptin receptor performs signal transduction. Biochemical and biophysical research communications 231:26-29.

29. Yamashita, T., Murakami, T., Otani, S., Kuwajima, M., and Shima, K. 1998. Leptin receptor signal transduction: OBRa and OBRb of fa type. Biochemical and biophysical research communications 246:752-759.

30. Ali, A., Hoeflich, K.P., and Woodgett, J.R. 2001. Glycogen synthase kinase-3: properties, functions, and regulation. Chem Rev 101:2527-2540.

31. Beurel, E., Michalek, S.M., and Jope, R.S. 2010. Innate and adaptive immune responses regulated by glycogen synthase kinase-3 (GSK3). Trends Immunol 31:24-31.

32. Beurel, E., and Jope, R.S. 2008. Differential regulation of STAT family members by glycogen synthase kinase-3. J Biol Chem 283:21934-21944.

33. Dugo, L., Collin, M., Allen, D.A., Patel, N.S., Bauer, I., Mervaala, E.M., Louhelainen, M., Foster, S.J., Yaqoob, M.M., and Thiemermann, C. 2005. GSK-3beta inhibitors attenuate the organ injury/dysfunction caused by endotoxemia in the rat. Crit Care Med 33:1903-1912.

34. Gong, J.H., Gong, J.P., Li, J.Z., He, K., Li, P.Z., and Jiang, X.W. 2013. Glycogen synthase kinase 3 inhibitor attenuates endotoxin-induced liver injury. J Surg Res 184:1035-1044.

35. Martin, M., Rehani, K., Jope, R.S., and Michalek, S.M. 2005. Toll-like receptor-mediated cytokine production is differentially regulated by glycogen synthase kinase 3. Nat Immunol 6:777-784.

36. Cuzzocrea, S., Crisafulli, C., Mazzon, E., Esposito, E., Muia, C., Abdelrahman, M., Di Paola, R., and Thiemermann, C. 2006. Inhibition of glycogen synthase kinase-3beta attenuates the development of carrageenan-induced lung injury in mice. Br J Pharmacol 149:687-702.

37. Giske, C.G., Monnet, D.L., Cars, O., and Carmeli, Y. 2008. Clinical and economic impact of common multidrug-resistant gram-negative bacilli. Antimicrobial agents and chemotherapy 52:813-821.

38. Rice, L.B. 2008. Federal funding for the study of antimicrobial resistance in nosocomial pathogens: no ESKAPE. The Journal of infectious diseases 197:1079-1081.

39. Spellberg, B., Guidos, R., Gilbert, D., Bradley, J., Boucher, H.W., Scheld, W.M., Bartlett, J.G., and Edwards, J., Jr. 2008. The epidemic of antibiotic-resistant infections: a call to action for the medical community from the Infectious Diseases Society of America. Clinical infectious diseases : an official publication of the Infectious Diseases Society of America 46:155-164.

40. Pendleton, J.N., Gorman, S.P., and Gilmore, B.F. 2013. Clinical relevance of the ESKAPE pathogens. Expert review of anti-infective therapy 11:297-308.

41. Fezeu, L., Julia, C., Henegar, A., Bitu, J., Hu, F.B., Grobbee, D.E., Kengne, A.P., Hercberg, S., and Czernichow, S. 2011. Obesity is associated with higher risk of intensive care unit admission and death in influenza A (H1N1) patients: a systematic review and meta-analysis. Obesity reviews : an official journal of the International Association for the Study of Obesity 12:653-659.

42. Mertz, D., Kim, T.H., Johnstone, J., Lam, P.P., Science, M., Kuster, S.P., Fadel, S.A., Tran, D., Fernandez, E., Bhatnagar, N., et al. 2013. Populations at risk for severe or complicated influenza illness: systematic review and meta-analysis. BMJ 347:f5061. 
43. Phung, D.T., Wang, Z., Rutherford, S., Huang, C., and Chu, C. 2013. Body mass index and risk of pneumonia: a systematic review and meta-analysis. Obesity reviews : an official journal of the International Association for the Study of Obesity 14:839-857.

44. Corrales-Medina, V.F., Valayam, J., Serpa, J.A., Rueda, A.M., and Musher, D.M. 2011. The obesity paradox in community-acquired bacterial pneumonia. Int J Infect Dis 15:e54-57.

45. Singanayagam, A., Singanayagam, A., and Chalmers, J.D. 2013. Obesity is associated with improved survival in community-acquired pneumonia. Eur Respir J 42:180-187.

46. Easterbrook, J.D., Dunfee, R.L., Schwartzman, L.M., Jagger, B.W., Sandouk, A., Kash, J.C., Memoli, M.J., and Taubenberger, J.K. 2011. Obese mice have increased morbidity and mortality compared to non-obese mice during infection with the 2009 pandemic H1N1 influenza virus. Influenza Other Respir Viruses 5:418-425.

47. Smith, A.G., Sheridan, P.A., Harp, J.B., and Beck, M.A. 2007. Diet-induced obese mice have increased mortality and altered immune responses when infected with influenza virus. The Journal of nutrition 137:1236-1243.

48. Conge, G.A., Gouache, P., Joyeux, Y., Goichot, J., and Fournier, J.M. 1988. [Influence of different types of experimental obesity on resistance of the mouse to infection by Salmonella typhimurium and Klebsiella pneumoniae]. Ann Nutr Metab 32:113-120.

49. Karlsson, E.A., Sheridan, P.A., and Beck, M.A. 2010. Diet-induced obesity in mice reduces the maintenance of influenza-specific CD8+ memory T cells. J Nutr 140:1691-1697.

50. Karlsson, E.A., Sheridan, P.A., and Beck, M.A. 2010. Diet-induced obesity impairs the T cell memory response to influenza virus infection. J Immunol 184:3127-3133.

51. Paich, H.A., Sheridan, P.A., Handy, J., Karlsson, E.A., Schultz-Cherry, S., Hudgens, M.G., Noah, T.L., Weir, S.S., and Beck, M.A. 2013. Overweight and obese adult humans have a defective cellular immune response to pandemic H1N1 influenza A virus. Obesity (Silver Spring) 21:2377-2386.

52. Smith, A.G., Sheridan, P.A., Tseng, R.J., Sheridan, J.F., and Beck, M.A. 2009. Selective impairment in dendritic cell function and altered antigen-specific CD8+ T-cell responses in diet-induced obese mice infected with influenza virus. Immunology 126:268-279.

53. Milner, J.J., and Beck, M.A. 2012. The impact of obesity on the immune response to infection. Proc Nutr Soc 71:298-306.

54. Fezeu, L., Julia, C., Henegar, A., Bitu, J., Hu, F.B., Grobbee, D.E., Kengne, A.P., Hercberg, S., and Czernichow, S. 2011. Obesity is associated with higher risk of intensive care unit admission and death in influenza A (H1N1) patients: a systematic review and meta-analysis. Obes Rev 12:653-659.

55. Karlsson, E.A., Marcelin, G., Webby, R.J., and Schultz-Cherry, S. 2012. Review on the impact of pregnancy and obesity on influenza virus infection. Influenza Other Respir Viruses 6:449-460.

56. Mancuso, P., Gottschalk, A., Phare, S.M., Peters-Golden, M., Lukacs, N.W., and Huffnagle, G.B. 2002. Leptin-deficient mice exhibit impaired host defense in Gram-negative pneumonia. Journal of immunology 168:4018-4024.

57. Hsu, A., Aronoff, D.M., Phipps, J., Goel, D., and Mancuso, P. 2007. Leptin improves pulmonary bacterial clearance and survival in ob/ob mice during pneumococcal pneumonia. Clin Exp Immunol 150:332-339.

58. Mancuso, P., Huffnagle, G.B., Olszewski, M.A., Phipps, J., and Peters-Golden, M. 2006. Leptin corrects host defense defects after acute starvation in murine pneumococcal pneumonia. Am J Respir Crit Care Med 173:212-218.

59. La Cava, A., and Matarese, G. 2004. The weight of leptin in immunity. Nat Rev Immunol 4:371-379.

60. Dixit, V.D., Mielenz, M., Taub, D.D., and Parvizi, N. 2003. Leptin induces growth hormone secretion from peripheral blood mononuclear cells via a protein kinase $C$ - and nitric oxide-dependent mechanism. Endocrinology 144:5595-5603.

61. Mancuso, P., Gottschalk, A., Phare, S.M., Peters-Golden, M., Lukacs, N.W., and Huffnagle, G.B. 2002. Leptin-deficient mice exhibit impaired host defense in Gram-negative pneumonia. J Immunol 168:4018-4024.

62. Zarkesh-Esfahani, H., Pockley, G., Metcalfe, R.A., Bidlingmaier, M., Wu, Z., Ajami, A., Weetman, A.P., Strasburger, C.J., and Ross, R.J. 2001. High-dose leptin activates human leukocytes via receptor expression on monocytes. J Immunol 167:4593-4599.

63. Caldefie-Chezet, F., Poulin, A., and Vasson, M.P. 2003. Leptin regulates functional capacities of polymorphonuclear neutrophils. Free Radic Res 37:809-814. 
64. Bruno, A., Conus, S., Schmid, I., and Simon, H.U. 2005. Apoptotic pathways are inhibited by leptin receptor activation in neutrophils. J Immunol 174:8090-8096.

65. Bellmeyer, A., Martino, J.M., Chandel, N.S., Scott Budinger, G.R., Dean, D.A., and Mutlu, G.M. 2007. Leptin resistance protects mice from hyperoxia-induced acute lung injury. Am J Respir Crit Care Med 175:587-594.

66. Kordonowy, L.L., Burg, E., Lenox, C.C., Gauthier, L.M., Petty, J.M., Antkowiak, M., Palvinskaya, T., Ubags, N., Rincon, M., Dixon, A.E., et al. 2012. Obesity is associated with neutrophil dysfunction and attenuation of murine acute lung injury. Am J Respir Cell Mol Biol 47:120-127.

67. Jain, M., Budinger, G.R., Lo, A., Urich, D., Rivera, S.E., Ghosh, A.K., Gonzalez, A., Chiarella, S.E., Marks, K., Donnelly, H.K., et al. 2011. Leptin promotes fibroproliferative acute respiratory distress syndrome by inhibiting peroxisome proliferator-activated receptor-gamma. Am J Respir Crit Care Med 183:1490-1498. 



\section{SUMMARY}


Obesity is a rapidly expanding epidemic globally, and is associated with dysregulation of the innate immune response. Multiple organ systems are affected by obesity, including the respiratory system. Pulmonary host defense is crucial in the fight against invading pathogens in numerous respiratory diseases, including respiratory infections and Acute Respiratory Distress Syndrome (ARDS). Conflicting evidence exist on the effect of obesity on susceptibility to and outcome of both respiratory infections and ARDS. This thesis sheds light on the mechanisms underlying the altered pulmonary innate immune and host defense in obesity.

In Chapter 1 we provide a critical review of the current literature regarding the key players in this thesis: obesity and host defense. Hereby looking into which parts of obesity and its associated comorbidities may be involved in the alterations of the pulmonary innate immune response and consequently host defense. Neutrophils and macrophage play major roles in host defense and previous studies indicated that obese subjects with ARDS had lower levels of several pro-inflammatory cytokines, suggesting that the inflammatory response may be altered in patients with ARDS and a high Body Mass Index (BMI). The aims and outline of this thesis was described in Chapter 2. In Chapter 3 the effects of obesity on pulmonary innate immune response and subsequently neutrophil behavior in pulmonary host defense were examined. We demonstrated that obesity attenuates the inflammatory response in an inhaled lipopolysaccharide (LPS) model of murine Acute Lung Injury (ALI), which led to a reduction in both pulmonary neutrophilia and injury in two different mouse models of obesity. In addition, the early pulmonary cytokine response was found to be normal and circulating neutrophil levels were increased in obese mice. The witnessed attenuation of pulmonary neutrophilia in the obese mice was shown to be due, in part, to obesityassociated abnormalities in CXCR2 signaling with associated defects in neutrophil chemotaxis. Altogether, these data suggest that neutrophil dysfunction plays a prominent role in the complex, multifactorial process underlying the obesity-associated attenuation of lung injury.

To further extend these findings on the effects of obesity on neutrophil function and its role in respiratory diseases, it was hypothesized that obesity-associated impairment of neutrophil function contributes to the increased risk for respiratory infection, yet that significant differences may exist between commonly used mouse models of obesity. The four murine models of obesity used in this study were: diet-induced obese mice (DIO), $\mathrm{db} / \mathrm{db}$ mice (ObRb deficient), $\mathrm{CPE}^{\text {fat/fat }}$ mice (mutation in carboxypeptidase $\mathrm{E}$ ) and ob/ob mice (leptin-deficient). As described in Chapter 4, this study revealed that there is an obesity-associated defect in host defense to bacterial pneumonia in mice. However, the course and severity of the infection, as well as the underlying mechanisms may be dependent on the obese mouse model used. Neutrophil function, which is shown to be crucial in pulmonary host defense, was found to be defective in obese animals. The impaired cytokines transcription, cell survival, downstream signaling response as well as neutrophil chemoattractant response may all contribute to the observed impairment in 
pulmonary host defense. However, the extent to which pulmonary host defense is impaired and neutrophil function is defective depends on the obese mouse model used. In conclusion, the diet-induced obesity model was found to mimic the human situation the best, since obesity is induced by a high fat diet in this model and factors associated with the metabolic syndrome were moderately elevated, as described in this Chapter.

Given the fact that obesity is associated with increased development for ARDS, yet is also associated with rapid attenuation of the inflammatory response and improved outcomes in both patients and animal models (Chapter 3), the possible mechanisms controlling this paradoxical 'shift' in the inflammatory environment of the lung following injury were examined in Chapter 5. Alveolar macrophage numbers are increased and showed baseline activation in uninjured diet-induced obese mice. Furthermore, increased lipid deposition was observed in alveolar macrophages from obese mice at baseline, which may, in part, explain the baseline activation. Whereas a more pro-inflammatory alveolar macrophage phenotype was observed at baseline in obese mice, this phenotype appeared to shift towards a more anti-inflammatory state after established lung injury, suggesting that obesity modulates the alveolar macrophage response in murine ARDS. Taken together, these results suggested that the phenotype 'shift' observed in alveolar macrophages from obese mice may underlie the paradoxical effects seen in obese ARDS, where there is an increased susceptibility, yet an improved outcome.

Obesity is associated with adipokine dysregulation and consequently a leptin-resistant state. The adipokine leptin, also known as the satiety hormone, is a critical mediator of the balance between food intake and energy expenditure and plays an important role in several physiological processes and has implications in the pathogenesis of disease. Chapter 6 provides a state-of-the-art overview on leptin and its functional role on the different resident cell types of the lung in health as well as in the context of respiratory diseases. Leptin was shown to be upregulated in the lung following injury and to exert diverse effects on leukocytes, influencing both chemotaxis and survival, which are the two key processes involved in the development of pulmonary neutrophilia in ALI. Therefore, the role of leptin on the development of pulmonary neutrophilia in infection and $\mathrm{ALI}$ was examined in Chapter 7. Pulmonary leptin levels were shown to be upregulated in both humans and mice following bacterial- and viral-induced pneumonia and ALI. Moreover, leptin was found to enhance pulmonary neutrophilia through, in part, leptin's action as a neutrophil chemoattractant as well as its effects on neutrophil survival, and intact leptin signaling was shown to be critical in pulmonary host defense.

Conditions associated with high circulating leptin levels (as observed in obesity) have been associated with an increased risk to develop pneumonia. In Chapter 8 a translational approach was used to investigate whether obesity-associated hyperleptinemia could be linked to the impaired response to pulmonary pathogens and increased susceptibility to infections. Plasma leptin levels were shown to be positively correlated with the risk for respiratory infection independent of BMI in healthy subjects. In addition, in patient with severe pneumonia resulting in ARDS, plasma leptin levels 
were positively correlated with subsequent mortality. Similar results were found in a murine model of diet-induced obesity with pneumonia, in which plasma leptin levels were associated with pneumonia severity. To further determine whether the associations between plasma leptin levels and pneumonia severity in the obese mice were due to leptin itself or other obesity-related factors, a mouse model of lean experimentally-induced hyperleptinemia was tested. The previous obtained results were confirmed in this model. Taken together, these studies showed that the observed effects of obesity on respiratory infection are attributable to increased systemic leptin levels independent of other metabolic and mechanical factors.

The insights resulting from the original research data described in this thesis (Chapter 28) were critically evaluated and integrated with current knowledge in Chapter 9, in order to provide exciting future perspectives. This chapter discussed the interplay of obesity and pulmonary host defense and focused on 1) the role metabolic variables and how they may contribute to the existence of the "obesity paradox" described in respiratory infections and ARDS, and 2) the importance of leptin and, in particular, balanced leptin levels, in pulmonary host defense. Furthermore, this chapter provides ample novel ideas and/or approaches to support the search for the impact of obesity and leptin dysregulation on respiratory diseases. It can be concluded that better insight into the pathogenesis of both respiratory infection and ARDS in obese subjects may direct future treatment strategies and may avoid progression of the disease to a more severe state and eventually decrease mortality. 


SAMENVATTING 
De longen dragen zorg voor de verdeling van zuurstof door het lichaam via het bloed. De long is dus één van de belangrijkste orgaansystemen van het lichaam. Behalve de afgifte van zuurstof aan het bloed hebben de longen nog meerdere belangrijke functies. De longen vormen ook een belangrijke barrière in het tegenhouden van schadelijke organismen of stoffen die het lichaam via inademing kunnen binnendringen. De afweerrespons van de long is dus cruciaal in het gevecht tegen ziekteverwekkers die bijvoorbeeld een longinfectie kunnen veroorzaken of kunnen leiden tot het ontstaan van longschade. Indien de afweerrespons van de long niet goed werkt kan een longinfectie in het ergste geval leiden tot het ontstaan van Acute Respiratory Distress Syndrome (ARDS). ARDS kan ontstaan ten gevolge van een longinfectie als ook door een ziekte elders in het lichaam. ARDS wordt gekenmerkt door een hevige ontstekingsreactie waardoor vocht, eiwitten en ontstekingscellen uit de bloedvaten treden en in het longweefsel terecht komen.

Obesitas dat gekenmerkt wordt door een Body Mass Index (BMI) van meer dan $30 \mathrm{~kg} / \mathrm{m}^{2}$ wordt gezien als een steeds verder uitbreidende epidemie. Obesitas is meer dan alleen overgewicht. Het gaat ook vaak gepaard met een hoge bloeddruk, slechte cholesterol waarden in het bloed en een verstoorde suikerspiegel. Samen worden deze kenmerken ook wel het metabool syndroom genoemd. Obesitas wordt ook wel geassocieerd met een ontregelde afweerrespons van het lichaam. Verschillende orgaan systemen kunnen beïnvloed worden door obesitas, waaronder de longen. Momenteel bestaan er tegenstrijdige bewijzen over het effect van obesitas op het ontstaan en verloop van zowel longinfecties als ook ARDS. In dit proefschrift worden de mechanismen onderliggend aan de verandering in de afweerrespons van de long, die gezien worden in obesitas, uitgediept en beschreven.

In Hoofdstuk 1 wordt een overzicht weergegeven van de belangrijkste literatuur die op dit moment voorhanden is over de twee belangrijkste elementen van dit proefschrift: obesitas en de afweerrespons van de long. Hierbij is er gekeken naar welke factoren die gepaard gaan met obesitas van invloed kunnen zijn op de veranderingen van de afweerrespons in de long. Neutrofielen en macrofagen zijn twee soorten ontstekingscellen die een belangrijke rol spelen in de afweer reactie van de longen. In voorgaande studies is er aangetoond dat in obese patiënten met ARDS de gehaltes van verscheidene ontstekingsbevorderende stoffen lager zijn. Dit suggereert dat de ontstekingsreactie in het bloed van patiënten met een hoog BMI veranderd kan zijn. De doelstelling en hypothese van het onderzoek uitgevoerd in dit proefschrift is beschreven in Hoofdstuk 2. In Hoofdstuk 3 zijn de effecten van obesitas op de afweerrespons van de long onderzocht, en meer specifiek is er gekeken naar het effect van obesitas op het gedrag en de functie van neutrofielen en hoe zij bijdragen aan de afweer van de long. Wij hebben aangetoond dat obesitas de ontstekingsreactie in de long verminderd na blootstelling aan een onderdeel van gram-negatieve bacterieën, lipopolysaccharide (LPS) genaamd, door inhalatie, en dat dit resulteerde in een verlaging van het aantal neutrofielen in de long in twee verschillende muismodellen van obesitas. LPS 
blootstelling wordt gebruikt als een model van acute longschade, ook wel gezien als een milder stadium van ARDS. Verder werd er gevonden dat de waarden van ontstekingsstoffen in de longen van obese muizen normaal waren, maar dat het aantal neutrofielen in het bloed van obese muizen verhoogd was in vergelijking met de aantallen in muizen met een normaal gewicht. De verminderde aantallen neutrofielen in de long van obese muizen na opwekken van acute longschade valt gedeeltelijk te wijten aan obesitas-geassocieerde abnormaliteiten in de CXCR2 signalering van neutrofielen die vervolgens defecten in neutrofiel migratie kunnen veroorzaken. Deze gegevens samen suggereren dat dysfunctie van neutrofielen een belangrijke rol speelt in het complexe en multifactoriële proces dat ten grondslag ligt aan de obesitas-geassocieerde vermindering van acute longschade.

Om de bevindingen van de effecten van obesitas op de neutrofiel functie en de rol hiervan in longziekten verder uit te diepen, was de hypothese van de volgende studie dat de obesitas-geassocieerde verminderde neutrofiel functie bij kan dragen aan het verhoogde risico op long infecties. Tevens is er onderzocht of er verschillen bestaan tussen de verscheidene veelgebruikte muis modellen van obesitas, te weten: dieetgeïnduceerde obese muizen (DIO), db/db muizen (deficiëntie in ObRb), $\mathrm{CPE}^{\text {fat/fat }}$ muizen (mutatie in carboxypeptidase E) en ob/ob muizen (leptine deficiënt). Zoals in Hoofdstuk 4 beschreven wordt, laat deze studie zien dat er een obesitas-geassocieerd defect is in de afweerrespons van de long na het veroorzaken van een bacteriële infectie in deze muizen. Het is gebleken dat het verloop en de ernst van de infectie, alsook de onderliggende mechanismen, afhankelijk zijn van welk muismodel van obesitas er gebruikt werd. Een gedegen functie van de neutrofielen is cruciaal in de afweerrespons van de long, en in deze studie werd er aangetoond dat deze functie verminderd is in obese muizen. De verminderde capaciteit van de neutrofiel om te migreren naar de plaats van infectie, alsook de verminderde afgifte van ontstekingsstoffen die het immuunsysteem verder activeren, de verandering in levensduur en signaleringsrespons dragen allen bij aan de vermindering van de afweerrespons in de long zoals deze gezien werd in obesitas. De mate waarin deze vermindering van de pulmonale afweerrespons en neutrofiel functie wordt waargenomen lijkt sterk afhankelijk te zijn van het obese muismodel dat gebruikt werd en dit kan te maken hebben met de variabele mate waarin factoren gerelateerd aan het metabool syndroom veranderd zijn. Uit deze studie kan geconcludeerd worden dat het muismodel, waarin obesitas geïnduceerd wordt door middel van een hoog vet dieet, de humane situatie het beste weergeeft.

Obesitas is geassocieerd met een verhoogd risico voor het ontwikkelen van ARDS, maar is aan de andere kant ook geassocieerd met een snelle resolutie van de ontstekingsreactie en verbeterde prognose in zowel ARDS patiënten alsook in muismodellen met ARDS (Hoofdstuk 3). De mechanismen die ten grondslag liggen aan deze tegenstrijdige verandering in de pulmonale ontstekingsreactie ten gevolge van acute longschade werden onderzocht in Hoofdstuk 5. Het aantal macrofagen in de longen van obese muizen was verhoogd en deze macrofagen lieten ook een 
ontstekingsbevorderend karakter zien. Verder bleken er ook vetdruppels aanwezig in de macrofagen van obese muizen, waarmee het ontstekingsbevorderende karakter gedeeltelijk verklaard kan worden. Na het induceren van acute longschade in deze muizen bleken de macrofagen een meer ontstekingsremmend karakter te hebben. Dit suggereert dat obesitas het macrofaag karakter in de long kan veranderen gedurende het verloop van de ontwikkeling van acuut longschade in deze muizen. De resultaten beschreven in dit hoofdstuk laten zien dat er een verandering plaatsvindt in het karakter van de macrofagen in de longen van obese muizen, en deze kunnen ten grondslag liggen aan de tegenstrijdige resultaten die gezien worden in obese patiënten met ARDS, welke een verhoogd risico hebben op het ontwikkelen van ARDS maar waarbij het verloop en de prognose van de ziekte verbeterd is.

Obesitas gaat gepaard met een ontregeling van adipokine gehaltes in het bloed. Eén van de meest bekende adipokines is leptine, ook wel bekend als verzadigingshormoon. Leptine speelt een belangrijke rol bij het reguleren van voedsel inname alsook verscheidene fysiologische processen. In Hoofdstuk 6 wordt een overzicht van de recente literatuur weergegeven waarin de rol van leptine op de verschillende cel types die de long bevat uitgediept in de context van zowel de gezonde situatie alsook in longziekten. Het is aangetoond dat leptine gehaltes in de long kunnen stijgen na het ontstaan van longschade, en verder kan leptine immuun cellen, zoals neutrofielen, beïnvloeden. De rol van leptine op het ontwikkelen van een neutrofiel ophoping in de long gedurende een longinfectie en acute longschade werd onderzocht in Hoofdstuk 7. Leptine gehaltes in de long waren verhoogd in zowel humaan alsook muizen longweefsel na een bacteriële of virale longinfectie. Verder werd er aangetoond dat leptine het aantal neutrofielen in de long kan verhogen. Dit wordt mede veroorzaakt doordat leptine migratie van neutrofielen naar de long stimuleert, maar ook doordat leptine ervoor zorgt dat de neutrofielen in de long een langere levensduur hebben.

Er zijn verschillende condities (obesitas, maar ook zwangerschap, nierfalen en diabetes) waarbij we hoge leptine gehaltes in het bloed (hyperleptinemie) zien, welke geassocieerd zijn met een verhoogd risico voor het ontwikkelen van longinfecties. In Hoofdstuk $\mathbf{8}$ is er gebruik gemaakt van een translationele studie opzet om de relatie tussen obesitas-geassocieerde hyperleptinemie en de verminderde afweerrespons in de long te onderzoeken. Leptine gehaltes in het bloed correleren positief met het risico voor het ontwikkelen van een longinfectie, ongeacht het BMI en factoren van het metabool syndroom in gezonde mensen. Verder correleerde leptine in het bloed ook positief met mortaliteit in patiënt met een ernstige longinfectie die tot ARDS was overgegaan. Vergelijkbare resultaten werden gevonden in een muismodel waarin obesitas geïnduceerd wordt door middel van een hoog vet dieet met een longinfectie. Om de effecten van verhoogde leptine gehaltes in bloed te kunnen testen zonder de invloed van een obese omgeving, is er een uniek muis model van experimenteel geïnduceerde hyperleptinemie ontwikkeld. Hierin zijn de humane bevindingen bevestigd. Deze studies laten dus zien dat de effecten die obesitas lijkt te hebben op longinfecties, 
gedeeltelijk, gedreven worden door verhoogde systemische leptine gehalten onafhankelijk van andere factoren van het metabool syndroom.

De kennis opgedaan uit de studies in dit proefschrift (Hoofdstuk 2-8), zijn kritisch geëvalueerd en geïntegreerd met de huidige kennis in de literatuur in Hoofdstuk $\mathbf{9}$. Verder zijn er ook aanbevelingen gedaan voor vervolgonderzoek. De actie van obesitas op de pulmonale afweerrespons wordt hier beschreven met een focus op 1) de rol van metabole variabelen en hoe deze kunnen bijdragen aan het bestaan van de obesitas paradox zoals beschreven voor longinfecties en ARDS, en 2) het belang van leptine, en meer specifiek de balans van leptine gehaltes, in de pulmonale afweerrespons. Dit hoofdstuk bevat ook nieuwe ideeën en technieken om het onderzoek naar obesitas en dysregulatie van leptine op longziekten te kunnen blijven onderzoeken. Het is dus cruciaal om vernieuwde en verbeterde inzichten te krijgen in het ziektebeeld van zowel longinfecties alsook ARDS in obese patiënten. Dit kan richting geven aan nieuwe behandelmethoden en daarmee verergering van de ziekte en uiteindelijk mortaliteit verlagen. 



\section{VALORISATION}




\section{Socioeconomic relevance}

Obesity is a rapidly expanding global epidemic - "globesity" - leading to a markedly increased number of overweight and obese adults $(27.5 \%)$ and for children $(47.1 \%)$ in the past 30 years (1). Recent reports from the World Health Organization (WHO) indicate that in 2014 more than 1.9 billion adults (18 years and older) were overweight (BMI>25), and of this overweight population, over 600 million people were obese (BMI>30). The increased prevalence of overweight and obesity has been accompanied by a substantial increase in the direct medical costs of these conditions. Obesity alone accounts for $0.7 \%$ - $2.8 \%$ of total health care expenditures worldwide $(2,3)$ and when costs associated with being overweight are also included, this figure increases to $9.1 \%(4,5)$. As indicated, obesity is a growing problem, not only from a public-health perspective, but also in relation to many communicable and non-communicable respiratory diseases. Pneumonia and respiratory infections are, according to the WHO, ranked among the leading causes of death worldwide. Therefore, the research described in this thesis is highly relevant looking from both the perspective of obesity, as well as from pneumonia and respiratory infections. Obesity has been associated with an increased susceptibility to and severity of both bacterial and viral respiratory infections (6), however the underlying mechanisms are poorly understood. The importance of investigating the impact of obesity on respiratory diseases is not limited to respiratory infections, but can also include other lung diseases including: obesity and asthma and obesity and primary pulmonary hypertension. The current thesis significantly adds to the understanding of obesity-associated defects in pulmonary host defense, which are accompanied by dysregulation of neutrophil and macrophage function. In addition, critical evidence was provided that the adipokine leptin is an important mediator of pulmonary host defense. Further understanding of the mechanisms underlying the impairment of pulmonary host defense in this at risk population (obese subjects), which is as mentioned before a large part of the general population, is of critical importance. Obese subjects are usually not mentioned separately when one makes a statement about the "general population", but the findings in this dissertation add to the view that these subjects have a different profile when it comes to health risks, especially when looking at infections and more specifically in the respiratory tract. Furthermore, obese subjects are not only at risk for developing respiratory infections, but recent studies also suggested that prophylactic measures such as flu-vaccinations are less effective in this population (7). Therefore, the obese population appears to be at higher risk for developing respiratory infections, even in the setting of appropriate prophylaxis. 


\section{Target groups}

\section{Health care providers and obese patients}

The present thesis provides important insights for health care providers. The prevalence of obesity is still increasing; in addition the incidence of respiratory infections in the obese population is high and likely underestimated. An increased awareness of the respiratory health risks associated with obesity is warranted, and healthy behavior and weight loss, until a healthy weight is reached, should be encouraged.

Several organizations can benefit from the work described in this thesis, including the European Lung Foundation (ELF). The ELF aims to bring together patients and the public with respiratory professionals to positively influence lung health within Europe. In some areas, such as Germany, obesity incidence is much higher compared to the incidence in the Netherlands, and with the help of the ELF the outcomes of the studies performed in this thesis can be communicated to the European public. Furthermore, the patient organizations of the Dutch Lung Foundation as well as the obesity society can also benefit from these studies. The Dutch Lung Foundation does have a "Longpunt" in the Limburg area (Maastricht, Sittard and Weert) where I will present and discuss my research to and with patients suffering of a lung diseases to inform them about the study outcomes, but also to receive their input for further research studies and grant applications. Furthermore, the study outcomes will also be communicated towards obese subjects and their relatives which are involved in the "Obesitas Vereniging". Furthermore, "Zwaartepunt", an organization aimed at competence-based training of health care providers (physicians, nurses, dieticians) related to obesity, organizes conferences, symposia and hands-on training courses related to the care and management of obese patients. The studies described in this dissertation have led to an increased understanding of the impact of body weight and nutritional status on pulmonary host defense, and will be communicated towards healthcare providers with the help of "Zwaartepunt".

\section{Science}

\section{Future research questions}

This thesis contributes to research in the field, as the results elucidate possible mechanisms which underlie the impaired pulmonary host defense in obesity. Although valuable new insights have emerged from the work presented in this dissertation, a number of issues remain unresolved and new questions arise. Foci of additional research should include examining the effects of obesity-associated metabolic abnormalities (dyslipidemia, hyperglycemia and adipokine dysregulation) on pulmonary host defense, which may lead to identification of subjects at elevated risk for developing respiratory infections and ARDS. In addition, further understanding of host defense and the specific 
mechanisms underlying its impairment in hyperleptinemic conditions, including not only obesity, but also pregnancy, renal failure and diabetes, is critical to further develop improved identification and treatment of populations at risk for pneumonia.

The importance of pulmonary host defense is not limited to protection against respiratory infections. Episodic airway infections can lead to a worsening of existing chronic lung diseases, such as Chronic Obstructive Pulmonary Disease (COPD). Such exacerbations of the disease have been shown to be more prevalent in underweight COPD patients, whereas obese subjects have a lower risk for exacerbations. Knowledge transfer through collaborations between a variety of respiratory professionals is needed to implement the findings of this dissertation in other respiratory diseases.

\section{Relevant mouse model to study obesity}

Several animal models of obesity have been used in literature to investigate the effects of obesity and associated comorbidities on the pulmonary immune response related to diverse acute and chronic lung diseases. However, important caveats may exist when studying the available murine models of obesity and these should be taken into account when interpreting the generated data, as well as extrapolating this to the own study set. In addition, with these caveats in mind, one should also be cautious when extrapolating studies performed in murine obesity models to human obesity. In Chapter 4 we investigated the pulmonary immune response and host defense, in particular neutrophil function, following an acute inflammatory insult in four models of murine obesity. In addition, several metabolic parameters were characterized. Until now, very few studies were performed which compare pulmonary host defense and immune function in obesity. Our work greatly enhances the understanding of how results obtained in the different models should be interpreted and to which extent the metabolic parameters vary between different models of obesity. The diet-induced model of obesity is the best model thus far to study pulmonary infection in the context of human obesity, however, caution should be used when extrapolating data from this model to the human situation as mice in this model may manifest features of a more 'metabolic healthy obese phenotype'.

\section{Personal development}

The outcomes of the studies described in this thesis have resulted in multiple scientific abstracts on national and international conferences. The abstract containing the results of Chapter 7 and Chapter 8 were awarded with an ERS Lung Science Conference Bursary in 2013 and an ATS abstract scholarship at the annual ATS conference in Denver, CO, USA in 2015, respectively. Furthermore, the results and insights gathered from the studies performed have served as the foundation for several grant applications of which one was shown to be successful already. 
The studies described in Chapter 3, Chapter 6 and Chapter 7 have been published in peer reviewed scientific journals in the fields of critical care medicine as well as respiratory medicine. The results of Chapter 7 were accompanied by an editorial describing the march of leptin from satiety hormone to an important immune modulator. The results of Chapter 8 are currently in revision. The study results of Chapter 4 are submitted and Chapter 5 will be submitted when additional experiments are performed.

The work described in this thesis was performed within the structural collaboration between the Department of Respiratory Medicine, Maastricht University Medical Center, Maastricht, The Netherlands and the Vermont Lung Center, University of Vermont College of Medicine, Burlington, VT, USA, thereby strengthening this collaboration. Furthermore, several national and international collaborations between the authors and other research groups including: the Department of Respiratory Medicine, Ghent University Hospital, Ghent, Belgium, the Cytokine Receptor Lab (CRL), VIB Department of Medical Protein Research, Ghent, Belgium and the Department of Pediatrics, National Jewish Health, Denver, CO, USA.

\section{Schedule and implementation}

The studies described in this thesis are already published in or submitted to international peer-reviewed scientific journals, and discussed during various national and international conferences, thereby facilitating scientific progress and contribution to the scientific community.

The studies presented in this thesis indicate that obese and/or hyperleptinemic subjects should be considered as high risk patients for severe pneumonia. Furthermore, the results of the studies described in this thesis contributed to the awareness and importance of this topic. The new research questions that arose from this thesis regarding the mechanisms underlying the impaired pulmonary host defense in obesity and how this can be integrated into clinical practice can consequently contribute to new therapeutic strategies and better care for the obese patients. In addition, the comparison of the four most commonly used mouse models of obesity provided by this work, shed light on the importance of understanding which metabolic factors are affected before extrapolating data from one model to another. 


\section{References}

1. Ng, M., Fleming, T., Robinson, M., Thomson, B., Graetz, N., Margono, C., Mullany, E.C., Biryukov, S., Abbafati, C., Abera, S.F., et al. 2014. Global, regional, and national prevalence of overweight and obesity in children and adults during 1980-2013: a systematic analysis for the Global Burden of Disease Study 2013. Lancet 384:766-781.

2. Detournay, B., Fagnani, F., Phillippo, M., Pribil, C., Charles, M.A., Sermet, C., Basdevant, A., and Eschwege, E. 2000. Obesity morbidity and health care costs in France: an analysis of the 1991-1992 Medical Care Household Survey. International journal of obesity and related metabolic disorders : journal of the International Association for the Study of Obesity 24:151-155.

3. Long, D.A., Reed, R., and Lehman, G. 2006. The cost of lifestyle health risks: obesity. Journal of occupational and environmental medicine / American College of Occupational and Environmental Medicine 48:244-251.

4. Finkelstein, E.A., Fiebelkorn, I.C., and Wang, G. 2003. National medical spending attributable to overweight and obesity: how much, and who's paying? Health affairs Suppl Web Exclusives:W3-219-226.

5. Withrow, D., and Alter, D.A. 2011. The economic burden of obesity worldwide: a systematic review of the direct costs of obesity. Obesity reviews : an official journal of the International Association for the Study of Obesity 12:131-141.

6. Phung, D.T., Wang, Z., Rutherford, S., Huang, C., and Chu, C. 2013. Body mass index and risk of pneumonia: a systematic review and meta-analysis. Obesity reviews : an official journal of the International Association for the Study of Obesity 14:839-857.

7. Milner, J.J., Sheridan, P.A., Karlsson, E.A., Schultz-Cherry, S., Shi, Q., and Beck, M.A. 2013. Diet-induced obese mice exhibit altered heterologous immunity during a secondary 2009 pandemic H1N1 infection. Journal of immunology 191:2474-2485. 




\section{LIST OF ABBREVIATIONS}


ALI

AMPK

APACHE

ARDS

ASM

BAL(F)

BEC

BMI

CCL2

CD

CFU

CHD

CLP

COPD

CPE

CRP

CSF

CVD

CXCL

CXCR

DC

DIO

FFMI

fMLP

FPR1

GM-CSF

GSK-3

HbA1C

HDL

HL

HMW

IACUC

IFN

IL

IRS

JAK

KC

LDL

LPS

Lyso-PS

MAPK

MCP-1 acute lung injury

AMP-activated protein kinase

acute physiology and chronic health evaluation

acute respiratory distress syndrome

airway smooth muscle

bronchoalveolar lavage (fluid)

bronchial epithelial cells

body mass index

chemokine ( $\mathrm{C}-\mathrm{C}$ motif) ligand 2

cluster of differentiation

colony forming units

coronary heart disease

cecal-ligation puncture

chronic obstructive pulmonary disease

carboxypeptidase $\mathrm{E}$

C-reactive protein

colony stimulating factor

cardiovascular disease

chemokine (c-x-c motif) ligand

$c-x-c$ chemokine receptor

dendritic cell

diet-induced obesity

fat free mass index

$\mathrm{N}$-formyl methionine-leucyl-phenylalanine

formyl peptide receptor 1

granulocyte macrophage colony stimulating factor

glycogen synthase kinase-3

glycated hemoglobin A1C

high density lipoprotein

hyperleptinemia

high molecular weight

institutional animal care and use committee

interferon

interleukin

insulin receptor substrate

janus kinase

keratinocyte cytokine

low density lipoprotein

lipopolysaccharide

lysophosphatidylserine

mitogen activated protein kinase

monocyte chemoattractant protein-1 


\begin{tabular}{|c|c|}
\hline M-CSF & macrophage colony stimulating factor \\
\hline MHO & metabolically healthy obesity \\
\hline MIP-2 & macrophage inflammatory protein-2 \\
\hline MPO & myeloperoxidase \\
\hline MPS & macrophage phagocyte system \\
\hline mTOR & mammalian target of rapamycin \\
\hline NASH & non-alcoholic steatohepatitis \\
\hline NHANES & national health and nutrition examination survey \\
\hline NK-cells & natural killer cells \\
\hline NO & nitric oxide \\
\hline o.p. & oropharyngeal \\
\hline ObR & leptin receptor \\
\hline ObRa & leptin receptor isoform a \\
\hline ObRb & leptin receptor isoform b \\
\hline PAMP & pathogen associated molecular pattern \\
\hline PEEP & positive end expiratory pressure \\
\hline PEG & polyethyleenglycol \\
\hline PI3K & phosphoinositide 3 kinase \\
\hline PMN & polymorphonuclear leukocyte \\
\hline PRR & pattern recognition receptor \\
\hline PS & phosphatidylserine \\
\hline PSGL & p-selectin glycoprotein ligand \\
\hline PTP1B & protein tyrosine phosphatase $1 \mathrm{~B}$ \\
\hline ROS & reactive oxygen species \\
\hline SOCS & suppressor of cytokine signaling proteins \\
\hline STAT & signal transducers and activators of transcription \\
\hline TGF & transforming growth factor \\
\hline TLR & toll like receptor \\
\hline TNF- $\alpha$ & tumor necrosis factor- $\alpha$ \\
\hline Tregs & t regulatory cell \\
\hline Tyr & tyrosine \\
\hline UCP & uncoupling protein \\
\hline WHO & world health organization \\
\hline
\end{tabular}





\section{ACKNOWLEDGEMENTS}

DANKWOORD 
Finally - that is the first thought that comes to my mind as I am starting to write the most read chapter of this PhD thesis - the acknowledgements. Now it is time to look back, see how far I have come, and reflect on a very challenging but exciting past 4.5 years. Hard work, motivation and willpower are needed to be able to start, but definitely to finish a PhD trajectory. However, without guidance and support this journey would not have been possible, and now I may finally thank everyone who has contributed to and supported me during this PhD trajectory.

Professor Wouters, thank you for providing me with the opportunity to perform my PhD project within the Department of Respiratory Medicine. You have always given me your full confidence, support and freedom in my projects. Your knowledge and vision on respiratory research have made this an outstanding learning experience. I am very grateful that you gave me the unique opportunity to continue the work I started during my masters' study in collaboration with the University of Vermont, in a PhD project. In my opinion this has been a crucial factor for the success of my projects and my development as a researcher. I look forward to start exciting new projects and to continue working in Maastricht.

Next I would like to thank my co-promotores. First, Professor Suratt, dear Ben, thank you for giving me the opportunity to work with you and the Suratt-lab members. When I first arrived in your lab in January 2011 as a master's student, I was mostly overwhelmed by the different environment and scientific culture. Soon after, I realized that this inspiring environment and scientific culture in which motivation, dedication and striving for scientific excellence is critical, was one that suited me. You have taught me more than I thought possible to attain. Your enthusiasm and dedication made me go the extra mile (or hour(s)) and led to multiple great chapters described in this thesis, which will hopefully all get published soon. Thank you for introducing me into the world of scientific conferences (both the scientific and social aspects) and allowing me to present our research on numerous occasions. I was astonished when I found out about your knowledge of the Dutch language. Maybe not so much regarding the quantity, but more so the "quality"....Although that does not count for you trying to pronounce my last name. Your never ending editing of my manuscripts have led to some frustration along the way, but those edits always provided me with new insights and a better representation of our data. Thank you for being a great mentor and making sure that, even when I was working in Maastricht, there was always an opportunity for weekly (skype) meetings to discuss data or plan new projects. I have a lot of respect for the way you run a basic science lab as a clinician. Although "research time" has become very limited, you always find some time to think out new approaches to investigate the problems you encounter in the clinic in a translational approach, and discuss them with the lab-members. I am happy that you will continue to be one of my mentors, albeit from a distance.

Second, Dr. Vernooy, dear Juanita, thank you for introducing me into the world of leptin research. I am glad that we have been able to extent your previous work on leptin in 
COPD to other diseases of the lung. Our work together has known its struggles, but this enhanced my ability to work independently and improved my communications skills. Two competences from which I will definitely benefit in my future career. In the past years your academic focus has become more towards education, and I wish you all the best with this new endeavor.

I would like to thank the members of the thesis reviewing committee consisting of Prof. Savelkoul (chairman), Prof. Herold, Prof. van der Poll, Prof. Roekaerts and Dr. Sverdlov for critically reviewing and evaluating this dissertation. Furthermore, I would also like to thank the members of the corona.

Graag wil ik ook mijn dank uitspreken aan France, Manon, Gaby, Lilian en de andere dames van het secretariaat Longziekten, voor alle ondersteuning en organisatie die grotendeels achter de schermen gebeurd. Verder wil ik ook alle collega's van de afdeling Longziekte bedanken.

Then I would like to continue to thank people that have been very important early on. To start with Dr. Langen, dear Ramon, your unlimited enthusiasm and ability to motivate students and colleagues to bring out the best in themselves are intriguing. I performed the first internship of my master's study under your supervision and the aforementioned aspects contributed towards my choice to pursue a career in academia. Thank you for everything I have learned from you. I always value your advice and am glad that you have been willing to free up some of your valuable time to talk about career choices and how to approach complex situations. Next to Ramon as the principal supervisor, the daily advisor of this internship, Dr. Pansters, introduced me to the world of animal work. Dear Nicky, as you mentioned in your own acknowledgement section not too long ago, "I was the first, and only, student you supervised". I am still not sure whether this was a good or a bad sign. Thank you for teaching me the ins and outs of various lab techniques, but also for all the fun parties and endless discussions in the past years. Best of luck with your job search.

Next I would like to thank all former and present members of the Suratt lab. Chris, Tatsiana, Lauren and Angela, thank you for introducing me into the world of neutrophil biology and the fun times in the lab. Elianne, it was great to be able to speak Dutch in the lab. I think that "winkelwagen" and "huishoudfolie" are the two Dutch words that almost everybody knew after a while. Thank you for joining me in lots of crazy experiments. I am glad that not all of them made us live in the lab for three days. I truly enjoyed our hiking trips, having drinks and baking as well as our sightseeing trips in San Francisco and San Diego. It is good to know that you are enjoying your job in Ghent and can finally be closer to your family. Then two lab members without whom I would not know the term "Stitchfix". Catherine and Maryellen, thank you for the fun times in- and outside the lab, and keeping me sane at times. Catherine, good luck with your studies and do not forget to visit when you are in Europe! Maryellen, I sometimes miss your organized chaos. It has always been a pleasure to discuss all sorts of life-issues with you, 
preferably when enjoying a drink. Aaron, without you a lot of research in the past 1.5 years would not have been possible. Thanks for all your help with the apoptosis and flow cytometry experiments. Estee, you did a great job managing the animal colony and managed to obtain some EM skills which led to a bunch of great images, thank you for all your help! Last but not least, Sebastian, tail vein injections were definitely not my strongest skill, but with your tremendous help most of the transplants were successful! Thank you!

I would also like to thank the colleagues on the $4^{\text {th }}$ floor of Given, Jen, Shannon, Laura, Phil, Ben and Chris. You all made lab-life a lot more fun, and I owe a big thank you to all for your help and advice on a variety of experiments.

Thanks to everyone in the Vermont Lung Center for creating a translational research environment. Dr. Poynter, thank you for your valuable advice and insights during the past 4 years. Drs. Stapleton and Dixon, without you the statistical analysis in the "hyperleptinemia chapter" would not have been possible, thank you! Dr. Wargo, many thanks for your help with the bacterial pneumonia modelling, as well as the most recent experiments looking at the lipid profile in the lung. Dr. Rincón, thank you for your help when studying the neutrophil intracellular signaling and sharing your insights regarding these processes.

Graag zou ik ook alle collega's in Maastricht willen bedanken. Dr. Dentener, beste Mieke, dankjewel dat jouw deur altijd open staat voor advies. Ik ben blij dat we sinds kort de "long-lijn" meetings weer hebben kunnen oppakken en ik hoop dat er nog vele zullen volgen. Dr. Reynaert, beste Niki, bedankt voor jouw waardevolle input tijdens labmeetings, ik heb altijd veel van jou kunnen leren. Ook een dikke dankjewel voor jouw kritische feedback tijdens het schrijven van recente subsidieaanvragen. Dr. Rohde, beste Gernot, hartelijk dank voor het delen van jouw klinische inzichten tijdens onze meetings, ik hoop dat we in de toekomst verder samen kunnen werken. Claudia, van jou heb ik een groot deel van het lab werk geleerd. Ook jij deed geregeld mee aan experimenten die misschien een beetje veel van het goede waren, maar voor 13 ELISA platen op één dag draaide jij je hand niet om, dankjewel daarvoor! Dr. Eurlings, beste Irene, samen zijn we begonnen als studenten bij PUL. Dankjewel voor de gezellige en leerzame tijd op het lab en zeker ook daarbuiten. Ik ben blij dat je het goed naar je zin hebt in je nieuwe baan en hoop dat er nog vele cocktailavondjes met de rest van de long-dames mogen volgen. Poornima, thanks for the interesting conversations and good luck finishing your PhD thesis. Dr. Perkins, dear Tim, it was great to work with you. I wish you all the best in your post doc position in Pittsburgh. Dr. Peeters, beste Pol, dankjewel voor jouw altijd opbeurende woorden en verrassende inzichten op zowel wetenschappelijk alsook persoonlijk vlak. Jouw doorzettingsvermogen is bewonderenswaardig! Jij bent een levensgenieter pur sang en het is mooi om te zien hoe jij altijd je weg weer vindt. Hopelijk tot snel! Gonda, waar moet ik beginnen (of kan ik beter vragen, hoe gaan we eindigen?). Aangezien wij samen zelfs de weg kwijt kunnen raken met een naar behoren werkend navigatiesysteem. Dankjewel voor de talloze koffietjes, babbels, 
skypegesprekken, maar ook adviezen op het lab. Hopelijk heb jij nu ook je plekje gevonden en kun je de komende jaren verder bouwen aan een wegwijzer richting jouw eigen promotie. Cheryl, bedankt voor de gezellige avondjes in Vermont en ik hoop dat er nog veel mogen volgen. Veel succes met jouw eigen onderzoek. Caspar, mijn nieuwe kamergenoot, dankjewel voor jouw enthousiasme, het heeft de afgelopen maanden goed meegeholpen als ik het even niet meer zag zitten. Veel succes met jouw onderzoek!

Drs. Gosker en Remels, beste Harry en Alex, bedankt voor jullie input tijdens de afgelopen jaren. Alex, dankjewel voor jouw hulp en interesse bij het schrijven van de Kootstra aanvraag. Astrid, jij hebt er mede voor gezorgd dat ik mijn senior stage in Vermont kon lopen. Dankjewel voor het leggen van dit eerste contact! Bram, Celine, Koen, Ilse en Ana, dank jullie wel voor de gezelligheid op het lab en jullie adviezen in het begin van mijn PhD onderzoek. Ana, good luck finishing your PhD thesis! Marco en Dr. Chiel, zonder jullie zou het lab lang niet zo soepeltjes draaien als dat nu het geval is. Bedankt dat ik altijd met mijn vragen bij jullie terecht kan. Chiel, mijn kloneringsexperimenten lopen telkens niet helemaal gesmeerd, bedankt voor jouw advies en hulp, 2016 wordt het jaar dat dit eindelijk gaat lukken....hoop ik. Frank en Anon ook een dikke dankjewel voor jullie gezelligheid op het lab. Dan de in mijn ogen nog steeds "nieuwe" lichting PhD studenten: Judith, jij bent nu ook bijna klaar met jouw onderzoek. Nog even doorzetten en dan is er ook voor jouw licht aan het einde van de tunnel. Positief blijven en dan komt dat helemaal goed! Rosanne, Anita, Pieter en Sarah dank voor jullie gezelligheid en veel succes met jullie onderzoek! Karin, bedankt dat ik je altijd om advies mag vragen. Jouw klinische kijk op dingen geeft mij vaak verassende inzichten. Hopelijk gaan jouw studies op korte termijn van start. Jules, de interesse die jij toont voor ieders onderzoek, ook als het niet direct gerelateerd is aan jouw eigen studies, is bewonderenswaardig en mag voor velen een voorbeeld zijn. Dankjewel voor jouw feedback tijdens presentaties. Met jouw positieve en coöperatieve instelling weet ik zeker dat jouw onderzoek een succes wordt!

Dan een woord van dank aan de studenten die bijgedragen hebben aan het tot stand komen van de studies beschreven in dit proefschrift. Lotte, jij hebt een grote bijdrage geleverd aan het genereren van preliminaire data waaruit de macrofaag projecten voortgevloeid zijn. Hartelijk dank daarvoor! Ik hoop dat jij nu je plekje gevonden hebt voor de klas. Alix bedankt voor jouw bijdrage aan het leptine werk. Ik hoop dat het een leerzame periode was waarin je een kijkje in de keuken van het labonderzoek gekregen hebt.

Verder wil ik de collega's van Medische Microbiologie bedanken: Frank Stassen, Marlies Mooij, Carla, Charlotte en Birke. Dank voor jullie input tijdens de MMB/PUL meetings. Ik heb altijd veel opgestoken tijdens deze besprekingen en ik hoop in de toekomst nog meer te kunnen leren over jullie onderzoek. 
Professor Tavernier en Dr. Zabeau, zonder jullie zouden de leptine hoofdstukken niet in hun huidige vorm tot stand gekomen zijn. Grote dank hiervoor. Jullie kennis over leptine is enorm en ik hoop in de toekomst nog veel van jullie op te mogen steken. Hartelijk dank!

Professor Brusselle, Professor Joos en Dr. Bracke, hartelijk dank voor de fijne samenwerking die geleid heeft tot een mooi review over de rol van leptine in longziekten.

Dr. Oligschläger, Yvonne, tijdens onze studie hebben we heel wat kilometers richting Diepenbeek en Maastricht samen afgelegd. Diep respect voor jouw enorme inzet en betrokkenheid bij alles wat je doet, jij bent voor mij zeker een voorbeeld als onderzoeker. Bedankt voor jouw interesse in mijn onderzoek en veel succes met alles!

René, het leven kan soms raar lopen. Dank voor jouw ondersteuning en interesse in mijn onderzoek. Ik hoop dat jij jouw dromen en carrière doelen waar kunt maken.

Renske, bedankt voor jouw hulp op het lab, maar zeker ook de koffiepauzes en stap- en cocktailavondjes. We hebben beide ervaren dat het leven zich niet altijd van zijn beste kant laat zien, maar gelukkig schijnt de zon nu weer volop! . Ik ben blij dat je na je werk bij PUL een fijne nieuwe baan gevonden hebt waar jouw talent tot uiting komt. Dankjewel voor jouw interesse in mijn onderzoek en jouw wijze raad op belangrijke momenten, ik ben blij dat jij als paranimf op deze belangrijke dag achter mij staat. Geniet van jouw grote dag samen met Dennis! Dr. Walenbergh, Sofie, ik heb met oprechte bewondering toegekeken hoe jij jouw onderzoek in goede banen leidt en zeer succesvol jouw promotie afgerond hebt. De frustraties waarmee we beide aan de eindstage van de master begonnen lijken ondertussen al heel lang geleden. Dankjewel voor alle gezelligheid van de afgelopen jaren, de peptalks, maar vooral ook de feestjes die gezorgd hebben voor mooie herinneringen. Super fijn dat jij mijn paranimf wilt zijn. Veel succes met het vervolg van jouw onderzoek!

There is more to life than just work and I would like to thank all of my friends for their support in the past years. Eveline, een vriendschap die meer dan 20 jaar geleden begon. Dankjewel voor jouw interesse in mijn onderzoek en de steun die je bood toen het leven even tegen zat. Geniet samen met Rick van jullie kleine man! Esther, samen hebben wij het HBO doorlopen waar een mooie vriendschap uit ontstaan is. Dankjewel voor jouw wijze woorden en de gezellige etentjes. Geniet van jouw grote dag samen met Wim! Krithika, I could not have wished for a better friend in Burlington. I always valued our scientific and non-scientific discussions; we also shared frustrations about grant and thesis writing. You are an amazing person and a great researcher. I am very sorry to have missed your wedding, but I wish you and Raghunandan all the best.

Graag wil ik ook Tim en Annet, Mark en Anke, Mandy en Bart, en Jill en Dolf bedanken voor hun interesse in mijn werkzaamheden. 
Mama en Wil, nu zit het er dan eindelijk op! Zonder jullie nooit aflatende steun was dit zeker niet gelukt. Een ritje naar het vliegveld, een extra bordje op tafel zodat jullie zeker wisten dat ik ook af en toe zou eten, en er was ook steeds een slaapplek beschikbaar op de momenten dat het leven even tegen zat. Nooit was het teveel. Bedankt ook voor jullie begrip tijdens mijn afwezigheid. Ik zal proberen in de toekomst op z'n minst op hetzelfde continent te blijven wonen! Ik hoop dat jullie leven op korte termijn in een rustiger vaarwater komt zodat jullie eindelijk weer kunnen gaan genieten van elkaar. Bedankt voor alles!!

Pap, ik ben niet altijd even trots op de eigenschappen die ik van jou mee gekregen heb, maar deze hebben er mede aan bijgedragen dat ik dit traject nu af kan ronden. Bedankt voor de interesse die zowel jij als Sabine getoond hebben.

Zusjes: Kelly, dankjewel dat jij altijd met wijze raad voor mij klaar staat, waar ter wereld ik ook ben. Het leven gaat niet altijd van een leien dakje, maar uiteindelijk komen we steeds weer op onze pootjes terecht. Vergeet niet om ook af en toe een stapje terug te doen en te genieten van het leven. Ook een dikke dankjewel dat je er samen met Marcel voor gezorgd hebt dat Coen en Lars weten wie "tante Niki" is, en dat ik niet te veel van hun eerste jaren heb gemist. Maak er samen iets moois van! Tessa, ook jij bent nu bijna klaar met je specialisatie. Daarna is het eindelijk tijd om samen met Jack te gaan genieten van Luc en David in jullie nieuwe woning. Dank voor jullie interesse! Dan de benjamin van de familie (al blijf ik helaas toch echt de kleinste): Romina, jij hebt de afgelopen jaren keihard gewerkt om jouw studie af te ronden en ik ben er trots op dat je nu al een vast contract hebt. Dankjewel dat jij elke keer als ik weer van huis was de zorg voor de paardjes op je nam, mijn dank daarvoor is enorm. Ik hoop dat we samen nog vele jaren met onze hobby bezig mogen zijn en mooie herinneringen kunnen maken. Geniet volop van het leven en ik hoop dat je samen met Peter een mooie toekomst op kunt bouwen.

Matt, how can I possibly thank you for everything you have done to help me to be the person I am today and to achieve this important goal. You believed in me whenever I was ready to give up, and supported me in every decision I made. Thank you for our endless discussions about science, sometimes even in the middle of the night. You are not only my best friend, but also my worst critic. You made me realize that there is more to life than work, and with the end of this PhD trajectory in sight, I truly hope that we can soon start building our life together without being more than 8000 miles apart. I look forward to our future together. 

LIST OF PUBLICATIONS 

Pansters NA, Schols AM, Verhees KJ, de Theije CC, Snepvangers FJ, Kelders MC, Ubags $\underline{\text { ND, }}$, Haegens A, Langen RC. Muscle-specific GSK-3 $\beta$ ablation accelerates regeneration of disuse-atrophied skeletal muscle. Biochim Biophys Acta. 2015 Mar;1852(3):490-506. (Impact Factor 2015: 4.381)

Ubags ND, Vernooy JHJ, Burg E, Zabeau L, Tavernier J, Abraham E, Poch KR, Nick JA, Dienz O, Zuñiga J, Wargo MJ, Mizgerd JP, Rincón M, Poynter ME, Wouters EFM, Suratt BT. The role of leptin in the development of pulmonary neutrophilia in infection and Acute Lung Injury. Crit Care Med. 2014 Feb;42(2):e143-51. (Impact Factor 2015: 6.312)

Vernooy JHJ, Ubags ND, Brusselle GG, Tavernier J, Suratt BT, Joos GF, Wouters EF, Bracke $\mathrm{KR}$. Leptin as regulator of pulmonary immune responses: Involvement in respiratory diseases. Pulm Pharmacol Ther. 2013 Aug;26(4):464-72. (Impact Factor 2015: 2.937)

Palvinskaya T, Antkowiak M, Burg E, Lenox CC, Ubags ND, Cramer A, Rincón M, Dixon AE, Fessler MB, Poynter ME, Suratt BT. Effects of acute and chronic low density lipoprotein exposure on neutrophil function. Pulm Pharmacol Ther. 2013 Aug;26(4):405-11. (Impact Factor 2015: 2.937)

Kordonowy LL, Burg E, Lenox CC, Gauthier LM, Petty JM, Antkowiak M, Palvinskaya T, Ubags ND, Rincón M, Dixon AE, Vernooy JH, Fessler MB, Poynter ME, Suratt BT. Obesity is associated with neutrophil dysfunction and attenuation of murine acute lung injury. Am J Respir Cell Mol Biol. 2012 Jul;47(1):120-7. (Impact Factor 2015: 3.985)

\section{In Revision:}

Ubags ND, Stapleton RD, Vernooy JH, Burg E, Bement Hayes CM, Zabeau L, Tavernier J, Wargo MJ, Littenberg B, Poynter ME, Wouters EF, Parsons PE, Dixon AE, Suratt BT. Hyperleptinemia impairs pulmonary host defense.

In revision in J Clin Invest (Impact Factor 2015: 13.215).

\section{Submitted/In preparation:}

Ubags ND*, Burg E*, Antkowiak ME, Wallace A, Hayes CM, Bement J, Vernooy JH, Wouters EF, Wargo MJ, Poynter ME, Suratt BT. A comparative study of pulmonary host defense in murine obesity models: important insights into neutrophil function.

Submitted to Am J Respir Cell Mol Biol (Impact Factor 2015: 3.985) * Authors contributed equally to this work.

Ubags ND, Wallace AM, Ventrone SB, Dilli E, Antkowiak ME, Frasch SC, Bratton DL, Wouters EFM, Suratt BT. Modulation of the pulmonary innate immune response in murine obese ARDS.

In preparation 



\section{CURRICULUM VITAE}



Niki Ubags was born on August 11, 1988 in Simpelveld, The Netherlands. In 2005 she acquired her secondary school diploma (Science \& Health) at Bernardinuscollege in Heerlen, The Netherlands. She started her Bachelor's education in Biology and Medical Laboratory Sciences at Hogeschool Zuyd (University of Applied Sciences) in Heerlen, The Netherlands in September of 2005. She performed a research internship at the Fraunhofer Institute for Molecular Biology and Applied Ecology (IME) in Aachen, Germany for 8 months under supervision of Dr. S. Jennewein. The research performed during this internship was described in her bachelor's thesis entitled "Metabolic Engineering of Saccharomyces cerevisiae". After obtaining her bachelor's degree in 2009, she started her Master's study in Clinical Molecular Sciences at Maastricht University, The Netherlands. During the first year of her Master's study she performed an internship at the Department of Respiratory Medicine of Maastricht University (UM) investigating the role of GSK-3 $\beta$ in skeletal muscle mass regeneration related to COPD. Subsequently, Niki performed an 8-months internship under supervision of Prof. B.T. Suratt at the Department of Medicine at the University of Vermont (UVM), Burlington, VT, USA. In 2011 she received her Master's degree with her thesis entitled: "The role of leptin on pulmonary neutrophilia in Acute Lung Injury". In November of 2011 she started her PhD trajectory within the school of Nutrition and Translation Research in Metabolism (NUTRIM) at Maastricht University. The project was performed at the Department of Respiratory Medicine at Maastricht University in close collaboration with the Vermont Lung Center at the University of Vermont under the supervision of Prof. Dr. E.F.M. Wouters (UM), Prof. B.T. Suratt (UVM) and Dr. J.H.J. Vernooy (UM). Her research focused on exploring the mechanisms underlying the altered pulmonary innate immune response and pulmonary host defense in obesity. Niki presented her work by means of poster and oral presentations at numerous national and international meetings, and received several awards for the work presented. She is currently working as a postdoctoral fellow at the Department of Respiratory Medicine at Maastricht University funded by a Kootstra Talent Fellowship for the project entitled "Obesity and Pulmonary Host Defense: the pulmonary epithelial barrier as an important mediator". 
